\title{
A New Model for eGovernment in Local Level Administrations in Libya
}

\author{
By: Yousef Forti
}

\begin{abstract}
A thesis submitted to the University of Gloucestershire in accordance with the requirements of the degree of Doctor of Philosophy in the School of Business and Technology
\end{abstract}

August 2019 


\section{ABSTRACT}

The assessment of eGovernment capability has often focused on assessing website functions and their use, whereas relatively little attention has been given to other aspects of local authority operations, particularly back-office processes. The study provides a literature review, from which a model for the assessment of eGovernment at individual process level is derived. The study provides a maturity stage model for analysing eGovernment based on technology deployment, organisational capability and process efficiency dimensions. For each of these three dimensions, a number of key change factors are identified and assessed to allow a positioning of the organisation in the stage model; and this is applied at individual process level within the organisation, as well as for the organisation as a whole.

This research reports on the use of the model in two case studies - Sabratha local authority and Rujban local authority in Libya. The study illustrates the potential of the model in assessing eGovernment readiness and identifying opportunities for investment and change. It highlights the need for process improvement to accompany technology deployment, and the key role of organisational factors in bringing about the necessary change for the move to e-Government.

The potential of the three-dimensional maturity model for developing appropriate strategies and plans for a transition to eGovernment is evidenced in the case studies. At Sabratha and Rujban local authorities, processes are generally not well developed, although in terms of technology deployment and organisational capability, there are some processes which have a reasonable basis from which to move forward. It is clear, however, that process maturity is generally weak in the local authorities studied, and this area needs appropriate focus and investment to allow the authorities to transition to an eGovernment in a planned and effective manner. 


\section{AUTHOR'S DECLARATION}

I declare that the work in this thesis was carried out in accordance with the regulations of the University of Gloucestershire and is original except where indicated by specific reference in the text. No part of the thesis has been submitted as part of any other academic award. The thesis has not been presented to any other education institution in the United Kingdom or overseas. Any views expressed in the thesis are those of the author and in no way represent those of the University.

Signed Date ...August 2019...

doi: 10.46289/KVTY4682 


\section{ACKNOWLEDGEMENTS}

After sincerely thanking Allah and then my parents for all blessings, I would like to extend my deep thanks and gratitude to all the people who contributed to enrich my knowledge and improve my competencies. I am grateful to my family for their prayers and enormous efforts to complete the journey of knowledge. Also, I would like to show my deep thanks to the supervisors Dr. Martin Wynn and Professor Kamal Bechkoum who provided me with their knowledge and experience, encouragement, and support, without which this study would not have been completed. I would like also to express my deepest thanks to those who participated in this research at Sabratha local authority and Rujban local authority by providing the information and data to support my research.

Yousef Bashir Forti

August 2019

London, UK 


\section{LIST OF PUBLICATIONS}

1. Forti, Y, Bechkoum, K, Turner, S, Ajit, S (2014). The Adoption of eGovernment in Arab

Countries.: The Case of Libya. In: 14 ${ }^{\text {th }}$ European Conference on e-Government, 2014, Romania.

2. Forti, Y, Wynn M, (2017). A New Model for EGovernment in Local Level Administrations in Libya. In: the $17^{\text {th }}$ European Conference on e-Government, 2017, Lisbon. 


\section{TABLE OF CONTENTS}

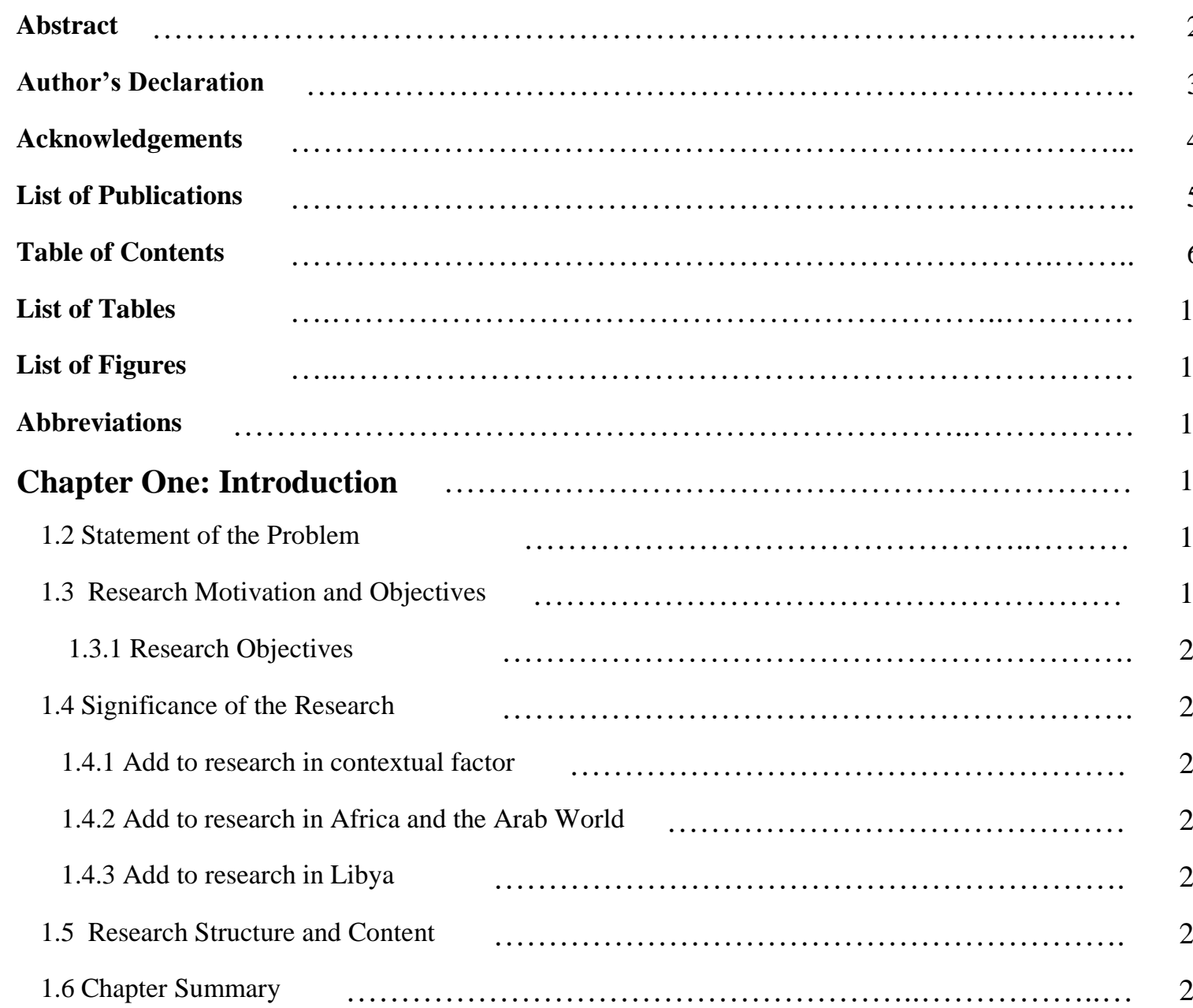

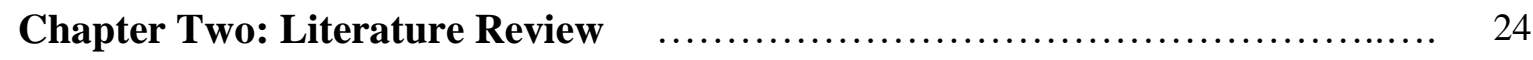

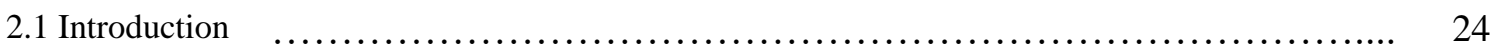

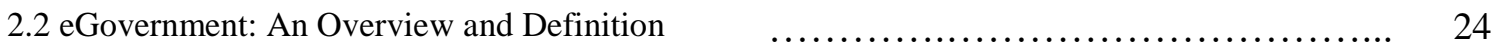

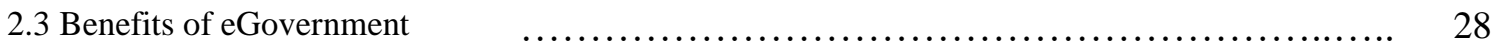

2.3.1 Classification of eGovernment Benefits $\quad$................................ 29

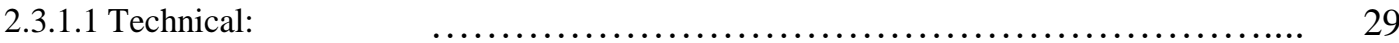

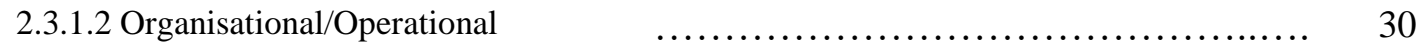

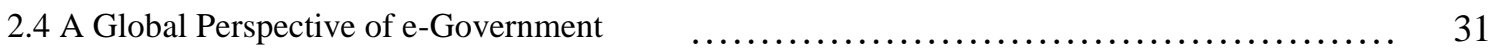

2.4.2 eGovernment in Developing Countries $\quad \ldots \ldots \ldots \ldots \ldots \ldots \ldots \ldots \ldots . \ldots . \ldots . \ldots$

2.4.2.1 eGovernment Challenges to Developing Countries $\quad$..................... 33

2.4.3 eGovernment in Developing versus Developed Countries $\quad \ldots \ldots \ldots \ldots \ldots \ldots \ldots \ldots \ldots . . . \ldots$

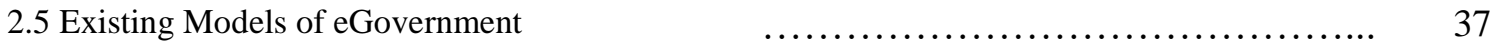


2.5.1 Sustainability Framework for eGovernment Success $\quad \ldots \ldots \ldots \ldots \ldots \ldots \ldots \ldots \ldots \ldots . . . \ldots$

2.5.2 eGovernment Implementation Benefits, Barriers and Risks $\quad$..................... 39

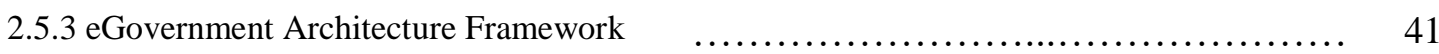

2.5.4 Layne and Lee Model $\quad$............................................ 44

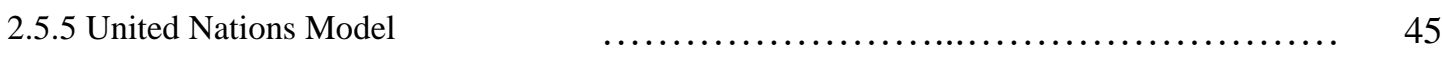

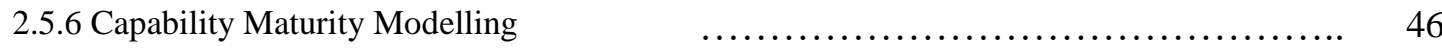

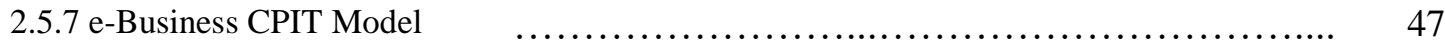

2.6 Critical Analysis of eGovernment Models $\quad \ldots \ldots \ldots \ldots \ldots \ldots \ldots \ldots \ldots \ldots \ldots \ldots . . \ldots \ldots$

2.7 Towards a Conceptual Model $\quad \ldots \ldots \ldots \ldots \ldots \ldots \ldots \ldots \ldots \ldots \ldots \ldots \ldots \ldots \ldots . \ldots \ldots$

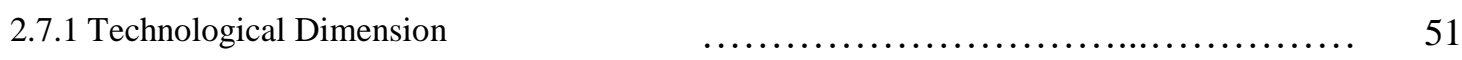

2.7.2 Organisational Dimension $\quad$................................. 52

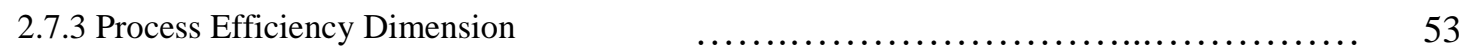

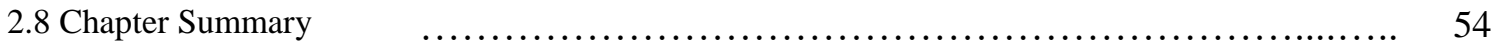

Chapter Three: Initial Conceptual Model Development $\quad \ldots \ldots \ldots \ldots \ldots \ldots \ldots \ldots .57$

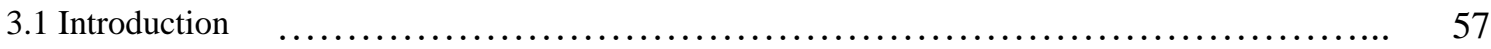

3.2 Justification for Model Development $\quad$.................................. 57

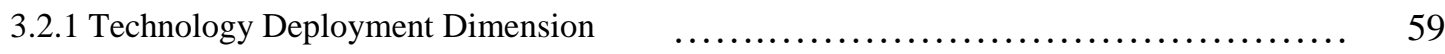

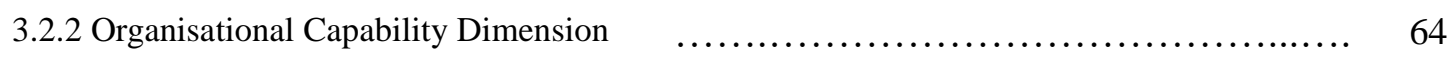

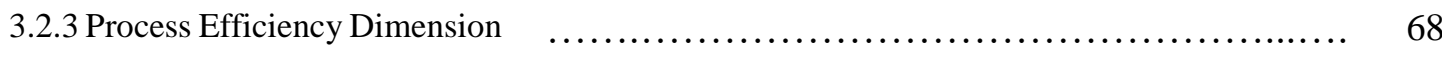

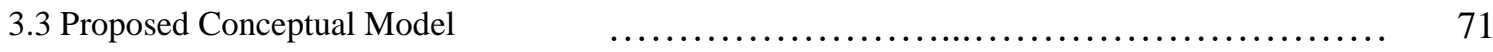

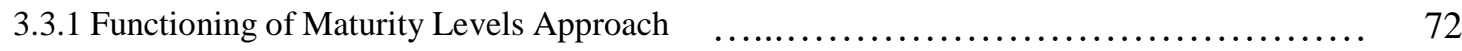

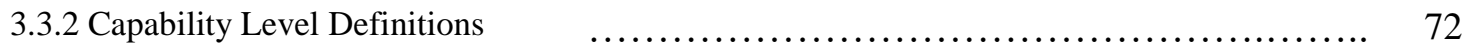

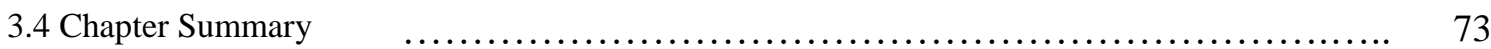

Chapter Four: Research Methodology and Design $\quad \ldots \ldots \ldots \ldots \ldots \ldots \ldots \ldots . \ldots \ldots$

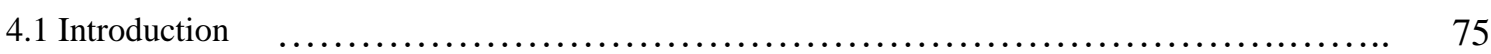

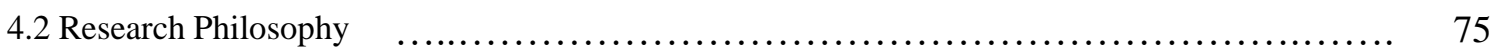

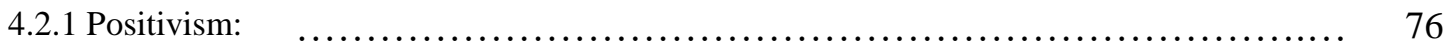

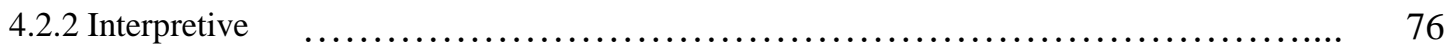

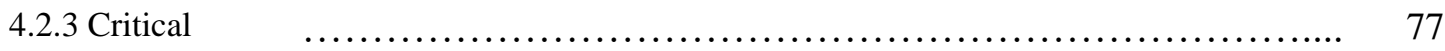

4.2.4 Research Philosophy Adopted in this Research $\quad$.......................... 77

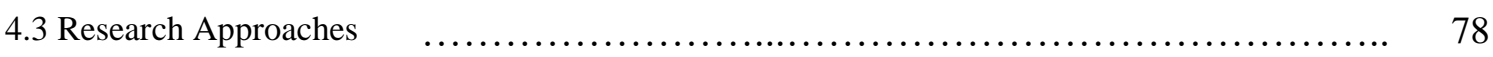

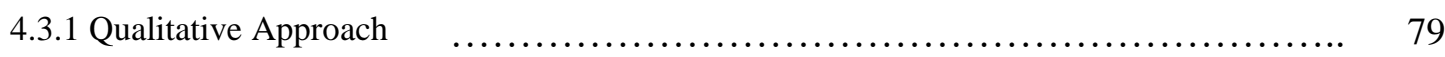

4.3.2 Justification for the Selection of Qualitative Analysis $\quad \ldots \ldots \ldots \ldots \ldots \ldots \ldots \ldots \ldots \ldots . . . \ldots 0$ 


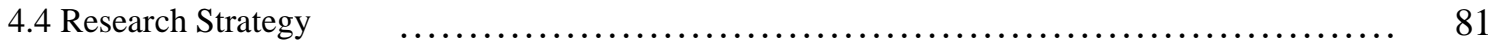

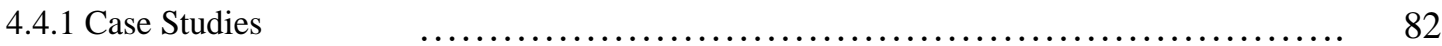

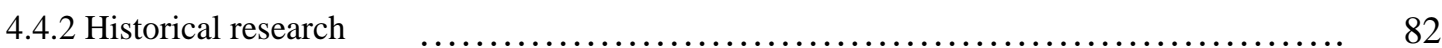

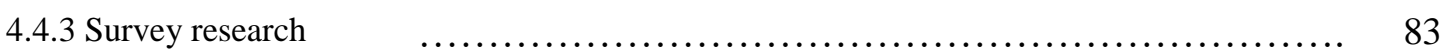

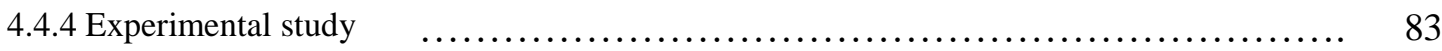

4.4.5 Justification for the Selection of Case Study Strategy $\quad \ldots \ldots \ldots \ldots \ldots \ldots \ldots \ldots \ldots . \ldots . \ldots . \ldots . \ldots$

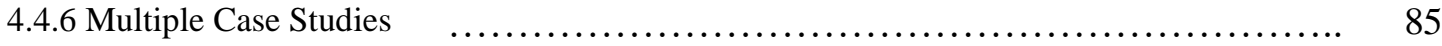

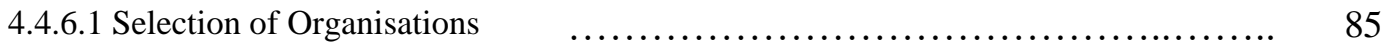

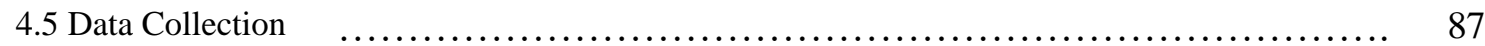

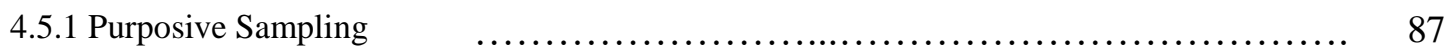

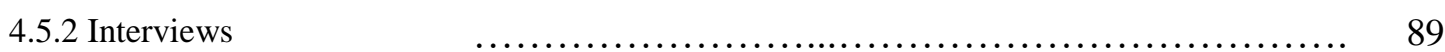

4.5.2.1 Justification for the Selection of Semi-Structured Interviews $\quad \ldots \ldots \ldots \ldots \ldots \ldots \ldots .91$

4.5.2.2 Interview Questionnaire and Pilot Testing $\quad \ldots \ldots \ldots \ldots \ldots \ldots \ldots \ldots \ldots \ldots \ldots . \ldots \ldots$

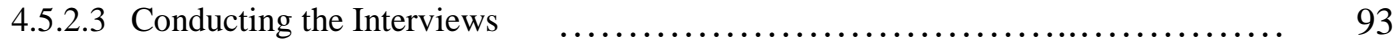

4.5.2.4 Interview Recording and Transcription $\quad \ldots \ldots \ldots \ldots \ldots \ldots \ldots \ldots \ldots \ldots \ldots \ldots \ldots \ldots \ldots . \ldots \ldots$

4.5.3 Documentation Analysis $\quad$............................................ 96

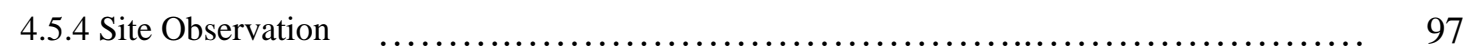

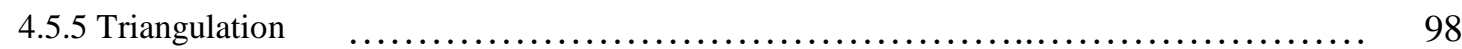

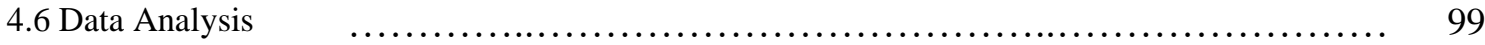

4.7 Ethical Considerations $\quad$............................................. 100

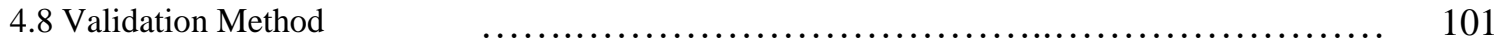

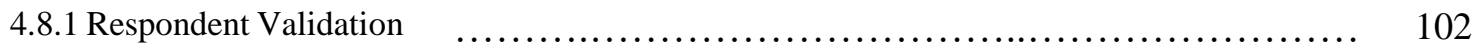

4.9 Chapter Summary $\quad$............................................ 103

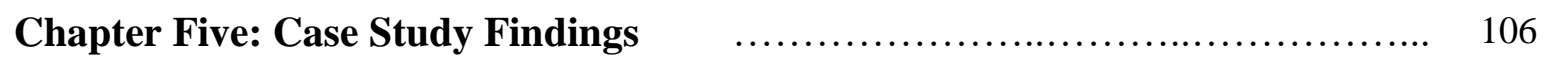

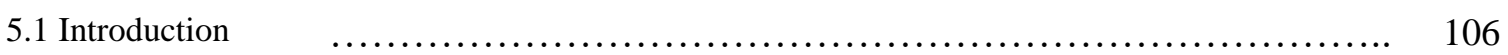

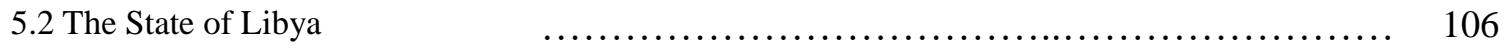

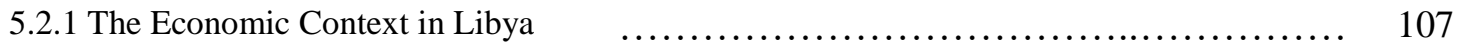

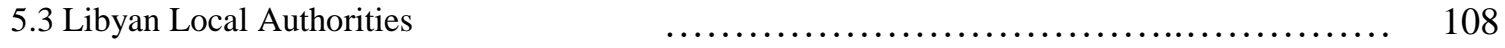

5.3.1 Structure of Local Authorities $\quad$..................................... 108

5.3.2 Case Study 1: Sabratha Local Authority $\quad$............................. 110

5.3.3 Case Study 2: Rujban Local Authority $\quad \ldots \ldots \ldots \ldots \ldots \ldots \ldots \ldots \ldots \ldots \ldots \ldots \ldots \ldots \ldots \ldots$

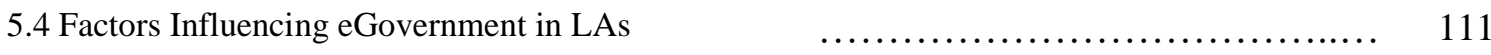

5.4.1 Case Studies: Technology Deployment Dimension $\quad$...................... 111 
5.4.2 Case Studies: Organisational Capability Dimension $\quad \ldots \ldots \ldots \ldots \ldots \ldots \ldots \ldots \ldots \ldots \ldots . \ldots \ldots 121$

5.4.3 Case Studies: Process Efficiency Dimension $\quad$....................... 132

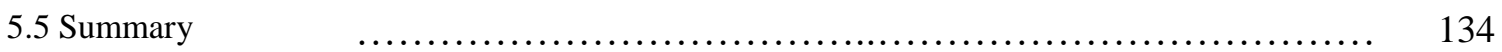

Chapter Six: Model Revision and Model Application $\quad \ldots \ldots \ldots \ldots \ldots \ldots \ldots . . \ldots \ldots$

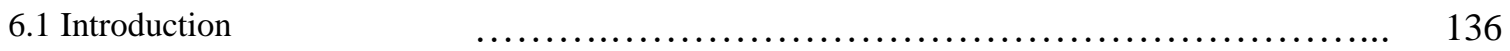

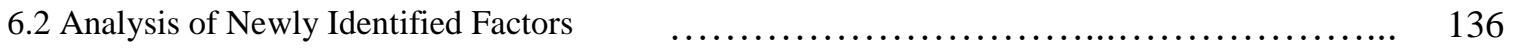

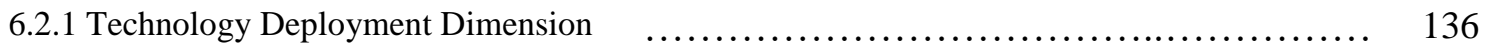

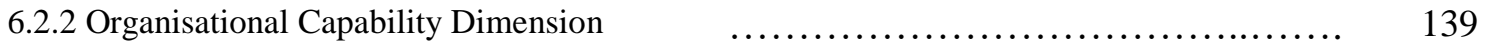

6.2.3 Process Efficiency Dimension $\quad$.................................... 141

6.3 Revised Conceptual Model $\quad$...................................... 142

6.3.1 Capability Level Definitions $\quad$.................................... 143

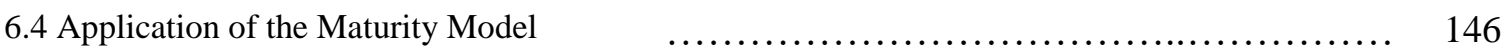

6.4.1 Case Study One: Maturity levels of SLA $\quad \ldots \ldots \ldots \ldots \ldots \ldots \ldots \ldots \ldots \ldots \ldots \ldots \ldots \ldots \ldots \ldots$

6.4.2 Case Study Two: Maturity levels of RLA $\quad \ldots \ldots \ldots \ldots \ldots \ldots \ldots \ldots \ldots \ldots \ldots \ldots \ldots \ldots$

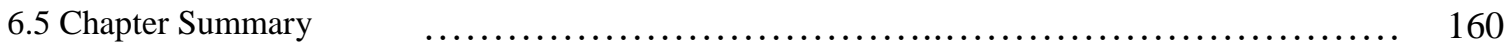

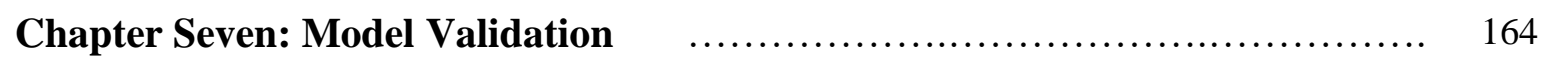

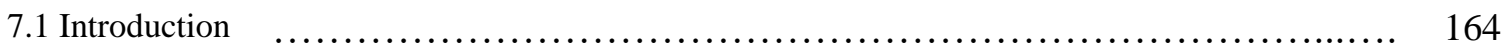

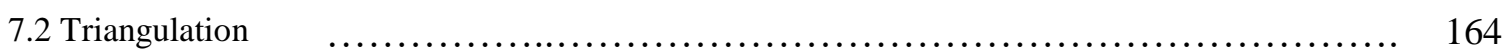

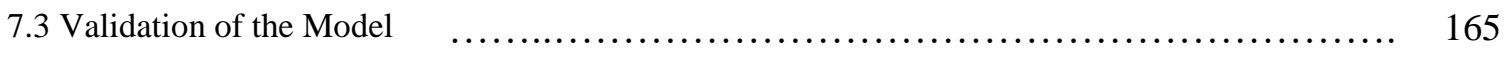

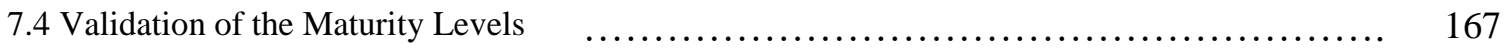

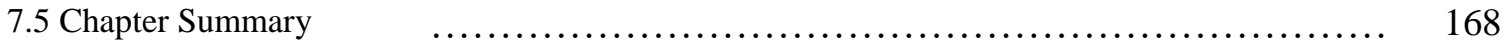

Chapter Eight: Discussion and Conclusions $\quad \ldots \ldots \ldots \ldots \ldots \ldots \ldots \ldots \ldots \ldots \ldots . \ldots \ldots 1$

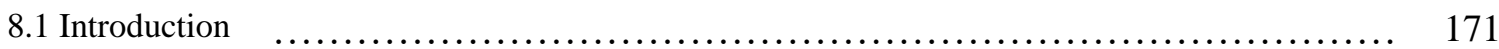

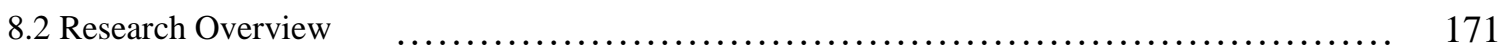

8.3 TOP Model: Comparison with Existing Models $\quad$. $\quad \ldots \ldots \ldots \ldots \ldots \ldots \ldots \ldots \ldots \ldots \ldots \ldots$

8.4 Model Advantages and Disadvantages $\quad \ldots \ldots \ldots \ldots \ldots \ldots \ldots \ldots \ldots \ldots \ldots . \ldots \ldots$

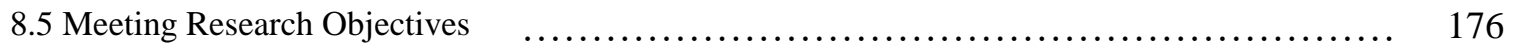

8.6 Research Contribution to the Body of Knowledge $\quad \ldots \ldots \ldots \ldots \ldots \ldots \ldots \ldots \ldots \ldots \ldots \ldots \ldots \ldots$

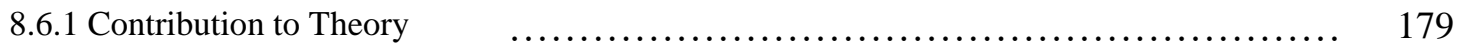

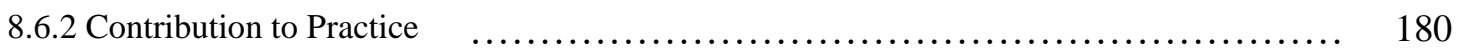

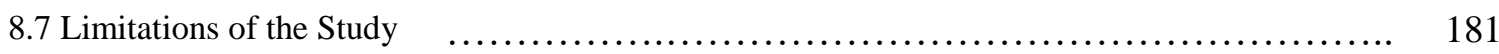

8.8 Recommendation on eGovernment Implementation $\quad$............................ 182

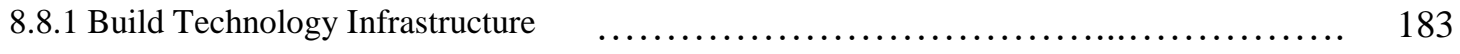




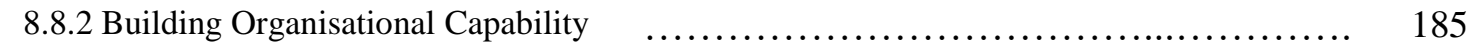

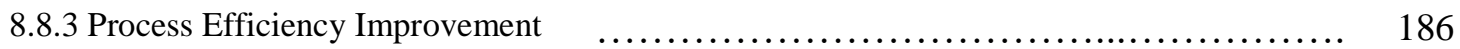

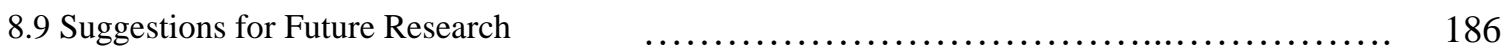

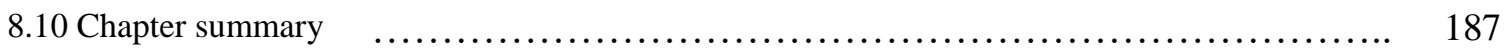

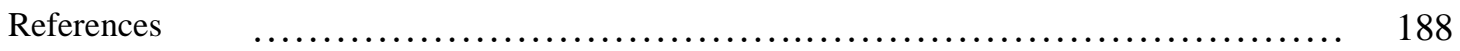

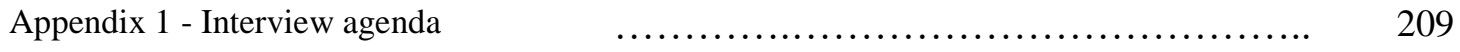

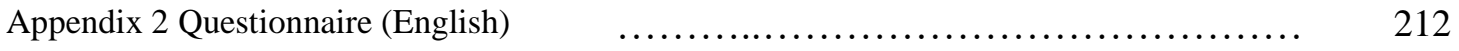

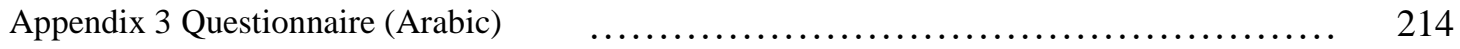

Appendix 4 Sample of Some Answers from interview $\quad \ldots \ldots \ldots \ldots \ldots \ldots \ldots \ldots \ldots \ldots \ldots \ldots . \ldots \ldots \ldots$

Appendix 5 Translation of Sample of Some Answers from interview $\quad \ldots \ldots \ldots \ldots \ldots \ldots \ldots . . . . .221$ 


\section{LIST OF TABLES}

Table 1. 1 eGovernment Ranking in the Africa 2016

Table 2. 1 eGovernment Definitions .26

Table 2. 2 World eGovernment leaders (Very High EGDI) in 2018 ......Error! Bookmark not defined.

Table 2. 3 Barriers to eGovernment implementation in developed countries Error!

\section{Bookmark not defined.}

Table 2. 4 eGovernment Development in the Middle East and North Africa (MENA) ..........33

Table 2. 5 Developing and Developed Countries: Aspects of eGovernment ..........................36

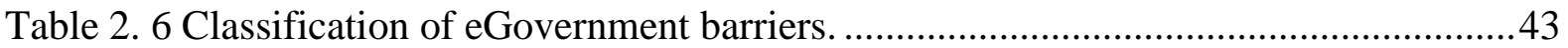

Table 2. 7 eGovernment Barriers Identified from the Literature ...........................................50

Table 2. 8 Challenges factors regarding technology dimension ............................................52

Table 2.9 challenges factors regarding organisational capability dimension ........................53

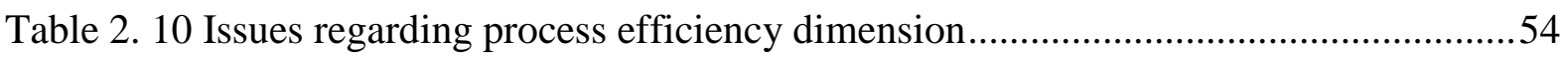

Table 3. 1 Sub-Factors of Documentation and Standardization ........................................... 70

Table 4. 1 Taxonomy of Epistemological Stances............................................................ 78

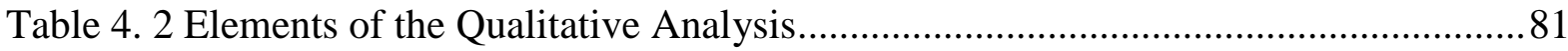

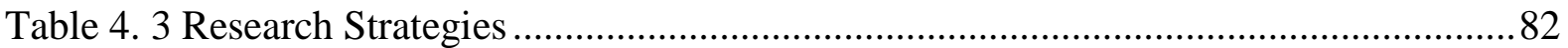

Table 4. 4 Selection of Organisations for Case Study Research........................................... 86

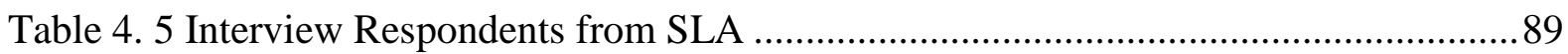

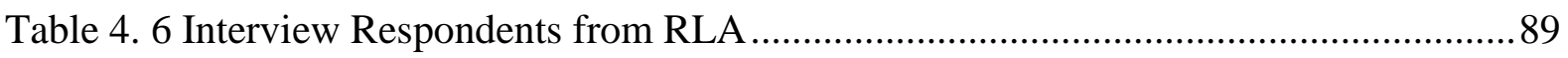

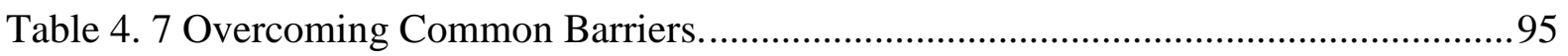

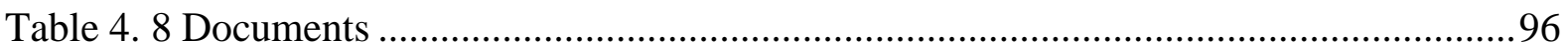

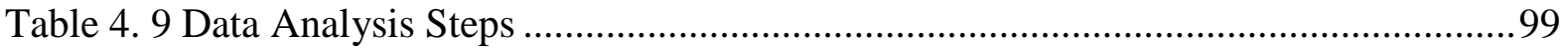

Table 4. 10 Interviewees for the Validation Process ......................................................... 102

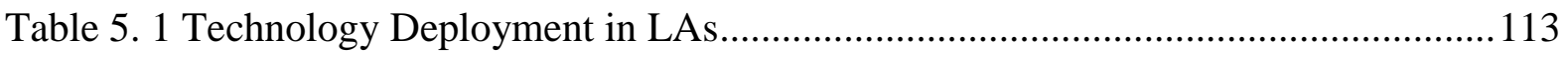

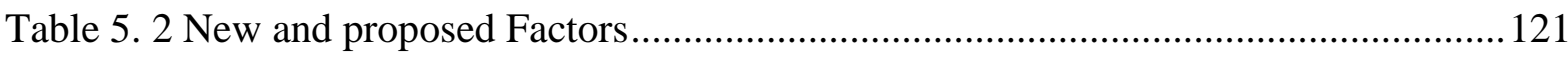

Table 5. 3 Organisational Capability New Factors ............................................................ 132 
Table 5. 4 Process Efficiency New Factors Error! Bookmark not defined.

Table 6. 1 Qualitative Model Definitions of Technology Deployment Dimension 145

Table 6. 2 Qualitative Model Definitions of Organisational Capability Dimension 145

Table 6. 3 Qualitative Model of Process Efficiency Dimension 146

Table 7. 1 Triangulation 164

Table 7. 25 Points Likert Scale 165

Table 7. 3 Dimension Factors and Sub-Factors: Survey Assessment......Error! Bookmark not defined.

Table 7. 4 Maturity Levels: Survey Assessment Error! Bookmark not defined.

Table 8. 1 Maturity models' stage names. Error! Bookmark not defined.

Table 8. 2 Comparison between TOP maturity model and previous models Error! Bookmark not defined. 


\section{LIST OF FIGURES}

Figure 1. 1 e-Libya objectives 17

Figure 2. 1 eGovernment Development Index (EGDI) in 2016 and 2018 .32

Figure 2. 2 Potential and risks of eGovernment in sub-Saharan Africa .35

Figure 2. 3 Sustainability Framework for eGovernment Success. Error! Bookmark not defined.

Figure 2. 4 eGovernment Implementation Benefits, Barriers and Risks 41

Figure 2. 5 Four Staged Model 44

Figure 2. 6 Stages of the UN model of eGovernment Development......Error! Bookmark not defined.

Figure 2. 7 Dimensions of eGovernment, Error! Bookmark not defined.

Figure 2. 8 Capability Maturity Model. .46

Figure 2. 9 The Connect-Publish-Interact-Transform (CPIT) Model.....Error! Bookmark not defined.

Figure 3. 1 Technology Deployment: Factors and Sub-Factors Error! Bookmark not defined.

Figure 3. 2 Organisational Capability: Factors and Sub-Factors 68

Figure 3. 3 Process Efficiency Dimension: Factors and Sub-Factors 70

Figure 3. 4 Proposed Conceptual Model .71

Figure 3. 5 Dimension Maturity Levels Error! Bookmark not defined.

Figure 4. 1 Interview Question Categories 92

Figure 4. 2 Convergence of Multiple Sources of Evidence 99

Figure 4. 3 Model Validation Error! Bookmark not defined.

Figure 5. 1 Map of Libya 107

Figure 5. 21 Libyan LAs Functional Structure (left) and Main Processes (right) 110

Figure 6. 1 The Revised Conceptual TOP Model. 143

Figure 6. 2 Dimension Maturity Model Levels. Error! Bookmark not defined.

Figure 6. 3 Main Processes for Libyan Local Administrations Error! Bookmark not defined.

Figure 6. 4 Overall eGovernment Maturity Level for SLA 162 
Figure 6. 5 Overall eGovernment Maturity Level for RLA

Figure 8. 1 Maturity Levels Strategic Gap. Error! Bookmark not defined.

Figure 8. 2 Suggested Systemized TOP Model Error! Bookmark not defined.

\section{ABBREVIATIONS}

\begin{tabular}{|l|l|}
\hline IS & Information Systems \\
\hline ICT & Information and Communication Technology \\
\hline EGDI & eGovernment Development Index \\
\hline SEI & Software Engineering Institute \\
\hline MLA & Ministry of Local Authorities \\
\hline LA & Local Authority \\
\hline PM & Procurement Management \\
\hline FM & Financial Management \\
\hline HR & Human Resource Management \\
\hline LAM & Legal Affairs Management \\
\hline CSM & Community Services Management \\
\hline
\end{tabular}




\section{Chapter one: Introduction}

\subsection{Background}

eGovernment has rapidly emerged in developing countries over the past decade. This is due to the benefits it can bring as an enabling mechanism to increase efficiency and enhance transparency within government organisations. eGovernment is a concept that is widely accepted by researchers, academics and practitioners in the information and communication technology (ICT) environment. For instance, the United Nation recognised the World Summit of the Information Society (WSIS), which encourages governments around the world to establish e-services (UN, 2014). According to the Information and Telecommunication Union (ITU, 2009), countries in all regions of the world and at all levels of development continue to make significant investments in the public sector, making eGovernment a priority to reform government organisations. Sweisi and Adams (2008) argue that governments have realised that ICTs help to interact and communicate with the citizens, businesses and others government agencies; and the availability of the internet, 24 hours a day, allows government information and services to be more available to more stockholders, at greater convenience and with increased satisfaction. They also pointed out that the rapid development in information technology (IT) made the adoption of eGovernment no longer an option for governments around the world, but rather an important necessity due to the needs of people and new demands of the information age (Sweisi and Adams, 2007).

Furthermore, in the current information age, ICT has a profound effect on most socioeconomic, political and cultural aspects of society and is a necessary tool for the implementation of national development plans in many countries. However, inadequate infrastructure and poor standards in public sectors in most developing countries is impeding progress towards the realisation of a digital society. Therefore, eGovernment is now attracting significant research interest and it is expected to become one of the most investigated applications of ICT in the coming years (UN, 2016). Research already conducted highlights the benefits that eGovernment offers to citizens, businesses and governments. In fact, the promise of efficiency in the provision of governmental services, reduction in paper work and 
corruption alleviation has inspired many researchers to examine eGovernment adoption and implementation in public sector organisations.

The existing literature suggests that many eGovernment initiatives have not been completed successfully, especially in the developing world. $60 \%-80 \%$ of eGovernment projects fail or do not achieve their goals (Abdalla, 2012). Many researchers found that eGovernment initiatives must take into account the diversity of government systems, technological infrastructure, culture, and political and economic conditions. They argue that the adopted values have to match the context within which eGovernment is carried out. Some suggest that the incompatibility between the context and the targeted goals and values (whether political, economic or even technical) can easily lead to failure. There is an inadequate context-based framework developed for the purpose of better adopting eGovernment and identifying the key issues and factors affecting the adoption process, in a developing country context.

eGovernment services provide many benefits to a country like Libya, which is very large and has long distances between cities. For instance, citizens who need to conduct many government transactions and activities must travel to local authorities or even to the capital which often requires making a journey of hundreds or thousands of kilometres which takes considerable time and money. However, eGovernment services provide the promise of removing the need to travel long distances. The basic needs for government information can be met via the web.

The context for this research is Local Authorities (LAs) in Libya because these constitute the public sector entities which provide services that directly affect the citizens. In the year of 2010, the Libyan Government mandated the Ministry of Communications and Informatics (MCI) to develop an eGovernment strategy to modernize government services. This initiative, known as 'E-Libya', aims at putting technology at the centre of government operations to enhance the services provided to all residents and businesses of Libya wherever they are and at all times, using modern communication networks and systems. Figure 1.1 illustrates the objectives of E-Libya. 
Figure 1. 1 e-Libya objectives

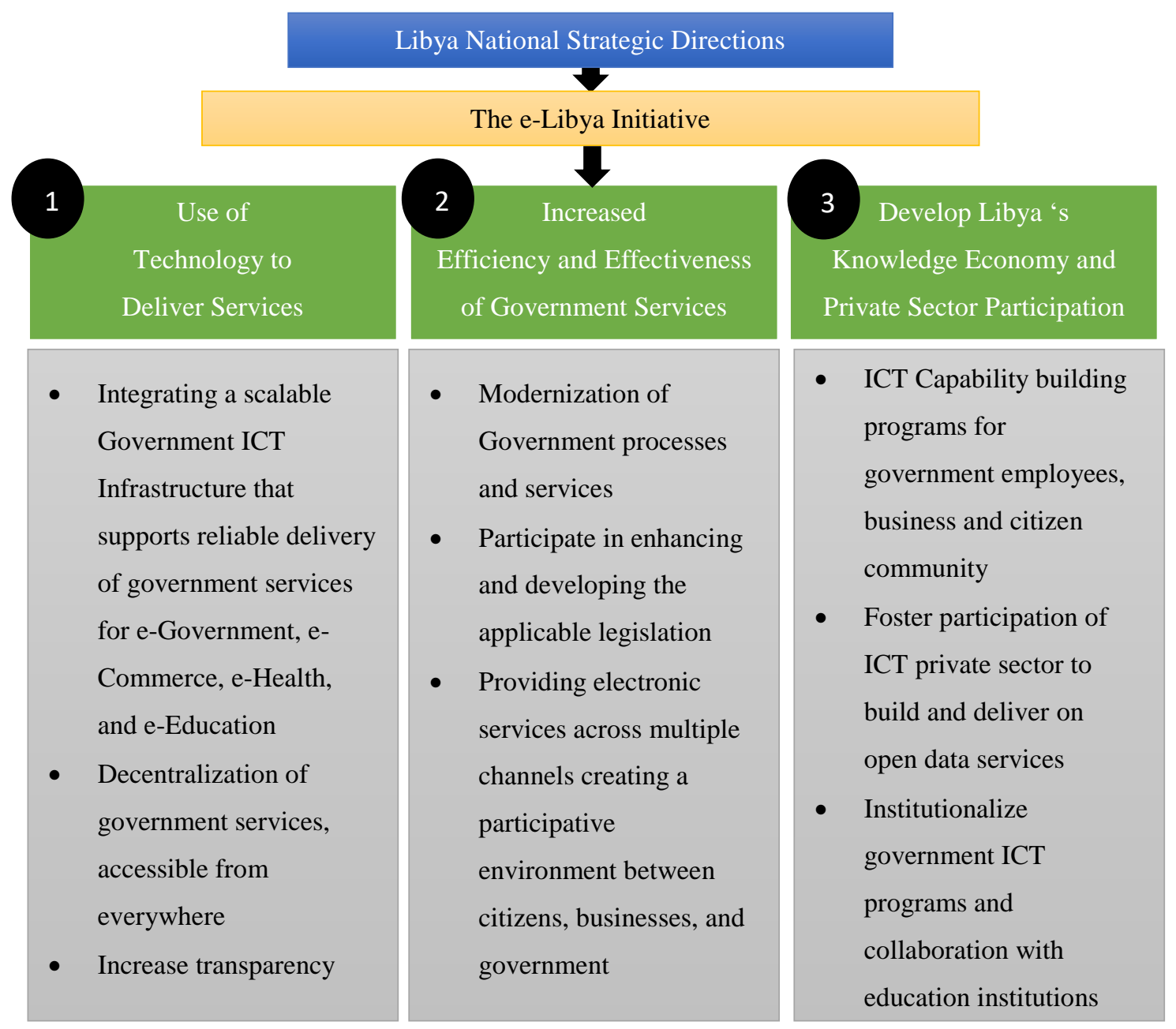

Source (e-Libya newsletter, 2012)

Although the e-Libya initiative is viewed as a major milestone for Libya to bridge the digital divide and to convert to an information-based society, the project was suspended in 2015 due to the unstable political situation. Late in 2017, the government started to resurrect the initiative by starting negotiations with PricewaterhouseCoopers to commence and provide a comprehensive eGovernment plan as previously agreed in 2012 .

\subsection{Statement of the Problem}

Although the eGovernment phenomenon can be witnessed widely in the public sector, many problems still surround its diffusion and adoption. The research problem in this study is identified through two main sources:

The literature examined in order to build the research background of eGovernment, understand the problems facing developing countries and identify the literature gap. 
The preliminary study conducted in LAs. The researcher conducted eighteen interviews with key executives to understand LAs' motivations to adopt eGovernment and what issues, challenges and factors influence the adoption process.

The findings from the literature review and the analysed data from the primary study highlighted several issues which led to the identification of the following problems:

- eGovernment is more than a technological dimension. It is a reengineering process affecting organizations' capabilities and process efficacy, which are thus fundamental in effecting this massive change. These change dimensions have received less attention when setting the strategic agenda, although they have greater impact in developing countries and in particular, Arab and African countries. In Libya as the focus of this research, these dimensions have a significant role in the decision making process. Therefore, better adoption can be achieved by directing the efforts and decisions to make the right choices and actions.

- The problem in using existing models is that they might not be applicable for developing countries, due to their different context and hence their different set of requirements. Therefore, there is a strong need for developing a conceptual framework that maps out a clearer picture of the specific needs and requirements in developing countries.

\subsection{Research Motivation and Objectives}

\subsubsection{Motivation}

The demand for eGovernment has increased in both developed and developing countries (Ahmed and As-Saber, 2018). Consequently, there has been an increasing interest in the eGovernment topic over the past decade and this interest is growing at a rapid rate. Many research studies, academic papers and conferences stress the need to further study eGovernment from different perspectives and in different contexts, using different approaches (Ahmed and As-Saber, 2018; Fatonah et al, 2018). In most of the developing countries, eGovernment is recognised as a main priority in their government organisations, and set as an important objective. Likewise, the decision makers in the Libyan government as mentioned earlier recognised the need to take advantage of the recent advances in ICT. Stakeholders' expectations of the government are getting higher, requiring a need for government to be competent, transparent, accessible and efficient. For this reason, the government encouraged and offered many scholarships for researchers who want to investigate eGovernment and e- 
services. This study is one of those research studies partially supported by the Libyan government.

A number of models have been developed to conceptualize the challenges involved in the adoption of eGovernment. These models often include the definition of stages that determine the maturity level of eGovernment services in a particular administration (Hu et al, 2018). They focus on the evolution of eGovernment using sequential steps - for instance, from immature to mature eGovernment with improved quality levels, as the organization advances through these steps (Abdallah and Fan, 2012).

From an academic perspective, the United Nation's model is the most referenced maturity model (Wirths and Peter, 2015; Hassan, 2011). It identifies four stages of eGovernment evolution, and has been used for assessing eGovernment at national level in different countries. In 2014, the model was used to assess 179 out of 192 UN members (United Nation, 2014). Libya was categorized in the "enhanced presence" stage (see Table 1.1).

Table 1. 1 eGovernment Ranking in Africa 2016

\begin{tabular}{|c|c|c|c|c|c|c|}
\hline Country & Region & Sub-Region & $\begin{array}{c}\text { Online } \\
\text { Service Index }\end{array}$ & $\begin{array}{c}\text { EGovernment } \\
\text { Development Index } \\
\text { EGDI }\end{array}$ & $\begin{array}{c}\text { EGovernment } \\
\text { Development Index } \\
\text { Level }\end{array}$ & $\begin{array}{l}2016 \\
\text { World } \\
\text { Rank } \\
\end{array}$ \\
\hline Mauritius & Africa & $\begin{array}{l}\text { Eastern } \\
\text { Africa }\end{array}$ & 0.7029 & 0.6231 & High & 58 \\
\hline Tunisia & Africa & $\begin{array}{c}\text { Northern } \\
\text { Africa }\end{array}$ & 0.7174 & 0.5682 & High & 72 \\
\hline South Africa & Africa & $\begin{array}{c}\text { Southern } \\
\text { Africa }\end{array}$ & 0.5580 & 0.5546 & High & 76 \\
\hline Morocco & Africa & $\begin{array}{c}\text { Northern } \\
\text { Africa }\end{array}$ & 0.7391 & 0.5186 & High & 85 \\
\hline Seychelles & Africa & $\begin{array}{l}\text { Eastern } \\
\text { Africa }\end{array}$ & 0.4058 & 0.5181 & High & 86 \\
\hline Cape Verde & Africa & West Africa & 0.4565 & 0.4742 & Medium & 103 \\
\hline Egypt & Africa & $\begin{array}{c}\text { Northern } \\
\text { Africa }\end{array}$ & 0.4710 & 0.4594 & Medium & 108 \\
\hline Botswana & Africa & $\begin{array}{l}\text { Southern } \\
\text { Africa }\end{array}$ & 0.2826 & 0.4531 & Medium & 113 \\
\hline Libyan & Africa & $\begin{array}{c}\text { Northern } \\
\text { Africa }\end{array}$ & 0.1087 & 0.4322 & Medium & 118 \\
\hline Kenya & Africa & $\begin{array}{l}\text { Eastern } \\
\text { Africa }\end{array}$ & 0.5580 & 0.4186 & Medium & 119 \\
\hline
\end{tabular}

Source: United Nations (2016)

The adoption of eGovernment is more than a technological issue, as it is influenced by many factors (Ciarniene and Stankeviciute, 2015; Ebrahim et al., 2004). For instance, organizational structure and human capabilities are important factors which are related to the nature of the government in a particular country, and its overall role and responsibilities in society (Lessa, 2017; Andersen and Henriksen, 2006). However, in spite of its growing deployment, there is 
increased concern about the failure rate of eGovernment projects. Heeks (2006) indicated that the failure rate of eGovernment projects in developing countries was high, almost $35 \%$ of projects being total failures, $50 \%$ partial failures, with only $15 \%$ being successful.

\subsubsection{Research Objectives}

This research project investigates the factors influencing eGovernment implementation and makes a contribution to knowledge in three regards. First, it provides a model that can be used by local level administrations; second, it analyses the administration at process level; and third, it develops metrics for assessing a number of different dimensions of eGovernment, these provisionally focusing on technology deployment, organisational capability, and process efficiency. The research addresses the following research objectives (ROs):

1. To critically analyse the extant literature and current practice regarding eGovernment in both the developed and developing worlds.

2. To explore and analyse the issues, factors and challenges faced by Libyan local government (at individual process level within the organization) with respect to the provision of eGovernment services.

3. To develop a new maturity model for the assessment and management of eGovernment services in Libyan local government

4. To apply and evaluate the model using two Libyan local government administrations as case studies.

\subsection{Significance of the Research}

This research investigates the adoption of eGovernment in LAs in Libya as a developing country. It is an important theme for researchers, professionals, politicians and decision makers in developing countries, which are characterized by low levels of diffusion and adoption. The findings and conclusions of this study will be useful for policy makers at both the national and organisational level; to guide them towards taking correct decisions, enhance their environments and prepare the public sector for the process of change. The significance of this research can be seen at different levels: 


\subsubsection{It provides a deeper understanding of contextual factors}

In previous eGovernment studies, much of conducted research, surveys, assessments and even training programmes focussed on technical factors. This research takes a holistic view by addressing the contextual issues, both technical and non-technical, that contribute to eGovernment adoption.

\subsubsection{It complements research on Africa and the Arab World}

Many governments in the Arab World and in Africa are embracing the digital era, but there needs to be significantly more examination, testing and knowledge development. However, there is relatively little research related to eGovernment in either region.

\subsubsection{It adds to research in Libya}

This research highlights the importance of eGovernment adoption in LAs in Libya as a significant issue for academics and professionals. There has been very little research examining this topic regarding Libya. The importance of this research is to help identify the challenges facing, and opportunities for assisting, the adoption process. Further, the analysis and findings from this research are expected to provide valuable information and guidelines for use in decision-making, regarding the adoption of eGovernment in LAs at process level.

\subsection{Research Structure and Content}

This study presents a detailed discussion related to the purpose, background, literature review, methodology, data collection and analysis, discussion of the findings and limitations, and recommendations for successful implementation of e-government projects in the LA in Libya. Accordingly, the thesis is divided into eight chapters. An illustration of the thesis structure is shown below. The description of the chapters is as follows:

Chapter one provides the background to the research with a clear statement of the importance and originality of the research objectives.

Chapter two provides an extensive literature review to better understand the area of eGovernment. It covers the current situation of eGovernment around the world and the critical factors influencing its adoption within the context of developing countries. Further, a research gap is identified in existing knowledge and a list of the challenges and barriers have been created and categorized into three dimensions. 
Chapter three provides a deep review of factors and sub-factors for each dimension and later in this chapter the proposed model was introduced.

Chapter four provides a description of the research strategy and the outline of the research methodology that has been followed to ensure that its design is appropriate to provide the answer to the objectives.

Chapters five sets out the major findings and outcomes resulting from the interpretation of all interviews from two case studies (Sabratha and Rujban local authorities)

Chapter six provides model refinement and assesses the maturity levels of each process within the SLA and RLA.

Chapter seven discusses the validation procedures adopted to ensure the quality and rigor of this research's findings as a qualitative research and the usefulness of the developed model.

Chapter eight shows how the research findings achieved the objectives of the research. The chapter also provide a summary of the entire work, including: the novelty of the developed model and the identified dimensions; and the contribution to knowledge in research and practice. In addition, the chapter presents the limitations of the research, the recommendations that help to make eGovernment successfully adopted and details future work that can guide research into areas where there is potential for practical and academic development.

\subsection{Chapter Summary}

The purpose of this chapter was to outline the fundamental research issues. The researcher has provided the rationale for the study, having presented the problems that are the motivation for this research. This was followed by background on Libya and its initiative of eGovernment (e-Libya). The importance of the research and the way it is adding to knowledge was also discussed. Accordingly, the research objectives were also set out.

The next chapter covers the review of existing literature of relevance to the field of eGovernment implementation. This allows a critical review of the existing literature to identify the research gap and generate and develop a new provisional model for analysis in chapter 3. 


\section{Chapter Two: Literature Review}

\subsection{Introduction}

The aim of this chapter is to review a range of literature in relation to eGovernment. In order to achieve this aim, the literature presented in this chapter is divided into a number of sections.

Section 2.2 explores how eGovernment has been defined and explained in existing literature. Section 2.3 discusses eGovernment benefits. Section 2.4 provides a global perspective of eGovernment Section 2.5 provides models of eGovernment where a number of models and frameworks of eGovernment are discussed. In Section 2.6, a critical analysis of eGovernment models is introduced. Section 2.7 discusses elements of the proposed conceptual model of the study. Section $\mathbf{2 . 8}$ provides a summary of the chapter as a whole.

\section{2 eGovernment: An Overview and Definition}

Governments have been searching for better ways to operate and provide improved services to the public since the 1980s (Abdallh, 2012). It is widely acknowledged that eGovernment has been a response to the need to improve local and national government operations (Jadi and Jie, 2017). In the 1990s, the emergence of network-based IT represented a turning point in the strategic route for government agencies, which now had the opportunity to exploit the technology of IT to achieve their goals. eGovernment came to the fore during the 1990s and since then it has been in a constant state of development; however, public sector organisations in developed and developing countries have realised the importance of making their services more effective, efficient and accessible by revolutionising governments' interactions with their stakeholders (Rammea and Grobbelaar, 2017; Affisco and Soliman, 2006).

In the last decade, there has been pressure and demand from citizens to provide government services online, due to growing technological maturity lowering the risk of adopting new technologies. There is also international pressure to participate in the eEconomy and be part of the global economic network (Hatsu and Ngassam, 2017). This pressure forced policy and decision makers, including those in poor and less developed countries, to facilitate the move to eGovernment systems. Unfortunately, the transformation has often been associated with complexity and difficulty due to the multiple dimensions and perspectives involved (Veenstra et al., 2011). It is evident that eGovernment is surrounded by political, economic, cultural, 
technological and organizational factors; and these factors greatly influence the various sectors and stages of eGovernment progress (Sunassee et al, 2017; Nguyen, 2014; Edington and Shin, 2006; AL-Shehry et al., 2006). The socio-technical nature of eGovernment suggests that these issues will need to be addressed as the contextual nature of a country can lead to eGovernment difficulties. Therefore, the complexity of eGovernment as a socio-technical system (Hafizi et $a l$, 2014) challenges the transformation in many developing countries such as Libya. It is clear that eGovernment offers great opportunities for governments to enhance efficiency and increase productivity, but it also raises many challenges.

There is no standard definition of eGovernment as academicians and practitioners have attempted to define this concept based on notion, context and application. Whilst Budd and Harris (2004) explained that the emergence of eGovernment was as a result of a shift from technology to management as well as the development of scope, performance and policy intentions. Backus (2001) defines eGovernment as a form of e-business in governance and refers to the processes and structures needed to deliver electronic services to the public (citizens and businesses), collaborate with business partners and to conduct electronic transactions within an organisational entity. It has become an explicit component of public sector reform, as an instrument to increase efficiency, strengthen competitiveness and enhance modernisation. On the other hand, Van Der Molen and Wubbe (2007) described eGovernment as the use of ICT to improve the activities of public sector organisations. They believed that eGovernment had become an issue in all fields of public administration.

Otubu (2017) defines eGovernment as the process whereby the use of ICT, is deployed and employed by the government in the delivery of services to members of the public, and in the internal running and linkages among different governmental agencies. Heeks (2006) also describe the concept of eGovernment as combination of the key characteristics of a technological department and public administration, and it concentrates on customer service front office, and organisational structure - back office.

Scholars and practitioners have attempted to define eGovernment based on different dimensions as shown in Table 2.1, which illustrates a range of different definitions of eGovernment based on exiting literature. 
Table 2. 1 eGovernment Definitions

\begin{tabular}{|c|c|}
\hline Sources & Definition \\
\hline Gunter (2006) & $\begin{array}{l}\text { The use of information and communication technologies (ICT) in order } \\
\text { to deliver public services to citizens and businesses and entails the } \\
\text { transformation of public services available to citizens using new } \\
\text { organisational processes as well as new technological trends. }\end{array}$ \\
\hline $\begin{array}{l}\text { Bélanger and Carter } \\
\qquad(2008)\end{array}$ & $\begin{array}{l}\text { eGovernment is information technology to enable and improve the } \\
\text { efficiency with which government services are provided to citizens, } \\
\text { employees, businesses and agencies. }\end{array}$ \\
\hline Khan et al. (2010, p200) & $\begin{array}{l}\text { "eGovernment refers to the use by government agencies of information } \\
\text { and communication technologies (such as Wide Area Networks, the } \\
\text { Internet, and mobile computing) that have the ability to transform } \\
\text { relations with citizens, businesses, and other arms of government" }\end{array}$ \\
\hline World Bank (2015) & $\begin{array}{l}\text { eGovernment refers to government agencies' use of information } \\
\text { technologies (such as Wide Area Networks, the Internet, and mobile } \\
\text { computing) that have the ability to transform relations with citizens, } \\
\text { businesses, and other arms of government. These technologies can serve } \\
\text { a variety of different ends: better delivery of government services to } \\
\text { citizens, improved interactions with business and industry, citizen } \\
\text { empowerment through access to information, or more efficient } \\
\text { government management. The resulting benefits can be less corruption, } \\
\text { increased transparency, greater convenience, revenue growth and/or cost } \\
\text { reductions. }\end{array}$ \\
\hline
\end{tabular}

There are many definitions of eGovernment that reflect different perspectives of experts and researchers in the field; there is no one definition that has broad acceptance. Lowery (2001) suggests that eGovernment is more than websites, e-mails or processing transactions via the internet, and that it differs depending on government perspectives as well as the community's goals and values. Ashaye and Irani (2012) inferred that eGovernment has no agreed definition due to reasons of its different dimensions, which can be viewed from different perspectives; for example, those of business, politics, and society. These dimensions also include the categories of interaction; for example, government to citizens (G2C), government to business (G2B), and government to government (G2G). Means and Schneider (2000) concentrated on the relationship between government and its stakeholders; they mentioned that eGovernment is the way that government uses technology, such as the internet, to deliver services and information to its citizens, businesses, and other agencies, to improve relations among them. 
The United Nations eGovernment Survey (2002) defines eGovernment as the use of ICT to facilitate the daily services of government. Moreover, InfoDev (2002) defines eGovernment through the benefits attained, such as providing greater access to government information; promoting civic engagement by enabling the public to interact with government officials; making government more accountable by making its operations more transparent, and thus reducing the opportunities for corruption and providing development opportunities, especially benefiting rural and traditionally underserved communities. Napitupulu et al. (2017) consider that eGovernment improves the relationship between the government and stakeholders by means of ICT. Sensuse et al. (2017) considers eGovernment to be a social, economic and political phenomenon without specific definition that delivers government services in an alternative way.

eGovernment encompasses different views from different perspectives, and this has produced a range of different eGovernment frameworks to be used in practice. Some scholars describe eGovernment as internet-based technology providing services, others restrict it to being a relationship between government and its customers, whilst others describe it as a new phenomenon changing the social, economic and political life. There are definitions that concentrate on ICT to deliver services such as those of the United Nations eGovernment Survey (2002), Fountain (2001), Duffy (2000), Heeks (2004) and others, which concentrate on the process of eGovernment services transformation, and what the benefits of delivering electronic government services are (Gunter, 2006; Means and Schneider, 2000; InfoDev, 2002); and those whose definitions describe eGovernment as a social, political or even economic phenomenon who include Sheridan and Riley (2006) and Riley (2001).

Despite the short history of research on eGovernment, it has been strongly characterised by its multi-disciplinary nature; the definition of eGovernment remains a vague and debatable issue among many eGovernment scholars. Heeks and Bailur (2007) suggest eGovernment can be viewed within a number of disciplines such as IT, public administration and political science. Sweisi and Adams (2016) pointed out that the meaning of eGovernment varies across the globe, and the definition of eGovernment depends upon the particular author's views.

For the purposes of this research, the researcher defines eGovernment as the intensive use of IT for the provision of public services, the improvement of managerial effectiveness and the promotion of democratic values and mechanisms. The term eGovernment denotes the use of 
IT to change the structures and processes of government organisations. This definition is in line with Gunter (2006) definition.

\subsection{Benefits of eGovernment}

eGovernment promises the potential to facilitate the use of IT systems in government comprising both operational and strategic uses (Cervena and Romanova, 2016). Anderson (2006) articulate that, the quest to implement eGovernment is motivated by policy goals of increased efficiency, effectiveness, and information quality, improved interaction mechanisms, and in turn better governance tools. Further, Askounis and Sarantis (2010) pointed that eGovernment uses ICT to promote more efficient government and enables more convenient services. Most importantly, it allows greater access to information and makes government more responsible to their citizens, businesses and other government bodies.

The adoption of eGovernment is also recognized as a tool to reduce corruption, increasing transparency, increasing revenue and cost reduction. Therefore, it will reduce discretion and flexibility of civil servants and alters accountability. Ashaye and Irani (2014) pointed out that eGovernment forces information sharing since services would be available online for all to access and provides easier and quicker access to organisational knowledge to all employees, thereby flattening hierarchy.

Gharibi and Khan (2014), in their study of the Arabic world, supported the need for exploring eGovernment services when they summarise the opportunities as:

- Raise the level of performance: increase the speed and accuracy of information transmission between the various governmental departments which reduces the duplication of data entry and facilitate the access to information from the commercial sectors and citizens.

- Increase the accuracy of data: The mutual confidence in validity of data is high and the errors of manual entry are reduced.

- Reduced the administrative procedures: the availability of information with the digital format, reduces the paperwork and mobilization of data manually and the availability of electronic submission.

- The optimal use of human energies: the digital information can be easily move, manipulate, disseminate and reused.

- Recognized public services: It increases the capacity of networking and connectivity with emphasis on the access of services to all regions and sectors effectively. 
Ndou (2004) also suggests the following points are benefits of eGovernment implementation:

- Cost reduction and efficiency gains

- Quality of service delivery to business and customers

- Transparency, anti-corruption and accountability

- Increase the capacity of government

- Network and community creation

- Improve the quality of decision making

- Promote the use of ICT in other sectors of the society

As far as most developing countries are concern, emphases are laid on opportunities such as transparency, anti-corruption accountability, cost reduction and efficiency gains and promoting the use of ICT. Despite the benefits, it is imperative to classify them into elements and these would enable researcher to formulate conceptual model that could be tested and validated through data analysis.

\subsubsection{Classification of eGovernment Benefits}

Review of literature suggests that eGovernment benefits could be classified under the following concepts:

\subsubsection{Technical:}

The technical benefits have been widely discussed in existing literature, some of which include the ability to transform the existing services and expanding the new service delivery; encouraging stakeholder's participation in government operations and changing the way of working within the public sector. Implementing electronic government will be to improve the efficiency of the current system (Paper based system). That would in return save money and time. The introduction would also facilitate better communications between governments and its stakeholders. For example: E-procurement facilitates $\mathrm{G} 2 \mathrm{G}$ and B2B communication; this will permit smaller business to compete for government contracts as well as larger business. hence the advantage of creating an open market and stronger economy. Business and citizens can obtain information at a faster speed and it is possible at any time of the day. The society is moving towards the mobile connections and the ability of an eGovernment service to be accessible to citizens irrespective of location throughout the country brings the next and potentially biggest benefit of an eGovernment service as we live in what is now termed as the Knowledge era. The anticipated benefits of eGovernment include efficiency, improved services, better accessibility of public services, and more transparency and accountability. 
Ashaye and Irani (2014) explored other benefits such as provision of portability between systems and applications to encourage one-stop shop and self-service; building trust and increasing reliability and accuracy of data sharing; reducing data collection, process and storage; and encouraging intra- and inter- organisational networking through enhancement of ICT infrastructure.

\subsubsection{Organisational/Operational}

The effectiveness of government is measured by the quality of its interactions with citizens. The processing of paperwork in a traditional government system is a difficult task which consumes a lot of resources; time spent on paperwork does not create much value for citizens. This issue becomes even more relevant when consider the fact that citizens and businesses are demanding more from government and public services. Therefore, the establishment of a centralised point of communication through eGovernment, governments can achieve high operational efficiency (Ashaye and Irani 2014). Chandler and Emanuels, (2012) also assure that eGovernment improve the organisation's policy effectiveness and reduces the time required to complete transactions within minutes, which would otherwise have taken days. They also argue that eGovernment enables restructuring of administrative functions and processes, and monitoring government performance. Which will ease the pressure that could occur in the organisation as a result of queuing in waiting rows and because of its flexibility, it improves efficiency of operations and the growth in public esteem for government.

Furthermore, United Nation eGovernment Survey (2016), identifies eGovernment benefits as follows:

- Reduction of customers' and organisations' time, effort and costs

- Improvement of service delivery and citizens' satisfaction

- Increase in users' ICT skills, internet knowledge and computer usage

- Creation of new business and work opportunities

In addition, the Organisation for Economic Cooperation and Development (OECD, 2001) identified many advantages of eGovernment implementation such as:

- Improves efficiency of government agencies in processing of data

- Improves services through better understanding of users' requirements, thus aiming for seamless online services

- Shares information and ideas between all government agencies and department 
to build one mega database

- Assists a government's economic policy objectives by promoting productivity gains inherent in ICT and e-commerce

- Improving transparency, accuracy and facilitating information transforming between government and customers

- Helps in building trust between governments and citizens, an essential factor in good governance by using internet-based strategies to involve citizens in the policy

- Process, illustrating government transparency and accountability.

The above pointes classify the eGovernment benefits for government sector organisations based on a fundamental categorisation that identified through a review of relevant literature (OECD, 2003; Ndou, 2004; UN, 2016; Ashaye and Irani, 2014)

\subsection{A Global Perspective of eGovernment}

The success of e-commerce in the private sector has encouraged the public sector to use web technology for non-profit applications (Kigwana et al., 2017). Consequently, there has been an increase in research activity in eGovernment in the last decade. The United Nations has been producing an annual eGovernment survey since 2001 to measure the progress in online services delivery. According to a survey by the UN (2018), most countries around the world are continuing to progress and develop eGovernment services. The survey found that many have put in place eGovernment initiatives and ICT applications to increase public sector efficiencies and streamline governance systems to support sustainable development.

The United Nations Department of Economic and Social Affairs developed an eGovernment Development Index (EGDI) survey, which is a composite index based on the weighted average of three normalized indices. One-third is derived from a Telecommunications Infrastructure Index (TII) based on data provided by the International Telecommunications Union (ITU), onethird from a Human Capital Index (HCI) based on data provided by the United Nations Educational, Scientific and Cultural Organization (UNESCO), and one-third from the Online Service Index (OSI) based on data collected from an independent survey questionnaire.

The survey assesses the national online presence of all 193 United Nations Member States. The results are tabulated and presented as a set of standardized index values on a scale from zero to one; one corresponding to the highest rated online services and zero to the lowest. The survey 
highlights a persistent positive global trend towards higher levels of eGovernment development and indicates that 40 countries in 2018 scored very-highly, with EGDI values in the range of 0.75 to 1.00 , and 29 countries in 2016 as compared to only 10 countries in 2003 . The survey also indicated that since 2014, all 193 member have been delivering some form of online presence and the average world EGDI has been increasing from 0.47 in 2014 to 0.55 in 2018 due to the continuous improvement of its subcomponents indices. This suggests that internationally, there has been steady progress in improving eGovernment and public services provision online. (See Figure 2.1)

Figure 2. 1 eGovernment Development Index (EGDI) in 2016 and 2018
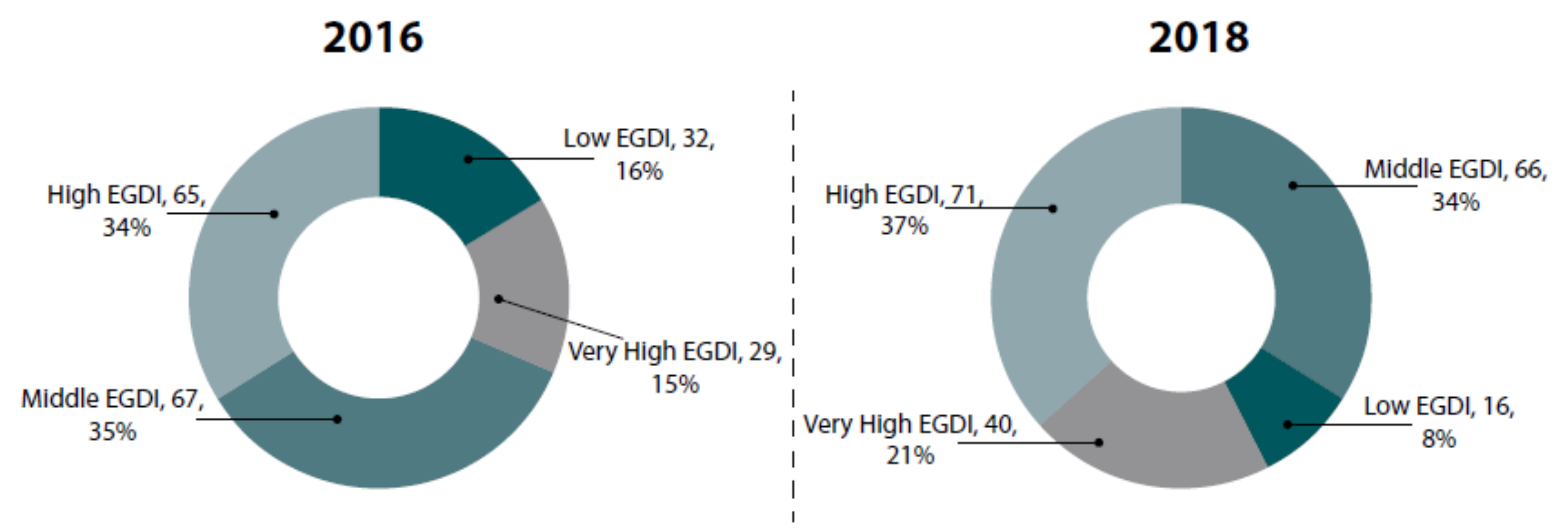

Source: United Nations eGovernment Survey (2018)

\subsection{1 eGovernment in Developing Countries}

Implementation of eGovernment in developing countries has always been a challenging problem due to technical, infrastructural, cultural, social, and political issues. United Nations surveys (United Nations eGovernment Survey, 2014; United Nations eGovernment Survey, 2016; United Nations eGovernment Survey, 2018) indicate that most African countries are considered as the least developed in terms of eGovernment. Hassan (2011) explains that the reasons why many countries in Africa lag in eGovernment development are the high deficiency in leadership, corrupt officials, and ambiguous ICT and eGovernment policies that are insufficient to address the contemporary role of ICT in government. As shown in Figure 2.2, some developing countries from the MENA region are also considered as the least developed in terms of eGovernment. Kim (2007) pointed out that the rich and developed westernised countries are more likely to have advanced technology, which allows them to have mature eGovernment services, whereas developing countries remain behind, and limited technology hinders the adoption of eGovernment. 
Nonetheless, it is important to realise that eGovernment applications around the world are not usually successful. Heeks (2006) estimated that $35 \%$ of all eGovernment initiatives are a total failure and only $15 \%$ can be considered as a success. Moreover, only 17 countries have reached advanced levels of maturity according to UNPAN (2014). It is argued that eGovernment initiatives are failing due to a lack of understanding regarding effective planning, development and deployment (Sharma et al., 2003), while others assert that the project goals are too ambitious given existing capacity. Heeks (2003) argues that the problem in developing countries often arises due to dissimilarities in technology, culture, economics, organisation, and various contextual factors. Nevertheless, this is not always the case, for example in the MENA region, eGovernment project in Emirates and Bahrain are ranked close behind the leading countries, whereas Libya and Algeria are ranked at the bottom of the EGDI list. There are similarities in the MENA region countries in social, political and cultural life as well as public administration, which is characterized by a surfeit of bureaucracy, centralised government and complex legislation. Nonetheless, each country has a different level of economic development, political stability and ICT infrastructure and this makes eGovernment practices unique in each country (see Table 2.4).

Table 2. 2 eGovernment Development in the Middle East and North Africa (MENA)

\begin{tabular}{|c|c|c|c|c|}
\hline Country & Region & 2016 EGDI & 2016 Rank & 2018 Rank \\
\hline Bahrain & Middle East & 0.7734 & 24 & 26 \\
\hline UAE & Middle East & 0.8295 & 29 & 21 \\
\hline Tunisia & North Africa & 0.6254 & 72 & 80 \\
\hline Saudi Arabia & Middle East & 0.7119 & 44 & 52 \\
\hline Egypt & North Africa & 0.4880 & 108 & 114 \\
\hline Libya & North Africa & 0.3833 & 118 & 140 \\
\hline Algeria & North Africa & 0.4227 & 129 & 130 \\
\hline
\end{tabular}

Source: United Nations eGovernment Survey (2018)

\subsubsection{1 eGovernment Challenges for Developing Countries}

While there is increasing adoption of electronic services by governments in developing countries, the level of implementation differs from country to country. However, the pace with which electronic services are made available and adopted is lower than planned in developing countries and governments tend to be slow in releasing new e-services. Citizens often prefer to conduct transactions with the government through paper forms and physical presence rather than using online methods (Hassan et al., 2011). 
Much literatures takes into consideration the differences between developing and developed countries, and they pay attention to the factors behind these differences concerning e-service development (Hamner and Al-Qahtani, 2009). The differences indicate that eGovernment in developing countries faces slower progress or even stagnation because it encounters multiple and complex barriers and challenges. Although some of these barriers are also faced by developed countries, the ability of these countries to recover and overcome challenges is far ahead of the developing countries' abilities.

Busoud and Zivkovic (2016) in study regarding Libya identified challenges that affect the adoption of process of eGovernment, they mentioned that numerous challenges were encountered in political, economic, social and technological aspects. Regarding social aspects, they argue that Libya suffer of lack of IT experts despite high literacy rate that places Libya in the 18th place on the world list. Regarding political aspect, they mentioned that political weakness for establishing good eGovernment practice is in poor legislation framework for IT sector that is departing potential investments in development of this sector and re-building infrastructure. Another problem is in great number of employees in public sector, which has no motivation to accepting e-Governance, because this advanced system brings considerable savings and greatly reduces the need for many employees. In term of technology aspect, they pointed out that validity of digital signature, cyber protection and acceptance of information from Internet source by government officials are also the problems that need to be solved.

Identifying and overcoming these barriers for Libya or any other developing countries is not always easy, given that most currently published e-service strategies are based on experiences from developed countries, which may not be directly applicable to developing countries. It takes several research disciplines to identify and understand these challenges. Moreover, planning for eGovernment requires deep comprehension and crucial recognition of the barriers that might stand in the way.

Schuppan (2009) articulates in his study the different challenges which must be considered when implementing eGovernment in African countries. The study provides some information concerning the general state of development of eGovernment in Sub-Saharan Africa. Three different cases are examined: Ghana, Uganda, and Kenya. As an orientation aid for understanding the case, the environmental conditions, the institutional and cultural administrative situation, as well as the potentials and risk of eGovernment have been summarized in the following. 
Figure 2. 2 Potential and risks of eGovernment in sub-Saharan Africa

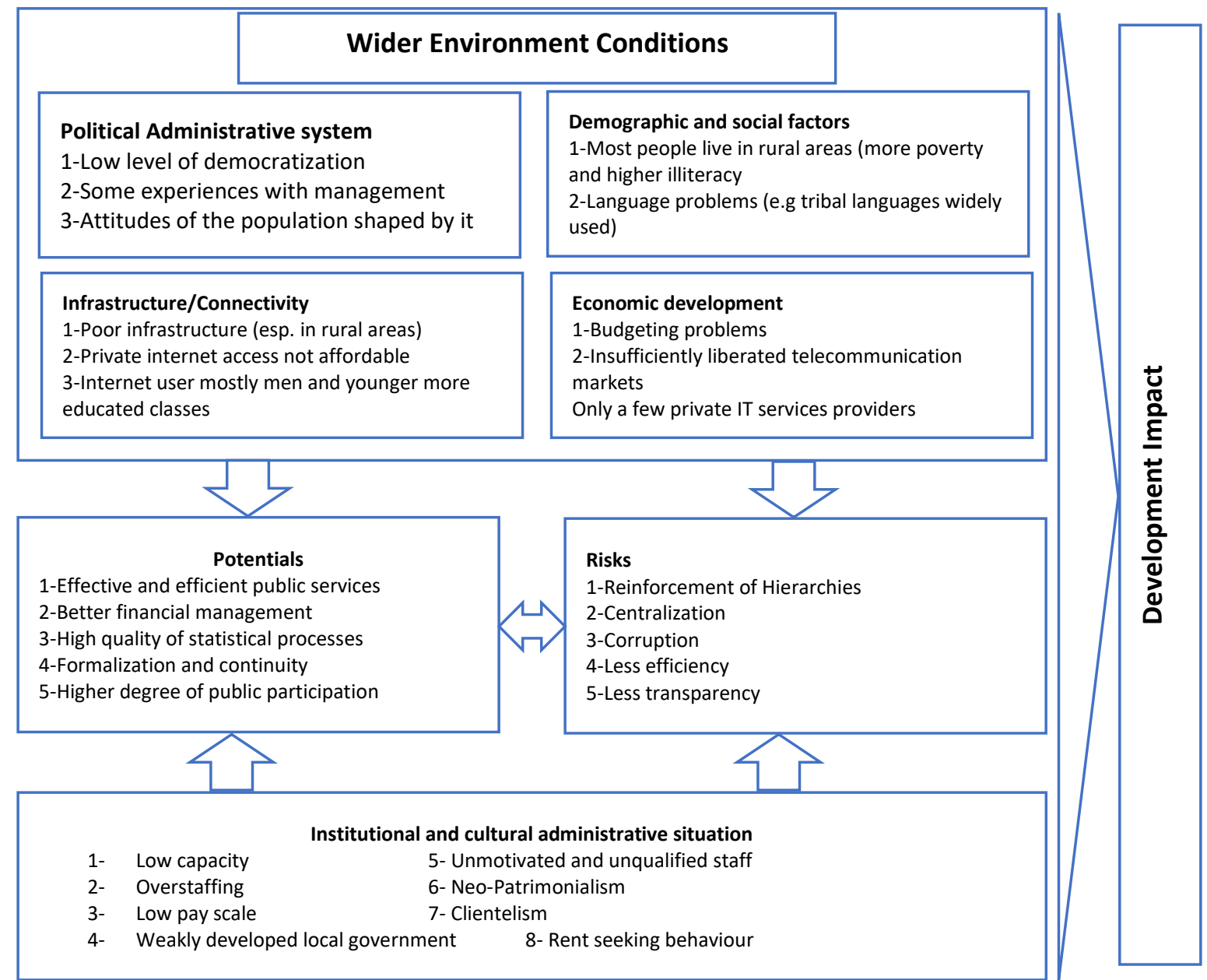

\subsection{2 eGovernment in Developing versus Developed Countries}

eGovernment in developing countries is still in its infancy and requires more effort to catch up with counterparts in developed countries. Developed countries such as Denmark, Australia, South Korea, Sweden, UK and others use the internet to deliver services, distribute information and enable dialogue between citizens and their government. Thus, they continue to launch multi-year programs to create and enhance more effective and efficient electronic services. Despite the fact that developed and developing countries have launched eGovernment projects, the challenges in ICT infrastructure, practices and usage remined a significant barrier to developing countries (Lutui et al., 2018). Furthermore, developing countries suffer from a lack of sufficient capital to build up the expensive national information infrastructures on which eGovernment is based; they also lack sufficient knowledge, skills and capacities to develop suitable eGovernment projects. Hence, successful implementation can be more challenging for developing countries. For example, governments of developing countries may face other obstacles, such as the digital divide, from which developed countries with sufficient resources 
would not suffer as much. These obstacles can be very critical issues, particularly for decisionmakers within developing countries, and can be the cause of eGovernment projects being abandoned.

According to the UN (2016), developing countries were reported to have relatively limited technological and human resources and less efficient management of these resources; those countries were categorized based on their Gross Domestic Product (GDP) per capita, their weak human assets and their high degree of economic vulnerability (UN, 2016). It was found that many developing countries have been investing in streamlining their national and ministry portals and websites to offer more electronic services and more actively engage citizens in dialogues with government; nonetheless, they may have to take more risks compared to developed countries in implementing their eGovernment initiatives. Table 2.5 compares developed and developing countries on five different categories.

Table 2. 3 Developing and Developed Countries: Aspects of eGovernment

\begin{tabular}{|c|c|c|}
\hline Category & Developed Countries & Developing Countries \\
\hline $\begin{array}{c}\text { History and } \\
\text { Culture }\end{array}$ & $\begin{array}{l}\text { Government and economy developed early, } \\
\text { immediately after independence } \\
\text { Economy growing at a constant rate, productivity } \\
\text { increasing, high standard of living } \\
\text { - } \quad \text { Relatively long history of democracy and more } \\
\text { transparent government policy and rule }\end{array}$ & $\begin{array}{l}\text { Government usually not specifically defined; } \\
\text { economy not increasing in productivity } \\
\text { - } \quad \text { Economy not growing or increasing productivity; } \\
\text { low standard of living } \\
\text { - Relatively short history of democracy and less } \\
\text { transparent government policy and rule }\end{array}$ \\
\hline $\begin{array}{l}\text { Technical } \\
\text { Staff }\end{array}$ & $\begin{array}{l}\text { - Has a current staff, needs to increase technical } \\
\text { abilities and hire younger professionals } \\
\text { Has outsourcing abilities and financial resources to } \\
\text { outsource; current staff would be able to define } \\
\text { requirements for development }\end{array}$ & $\begin{array}{l}\text { Do not have a staff, or have very limited in house } \\
\text { Staff } \\
\text { Do not have local outsourcing abilities and rarely } \\
\text { have the financial ability to outsource; current staff } \\
\text { may be unable to define specific requirements }\end{array}$ \\
\hline Infrastructure & $\begin{array}{l}\text { - } \quad \text { Good current infrastructure } \\
\text { - } \quad \text { High Internet access for employees and citizens }\end{array}$ & $\begin{array}{l}\text { - } \quad \text { Bad current infrastructure } \\
\text { - } \quad \text { Low Internet access for employees and citizens }\end{array}$ \\
\hline Citizens & $\begin{array}{l}\text { - High internet access and computer literacy; still has } \\
\text { digital divide and privacy issues } \\
\text { - } \quad \text { Relatively more experienced in democratic system } \\
\text { and more actively participate in governmental } \\
\text { policy-making process }\end{array}$ & $\begin{array}{l}\text { - Low internet access and citizens are reluctant to } \\
\text { trust online services; few citizens know how to } \\
\text { operate computers } \\
\text { - Relatively less experienced in democratic system } \\
\text { and less active participation in governmental policy- } \\
\text { making process }\end{array}$ \\
\hline $\begin{array}{c}\text { Government } \\
\text { officers }\end{array}$ & $\begin{array}{l}\text { Decent computer literacy and dedication of } \\
\text { resources; many place eGovernment at a high } \\
\text { priority }\end{array}$ & $\begin{array}{l}\text { Low computer literacy and dedication of resources; } \\
\text { many do not place eGovernment at a high priority } \\
\text { due to lack of knowledge on the issue }\end{array}$ \\
\hline
\end{tabular}

Source: Adapted from Chen et al. (2006) 
The comparison is built on five different aspects: History and Culture, Technical staff, Infrastructure, Citizens, and Government Officers. Ashaye (2012) argue that in many cases, eGovernment strategies and implementation in developing countries have been based on theories and experiences of developed countries. Thus, implementation and experiences from developed countries may not be directly applicable to developing countries due to these differences, and thus eGovernment projects in developing countries are either never implemented or abandoned immediately after implementation or partially fail in their major goals, causing significant undesirable outcomes. To understand the issues related to developing countries, more studies and research need to be done in preparation for the implementation process.

\subsubsection{1}

eGovernment experts around the world take the view that implementing a robust eGovernment infrastructure needs a staged approach, which transfers from immature to mature stages, and where full integration with public services is offered. Irani et al. (2006) suggest that having a staged approach when implementing eGovernment will create momentum that can be then reviewed and allow government agencies to attract more citizens to use e-services, until it becomes the norm and secure, so that citizens and businesses trust to deal with government portals as part of their standard services. There is a range of models and frameworks suggesting critical factors, useful from a variety of perspectives. The models are intended to provide a better understanding and visualisation of eGovernment adoption. However, the challenge of identifying the individual factors and their optimal combination remains an issue for researchers (Edington and Shin, 2006). Despite the fact that many studies have sought to identify the factors that contribute to eGovernment adoption (Moon, 2002), Edington and Shin (2006) argue that "there is a gap when it comes to integrating these factors into a holistic model".

An effective eGovernment with higher levels of diffusion and adoption requires an enabling context. This highlights a key issue - that of a comprehensive understanding of the real context of the state or organization in which the initiative is taking place (Bwalya and Healy, 2010). In the general area of technology adoption, much of the literature has focused on IT adoption in the public sector and how this helps to enhance its efficiency and effectiveness. Some other scholars argue that eGovernment needs to focus on a different collection of attitudes and values along with social, organisational and cultural factors (Lutui et al., 2018). 
In this context, different eGovernment models have been developed by individual researchers and they are discussed in this section, which contributes to the development of the model for this research.

\subsubsection{Sustainability Framework for eGovernment Success}

Lessa (2019) propose a framework for understanding success and sustainability of eGovernment initiatives, by uncovering the relationship between enablers of eGovernment success and sustainability, considering the role of IT-enabled administrative processes as a potential trajectory between these two concepts. The researchers examined the problem of sustaining eGovernment projects through interpretivist exploratory case study, to explore potential relationship between eGovernment success and sustainability in four different districts in Ethiopia, that already adopted $\mathrm{G} 2 \mathrm{G}$ project called WoredaNet. Figure 2.3 maps the relationships between the enablers of the two concepts. Noticeable findings of the multiple case study can be summarized as follows:

- Lack of awareness about ICTs among top management

- Leadership commitment at district level significantly affected the implementation and operation of WoredaNet services through provision of political support, availing required resources, recognizing ICT services, and making periodic monitoring and evaluation of ICT related activities

- Need-based and hands-on short-term trainings impacted the management and civil servants to be aware and competent to use the technology

- Infrastructure challenges hampered implementation of WoredaNet among districts

- Limited knowledge, experience, and skill of ICT professionals at district level

- Good change management culture brought difference in the adoption of technology

- Availability of motivated and capable ICT staff is vital in performing activities of the WoredaNet centres.

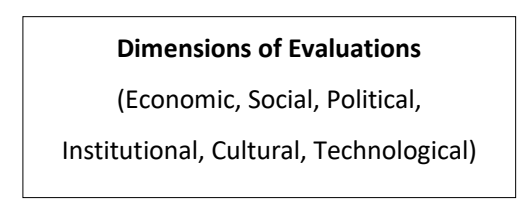


Figure 2. 3 Sustainability Framework for eGovernment Success

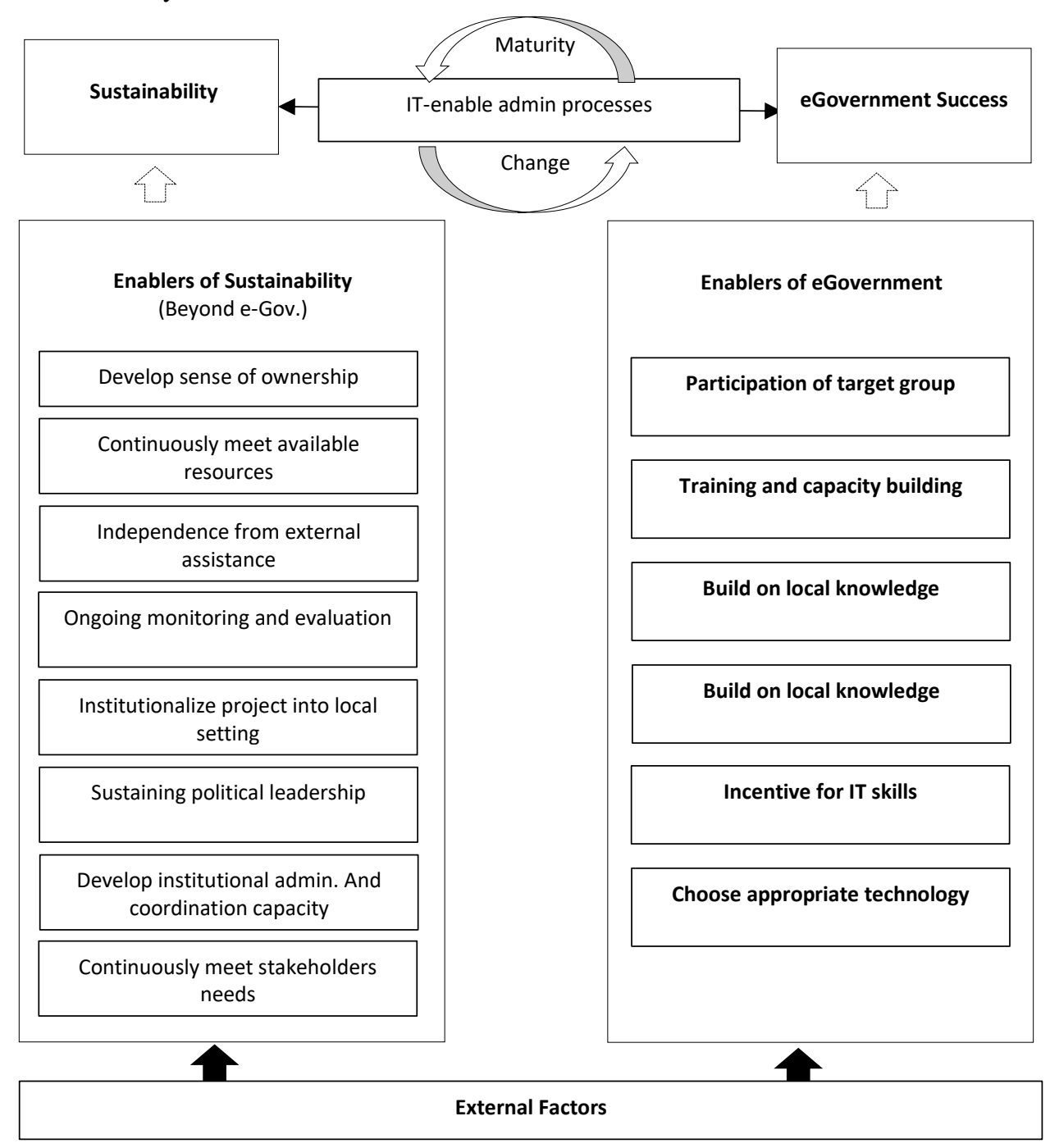

Source Lessa (2019)

\subsection{4 eGovernment Implementation Benefits, Barriers and Risks}

Ashaye and Irani (2014) developed a framework for eGovernment implementation which can support the execution process within the context of developing countries (specifically in Nigeria). Ashaye and Irani (2014) identified four parts in the framework: implementation factors (external and internal); implementation characteristics (benefits, barriers and risks); key actors (government, technologically-advanced countries, companies and users) and main activities; and the development (pre-implementation, implementation and postimplementation) stages.

Implementation factors - Identifying the external and internal factors and it was noted that some factors apparent in some developed countries have not yet appeared in many developed countries, Thus the model suggest that some drivers in developed countries might even appear as barriers in some of the developing countries. 
Implementation Characteristics: identifying benefits, barriers and risks of implementing eGovernment.

Identifying eGovernment implementation: key actors, main activities and good practice guidelines.

Development Life cycle: these comprises pre-implementation, during implementation and post-implementation phases.

Ashaye and Irani (2014) highlights the importance of the factors that influence eGovernment implementation, both within and outside the organisation and linking that to eGovernment implementation concepts in respect of the benefits, barriers and risks. The framework was applied to Federal Ministry of Housing, Land and Urban Development, and National Environmental Standards and Regulations Enforcement Agency in Nigeria.

Based on the research findings, the researcher was able to identify the benefits, barriers and risks influencing eGovernment implementation in Nigeria public sector context and additional factors were identified some of which are specific to the case studies context. Figure 2.4 illustrate the framework. 
Figure 2. 3 eGovernment Implementation Benefits, Barriers and Risks

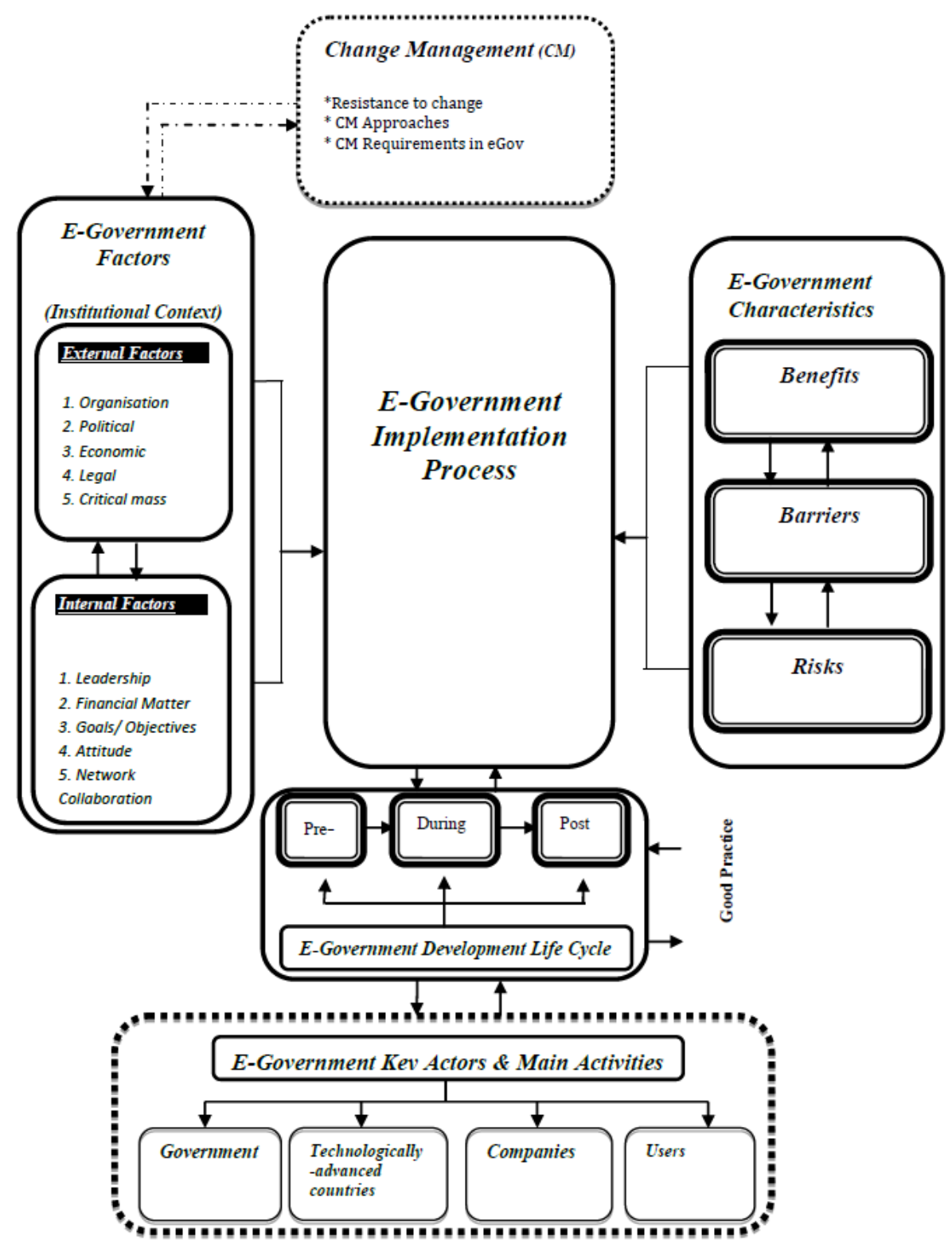

\subsection{5 eGovernment Architecture Framework}

Ebrahim and Irani (2005) argue that the eGovernment architecture framework helps IT practitioners in the public sector to learn how to use and manage information technologies to revitalise business processes, improve business decision-making, and gain competitive advantage from the adoption of eGovernment. The architecture framework defines standards identifies the infrastructure components, applications and technologies that are the guidelines for eGovernment adoption. Since it could be viewed in various perspectives, the authors have highlighted the importance of integrating the existing information systems and applications in public sector organisations in order to establish an efficient framework for eGovernment architecture. The authors emphases that the architecture framework is to reduce any confusion 
surrounding the eGovernment infrastructure in the public sector, by understanding the implementation process, identifying the requirements of ICT tools, highlighting the importance of the organisational management resources and the impact of barriers. The authors suggest that the architecture of eGovernment can be divided into four layers:

- Access layer: The access layer involves the channels that government users can access the various services.

- eGovernment layer: eGovernment layer discusses the approaches to improve these channels through integrating the digital data of different public-sector organisations into a single government web-portal.

- e-Business layer: Focuses on integration, coordination and interaction within and between individual systems in public sector organisations. It integrates front-end eGovernment layer applications with back-end activities to support the relationship and interaction of G-to-G and G-to-E.

- Infrastructure layer: provides a reliable foundation for the rest of layers, such as access layer, eGovernment layer, and e-business layer

The authors identify and analyse significant barriers to the adoption of eGovernment. Some of these barriers would appear to stand directly in the way of movement toward the various stages of eGovernment infrastructure maturity. Then, the authors classify these barriers into dimensions with practical examples as shown in Table 2.6.

The researcher therefore attempts to adopt some of the elements of the framework in structuring the perceived barriers in order to develop a conceptual model for eGovernment implementation. The proposed framework therefore considers only the factors that hinder implementation in eGovernment projects, in particular and IS/IT in general. 
Table 2. 4 Classification of eGovernment barriers.

\begin{tabular}{|c|c|}
\hline Dimension & Examples \\
\hline IT infrastructure & $\begin{array}{l}\text { - } \quad \text { Shortage of reliable networks and communication - } \\
\text { - } \quad \text { Inadequate network capacity or bandwidth } \\
\text { - } \quad \text { Lack resources standards and common architecture policies and definitions } \\
\text { - } \quad \text { Existing systems are incompatible and complex } \\
\text { - } \quad \text { Existing internal systems have restrictions regarding their integrating capabilities } \\
-\quad \text { Lack of integration across government systems } \\
-\quad \text { Integration technologies of heterogeneous databases are confusing } \\
-\quad \text { Lack of knowledge regarding eGovernment interoperability } \\
-\quad \text { High complexity in understanding the processes and systems in order to redesign and integrate them } \\
-\quad \text { Lack of enterprise architecture } \\
-\quad \text { Availability and compatibility of software, systems and applications } \\
\text { - } \quad \text { Lack of documentation }\end{array}$ \\
\hline Security and privacy & $\begin{array}{ll}\text { - } & \text { Threats from hackers and intruders } \\
\text { _ } & \text { Threats from viruses, worms and Trojans } \\
\text { - } & \text { Absence of privacy of personal data } \\
\text { - } & \text { High cost of security applications and solutions } \\
- & \text { Unauthorised external and internal access to systems and information } \\
- & \text { Lack of knowledge for security risks and consequences } \\
- & \text { Assurance that transaction is legally valid } \\
- & \text { Lack of security rules, policies and privacy laws Inadequate security of government hardware and } \\
& \text { software infrastructure } \\
- & \text { Lack of risk management security program } \\
- & \text { Unsecured physical access to building or computers rooms }\end{array}$ \\
\hline IT skills & $\begin{array}{ll}- & \text { Lack of IT training programmes in government } \\
- & \text { Shortage of well-trained IT staff in market } \\
- & \text { Lack of employees with integration skill } \\
- & \text { Developing web site by unskilled staff } \\
- & \text { Unqualified project manager } \\
- & \text { Shortage of salaries and benefits in public sector } \\
- & \text { Flow of IT specialist staff }\end{array}$ \\
\hline Organisational & $\begin{array}{l}\text { - } \quad \text { Lack of coordination and cooperation between departments } \\
\text { - } \quad \text { Lack of effective leadership support and commitment amongst senior public officials } \\
\text { - } \quad \text { Unclear vision and management strategy } \\
\text { - } \quad \text { Complex of business processes } \\
\text { - } \quad \text { Politics and political impact } \\
-\quad \text { Cultural issues } \\
-\quad \text { Resistance to change by high-level management } \\
-\quad \text { Time consuming for reengineering business process in public organisations }\end{array}$ \\
\hline Operational cost & $\begin{array}{ll}- & \text { Main supply comes from central government } \\
- & \text { Shortage of financial recourses in public sector organisations } \\
- & \text { High cost of IT professionals and consultancies } \\
- & \text { IT cost is high in developing countries } \\
- & \text { Cost of installation, operation and maintenance of eGovernment systems } \\
- & \text { Cost of training and system development }\end{array}$ \\
\hline
\end{tabular}

Source: Ebrahim and Irani (2005) 


\subsubsection{Layne and Lee Model}

Layne and Lee (2001) proposed four stages model to illustrate a possible integrated approach for a One-Stop eGovernment. The model has been quoted frequently by various research communities and is one of few examples of studies within eGovernment where one can identify a linkage and additive value (Grant and Chau, 2005; Reddick, 2004; Yang, 2003). According to this model, eGovernment evolves through several stages. These stages are presented as the guidelines to follow in order to develop a successful integrated eGovernment project. The proposed model encompasses four stages of growth as follow: a) Cataloguing, b) Transaction, c) Vertical Integration, and d) Horizontal integration. The model entails an increasing level of complexity (see Figure 2.5).

Figure 2. 4 Four Staged Model

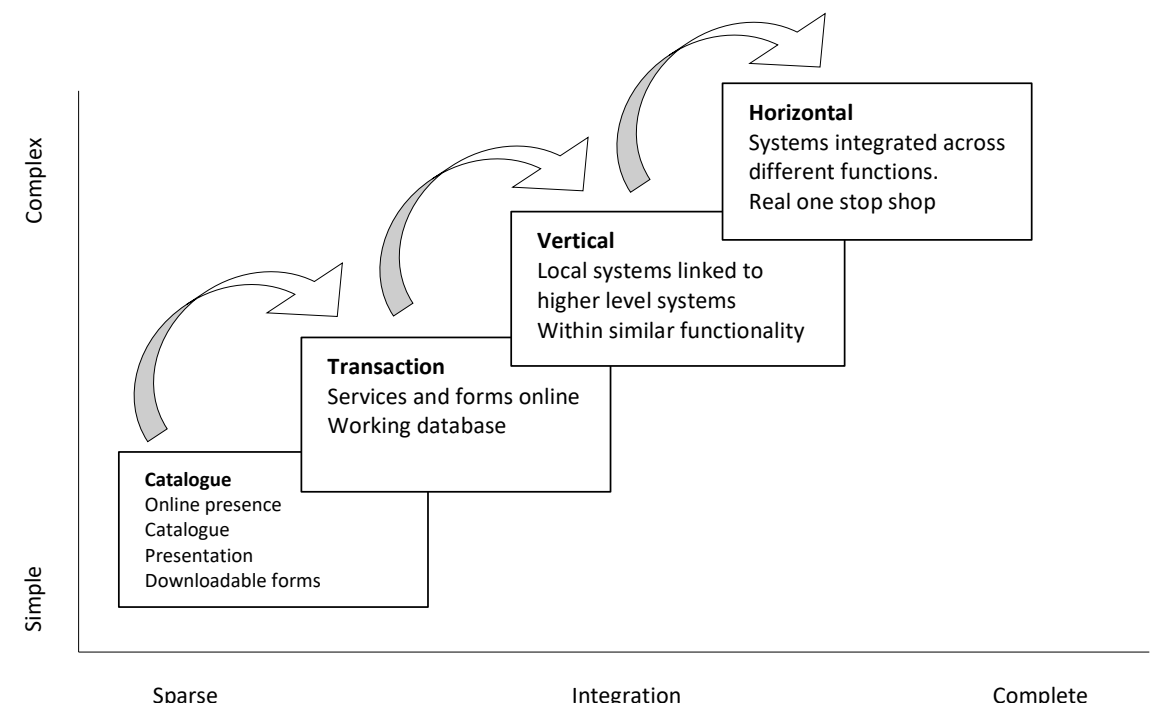

Source: Layne and Lee Model (2001)

a) Cataloguing: Creating websites and making government information and services available online.

b) Transaction: Enables citizens to interact with their governments electronically. The functionality of the transaction stage encompasses government moving from providing only facts to becoming an active respondent, i.e. two-way communication, forms are filled out and government responds with confirmation and receipts, citizens move from passive to active role and can participate in online forums. 
c) Vertical Integration: focuses on the automation of more government workflows and also transformation of government services; it includes integrating government functions at different levels such as these of local and states governments.

d) Horizontal integration: Focuses on integration of government services for different functions horizontally. The functionality of horizontal integration encompasses databases across functional areas to communicate and share information; information obtained by one agency will propagate throughout all government functions.

\subsubsection{United Nations Model}

The UN model identifies four stages of eGovernment evolution (see Figure 2.6) and has been used for assessing eGovernment at national level in different countries. In 2018, the model was used to assess 179 out of 192 UN members (United Nation, 2018).

Figure 2. 6 Stages of the UN model of eGovernment Development.

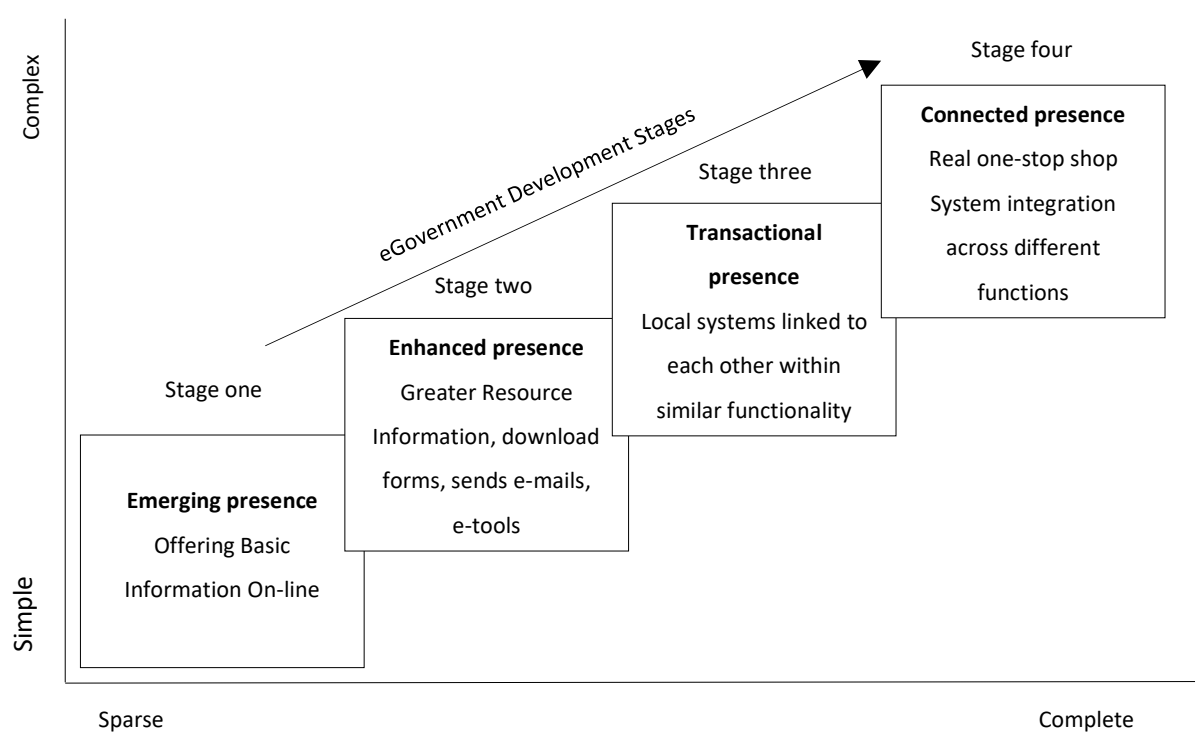

Source: United Nations eGovernment Survey (2018)

The UN model is a composite measure of three important dimensions of eGovernment (see Figure 2.7) namely: provision of online services, telecommunication connectivity and human capability. Each one of these sets of indices is in itself a composite measure that can be extracted and analysed independently. The global eGovernment ranking, as derived from the EGDI, is not designed to capture eGovernment development in an absolute sense, rather it aims to give a performance rating of national governments relative to one another. 
Figure 2. 7 Dimensions of eGovernment,

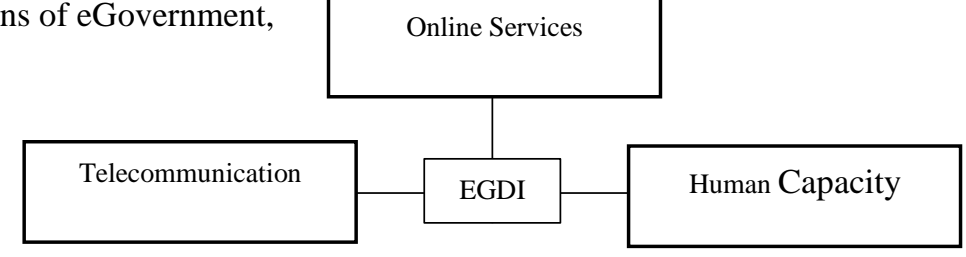

Source: United Nations eGovernment Survey (2018)

\subsubsection{Capability Maturity Modelling}

Maturity modelling for management and control over IT processes is based on a method of evaluating the organisation, so it can be rated from a maturity level of, typically, initial (one) to optimised (five). This approach is derived from the maturity model that the Software Engineering Institute (SEI) defined for the maturity of software development capability. The maturity levels are designed as profiles of IT processes that an enterprise would recognise as descriptions of possible current and future states. They are not designed for use as a threshold model, where it is not possible to move to the next higher level without having fulfilled all conditions of the lower level. The popular models are those belonging to the Capability Maturity Model (CMM) and Capability Maturity Model Integration (CMMI) family (see Figure 2.8) developed by Software Engineering Institute (SEI). They are typically used to describe best practices and support process improvement by providing evolutionary scales (defined for the maturity of software development capability) that describe improvement roadmaps. The original CMM has a specific focus on the evaluation of software development processes, this model has been varied and extended in a number of approaches and is now applied to the evaluation of IT infrastructure management, enterprise architecture management and knowledge management. The CMM model is a useful tool to assess the maturity level of the eGovernment at different stages and the CMM model could also be used to assess other dimensions apart from IT once stages of the model are defined.

Figure 2. 5 Capability Maturity Model.

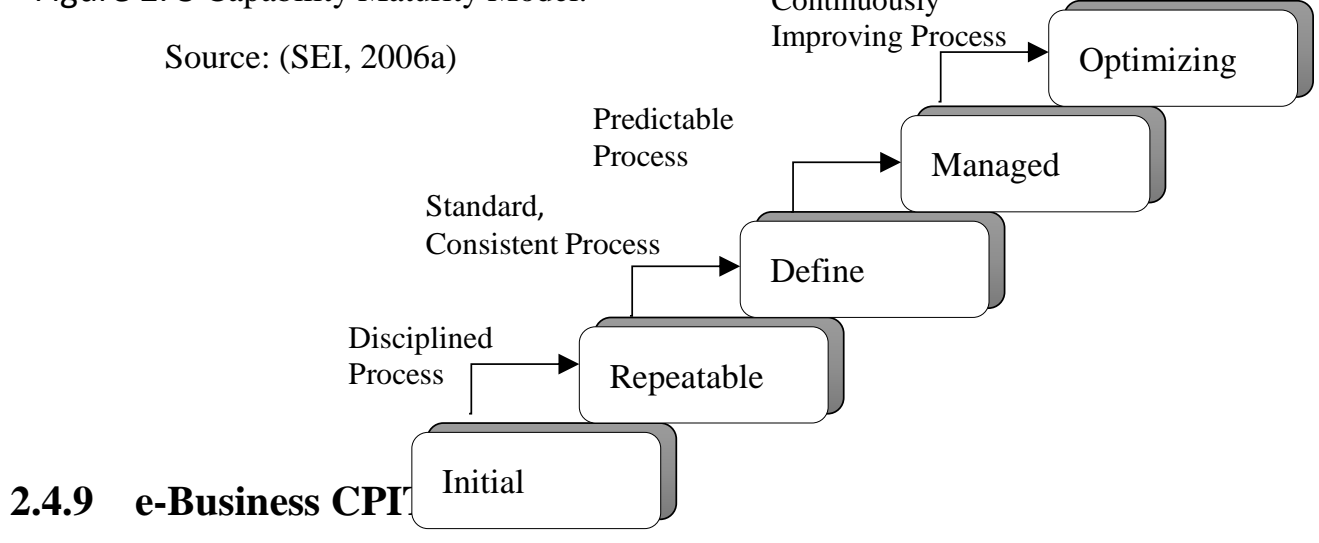


The Connect-Publish-Interact-Transform (CPIT) model analyses e-Business adoption at individual process level within organisation, allowing a more in-depth assessment of the impact of e-Business on organisational operations (Wynn et al., 2013). In this model, 'Connect' indicates the basic use of ICT applications such as e-mails for messaging, and internet tools for information gathering. 'Publish' refers to the publishing of electronic information, generally via an organisation's website. 'Interact' indicates some interaction between customers, employees or business partners with the host organization via their website, which could be, for example, the placement of an order by a customer or end consumer (see Figure 2.9).

Figure 2. 9 The Connect-Publish-Interact-Transform (CPIT) Model.

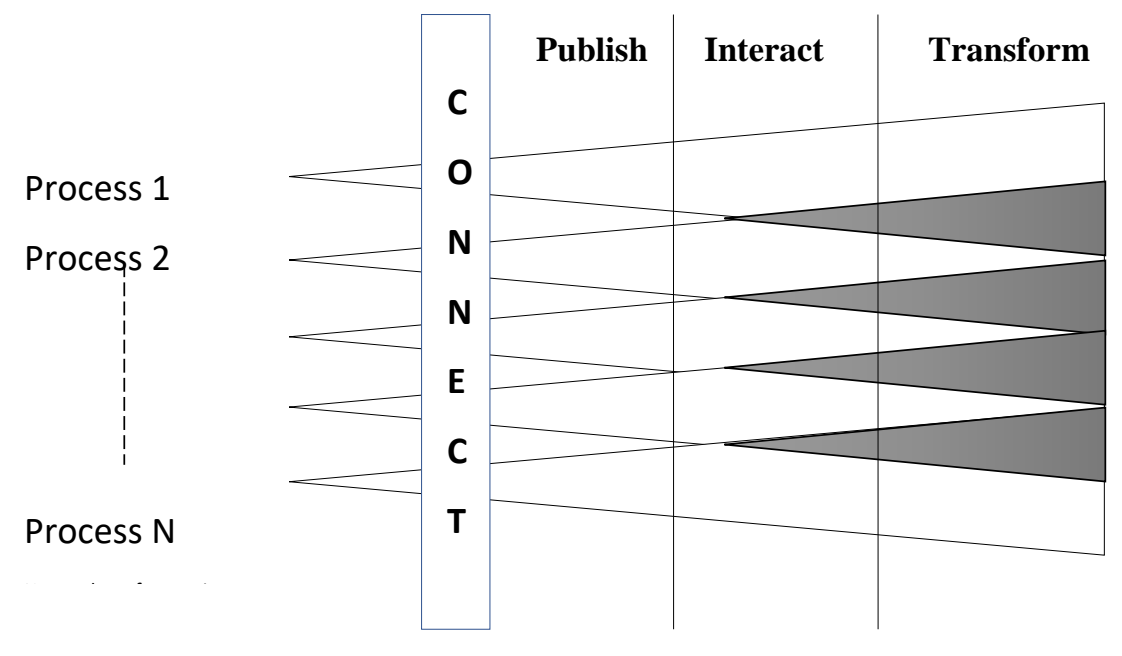

Source: Wynn, Turner and Lau (2013)

\subsection{Critical Analysis of eGovernment Models}

The adoption of eGovernment is more than a technology issue, as it is influenced by many other factors (Heeks, 2006; Ebrahim et al., 2004). For instance, organizational structure and human capabilities are important factors which are related to the nature of the government in a particular country, and its overall role and responsibilities in society (Gupta et al., 2008; Andersen and Henriksen, 2007). The researcher categorized the aforementioned models into two categories: Critical Succus Factors models and Stage Level Approach:

Sustainability Framework for eGovernment Success model is of paramount importance for governments of developing countries. The model, thus, tries to explore the potential relationship between two concepts (eGovernment success and sustainability) in an integrated manner. The model indicated that sustainability aspect of eGovernment initiatives is a neglected topic and calls to extend eGovernment research beyond success. The model is 
however applicable to beyond eGovernment adoption and tires to understand the aspect that makes eGovernment project sustainable and not this study where the researcher's focus is on assessment of an organisation prior eGovernment adoption.

eGovernment Implementation Benefits, Barriers and Risks model is framework that incorporates environmental factors as well as implementation benefits, barriers, and risks influencing eGovernment implementation within institutional context of public sector organisations. The model also can help managers and academicians to understand the step-bystep guide to eGovernment implementing process. However, the model has been applied in Nigeria on public sector organisations as a whole whereas this study looking at individual process level and then organisation as a whole. It is also applied to fit Nigeria context; however, some factors might be relevant to Libya context.

eGovernment architecture framework was adopted from Ebrahim and Irani (2005) is relevant for study of information systems especially barriers of eGovernment which could be used as a checklist for project planning or evaluation. The study revealed a broad set of barriers to eGovernment integration and classified them into IT infrastructure, Security and privacy, IT skills, Organisational and Operational cost. It emphasised on the nature of eGovernment services that necessitates closer working relationships between government stakeholders. This framework will therefore be relevant in formulating good practice guidelines for eGovernment implementation.

Although several eGovernment models have been developed to assess organisations in terms of eGovernment at a national level, there is no framework to assess eGovernment at department level. For instance, the United Nations model "is not designed to capture eGovernment development in an absolute sense; rather, it aims to give a performance rating of national governments" (United Nation, 2018, p.13). Janssen (2014) suggests that the existing eGovernment maturity models, including the United Nations model, often assess the level of eGovernment from the outside, i.e. by observing the availability of front-end services, and paying scant attention to back-end systems and processes which provide the foundation for eGovernment as a whole. This may be a logical focus when taking the citizens' point of view, or from the perspective of other stakeholders who are not directly involved in improving the overall provision of eGovernment; however, it provides only a partial view of eGovernment systems and processes. 
Although, these staged approach models present large similarities between them, they still suffer from some limitations as the following:

- Not all of them focus on the same set of factors. For instance, while some maturity models include some important factors (best practices), it seems that others are just ignoring them.

- The maturity models are not providing directions and guidelines for agencies to move to an upper stage of maturity.

Another shortcoming of existing models is that they do not assess governmental organisations at department level. In this context, research in the UK that has assessed e-Business capability at process level within organisations (Wynn et al., 2013) is of relevance. This aspect is not evidenced in any of the existing models.

To conclude, this review found limited research and few conceptual and theoretical frameworks on information systems (IS) in respect of eGovernment implementation in developing countries, particularly Libya, which is the focus of this research. The researcher therefore intends to use a combination of models and theories in developing the conceptual model for eGovernment implementation since there is currently no framework that maps the aforementioned three categories together (Technology, Organisational Capability, Process Efficiency). It could be argued that it will be useful for organisations to have a holistic view of eGovernment readiness and the implementation process at departmental or process level. There is also the need for practitioners to have a step by step guide in the form of a frame of reference on how to identify and map the implementation factors and characteristics, which is not available at the moment in Libya's organisations.

\subsection{Towards a Conceptual Model}

Implementing eGovernment is costly and has multiple requirements, including stable technical infrastructure, a stable political system, a legal framework in place, and highly skilled people (Stoltzfus, 2005). These challenges, whether managerial or technical, appear in both developed and developing countries. The difference lies in the level of complexity and the approach of how to handle the problem. Developing countries face the greater challenges, as they need to leap-frog multiple generations of technology (Lessa, 2017). Moreover, the ICT in developing countries is far behind that of developed countries (Napitupulu et al., 2017). Reviewing the existing models demonstrates that there is no single way of listing eGovernment challenges (Gil-García and Pardo, 2005). Some classify the challenges on a technology basis; others focus more on the context in which eGovernment was implemented, drawing more attention to the 
cultural and social aspects. It is assumed that the cultural values and behaviours determine different goals and objectives, and therefore different challenges are explored. Table 2.7 lists a wide range of prior literature in terms of barriers to eGovernment with a special focus on the context of developing countries

Table 2. 5 eGovernment Barriers Identified from the Literature

\begin{tabular}{|c|c|}
\hline Barriers & References \\
\hline Resistance to change & $\begin{array}{l}\text { (Napitupulu et al., 2017; Otieno and Omwenga, 2015; Deakins et al., 2010; } \\
\text { Ebrahim and Irani, 2005) }\end{array}$ \\
\hline $\begin{array}{l}\text { Lack of suitable legal framework/ } \\
\text { Unsuitable legislation }\end{array}$ & $\begin{array}{l}\text { (United Nations eGovernment Survey, 2018; Sensuse et al., 2017; } \\
\text { Verkijika and Wet, 2016) }\end{array}$ \\
\hline Lack of awareness/ information & (Verkijika and Wet, 2016; Hatsu and Ngassam 2016) \\
\hline Absence of/ Poor policy making & (United Nations eGovernment Survey, 2018; Dwivedi, 2009) \\
\hline Lack of financial resources & $\begin{array}{l}\text { (Napitupulu , et al., 2017; Deakins et al., 2010; Mberi et al., 2017; Ebrahim } \\
\text { and Irani, 2005) }\end{array}$ \\
\hline Lack of clear vision and strategy & (Kigwana et al., 2017; Hatsu and Ngassam 2016) \\
\hline Lack of ICT skills/ professional staff & (Ahmed, 2013 ; Bhuiyan, 2010; Gagnon et al., 2010) \\
\hline Lack of coordination among organisations & (Napitupulu , et al., 2017; Alkhilani, 2014; Gagnon et al., 2010) \\
\hline Complex or poor organisational structure & (Verkijika and Wet, 2016; Al-Fakhri et al., 2008; Altameem et al., 2007) \\
\hline $\begin{array}{l}\text { Insufficient support from the top } \\
\text { management }\end{array}$ & $\begin{array}{l}\text { (Jadi and Jie, 2014; Bhuiyan, 2010; Lau et al., 2008; Altameem et al., } \\
\text { 2007) }\end{array}$ \\
\hline Negative attitude towards technology & (Elaswad and Jensen, 2016; Chalhoub, 2010) \\
\hline $\begin{array}{l}\text { Lack of e-communications with all } \\
\text { constituents for e-service delivery }\end{array}$ & (Hatsu and Ngassam 2016; S; Fedorowicz et al., 2010; Zhang et al., 2005) \\
\hline $\begin{array}{l}\text { Security of confidential data } \\
\text { Privacy of personal data }\end{array}$ & $\begin{array}{l}\text { (Elaswad and Jensen, 2016; Alenezi et al., 2013; Fedorowicz et al., 2010; } \\
\text { Al-Fakhri et al., 2008; Basu, 2004) }\end{array}$ \\
\hline Use of outdated technology & (Alenezi et al., 2013; Gagnon et al., 2010) \\
\hline Poor technological infrastructure & (Elaswad and Jensen, 2016; Al-Sobhi et al., 2010; Bhuiyan, 2010) \\
\hline Unreliable Internet access & (Jadi and Jie, 2014; Jaeger and Thompson, 2003) \\
\hline Changing organisational culture & $\begin{array}{l}\text { (Alkhilani, 2014; Chen et al., 2007; Altameem et al., 2007; Gagnon et al., } \\
\text { 2010) }\end{array}$ \\
\hline $\begin{array}{l}\text { Lack of methods for productivity and } \\
\text { progress monitoring and accountability }\end{array}$ & $\begin{array}{l}\text { (Kigwana et al., 2017; Salem, 2006; Jaeger and Thompson, 2003; } \\
\text { Schwester, 2009; Alenezi et al., 2013) }\end{array}$ \\
\hline $\begin{array}{l}\text { Incompatible data standards/ different } \\
\text { security models }\end{array}$ & (Alenezi et al., 2013; Hafizi et al., 2014; Reffat, 2003) \\
\hline Lack of organisational readiness & (Hafizi et al., 2014; Reffat ; Kigwana et al., 2017; Fedorowicz et al., 2010) \\
\hline Corruption & (Alenezi et al., 2013; Bhuiyan, 2010) \\
\hline Poor project management & (United Nations eGovernment Survey, 2018) \\
\hline
\end{tabular}


Although there have been research studies on eGovernment stakeholders, most of the studies have been based on general categorisation. In fact, there have been some with special purpose categorisations (Heeks, 2003; Irani et al., 2007; Al-Rashidi, 2012). There is no research that specifically investigates technology in the organisation simultaneously with organisation capability, work efficiency and other aspects in Libyan organisations. The researcher therefore intends to use a combination of models in developing the conceptual framework for eGovernment assessment prior to implementation in government organisations.

Based on the critical success factors models, the researcher defined three different dimensions of barriers and challenges, that are likely to influence the adoption and implementation of eGovernment. The researcher contends that these different dimensions will have a significant impact eGovernment implementation. The three main dimensions that constitute key elements of the conceptual framework are:

\subsubsection{Technological Dimension}

Technology is considered as the main source of change and power for enabling the transformation process of eGovernment (Al-Solbi and Mayhew, 2005). However, there are many components and sub-components in ICT technology. For example, the emergence of eGovernment and IT service delivery is directly related to the ICT infrastructure, the telecommunication network infrastructure, and their capacity, reliability and affordability. Alenezi et al., (2013) also indicated that organisations that intend to adopt eGovernment should use web services application that offer standardized service interfaces and common communication protocols, which provides comprehensive and dynamic integration capability with back-end systems. Kigwana et al., (2017) consider security and privacy are important, stating that the lack of software security tools is a possible danger that might be used to exploit a vulnerability to breach security and therefore cause possible harm to eGovernment systems. Kigwana et al., (2017) also stated that cybersecurity and its underlying infrastructure are vulnerable to a wide range of risk stemming from both physical and cyber threats and hazards. Sophisticated cyber actors and nation-states exploit vulnerabilities to steal information and money and are developing capabilities to disrupt, destroy, or threaten the delivery of essential services.

The threat of attacks on web applications to extract data or to distribute malicious code persists. Cyber criminals distribute their malicious code via legitimate web servers they've 
compromised. But data-stealing attacks, many of which get the attention of media, are also a big threat. Now, governments need a greater emphasis on protecting web servers and web applications. Web servers are especially the best platform for these cyber criminals to steal the data. Hence government must always use a safer internment environment especially during important transactions in order not to fall as a prey for these crimes. System compatibility is also considered to be an important factor, that requires avoiding any hardware or software systems barriers that would hinder the implementation of eGovernment systems (Elaswad and Jensen, 2016; Verkijika and Wet, 2016; Ebrahim and Irani 2005). Table 2.8 presents issues regarding technology.

Table 2. 6 Challenges factors regarding technology dimension

\begin{tabular}{|l|l|}
\hline \multicolumn{1}{|c|}{ Dimension } & \multicolumn{1}{c|}{ Barriers and challenges } \\
\hline \multirow{2}{*}{ Technology Deployment } & Poor technological infrastructure \\
Security / privacy/ encryption requirements \\
Lack of standards for quality, design of websites/portals \\
Digital divide \\
Unreliable internet connections \\
Lack of systems and applications \\
Lack of hardware \\
Lack of compatibility between IT systems \\
Lack of secure electronic identification and authentication \\
Low levels of internet use amongst certain groups
\end{tabular}

\subsubsection{Organisational Dimension}

The recent introduction of ICT has led to fundamental changes in the way public organisations accomplish their activities. Therefore, more researchers are investigating the organisational factors and examining their impact on technology adoption. Alkhilani (2014) states that IT and organisational arrangements are connected reciprocally. Scholars have started to focus more on organizational issues and address the relationship between IT and human activity; organizational culture and structure; and change management. The redefinition of these factors is a prerequisite to achieve successful change processes. According to Hafizi et al. (2014) these are critical factors in organisational technology adoption. Many studies show that a high number of eGovernment initiatives, in different types of organisation, fail or do not achieve their goals. The literature attributes the failure to a variety of reasons, including the employee's 
skills and capability as Schein (2010) indicated that it is a basic requirement for eGovernment adoption to have employees capable of accessing, and using information in a powerful and efficient way. Scholars also have indicated that organisational culture issues impede the adoption of technology (Altameem et al., 2007; Schein, 2010). Senior management presents an important aspect for implementation of eGovernment system, many eGovernment projects tend to fail because of the lack of the leaders' understanding of eGovernment and their inabilities to show consistency from inception to completion of the projects (Porras and Amaya, 2018; Rammea, and Grobbelaar, 2017). Leadership and awareness are crucial factors that scholars argue should be considered, especially prior to implementation of eGovernment (Jadi and Jie, 2014; Hatsu and Ngassam 2016; Jaeger and Thompson, 2003). Table 2.9 illustrates the most common factors that affect eGovernment implementation regarding the organisational capability dimension.

Table 2. 7 challenges factors regarding organisational capability dimension

\begin{tabular}{|l|l|}
\hline \multicolumn{1}{|c|}{ Dimension } & \multicolumn{1}{c|}{ Barriers and challenges } \\
\hline \multirow{3}{*}{ Organisational Capability } & $\begin{array}{l}\text { Complex or poor organisational structure } \\
\text { Poor project management } \\
\text { Lack of innovation incentives in public sector organisations } \\
\text { Weak policy implementation } \\
\text { An Agency-centric rather than a Customer-centric focus } \\
\text { Lack of skills amongst staff } \\
\text { Lack of expert assistance } \\
\text { Insufficient budget for IS projects and training } \\
\text { Lack of suitable legal framework/ Unsuitable legislations } \\
\text { Lack of awareness/ information } \\
\text { Resistance to change } \\
\text { Changing organisational culture }\end{array}$ \\
\hline
\end{tabular}

\subsubsection{Process Efficiency Dimension}

Process management is a systematic approach to making an organization's workflow more effective, more efficient and more capable of adapting to an ever-changing environment. The goal of process management is to reduce human error and miscommunication and focus stakeholders on the requirements of their roles (Rouse, 2014). Effective process management combines electronic document management services with workflow technology to automate key business processes. The continuous refinement and improvement of processes build layers of efficiency and agility within the organisation, resulting in a more productive and more 
profitable infrastructure. Stratigaki et al., (2016) argue that researchers have documented many experiences in business process efficiency in private organisations, but very little is known about it in the public sector. However, some argue that the documented methods and insights may apply equally in public organisations (Stratigaki et al., 2016). Since the 1990s, private organisations have achieved major business process changes and recorded many associated successful initiatives in the information system arena (Haider et al., 2015). Veenstra et al. (2011) argue that change programmes in eGovernment are likely to be inadequate without business process efficiency gains. Another issue associated with process efficiency and related to process documentation is standardization which means that a workflow within the organisations may completed in in different ways each time. Kamal, (2008) reports that eGovernment projects have an increasing impact on how business processes develop and change. Veenstra et al. (2011) also confirm that public sector agencies face pressures to increase efficiency and effectiveness of operations of their departments to provide successful eGovernment services. Therefore, before eGovernment adoption, business processes should have been designed in a way that limits bottlenecks, reduces duplicative efforts, and reduces processing time. Haider et al. (2015) also report that, while most eGovernment projects are focused on $\mathrm{G} 2 \mathrm{C}$ interaction, the other two categories - G2B and G2G - also emphasized internal effectiveness and efficiency along with organisations' departments. Thus, better service provision requires the development and integration of business processes across government organisations, due to which significant changes to the business logic becomes a necessity (Cahyaningsih et al., 2016). Table 2.10 illustrates the most common factors that affect eGovernment implementation regarding the Process Efficiency dimension.

Table 2. 8 Issues regarding process efficiency dimension

\begin{tabular}{|c|l|}
\hline \multicolumn{1}{|c|}{ Dimension } & \multicolumn{1}{c|}{ Barriers and challenges } \\
\hline \multirow{3}{*}{ Process Efficiency } & Lack of process documentation \\
& Difficulty in re-engineering of internal processes \\
& No standard administrative processes \\
& Lack of methods for productivity and progress monitoring \\
\hline
\end{tabular}

\subsection{Chapter Summary}

The literature review in this chapter has examined the barriers impeding successful eGovernment implementation, as well as addressing the many opportunities provided to 
improve government efficiency and effectiveness. The literature review focussed principally on these issues in developing countries, including the Arab world and Africa. The review emphasised the relative lack of research dedicated to developing countries. The investigation of eGovernment models and frameworks, addressing critical factors of adoption, highlight many contextual factors related to technology, organisational capability and process efficiency issues. The literature review clearly demonstrates that ignorance of these challenges can easily lead to failure. 


\section{Chapter Three: Initial Conceptual Model Development}

\subsection{Introduction}

The aim of this chapter is to develop a conceptual model for eGovernment assessment prior to the implementation process, which is an essential step that can support the execution process within the context of Local Authorities (LAs) in Libya as a developing country. The model consists of three dimensions: Technology Deployment, Organisation Capability and Process Efficiency (TOP). The chapter also justifies the development of a conceptual model, since there has been limited research in eGovernment assessment, especially in identifying the three dimensions (TOP) simultaneously as discussed in section 2.7 in chapter two.

The chapter is divided into five sections. Section 3.2 explains and discusses justification of model development, describing in detail the model dimensions, factors and sub-factors. These dimensions and their factors and sub-factors are derived from the eGovernment literature and identified as Technology Deployment, Organisational Capability and Process Efficiency. Section 3.3 illustrate proposed conceptual model explains, functioning of the model and further provides the maturity level names. Section 3.4 summary of the chapter.

\subsection{Justification for Model Development}

With the development of technology in the private sector, public sector organisations have also needed to adapt to change in organisational capability (Al-Rashidi, 2012). This has brought about a new awareness among the top managers in the public sector on the need to concentrate on improving their business processes, performance and strategies through eGovernment implementation. However, the risks associated with the implementation of eGovernment in public sector organisations remain a significant issue.

In the previous chapter, a number of studies were discussed on the architecture or components of eGovernment (e.g. Lessa, 2019; Ashaye and Irani 2014; Ebrahim and Irani, 2005; Layne and Lee, 2001; United Nations, 2018; SEI, 2006a; Wynn et al., 2013). However, these studies did not address the aspect of organisational capability factors and process efficiency factors and how they align with the IT infrastructure within public organisations. Since eGovernment goes beyond the IT infrastructure, the contribution of this study is to provide a model for 
eGovernment that assesses public organisations, particularly Libyan Las, prior the adoption of eGovernment in terms of alignment of technologies infrastructure with organisational capability and process efficiency and scale the maturity level for each process individually.

There appears to be limited literature and few conceptual and theoretical frameworks on information systems (IS) analysing eGovernment implementation processes in developing countries. A majority of the models developed have been based on generalising the factors into two categories (Technology category and Organisation category). For example, many challenges, such as lack of process documentation, difficulty in re-engineering of internal processes, no standard administrative processes, lack of methods for productivity and progress monitoring, have been categorized into the Organisation category, whereas it can be argued that such challenges are related to process efficiency, which is seen by the researcher to be an important dimension in this study.

Since review of the literature suggests that many developing countries do not have the infrastructure necessary to deploy eGovernment systems, it is necessary to investigate the LAs from different perspectives in order to help the implementation of eGovernment. Issues and challenges that have been categorised in section 2.7 in chapter two facilitated the development of the model, as described below:

The model builds on prior literature in the area of eGovernment models, and approaches that have been discussed in chapter two, the review and incorporation of previous studies that have conceptualised the e-service challenges within the government sector have facilitated the development of the proposed model.

Although there have been research studies on eGovernment, most of the studies have been based on general categorisation (e.g. Scholl, 2004; Scott, 2005, Heeks, 2006). In fact, there have been some with special purpose categorisations (Heeks, 2003; Irani et al., 2007; AlRashidi, 2012), there is no research specifically identifying the three dimensions (TOP) simultaneously. As a result of this gap in the literature, the researcher intends to develop a model able to incorporate models from Critical Success Factors, such as the eGovernment architecture model that was developed by Ebrahim and Irani (2005), which has been successfully applied to eGovernment implementation in Bahrain, and the drivers and barriers model developed by Hamed (2009), which has been applied to e-Commerce adoption in Libya. These have proven to be reliable models which could be adopted by researchers in any 
eGovernment or e-Commerce development project as the factors vary from country to country. Other models, from the stage level approach such as the United Nations model presented by United Nations (2018).

In other words, the challenges that influence the adoption of eGovernment are contained in the critical success factor models, specifically the categorization of the challenges that agencies and eGovernment projects should address (e.g., Technological, Organisational Capability and Process Efficiency) and how these challenges are related and grouped together.

The researcher has also adopted models from staged level approaches such as United Nations (2018), Layne and Lee (2001) CMM model (2006a), which are a set of stages (from basic to advanced) that can be used to determine the maturity stage of LAs at process levels. Specifically, they are definitions of what each stage implies and what is needed to move up from one stage to the next. In addition, the capability and maturity levels structure and assessment mechanisms from software engineering (capability maturity model), and its stage definition of each level, have inspired the researcher to adopt them in this study.

Previous studies have not focused extensively on TOP dimensions, as most of the factors vary from locality to locality and if not considered carefully, could impact on eGovernment initiatives, particularly in Libya as a developing country, which is the focus of this study.

Three main dimensions are important to be assessed and measured in public sector organisations' back office. These dimensions are as follows:

\subsubsection{Technology Deployment Dimension}

Building an eGovernment system within an organisation requires a technology infrastructure that reaches out to all parts of the public sector organisation. However, electronic communication within and between public sector organisations is expensive and inefficient without an effective infrastructure and agreed standards and protocols between communicating systems (Verkijika and Wet, 2016; Al-Solbi and Mayhew, 2005). Therefore, this dimension focuses on technologies that should be in place before eGovernment services can be offered reliably and effectively to the public (see Figure 3.1). The potential of these technologies is to support and integrate the operations of IS and applications in business processes across organisation by offering the necessary standards and protocols through network and communication infrastructure approaches (Alenezi et al., 2013). To have a successful 
eGovernment strategy, the public sector must create an IT infrastructure that is optimised to support the new applications that are necessary for eGovernment (Gil-Garcia and Pardo, 2005; Eynon and Dutton, 2007). Therefore, ICT infrastructure is an essential part of eGovernment implementation and diffusion. It enables government agencies to cooperate, interact and share work; facilitating the daily tasks and using technology to save employee's time and effort (Alshehri and Drew, 2010). A number of different models such as those proposed by (Ebrahim and Irani, 2005; Napitupulu et al., 2017; Otieno and Omwenga, 2015; Chen et al., 2007; Heeks, 2003) classify the factors that hinder the adoption of eGovernment which includes internet, network, software and hardware equipment, security and system compatibility. These factors integrate office functions and automation of the work in the business process. Thus, the implementation of this dimension will improve the relationship and interaction between business processes and make a strong foundation to build eGovernment project. Therefore, the researcher considers that business processes at any public-sector organisation should have these essentials technologies before eGovernment adoption (Irani, 2005) which described as follow:

\section{- Software and Hardware}

Building an information community requires hardware equipment that reaches out to all parts of public sector organisation. This can be done by providing highly professional and powerful computers and other equipment that runs and hosts application and provides high speed access to government data and services, which supports and integrates the operations of IS and applications across organisations (Alkhilani, 2014; Al-Sobhi et al., 2010; Bhuiyan, 2010; Altameem et al., 2007). The researcher considers that hardware equipment should be in place before eGovernment adoption takes place. Ebrahim and Irani (2005) concluded in their proposed architecture model for eGovernment adoption where they defined fundamental technological requirement that are necessary for the eGovernment adoption include computers, powerful servers, printers. Therefore, the researcher considers that the availability of these hardware technologies within business process are critical sub-factors and helps to create successful eGovernment adoption.

In addition, the software application refers to end user programs that facilitate the automation of the business process. The potential of these software applications is to support and integrate the work across organisations by offering the necessary a seamless, automatic and real-time communication between end users within or across the business processes, and integrate frontend eGovernment services with back-end activities (Schuppan, 2009; Lam, 2005). This include 
basic application, such as Microsoft Office, and advanced applications for database exchange that align governmental business processes with citizen needs (AlShihi, 2006). The implementation of these software applications will make a strong foundation to build single eGovernment portal and therefore the researcher considers it as critical sub-factor that helps to create successful eGovernment adoption.

An analysis of the current literature suggests for an organisation willing to present its services online, it should have the minimum hardware equipment such as computers, powerful servers, printers and scanners; and Software System such as in-house systems and bundled product suites such as Microsoft Office and other software packages.

To conclude: Software applications and Hardware equipment have been considered as subfactors that should be assessed before eGovernment adoption takes place.

\section{- Communication}

A computer network is a group of computer systems and other computing hardware devices that are linked together through communication channels to facilitate communication and resource sharing among a wide range of users. A local area network is a private network accessible only to an organization's staff. Generally, a wide range of information and services from the organization's internal IT systems are available that would not be available to the public from the internet. Computer networks, particularly local area networks, streamline business processes within an organisation and between departments (Schuppan, 2017; Hamner and Al-Qahtani, 2009). Researchers such as Helbig et al. (2009) and Janssen et al. (2009) indicate that the implementation of client server networks make a strong foundation to build a single eGovernment portal and provide a seamless, automatic and real-time communication between systems at back office and between process levels, which enhances the workflow across departments. The importance of computer networks, whether peer to peer networks or client server networks across any organisation, is essential and considered as critical factors that should be in place before the adoption of eGovernment. In addition to networks, another important sub-factor is the internet connection, as public agencies have utilised internet technologies to facilitate the creation of a web site, perceiving it as a crucial medium in enhancing communication between themselves and citizens. IBM (2010) indicated that external e-mails provisions were acknowledged by agencies as an important first step in digitising government by allowing public direct access and contact with specific representatives and helping to personalise communication. Abdallah and Fan (2012) argue that 
internet technologies have the potential to provide benefits for their organisations and citizens, they indicate that in Sudan as a developing country, the main benefit of the internet for public sector was greater accessibility in terms of how citizens interact with agencies, which enabled them to access information and services whenever and wherever they chose, 24 hours a day. For example, in the case of LA, it would be possible to facilitate the internet to allow citizens, businesses and other government agencies to access departmental services (Jaeger and Thompson, 2015; Vassilakis et al., 2005). Such a development would lead to a more informed society and therefore, the researcher considered communication as a critical factor that should be in place before the adoption of eGovernment.

To conclude: an analysis of the current literature suggests for an organisation willing to present its services online should have communication tools in place, such as tools that would be local area networks and internet connectivity that facilitate the workflow between business processes within the organisation, these two tools are important and considered the backbone of the eGovernment online presence. Therefore, these tools have been considered as sub-factors by the researcher that should be assessed before eGovernment adoption takes place.

\section{- Security and Privacy}

Information is an asset, and having specific, relevant and correct information can make a massive difference to an organization's efficiency. With the huge number of available technologies, it is possible for information to be collected, shared, sold, exchanged and distributed without citation or notice to the owner. Therefore, security and privacy issues are seen by eGovernment implementers and users as one of the most critical concerns due to the high level of sensitive information being stored or/and exchanged. According to Al-Fakhri et al. (2008) information security doesn't cover only the information itself but also the entire infrastructure that facilitates its use (Murah and Ali, 2018). It covers hardware, software, threats, physical security and human factors, where each of these components has it is own characteristics. The threat of attacks on web applications to extract data or to distribute malicious code persists. Cyber criminals distribute their malicious code via legitimate web servers they've compromised. But data-stealing attacks, many of which get the attention of media, are also a big threat. Now, governments need a greater emphasis on protecting web servers and web applications. Web servers are especially the best platform for these cyber criminals to steal the data. Hence government must always use a safer internment environment especially during important transactions in order not to fall as a prey for these crimes 
In order for organizations to achieve a stronger protection of their information, the recognition of the main threats facing organizational information is urgently required. The following threats have been identified by these publications:

Security threats: computer viruses; natural disaster; spam emails and hacking incidents.

Security Policy: installation or use of unauthorized hardware, peripherals; abuse of computer access controls; physical theft of hardware or software; human error mistake; damage by displeased employee; use of organization resources for illegal communications or activities, lack of security policies and installation or use of unauthorized software.

The implementation of a strong security environment creates a strong foundation to build a single eGovernment portal, consequently citizens and businesses can trust it to make transactions, and therefore the researcher considers it as a critical factor.

To conclude: an analysis of the current literature suggests for an organisation willing to present its services online should have a solid security environment in place; such environments, which would be relevant to security threats (internal and external), and security polices, have been mentioned earlier. Therefore, these threats are considered as sub-factors of the communication factor that should be assessed before eGovernment adoption takes place.

\section{- Systems Compatibility}

Achieving advanced successful eGovernment that provides seamless data flow from one business process to another, needs systems compatibility standards in hardware and software applications to support the data exchange and increase the ease with which information is shared among these business processes (Abdallah and Fan, 2012). eGovernment initiatives require all government agencies and their processes to adopt standards. The applications of these standards are considered by researchers and IT professionals to be one of the ICT's most valuable contribution. They are used to improve data collection and access and to overcome the difficulty of using different types of IS by introducing a single interface. This can be achieved through the introduction of technical compatibility model, that includes the polices, standards, and guidelines that can help government agencies to exchange data and allow information sharing (Schuppan, 2017; Vassilakis at el., 2005). It is also argued that the adoption of eGovernment requires system compatibility if it is to be accepted by managers and employees within public sectors. Therefore, system compatibility addresses the question of whether the technology related to eGovernment will be compatible with the existing systems installed in government agencies. 
To conclude: an analysis of the current literature suggests for an organisation wishing to present its services online, it should have systems compatibility across its processes. Such compatibility would be sharing data between processes without issues and the extent to which existing hardware is compatible with technology related to eGovernment. Therefore, these threats have been considered as sub-factors of the systems compatibility factor that should be assessed before eGovernment adoption takes place.

Figure 3. 1 Technology Deployment: Factors and Sub-Factors

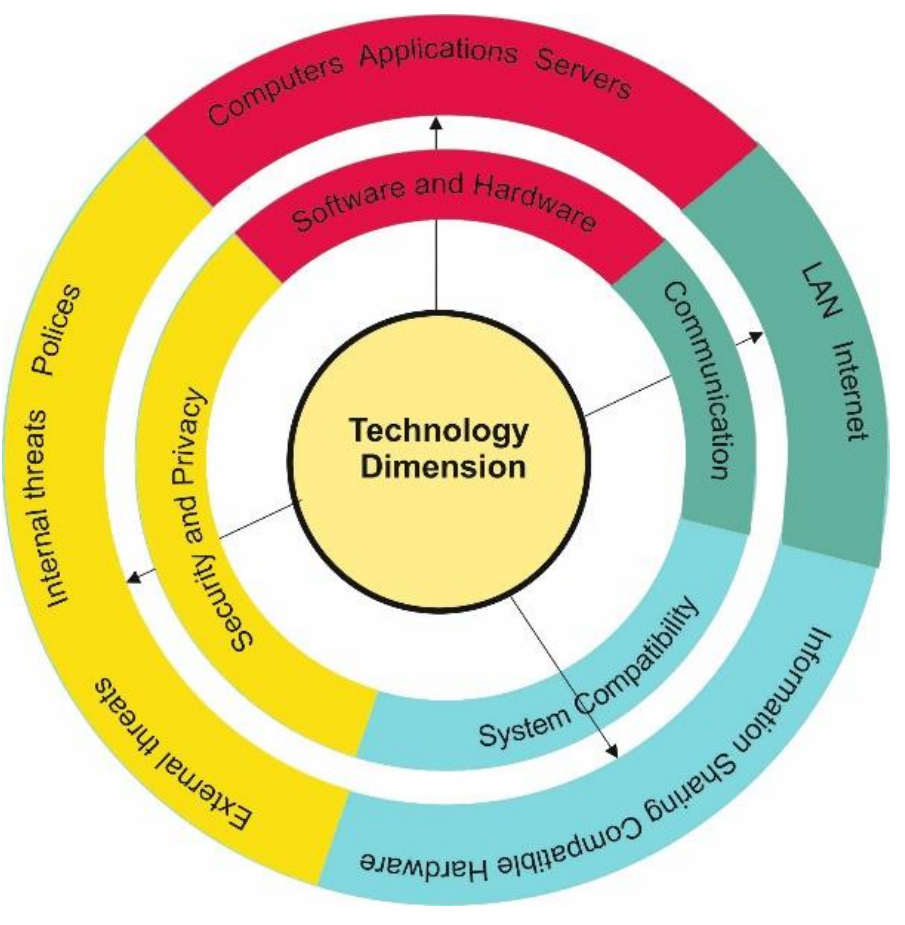

\subsubsection{Organisational Capability Dimension}

Abdalla (2012) concluded that most eGovernment readiness assessments involve measuring the adequacy of organisation resources (Ojo et al., 2007). It is a basic requirement for eGovernment adoption to have employees capable of accessing and using information in a powerful and efficient way. However, this is a challenging requirement in public organisations, particularly in developing countries. According to UN (2018), the percentage of illiteracy in developing countries is often high and the percentage of ICT illiteracy even worse, and Libya as a developing country is no exception (Sweisi and Adams, 2006). Many researchers (Kigwana et al., 2017; Hatsu and Ngassam 2016; Heeks, 2006) have stated that having successful eGovernment adoption requires important factors. For the purpose of this study, the organisational capability dimension includes factors related to skills and capability, organisational culture and senior management support, (see Figure 3.2). The researcher 
consideres that the maturity of the organisational capability dimension lies on the capability level of the critical factors, which is described below:

\section{- Skills and Capability}

Heeks (2006) stated that the more computer literate employees are, the bigger the chance eGovernment succeeds. However, some argue that staff training should not simply be seen as a means to acquire basic skills, instead it is a lifelong learning process. Alshehri and Drew (2010) argue that significate and persistent deficits around core skills already exist in government organisations, particularly in developing countries. These deficits, particularly around information processing and communication skills, undermine both competence and confidence. This in turn restricts the ability of staff and organisations to learn, develop and adapt to change. Therefore, establishing ICT training programs for both basic skills and professional levels is very important for producing skilled staff and hence, improving chances of eGovernment adoption. Many researchers agree that the ability of staff and organisations to deliver high-quality, person-centred care and support depends on crucial functional skills and employability skills. These skills underpin both capability and confidence, and staff need these skills to secure, sustain and then progress in work, so organisations can function effectively. Functional skills mean the ability to use information and communicate effectively.

To conclude: an analysis of the current literature suggests a government organisation wishing to present its services online should consider skills and capability issues that impact on the organisation's performance and effectiveness as well as the adoption of eGovernment. Such issues are functional skills, employability skills, and training courses that should be provided to the employees by organisations. Therefore, these issues have been considered by the researcher as sub-factors that should be assessed before eGovernment adoption takes place.

\section{- Organisational Culture}

Organisational culture is a group of beliefs that differentiate members of different organisations. Irani et al. (2005) argues that eGovernment deployment might be affected by many organisational culture issues. Therefore, governments are required to be ready for these changes and consequently adopt new strategies for eGovernment initiation (Burn and Robins, 2003). Moreover, many researchers have highlighted the strong relationship between organisational development and organisational culture and related that to staff's positive or negative attitude. According to Zarei et al. (2008), the consequences of a culture characterized by a negative attitude reduces the commitment of employees when new technology is 
implemented. Such negative attitudes may generate individual resistance. Furthermore, Ledbetter et al. (1985) examine staff behaviour and acceptance of office automation, they point out that certain important factors influence the acceptance of office automation, ensuring the system's success. Such factors include staff's attitude towards technology and towards management, (for instance, staff commitment to work that should be completed or followed within a given time, staff commitment to accept and use the technology). The researcher considered that the organisational capability dimension lies on the capability level of organisational culture factor, which can be measured by staff commitment towards work and management, and staff commitment towards accepting technology.

To conclude: an analysis of the current literature suggests that a government organisation wishing to present its services online should consider organisational cultural issues that impact on the organisation's performance and effectiveness. Such issues that impede the success of eGovernment adoption include resistance to change by staff to accept new technology, staff in many cases are not really resisting the change itself, but rather they may be resisting the loss of status, loss of pay, or loss of comfort and staff commitment to work, where the productivity in developing countries is low due to staff commitment. Therefore, these issues have been considered by the researcher as sub-factors of the organisational cultural factor that should be assessed before eGovernment adoption takes place.

\section{- Top Management Support}

eGovernment is a project that requires strong support throughout the implementation period. It needs continuous approval and commitment from a high authority to sustain and to continue without any unanticipated delays or project failures (Ashaye and Irani 2013; Heeks, 2003). Scholars such as Irani et al. (2007) and Weerakkody and Dhillon (2008) suggest that senior managers should fully understand the strategic objectives of eGovernment and the associated benefits and should provide success factors that increase eGovernment implementation success. Chen and Gant (2001 argue that "continual top management support is necessary for dealing with possible initial resistance and ensuring interdepartmental communication and cooperation". Such sub-factors that facilitate eGovernment adoption are: funding, awareness and strategy. For example, funding facilitates the fundamental infrastructure (such as buildings, technology, human resources) that are needed to implement eGovernment and helps attain the associated targets and milestones in terms of eGovernment implementation, Al-Shafi and Weerakkody (2010) argue that eGovernment initiatives are long term projects and therefore 
need long term financial support from the government. The major challenge is when the funding has to come from a government where political influence may interfere with decisions taken by high level government officials. Awareness is another important sub-factor in the adoption of an eGovernment project. Al-Shehry (2006) points out that it is important to raise the awareness of eGovernment benefits among senior management and staff to accept and embrace the eGovernment project as part of their daily operations. The researcher believes that awareness among organisation's staff and its senior management comes in priority to the stakeholders and justifying that concentrating on stakeholders rather than eGovernment services awareness, will be like buying paint before building the house. Regarding vision and strategy, Abdallah and Fan (2012), describe strategy as a methodology to set up a plan that integrates an organisation's major goals and action sequences in a cohesive whole. It is essential that after deciding to enter an eGovernment program, a well-defined strategy is set up. For instance, the plans should be designed based upon the available resources and environmental forces in a given context and should seeks to match the whole of eGovernment initiative that is provided by country's eGovernment strategy.

To conclude: an analysis of the current literature suggests that a government organisation willing to present its services online should consider senior management issues that impact on the eGovernment implementation process. Such issues are funding, awareness and vision and strategy, which should be well prepared. Therefore, these three issues are considered by the researcher as sub-factors that should be assessed before eGovernment adoption takes place. 
Figure 3. 1 Organisational Capability: Factors and Sub-Factors

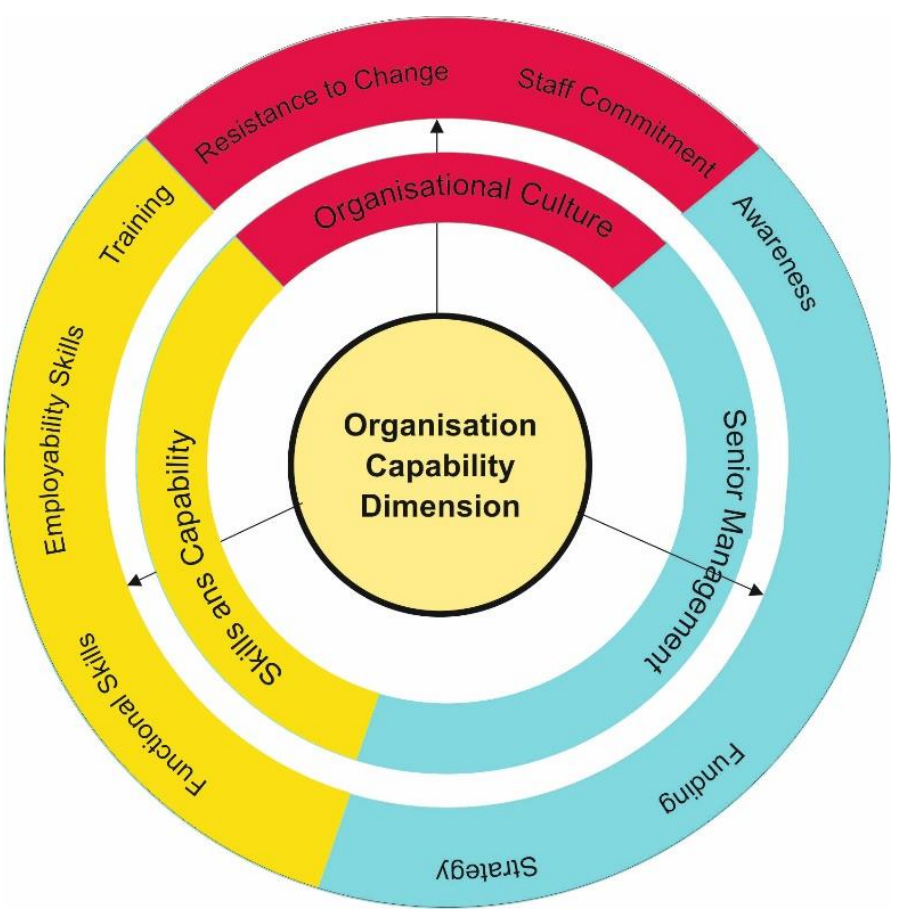

\subsubsection{Process Efficiency Dimension}

Business process management is a systematic approach to making an organization's workflow more effective, more efficient and more capable of adapting to an ever-changing environment. The goal of business process management is to reduce human error and miscommunication and focus stakeholders on the requirements of their roles (Rouse, 2014). Process management combines electronic document management services with workflow technology to automate key business processes. The continuous refinement and improvement of processes builds layers of efficiency and agility in the organization, resulting in a more productive and more profitable infrastructure (CMMC, 2016). Scholl (2005) argues that researchers have documented many experiences in process efficiency in private organisations, but very little is known about it in the public sector. However, some argue that the documented methods and insights may apply equally in public organisations (Scholl, 2005). Since the 1990s private organisations have been applying major business process change (Burn and Robins, 2003) and recording many successful initiatives in the information system area (Ashaye and Irani 2013; Thong et al., 2000). Veenstra et al. (2011) argue that transformation in eGovernment can be insufficient without efficient business processes. There are two aspects that have been considered as critical sub-factors to make tasks within the process efficient: documentation, and standardisation (see Figure 3.3). 


\section{- Documentation}

Documenting business processes has become an important initiative for many organizations. The advantages of identifying, understanding and evaluating key business processes to determine their effectiveness in meeting business objectives has been recognized as a key factor in developing successful eGovernment application. Veenstra et al. (2011) argued that transformation in eGovernment cannot be realised without efficiency in business process. James (2013) stated that part of the problem in government organisations is lack of business process documentation, he argues that if the process is efficient and not documented then it would be less functional because employees need a process documentation to show them their responsibilities and how their work fits into everyone else's. If there is no formal process-based way to train new hires, it delays the time it takes before they are making a positive contribution. Veenstra et al. (2011) also argued that, if process isn't defined and only one employee knows how something is done, then this leads to a process black hole, particularly when the employee leaves the organisation permanently. One-way that an employee gets organized in a new role or stays organized in a changing role is to document the workflow and processes. This was also argued by Haider et al. (2015) that consistency in operations is important for an organisation's growth, and consistency remains an issue because of the employees' different ways of performing the same task. This due to the fact that employees' education experience and skill levels determine their own styles and differences in their styles cause variations in process output. If process well documented, then an organisation will be able to operating procedures in the best way and variations will be minimized and best quality services will be offered to stakeholders.

\section{- Standardization}

On the other hand, standardization is defined as the degree to which work rules, policies, and operating procedures are formalized and followed. Scholl (2013) argue that standards and documents, established by consensus and approved by a recognized body, that provides, for common and repeated use, rules, guidelines or characteristics for activities or their results, aimed at the achievement of the optimum degree of order in a given context.

Many researchers and practitioners alike have shown increased interest in the potential value of business process standardization. Wullenweber et al., (2008) argue that process standardization can benefit the company as well as its customers. 
With standardization, the production or service process becomes routine, with well-defined tasks. Wullenweber et al., (2008) argued that, even in the most structured organizations, many workplace processes are chaotic and disorganized. There is duplication of effort, which means different employees carry out the process in a slightly different way, or the same employee does something slightly different each time. This is stressful for employees and costly for organizations.

To conclude: an analysis of the current literature suggests that a government organisation willing to present its services online should consider process documentation and standardization issues, such issues are presented in table 3.1 which have been considered by the researcher as sub-factors that should be assessed before eGovernment adoption takes place. Table 3. 1 Sub-Factors of Documentation and Standardization

\begin{tabular}{|c|l|l|}
\hline \multicolumn{1}{|c|}{ Documentation } & \multicolumn{1}{|c|}{ Description } & \multicolumn{1}{|c|}{ Source } \\
\hline Documentation process & $\begin{array}{l}\text { Degree to which the business process in question is } \\
\text { modelled and documented in written form. }\end{array}$ & \multirow{1}{|c|}{ (Weitzel, } \\
\cline { 1 - 2 } Standardization & \multicolumn{1}{|c|}{ Description } \\
Standardized workflows & $\begin{array}{l}\text { a common and repeated use, rules, guidelines or } \\
\text { characteristics for activities or their results, aimed at the } \\
\text { achievement of the optimum degree of order in a given } \\
\text { context. }\end{array}$ & \\
\hline
\end{tabular}

Figure 3. 2 Process Efficiency Dimension: Factors and Sub-Factors

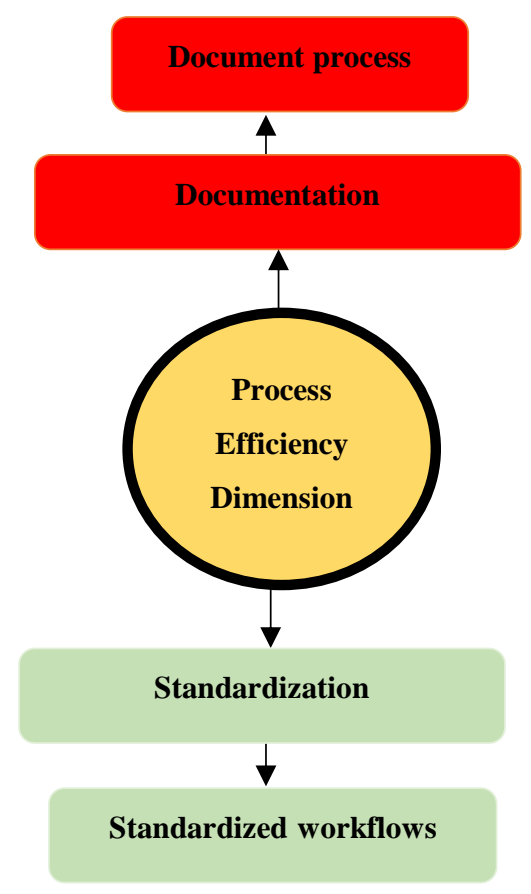




\subsection{Proposed Conceptual Model}

There is an apparent need to develop a conceptual model necessary for identifying eGovernment implementation factors. This is as a result of the gaps in the review of literature identified in previous sections and discussions in Chapter two. The proposed conceptual model consists of three dimensions that are believed to influence eGovernment implementation.

Figure 3.4 shows the conceptual model that has been proposed and it comprises multidimensional aspects of technology deployment, organisational capability and process efficiency.

Technology Deployment Dimension: identifies the minimum requirement of infrastructure needed prior to eGovernment implementation:

Organisational Capability Dimension: identifies the minimum staff requirement and organisation capability prior to eGovernment implementation.

Process Efficiency Dimension: identifies the minimum requirement of work efficiency prior to eGovernment implementation.

Figure 3. 3 Proposed Conceptual Model

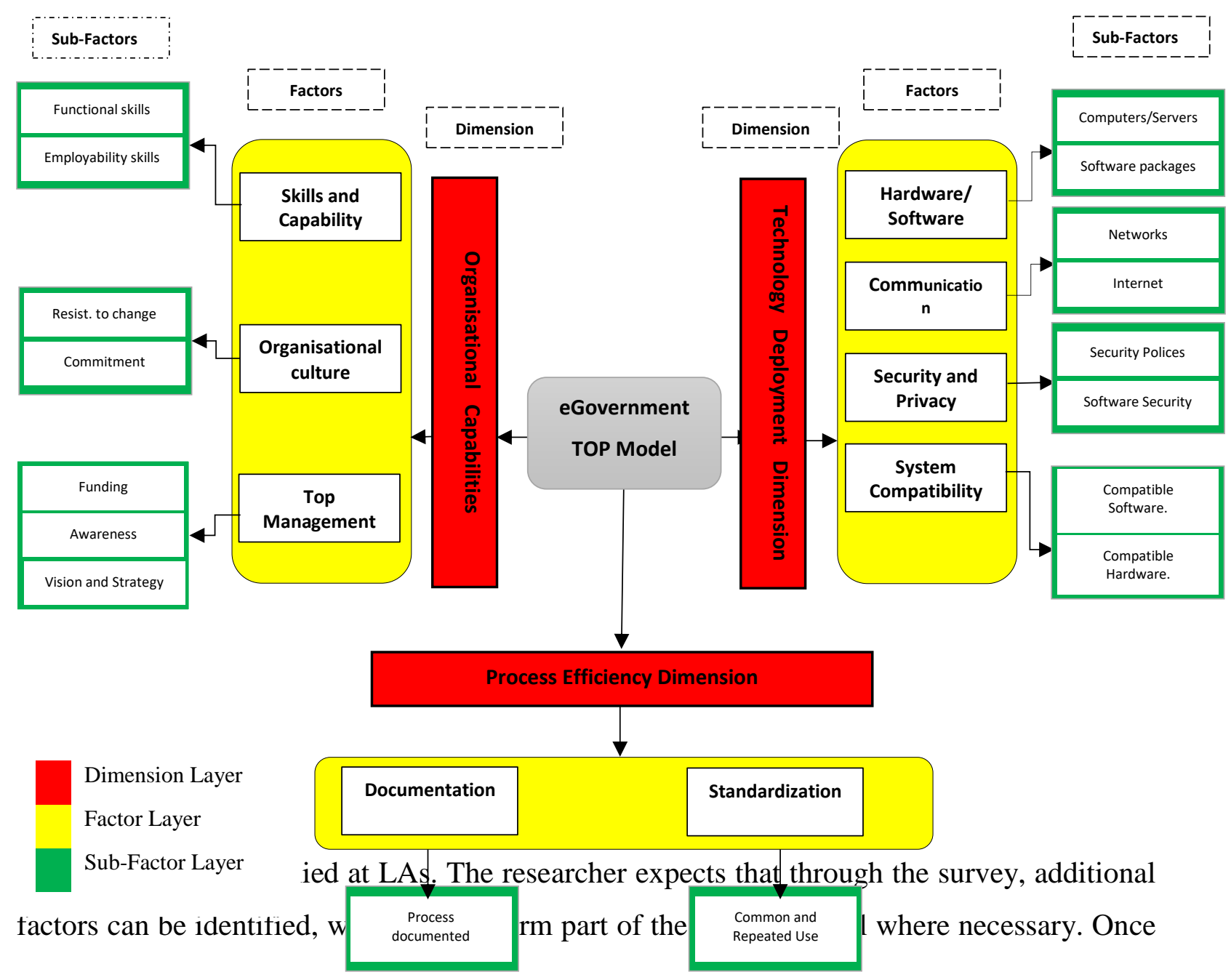


the conceptual model has been revised, a staged definition for each dimension will be extracted from the revised model and then will be applied at staged level approach at individual process levels as follow:

\subsubsection{Functioning of Maturity Levels Approach}

The Maturity level approach will be applied at individual process level. Each main process will be assessed against the three dimensions (TOP). Generally, each dimension has a staged level scale range (Chaotic, Basic, Intermediate, Standardized, Optimized), and is associated with qualitative definitions. The dimension must mature further in practice and therefore are subject to evaluation, which is done by measuring their capabilities through their factors and subfactors.

\subsubsection{Capability Level Definitions}

The staged level approach is derived from the maturity model that the SEI defined for the maturity of software development capability. Although the concept of software engineering approach was followed, this model differs considerably from the original SEI model. In this model, specific definitions are provided for the model maturity scale for each dimension (TOP). The maturity levels are not designed for use as a threshold model, where one cannot move to the next higher level without having fulfilled all conditions of the lower level. This model is likely to result in the dimensions being scored in different maturity levels, as illustrated in (see Figure 3.5).

Figure 3. 5 Dimension Maturity Levels

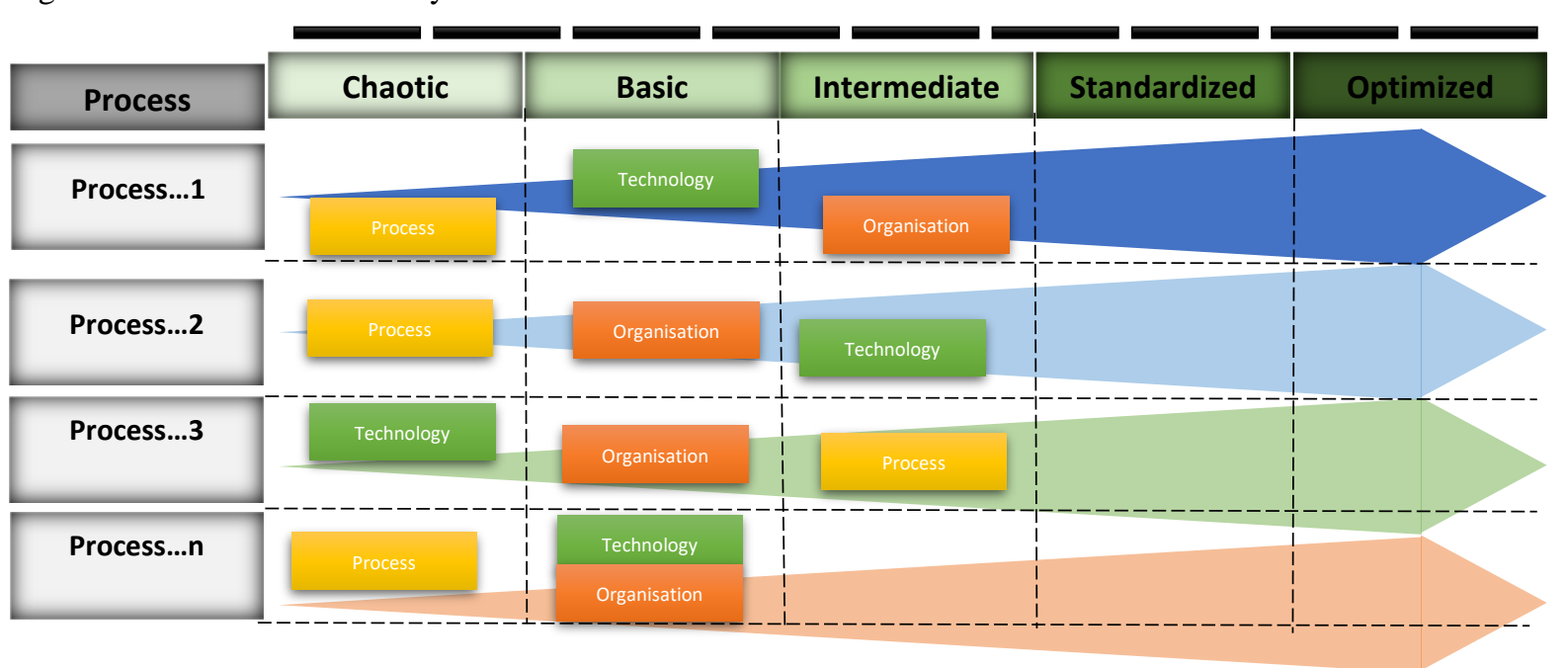




\subsection{Chapter Summary}

This chapter aimed to clarify the challenges surrounding eGovernment using literature and theoretical contexts from the perspectives of implementation and adoption from both developed and developing countries. The chapter concludes by offering a conceptual model that maps the possible dimensions that affect the eGovernment implementation and adoption. The conceptual model offers the main frame of reference and potential lines of inquiry for the empirical research that will be carried out in this research to explore the factors influencing eGovernment prior implementation. This chapter also offers a staged level approach represented in maturity levels from chaotic to optimized. The proposed model is novel because it combines assessment of three dimensions (TOP) simultaneously. To the researcher 's best knowledge, no previous studies exist that have attempted to combine three dimension (TOP) influencing eGovernment prior implementation process. The proposed model could be used as a frame of reference by government institutions that seek to assess their organisations prior implement and adopt eGovernment systems. Further, this model can also be used by researchers and scholars in the field of eGovernment to analyse and understand eGovernment system implementation and adoption. The proposed conceptual model is anticipated to be validated after the research analysis and findings in Chapter five of this research study. 


\section{Chapter Four: Research Methodology and Design}

\subsection{Introduction}

In this chapter, the methods used to address the research objectives are explained. It explains and justifies the choice of the methodology that the researcher employed in conducting the empirical research. This chapter comprises the following sections: Section 4.2 provides an overview of the research philosophy and includes a discussion of three philosophical paradigms: Positivist, Interpretive and Critical; it also discusses the epistemological stances involved in IS research and justifies the selections made for this research. Section 4.3 discusses research approach and explains the qualitative method which seeks to describe, decode and translate data, this section also explains the rationale behind the selection of the qualitative approach. Section 4.4 explains the research strategy and rational behind the selection of case study. Section 4.5 discusses the data collection strategy which has been used to collect the data. Section 4.6 explains the data analysis techniques employed in this research. Section 4.7 discusses ethical considerations. Section 4.8 outlines the method that was followed to validate the model. Section 4.9 provides a summary of the chapter.

\subsection{Research Philosophy}

Philosophy of research means the basic beliefs about the world we live in. There are two assumptions that shape the way of thinking about these beliefs: the 'ontology' and 'epistemology' assumptions (Aliyu et al., 2014). Ontology refers to the nature of the world or reality. The field is dedicated towards understanding whether things exist or do not exist. Ontology also studies how various existing entities can be grouped together on the basis of similar characteristics and it tries to find out those similarities. The field also tries to find a relation between the objects that exist. People who deal in ontology try to understand why a particular thing occurs and how it is related to other things. On the other hand, epistemology is concerned with the study of knowledge and what we accept as being valid knowledge. Epistemology answers the question of how things really work, and what are the best ways to acquire knowledge (Alkhalifah, 2017. As regards IS research, the three philosophical paradigms that are commonly adopted are: positivism, interpretivism and critical (Aliyu et al., 2014; Oates 2006). 


\subsubsection{Positivism}

Positivist studies generally attempt to test theory, in an attempt to increase the predictive understanding of phenomena (Aliyu et al., 2014). Several researchers classified IS research as positivist if there was evidence of formal propositions, quantifiable measures of variables, hypothesis testing, and the drawing of inferences about a phenomenon from the sample for a stated population (Aliyu et al., 2014; Oates 2006). The key idea of positivism is that the social world exists externally, and that its properties should be measured through objective methods, rather than being inferred subjectively through sensation, reflection or intuition (Easterby et $a l ., 2002)$. Scholars consider it as a quantitative and deductive method since it uses general results to attribute properties to explicit instances (Strauss and Corbin, 2008; Saunders et al., 2007). Many philosophers of science criticise that this research paradigm plays an important role in theory/hypothesis conception, but a highly structured research design imposes constraints on the results and may ignore other relevant findings (Collis and Hussey, 2009). A number of other assumptions can be made from the positivism paradigm (Easterby et al., 2002; Weber, 2004; Lowery and Evans, 2004). These include:

- The use of laboratory and field experiments and surveys as the preferred research methods;

- The statement made by a researcher is true when it has one-to-one mapping to the reality that exists beyond the human mind;

- The research is reliable only if results can be replicated by the researcher herself/himself and other researchers;

- Science proceeds through a process of hypothesising fundamental laws and then deducting what kinds of observations will demonstrate the truth or falsity of these hypotheses.

\subsubsection{Interpretivism}

Interpretive studies generally attempt to understand phenomena through the meanings that people assign to them. Interpretive methods of research in IS are aimed at producing an understanding of the context of the information system, and the process whereby the information system influences and is influenced by the context (Hammersley, 2013). Interpretivism is the belief that social reality is subjective because it is socially constructed. As a result, each person has his or her own sense of reality and there are multiple realities. It is regarded as the philosophical paradigm that emerged after positivist to cover the inadequacies 
of methods applied to social science, which are only applicable to natural science. Scholars also argue that an interpretivist approach could be used from the perspectives of respondents directly involved with a particular phenomenon in order to understand the exploration of the phenomena. The interpretive paradigm believes that social reality is not objective but in individuals' minds and highly subjective; this is due to the fact that it is shaped by our perceptions. Thus, it revolves around people's perceptions of their world (Myers and Avison, 2002; Klein and Myers 1999).

Interpretivism rests on the assumption that social reality is also multiple and affected by the act of investigating it. There is the belief that social constructions such as language, shared meanings, perceptions, consciousness and understanding enable reality to be accessed and communicated to other individual or a group. Where research findings could not be generalised, interpretivism allows the researcher to transfer and apply qualitative data to other similar perspectives (Tuli, 2010; Myers and Avison 2002; Oates 2006; Ryan et al., 2007; Collis and Hussey, 2009). Table 4.1 below presents the epistemological stances involved in IS research.

\subsubsection{Critical}

Critical researchers assume that social reality is historically constituted and that it is produced and reproduced by people. Although people can consciously act to change their social and economic circumstances, critical researchers recognise that their ability to do so is constrained by various forms of social, cultural and political domination. The main task of critical research is seen as being one of social critique, whereby the restrictive and alienating conditions of the status quo are brought to light (Myers and Avison; 2002).

\subsubsection{Research Philosophy Adopted in this Research}

Both positivist and critical paradigms are unsuitable for this research study, which aims to evaluate and investigate what principles should guide successful implementation of eGovernment systems in the context of the developing countries. The objectives include developing conceptual theories or models and recommending how decision makers are able to address the change management issues, in relation to eGovernment implementation, interpretivism would be most suitable approach for this research since it is qualitative, subjective, humanist and phenomenological (Collis and Hussey, 2009). The researcher also considers the implementation of eGovernment as a complex process that is taking place within organisational context; it influences and influenced over time. In addition, eGovernment can be shaped according to many technological and organisational issues; they can affect every 
aspect of how government organisation deliver their services to citizens, business and other government agency. Therefore, it is very important to gain an in-depth understanding of eGovernment implementation through the meaning that its stakeholders assign to it.

Furthermore, eGovernment as social phenomena must be studied within their natural setting and interpretive approach assumes that social phenomena are situated within and cannot be isolated from their social context, interpretations of such phenomena must be grounded within their socio-historical context and finally interpretive studies tend to produce qualitative data which will help the researcher gain in depth insights on eGovernment issues.

Table 4. 1 Taxonomy of Epistemological Stances

\begin{tabular}{|c|c|c|}
\hline Approach & Description & References \\
\hline Positivist & $\begin{array}{l}\text { Positivist studies tend to produce quantitative data as they presume } \\
\text { reality as being accurately given. Relates to test theory, and hypothesis } \\
\text { testing, formal quantifiable measures of variables and an attempt to } \\
\text { increase the predictive understanding of phenomena. Also drawing of } \\
\text { inferences about a phenomenon from the sample for a stated } \\
\text { population, with highly specific and precise data. }\end{array}$ & $\begin{array}{l}\text { Orlikowski and } \\
\text { Baroudi, 1991; Yin, } \\
\text { 2003; Straub et al. } \\
2005 .\end{array}$ \\
\hline Interpretive & $\begin{array}{l}\text { Interpretive studies generally seek to describe, understand and } \\
\text { translate phenomena through meanings that people assign to them in } \\
\text { order to comprehend the context of information system. Enables } \\
\text { understanding of deeper structure of phenomenon within cultural and } \\
\text { contextual situation. Interpretive studies tend to produce qualitative } \\
\text { data and allows theory generation. }\end{array}$ & $\begin{array}{l}\text { Walsham, 1995; } \\
\text { Hussey and } \\
\text { Hussey, 1997; Yin, } \\
2003 .\end{array}$ \\
\hline Critical & $\begin{array}{l}\text { Critical studies are mainly used philosophically to gain knowledge in } \\
\text { respects of focusing on the oppositions, conflicts and contradictions } \\
\text { in contemporary society. Academicians have argued that critical } \\
\text { paradigm concerns attempt to criticise, analyse, evaluate, transform } \\
\text { the social reality and modify the status quo. Researchers also assume } \\
\text { that social reality is historically constituted. The restrictive conditions } \\
\text { of the status quo are brought to light with the main task seen as social } \\
\text { critique. }\end{array}$ & $\begin{array}{l}\text { Myers and Avison } \\
\text { 2002; Oates } 2006 .\end{array}$ \\
\hline
\end{tabular}

(source: Ashaye, 2014)

\subsection{Research Approaches}

The researcher first decides which approach best identifies appropriate solutions from which to draw suitable conclusions to the issue under investigation. Galliers (1994) noted that the 
selection of an appropriate research approach for IS-related phenomena is not an easy task. This is because IS enables researchers to select a suitable method from different research approaches, as they are not related to a single theoretical perspective (Saunders et al., 2007). In selecting an appropriate research approach, there are three main research methodologies qualitative, quantitative and a mixture of both methods.

\subsubsection{Qualitative Approach}

The qualitative research method was developed in the social sciences to allow researchers to study social and cultural phenomena. The word qualitative implies an emphasis on the quality of entities and on processes and meanings that are not experimentally examined or measured in terms of quantity, amount, intensity or frequency. The techniques are defined as an array of interpretative procedures which seeks to describe, decode, translate, and otherwise come to terms with the meaning (Queiros et al., 2017).

In qualitative research, data are collected in the format of documents, interviews and observations, rather than in a numerical format. The approach is selected when the phenomena of interest typically requires an exploration of detailed in-depth data, as qualitative methods stress the values of rich descriptions of the social world (Queiros et al., 2017; Johnson and Harris, 2002; Robson, 2002). As opposed to the controlled environment of the quantitative approach, the researcher here conducts study in a 'natural setting'. Qualitative sources include observation and respondent observation (fieldwork), interviews, documents and texts, and include the researcher's impressions and reactions. It is exploratory and seeks to explain 'how' and 'why' a particular social phenomenon, or program, operates as it does in a particular context. It tries to help researchers to understand the social world in which we live, and why things are the way they are (Mohajan, 2018; Myers and Avison, 2002).

Qualitative research does not include statistical or empirical calculations as mentioned earlier. The researcher is the primary instrument for data collection and analysis. It is usually involved with fieldwork. The researchers must go to the people, setting, site, and institutions to observe behavior in its natural setting. It builds abstractions, concepts, hypothesis, or theories rather than tests existing theory. Different types of qualitative research have some common characteristics as follows (Mohajan, 2018; Hammersley and Atkinson, 1993):

- The researcher has the opportunity of collecting data directly from the respondents through direct encounters with individuals, through one to one interviews or group interviews or by observation. 
- Data are used to develop concepts and theories that help us to understand the social world.

- It is concerned with the opinions, experiences, and feelings of individuals producing subjective data

- It is conducted in 'real life' and day-to-day settings, not in controlled or laboratory settings.

- It seeks to establish a holistic perspective of a given situation.

- It has the ability of the researcher to use their motivation and personal interest to stimulate the study.

- Typically, the findings are in the form of themes, categories, concepts or tentative hypotheses or theories

- It focuses on discovery and understanding which requires flexibility in the research design

\subsubsection{Justification for the Selection of Qualitative Analysis}

eGovernment deployment is relatively new and there is little empirical research information available on its implementation in developing countries. However, due to the nature of the data required and the research focus of this study, a qualitative approach is the preferred methodology. This allows the examination of full context and researcher will be able to interact with respondents and data will also be collected face-to-face or over Skype with respondents. In summary, the main reasons for opting for the qualitative approach are as follows:

- There are few empirical research materials on eGovernment implementation in developing countries within the context of government organization. Thus, the qualitative approach enables deeper understanding of the implementation process, which would allow for the building of theories.

- The complexities surrounding the eGovernment adoption process in government organisations need rich and deep empirical data. Using qualitative data means providing a level of richness that will allow the researcher to conduct an in-depth investigation.

- The qualitative approach fits perfectly into this research work since it is inductive, specific instances that could be used to arrive at overall generalisations. It would also play an important role in development of a conceptual model - which is not suitable for quantitative approach where focus is on hypothesis testing.

- There are few empirical research resources on eGovernment maturity models that assess the prior implementation of eGovernment in developing countries, especially the focus on eGovernment at the back office. The qualitative approach enables deeper understanding of 
government processes, which allows for assessment of the back office and introducing maturity levels.

- The qualitative approach is suitable for a case study approach. In addition, the data sources will include: interviews and documentation. This is because eGovernment implementation requires close connection with the people and organisation, which would be most effective through interviewing.

Based on the available facts the researcher was satisfied that the qualitative approach was most appropriate. Table 4.2 below summarises elements of the qualitative analysis:

Table 4. 2 Qualitative Analysis Characteristics

\begin{tabular}{|c|l|}
\hline Characteristics & \multicolumn{1}{|c|}{ Qualitative Analysis } \\
\hline Approach & \multicolumn{1}{|c|}{ Inductive } \\
\hline Purpose & $\begin{array}{l}\text { Describing multiple realities, developing deep understanding, theory } \\
\text { building, capturing everyday life. }\end{array}$ \\
\hline Research Focus & $\begin{array}{l}\text { Examines full context, interact with respondents, collects data face-to- } \\
\text { face with respondents, observation. }\end{array}$ \\
\hline Research Strategy & Unstructured and open \\
\hline Research Plan & $\begin{array}{l}\text { Begins with initial idea that evolves as researcher learns more about } \\
\text { respondents and setting flexible, tentative proposal. }\end{array}$ \\
\hline Research Methods & $\begin{array}{l}\text { Action research, case study research and ethnography. Qualitative data } \\
\text { sources include: Observation and respondent, observation, interview and } \\
\text { questionnaire, documents and texts, and researcher's impression and } \\
\text { reaction. }\end{array}$ \\
\hline Nature of Data & Rich, deep and complex \\
\hline Data Analysis & Mainly interpretive, descriptive \\
\hline
\end{tabular}

\subsection{Research Strategy}

The choice of which strategy to follow is dependent upon the nature of the research problem (Noor, 2008). Research strategy provide a direction of the research including the process by which the research is conducted. It is also considered as the general plan of how the researcher will go about answering the research questions, or a general orientation to the conduct of research (Saunders et al., 2009). Academicians have considered the determination of an appropriate research methodology to be an important element in a research study (Bryman, 2012; Saunders et al., 2009). Yin (1994) argues that there are few possible research strategies 
to carry out social research: case studies, experiment, surveys, histories and analysis of archival information. Orlikowski and Baroudi (1991) highlighted six research designs as: survey; case study; laboratory experiment; field experiment; action research and others - articles that are practitioner-oriented, non-experimental pieces, or descriptive / argumentative However, there many main research strategies that could be adopted in practice as: case study; historical research; survey research and experimental study (Galliers, 1991; Yin, 1994; Klein and Myers, 1999). Creswell (2013) also identified five research strategies under the qualitative approach, with different criteria and explanations, such as case study, ethnography, grounded theory, biography and phenomenology, whereas (Robson, 2002) identified case study, grounded theory and ethnography. Table 4.3 shows different research strategies and the type of questions they answer.

Table 4. 3 Research Strategies

\begin{tabular}{|l|l|}
\hline \multicolumn{1}{|c|}{ Research strategy } & \multicolumn{1}{c|}{ Question Type } \\
\hline Case study & How, why and what \\
\hline Historical research & How and why \\
\hline Survey & Who, what, where, how much and how many \\
\hline Experiment & How and why \\
\hline
\end{tabular}

Source: (Yin, 1994)

\subsubsection{Case study}

Case study is described as collection of considerable details, from multiple sources about a particular, contemporary phenomenon within its real-world setting, where the boundaries between the phenomenon have not been clearly evident. This type of research study generally uses detailed contextual analysis of a single individual, group and event to explore underlying principles. The case study inquiry usually relies on multiple sources of evidence (Yin, 2009).

\subsubsection{Historical research}

Historical research literarily means the method of systematically examining past events to give an account; it includes interpretation to recapture the nuances, personalities, and ideas that influenced these events. Historical research is thus the act of researching the events that have happened in history or to communicate an understanding of past events. An advantage of this research type is that can display patterns which had occurred in the past and over time that can help in understanding where we came from and what kinds of solutions we have used in the past. Historical research is the process of systematically examining past and current events to discern the meaning of events (Leedy, 1997). 


\subsubsection{Survey research}

Survey research is described as a method of sociological investigation that uses question- based or statistical survey to collect information about how people think and act. Survey research is useful for documenting existing community conditions, characteristics of a population, and community opinion. This type of research is one of the most important areas of measurement procedures that involve asking questions of respondents. Academicians have described it in many ways. For instance, Rates (2004) defines survey research as a means of determining and explaining practical phenomena (McClure, 2002; Mohajan, 2018).

\subsubsection{Experimental study}

Experimental study includes both laboratory and field experiments. It applies a research activity under controlled conditions and environments to explain "cause and effect" relationships. Whilst the laboratory relates to studies carried out within a designed, controlled environment, and special treatments of different groups to contrast the precise relationships among variables; Field experiments however are conducted in real-world situation, since the object of study is subjected to direct observation by the researcher. Overall, the experiment study endeavours to be responsible for the research situation through the study, and assuming certain input variables which are suspicious as the cause of whatever change has been taken place within the investigation design (Mohajan, 2018).

\subsubsection{Justification for the Selection of Case Study Strategy}

There are single and multiple case studies. A single case study provides valuable information about the research question from one organisation, which can provide rich information of the organisational context. On the other hand, multiple case studies can strengthen the results by replicating pattern-matching (Yin, 1994). Yin (2009, p.18) defines a case study as follows: "a case study is an empirical inquiry that investigates a contemporary phenomenon within its reallife context, especially when the boundaries between phenomenon and context are not clearly evident." He also suggests that if a researcher has sufficient access to cases for replication, then conducting multiple case studies is more valuable. Therefore, case study is a powerful strategy, which allows the researcher to explore the phenomena comprehensively.

To select an appropriate research strategy, the researcher applied the conditions suggested by Yin (2003) which is based on the research objectives to be addressed (outlined in Chapter One) and the context of the research which is public sector organisations in the developing countries. However, due to the research objectives for this research, that relate to building a conceptual 
model for evaluating eGovernment prior implementation process within developing countries context, the researcher intends to highlight the factors influencing eGovernment implementation.

As a result of the limited research in this area in Libya, and the need to be subjective, the case study strategy is the preferred strategy. In addition, case study research has been advocated as a "valid research strategy in management information systems and as a distinctive evaluation tool with the ability to adapt to the availability of different types of evidence" (Ashaye and Irani, 2014). The research phenomenon is interpretive, aims at understanding of the context of the information system. Therefore, case study is however the most appropriate research approach for this study. The case study approach has been adopted to investigate two government organisations in Libya, since the research intend to explore and analyses the issues, factors and challenges faced by government organisations with respect to the provision of eGovernment services, develop and validate a sold model for the assessment and management of eGovernment services. Yin (1994) emphasized that it is important to clarify the deeper causes behind a given problem and its consequences than to describe the symptoms of the problem and how frequently they occur.

Bryman (2012) claim that case studies can be used to describe phenomena, build theory and test theoretical concepts and relationships. In view of the nature and complexity of the eGovernment implementation process, and the combination of many complex systems such as technologies, business processes, and human resources, the case study method can be an ideal choice. Some researchers consider the case study as a method when holistic, in-depth investigation is required and when there is lack of existing knowledge. Collis and Hussey (2009), and many other researchers (e.g Yin, 2003; Easterby et al., 2002; Ravenswood, 2011) prefer case studies as they provide the following features: The phenomenon is examined in its natural setting; there is little or no control over events; more than one entity can be examined at the same time; more than one method can be used for collecting data; changes in site selection or data gathering instruments can take place; knowledge is constructed rather than discovered or found; generalisation is based on a limited number of cases

From the discussion above, the case study as a research strategy is expected to significantly support understanding of the challenges and issues of eGovernment implementing in public organisations. Hence, the researcher asserts that it is a suitable strategy for this study because an in-depth investigation of the nature and context of the environment related to technology, 
organisational capability and process efficiency is required to assess the relevant dimensions shaping the adoption of eGovernment at government organisation

Based on the above discussion, the researcher has chosen to investigate and evaluate the phenomenon, using case study as a vehicle for the empirical research, and the model that has been developed to help the study gather data.

\subsubsection{Multiple Case Studies}

Case study remains a very powerful methodology for researchers and most common qualitative method that is particularly well suited to be used in information systems research (Ponelis, 2015) which relates to this research study.

Scholars have classified case studies into single, which is holistic in nature, or multiple unit of analysis, which is embedded. There is no standard specification for selecting the number of fieldwork to be undertaken. Thus, the number of cases to be selected would depend largely on the type of concepts that are acknowledged; however, some scholars have recommended one to three cases (Yin, 2009; Dul and Hak, 2008). The researcher has therefore selected multiple case study; two cases since multilabel case studies allows the researcher to explore the phenomena comprehensively and can strengthen the results by replicating pattern-matching (Yin, 1994). The researcher therefore decided to focus on two different size of organisations consisting of small and medium size with different level of ICT facilities and capability.

\subsubsection{Selection of Organisations}

In selecting the appropriate organisations suitable for this study, the researcher considered the government organisations which would enable determination of the factors that play a crucial role of implementation process of an eGovernment project.

For this research, two organisations were selected for the following reasons:

- The organisations are government organisations and represent local authority that provides daily services to its stakeholders, and eGovernment project is essential to adopt whether now or in the future.

- The researcher was able to access information and communicate effectively with the staff and managers in the organisations using his own personal contacts.

- As $80 \%$ of local authorities are small to medium size (Libya Business, 2018), the researcher believes that the selection of SLA as medium size and RLA as small size are representative case studies. 
The first organisation selected was SLA, the city is located in the northwestern part of Libya 70 kilometers east of Tripoli, on a point of rocky land projecting into the Mediterranean Sea. The city was the westernmost of the ancient "three cities" of Roman Tripolis, and the population numbers 152,521 people (World Bank, 2016). SLA provides a large number of different services to its stakeholders (citizens, businesses, governments). The most important services are: water supply, sewage collection and disposal, refuse removal, electricity and gas supply, health services, roads and storm water drainage, street lighting, parks and recreation, taxation, licenses, schools etc. SLA is keen to provide affordable services in a sustainable way to all citizens, businesses and governments.

Process mapping suggests that there are five main processes (Procurement management, Legal Affairs management, Human Resource management, Community and Services management, and Financial management) operating at SLA. The processes are situated in separate and scattered locations within Sabratha City which make it difficult to adopt eGovernment strategy as if it was in the same building.

The second organisation was RLA. Rujban is a small city which lies on the Nafusa mountain chain more than 150 kilometers south-west of Tripoli (the capital city of Libya) and it is inhibited by 18,000 people. The LA have less financial and administrative powers compared to bigger local authorities such as SLA, but they have responsibilities also in planning and administering number of core services for its stakeholders. There are four processes which have been investigated in this case study. They are the procurement management process, finance management process, human resource management process, and community and services management process, the reason the Legal Affairs has not been selected in RLA because it is an entity within Human Resource management . As in RLA these management processes are located in a variety of buildings across Rujban city.

Table 4.4 below outlines the selection criteria for determining appropriate organisations chosen for case study research.

Table 4. 4 Selection of Organisations for Case Study Research

\begin{tabular}{|c|c|c|l|}
\hline No & Organisation size & Organisations name & \multicolumn{1}{|c|}{ Processes investigated } \\
\hline \multirow{3}{*}{1} & \multirow{3}{*}{ Medium } & SLA & $\begin{array}{l}\text { Procurement management, 2: Legal Affairs } \\
\text { management, 3: Human Resource management, 4: } \\
\text { Community and Services management, 5: Financial } \\
\text { management }\end{array}$ \\
\hline
\end{tabular}




\begin{tabular}{|c|l|l|l|}
\hline 2 & Small & RLS & $\begin{array}{l}\text { 1: Procurement management, 2: Human Resource } \\
\text { management, 3: Community and Services } \\
\text { management, 4: Financial management }\end{array}$ \\
\hline
\end{tabular}

\subsection{Data Collection}

Data collection is an important aspect of a qualitative research study. It involves the process of collecting, gathering and measuring information on variables of interest, in an established time frame and systematic fashion. This would allow the researcher to address the research objectives and evaluate outcomes. Data collection makes a case study research more rigorous and increases its power of interpretation when it is addressed properly. Moreover, when researchers understand their fieldwork very well, they are able to strategically question respondents and systematically take notes of their qualitative research. This method also allows researchers to increase the rigour and reliability of the case study research, since inaccurate data collection can impact the outcomes of a study and ultimately lead to invalid results (Parikh, 2002). Data collection approaches for qualitative research usually involve direct interaction with individuals on a one to one basis or in a group setting. Since qualitative research data collection methods are time consuming, the data has to be collected from a smaller sample of individuals of SLA and SLA than would be the case for quantitative approaches, where large samples are collected. The benefits of the qualitative approach are that the information is richer and has a deeper insight into the phenomenon under research study.

Primary and secondary data are the two types of data used in this research project. Whereas primary data are raw data collected through interviews, questionnaires, survey, on other hand secondary data are collected from review of documents such as books, articles and on the internet. Secondary data can also be assembled faster than primary data, since the data are readily available in most instances. There are many techniques and methods for collection of data. However, for this case study research, data are collected through two different main sources: Interviews and Documentation, (Yin, 1994; Saunders et al., 2007).

\subsubsection{Purposive Sampling}

The main goal of purposive sampling is to focus on particular characteristics of an employee that are of interest, which will best enable the researcher to achieve research objectives. Purposive sampling strategy depends on the judgement to select cases very close to the research study purpose. The samples tend to be small and are very convenient for case study research. While the logic of probabilistic sampling lies in selecting a random and representative sample 
which will permit confident generalisations from the sample to a larger population (Patton, 1990), the logic of purposive sampling is suited to research with different aims which lies in the selection of cases rich in information about the substantive research problem.

In considering the organisations involved in the research, it was decided that purposive rather than random sampling would be an effective way of selecting case projects, rich in data pertinent to understanding the research problem. The selection of cases and interviewees in this research relied on selective purposive sampling, rather than random statistical sampling. Therefore, steps were taken to sample decision-makers such as departmental directors, and employees with different work experiences, who acted as representatives of the organisations selected. The proposed sample of interviewees was 18 respondents and covered whole dimensions in every process.

To select respondents for a qualitative study, researchers use purposive or purposeful sampling, choosing people who fit the characteristics they wish to study. Hence, one of the most important tasks in the study design phase is to identify appropriate respondents. Decisions regarding selection the respondents was based on the following questions:

- Who has the relevant information?

- Who is accessible?

- Who is willing to give relevant information?

- Who is most able to give the information?

The researcher was able to meet relevant senior management in both case studies and they suggested people who could give relevant information about the research objectives. Table 4.5 and Table 4.6 presents the characteristic of the interviewees for both case studies. It can be noted that the sample include a wide range of age and educational level backgrounds. The researcher was keen to select the appropriate interviewees, thus, as suggested, he selected senior managers, deputy managers and expert employees. 
Table 4. 5 Interview Respondents from SLA

\begin{tabular}{|c|c|c|c|}
\hline Process's name & & Respondents & Code \\
\hline \multirow{2}{*}{ Procurement } & \multicolumn{2}{|c|}{ Director of Procurement process/ management and leadership specialist } & $\mathrm{S} 1$ \\
\hline & \multicolumn{2}{|c|}{ Expert staff / IT consultancy } & $\mathrm{S} 2$ \\
\hline \multirow{2}{*}{ Human Resource } & \multicolumn{2}{|c|}{ Member of recruiting committee } & S3 \\
\hline & \multicolumn{2}{|c|}{ Deputy manager of Human Resource process/ Data Analytic specialist } & S4 \\
\hline \multirow{2}{*}{$\begin{array}{l}\text { Financial } \\
\text { Management }\end{array}$} & \multicolumn{2}{|c|}{ Director of Financial Management/ Accountant and auditor expertise } & S5 \\
\hline & \multicolumn{2}{|c|}{ Deputy manager/ Statistics and Information Technology } & S6 \\
\hline \multirow{2}{*}{ Legal Affairs } & \multicolumn{2}{|c|}{ Expert staff/ member of law consultancy team } & S7 \\
\hline & \multicolumn{2}{|c|}{ Deputy manager/ management and Law expert } & S8 \\
\hline \multirow{2}{*}{$\begin{array}{l}\text { Community and } \\
\text { Services }\end{array}$} & \multicolumn{2}{|c|}{ Deputy manager / Statistics and Information Technology } & S9 \\
\hline & \multicolumn{2}{|c|}{ Expert staff/ IT Support } & S10 \\
\hline \multicolumn{3}{|l|}{$\begin{array}{l}\text { Total number of } \\
\text { respondents }\end{array}$} & \\
\hline Age range & $28-61$ & $\begin{array}{l}\text { Education level: } \\
1 \mathrm{PhD}, 2 \mathrm{MSc}, 7 \mathrm{BSc}, \mathrm{BA}, \mathrm{HND}\end{array}$ & \\
\hline
\end{tabular}

Table 4. 6 Interview Respondents from RLA

\begin{tabular}{|c|c|c|c|}
\hline Process name & & Respondents & Code \\
\hline \multirow{2}{*}{ Procurement } & \multicolumn{2}{|c|}{ Director of Procurement process/ Management } & R1 \\
\hline & \multicolumn{2}{|c|}{ Expert staff/ Statistics and Information technology expert } & $\mathrm{R} 2$ \\
\hline \multirow{2}{*}{ Human Resource } & \multicolumn{2}{|c|}{ Expert staff / Consultant and adviser } & $\mathrm{R} 3$ \\
\hline & \multicolumn{2}{|c|}{ Expert staff/ ERP and IT specialist } & $\mathrm{R} 4$ \\
\hline \multirow{2}{*}{$\begin{array}{l}\text { Financial } \\
\text { Management }\end{array}$} & \multicolumn{2}{|c|}{ Director of Financial Management/ accountant } & R5 \\
\hline & \multicolumn{2}{|c|}{ Expert staff/ Information technology expert } & R6 \\
\hline \multirow{2}{*}{$\begin{array}{l}\text { Community and } \\
\text { Services }\end{array}$} & \multicolumn{2}{|c|}{ Deputy manager of Community and Services/ Management } & R7 \\
\hline & \multicolumn{2}{|c|}{ Expert staff/ Software developer and IT support } & $\mathrm{R} 8$ \\
\hline $\begin{array}{l}\text { Total number of } \\
\text { respondents }\end{array}$ & 8 & \multirow{2}{*}{$\begin{array}{l}\text { Education level: } \\
3 \mathrm{MSc}, 5 \mathrm{BSc}, \mathrm{BA}, \mathrm{HND}\end{array}$} & \\
\hline Age range & $28-50$ & & \\
\hline
\end{tabular}

\subsubsection{Interviews}

An interview is generally a qualitative research technique, which involves asking questions to converse with respondents and collect elicit data about a subject. There are several advantages of using the interview approach. First, interviews are flexible; the interviewer can adapt the situation to each subject. Second advantage, interview may also result in more accurate and 
honest responses since the interviewer can explain and clarify both the purpose of the research and individual questions. and third advantage is that the interviewer can follow up on incomplete or uncertain responses by asking additional probing questions (Alshenqeeti, 2014). There are three fundamental types of interviews in research:

- Structured interviews: questions in this interview are pre-decided according to the required detail of information and the questions are asked in a set standardized order and the interviewer will not deviate from the interview schedule or probe beyond the answers received, (closed-ended questions, so they are not flexible). This means new questions cannot be asked impromptu (i.e. during the interview) as an interview schedule must be followed (Alshenqeeti, 2014).

- Unstructured interviews: Unstructured interviews is an interview in which there is no specific set of predetermined questions, although the interviewers usually have certain topics in mind that they wish to cover during the interview. Unstructured interviews uses 'open-ended' or 'open' questions so that the researcher can see in what direction the interviewees take things in their response. Stewart and Cash (2006) suggests that an unstructured interview is most appropriate when the information area is extremely broad. This means that an unstructured interview gives the interviewer unlimited freedom to probe into answers and to adapt to different interviewees and situations (Alshenqeeti, 2014). However, it can be time consuming to conduct an unstructured interview and analyze the qualitative data and the interviewer won't ask exactly the same question every time, so it could be said that this method is less reliable.

- Semi-structured interviews: semi-structured interviews are those in-depth interviews where the respondents have to answer preset open-ended questions and thus are widely employed by different professionals in their research. Semi-structured, in-depth interviews are utilized extensively as interviewing format possibly with an individual or sometimes even with a group (Corbin and Strauss, 2008). Saunders et al., (2007) argue that these types of interviews are conducted once only, with an individual or with a group and generally cover the duration of 30 min to more than an hour. Semi-structured interviews contain mostly prepared questions that can be supplemented with additional questions and does not limit respondents to a set of pre-determined answers (unlike a structured interview) and the interviewer can deviate from the original questions and therefore this type of interview typically produces rich qualitative data. 


\subsubsection{Justification for the Selection of Semi-Structured Interviews}

Among these three interview techniques, the semi structured interview technique was selected as a vehicle for data collection. The reason behind choosing semi-structured interview was that, it offers flexibility and ability to extract more detailed information from the interviewees, also allow the exploration of the areas of interest where the interviewee perceives gaps, contradictions and difficulties which would not be picked up via preset structured questions. In this research, semi structured interviews have been carried out with different employees in different fields across LAs and were used to get an insight into the thoughts and experiences of staff. However, they were used in conjunction with other data collection such as documents that were available in the LAs with the aim of overcoming the shortcoming of this technique. This approach enabled the researcher to obtain in-depth the views and experience of knowledgeable interviewees on how the dimensions identified in the conceptual model impact on reality; and how it might influence the adoption of eGovernment in Libyan local authorities.

\subsubsection{Interview Questionnaire and Pilot Testing}

Saunders et al., (2003) attributed the validity and reliability of data collected to the rate of response, to the design of the questions, its structure and the rigour of the pilot testing. Malhotra (2004) argued that there are no specific or strict steps to follow for designing an interview questionnaire, or scientific principles that guarantee a perfect and ideal questionnaire. The questionnaire design adopted consisted of a number of steps starting with defining the research objectives, selection of an appropriate format and design layout, pilot testing and then implementing the questionnaire (Wilson, 2003; Saunders et al., 2003). The design format adopted involved open and closed questions using simple language. The interview questionnaire was designed included three groups according to conceptual TOP model that was developed in chapter three (see Figure 4.1), each group represent a dimension. For example, one group represent technology deployment dimension and includes all hardware and software, internet technical issues and other technical issues. A total number of 26 questions was prepared to cover the three dimensions (see appendix 2).

The pilot interviews were conducted with different interviewees from different processes with the aim of testing the interview questions and the time needed for each interview. The researcher interviewed three different experts (IT expert from SLA, Human resource expert from SLA and management expert from RLA). The interview questions covered the conceptual model dimensions with special emphasis on problems, barriers or challenges that had been encountered. The pilot study provided the researcher the following: 
- Tape-recording was not preferred by some interviewees: this has put more pressure on the researcher as he had to write up the answers.

- The interviewees asked the researcher that their names should not be mentioned in the research, however this was already previously planned, and researcher decided to keep personal information anonymous.

- It was noted that there is a need to explain to the interviewees some questions in more details to get the satisfied answers.

Based on the pilot interview feedback, the research questions were reviewed. The aim was to collect the most relevant data within the shortest possible time. The researcher did not ask all interviewees the same questions but rather questions were asked depending on which dimensions the interviewees belong to, his/her roles and position. Furthermore, all interviewees were asked some open questions with the aim of giving them the chance to speak with more freedom, and some unplanned questions were emerged from the interviewees' answers. Some irrelevant/redundant questions were deleted or moved to another category. It was decided to conduct all interviews in the Arabic language because the respondents preferred the Arabic language to express their answers more accurately. However, some of the technological terminologies used were in English language.

In addition, the researcher gave the interviewees the possibility of studying the background of the research in advance to maximize the reliability of the research. This enhanced the quality of the answers since interviewees could give more consideration of their responses. The interviews were conducted using a printed standardized instrument as an interview guide for semi-structured interviews. All interviewee's answers were written up by the researcher as draft responses and then each was given the opportunity to review the final draft of their answers so that they had the opportunity to update or change what they said.

Figure 4. 1 Interview Question Categories
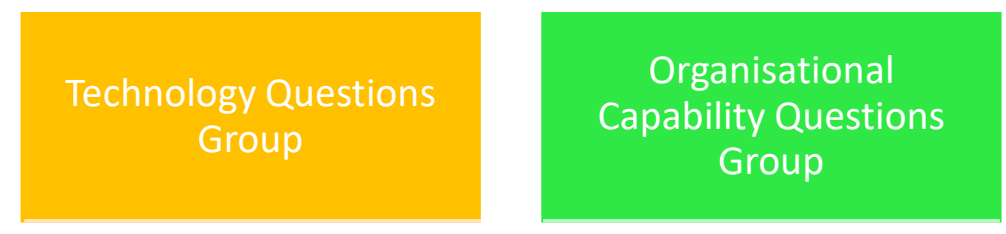


\subsubsection{Conducting the Interviews}

The empirical research was conducted in Libya at two LAs. The first phase was conducted between 15 August 2016 and 30 November 2016 to gather data from SLA and second phase was conducted between 3 Jan 2017 to 1 April 2017 to gather data from RLA. In both LAs, a similar procedure was followed to structure the interviews, the process of developing the procedure includes:

- Gaining permissions and interview Access

- Time arrangement.

- Gaining the respondent's cooperation.

- Overcoming common barriers.

\section{Gaining Permissions.}

There are many issues to consider when deciding how to contact the interview respondents. For research done within the workplace, many of these access issues are much easier. If the researchers do not have a professional relationship with the respondents, then there are more decisions and more difficult challenges. In some instances, the interviewer might be able to contact the respondent directly. In other cases, the interviewer will need to send information in advance or have someone else make the initial contact. In this research, the researcher approached the responsible authority for each LA and requested permission for the interview. The permissions were received from most of the interviewees to conduct the interviews at their premises. Permission was also obtained for using tape-recording devices before the interviews took place. The respondents were all helpful and filled a form that includes their emails, mobile phones and job positions to easily contact them to arrange time for the interviews (see appendix 1).

\section{Time Arrangement.}

An arrangement had been made to conducting the interviews for most SLA's respondents by mobile phones. date and time were setup prior each interview. The employees with their directors were very supportive, friendly and were able to provide information required. In RLA the researcher initially had difficulties to setup and arrange interview time with few employees. After constant chasing up, the time arrangement was received from the respondents as the researcher had to liaise directly with the Chairman of RLA. After each interview. In both LAs, 
some of the dates and times were shifted, as requested by the respondents due to other important commitments, but it was able to work around this as the researcher had made arrangements for re-scheduled appointments.

\section{Gaining the Respondent's Cooperation.}

"It may be beneficial to send an advance email or letter with a brief research description. Regardless of how the respondent is initially contacted, the researcher should inform him or her of the researcher's purpose and intent of the research" (NDRI, 2018, p63). To better utilize the interview and enable the respondents to assemble their thoughts beforehand; arrangement was made by mobile phones to each respondent before the interview to remind them of the background of the study and explain to them why their opinion is important for this research, to ensure consistency across interviews. This also done by sending emails to the respondents includes same description about the study and the same explanation about why and how he or she was selected as a respondent. Regarding anonymity and confidentiality, the researcher assured to keep their personal details anonymous rather than publishing them in this research. Next points were sent to each respondent with the following information:

- The researcher's name and his details.

- Purpose of the research.

- The estimated time required to conduct the interview.

- Assurance was given to them that there is no risk to participate in the interview and agreed that it would remain confidential.

Eighteen interviews were undertaken with the respondents who were chosen across the staffmanagement level from both LAs covering the three dimensions Technology Deployment dimension, Organisational Capability dimension and Process Efficiency dimensions. Most of employees with and directors were very supportive, friendly and were able to provide information required.

After each interview, the researcher wrote a transcript for the whole interview then sent it back to the interviewee to ensure that there was agreement about the context of the subject. Furthermore, this allowed the interviewee to state whether or not was satisfied with procedure of the researcher and ascertain if he/she wanted to omit or add any information. The average of the interview time was 2 to $2 \frac{1}{2}$ hours and the interviews were conducted face to face and 
separately except from seven interviewee from RLA were interviewed separately over Skype due to private circumstances.

The respondents who were interviewed were profiled beforehand to ensure that they had sufficient experience. The interviews were sufficiently in-depth to generate a significant amount of data saturation as the researcher noticed that the interviews tended to be repeated points that already mentioned rather that raise new challenges. Yin (2003a) also confirmed this as he pointed out that after the tenth interview, subsequent interview tends to be repeat points rather than raise any new ideas. At each interview an introduction was provided to introduce the researcher and his study to the respondent. He provided an overview of the study, information on data use, and any assurances about confidentiality. He also offered the respondent an opportunity to ask questions about the study. The researcher starts the interview by trying to understand the interviewees' roles and responsibilities and their knowledge of eGovernment in general, before going into depth of the interview and make the interviewees feel relax and to gain their support and confidence throughout the interview process.

\section{Overcoming Common Barriers.}

Barriers to the interview existing in the respondent's mind need to be overcome. The researcher had taken the initiative to address those concerns. Knowing how to address concerns help to avert refusals. Having brief, prepared answers provides enough information to gain cooperation without sacrificing considerable time with lengthy conversations. Table 4.7 provides some common concerns expressed by few respondents where addressed.

Table 4. 7 Overcoming Common Barriers.

\begin{tabular}{|c|c|}
\hline Barriers & Action taken \\
\hline I'm not interested & $\begin{array}{l}\text { The purpose of research was given and explanation to remind } \\
\text { them that it's an opportunity for their opinions to be heard. }\end{array}$ \\
\hline I'm too busy. How long will this take? & Schedule of other convenient time was discussed and agreed. \\
\hline Fear of being inadequate & $\begin{array}{l}\text { Reassurance that the researcher wanted their opinion and that } \\
\text { there were no right or wrong answers. }\end{array}$ \\
\hline Have a negative reaction to research & $\begin{array}{l}\text { The researcher reiterated why the research is important and } \\
\text { provided more information on the research. }\end{array}$ \\
\hline Confidentiality concerns & $\begin{array}{l}\text { Assurance was given to them that there is no risk to participate } \\
\text { in the interview and agreed that it would remain confidential. } \\
\text { Clarification that their answers will be combined with other } \\
\text { answers from others and presented in aggregate form; no names } \\
\text { will be reported }\end{array}$ \\
\hline
\end{tabular}




\subsubsection{Interview Recording and Transcription}

Note taking increases the respondents' attention to what is being said. Saunders et al., (2003) pointed out that the interviewer can rarely take notes fast enough to record exactly what was said, and also may hamper the flow of information because interviewees may become fearful or curious about what the interviewer is writing. Such problems did not occur during this research because the researcher paid attention more to the interviewees' comments and relied more on the tape recording. Stewart and Cash (2006) argue that using tap recording allows the interviewer to concentrate on the interview. This enables the interviewer and interviewee to relax and focus on what is being said and implied. A digital audio recorder was used through all interviews (except for two interviewees who did not accept tape recording). The interviewer experienced none of the problems mentioned above because the researcher checked the tape recorder before each (Appendix 4).

\subsubsection{Documentation Analysis}

Document analysis is an important research tool and is an invaluable part of most schemes of triangulation. The detailed examination of documents took a variety of forms from the written word to articles. Documentation provides historical circumstances. According to Oates (2006), documents can be classified as found documents (already existing documents in organisations such as personnel or public records) or research-generated documents (created by the researcher for the purposes of the research such as notes and images). However, for this research study, different documents from different sources were collected such as papers, archival records, eGovernment strategic plan and progress reports, including other documents that provide information in respect of the background of the case study organisations (see Table 4.8).

Table 4. 8 E-government Documents regarding Libya

\begin{tabular}{|l|l|l|l|}
\hline \multicolumn{1}{|c|}{ Type of document } & \multicolumn{1}{|c|}{ Topics } & No & Source \\
\hline $\begin{array}{l}\text { eGovernment } \\
\text { workshop reports }\end{array}$ & $\begin{array}{l}\bullet \begin{array}{l}\text { Vision statement for Libya's government } \\
\text { initiative } \\
\text { eGovernment Future plan } \\
\text { The goals of eGovernment in Libyan } \\
\text { organisations }\end{array} \\
\text { SLA ICT incidents }\end{array}$ IT incidents report 2013-2017 & 2 & SLA archive \\
\hline RLA ICT incidents & IT incidents report 2014 -2017 & 1 & SLA archive \\
\hline $\begin{array}{l}\text { Libyan Audit } \\
\text { bureau }\end{array}$ & Libyan Audit bureau report 2018 & 1 & RLA archive \\
\hline
\end{tabular}




\begin{tabular}{|l|l|l|c|}
\hline Libyan & Towards eGovernment in Libya & & General Authority for \\
eGovernment & Quarter national strategy for ICT industry & 2 & communication and \\
Initiative & $\begin{array}{l}\text { The importance of Internet services } \\
\text { Key factors for the success of Libya's electronic } \\
\text { program }\end{array}$ & & informative \\
\hline
\end{tabular}

The documents were used as complementary sources of evidence for data collection and helped a great deal in revealing meanings and discovering insights. The researcher was able to derive a valuable background information on the history and operation of previous IT projects.

\subsubsection{Site Observation}

Observation is one of the research instruments used in case studies, Yin (2003a) divided observation into two main categories. Direct observation and respondent observation, direct observation takes place when the researcher makes a visit to the case study site to observe the activates within organisation. On the other hand, respondent observation takes place when a researcher considers him/her self as an active by assuming a variety of roles. As the observation is an important tool, the researcher found it useful to bridge certain gaps and reach data saturation. The researcher conducted field trips to the SLA and RLA. The research visits were successfully carried out to obtain first-hand information about certain issues and gave the researcher the opportunity to meet some employees including decision makers. The researcher carried out two site visits for the purpose of observation for both case studies. However, before conducting any observation session, the researcher was able to agree with the departments on certain dates. In both cases, the researcher was allowed to obtain and look at documents, meet and build personal relationships with many employees.

The researcher identified certain issue that was not clear from interviews; the researcher listed issues and identified departments that the observation is mostly needed. Due to time limitation of the research and some other issue related to the LAs, the researcher was able to carry out two observations in both LAs. Departments had been observed was community and services in SLA and RLA and the missing information and misunderstandings that took place in using the interviews was information regarding Process Efficiency dimension (how long and accurate an activity took to perform in community and services SLA and RLA).

The researcher was able to observe and write down the tasks that given to certain employees:

- Time of same tasks to be completed.

- Business process documentation. 
- Procedure to complete same task.

\subsubsection{Triangulation}

Case study is known as a triangulated research strategy (Creswell, 2013). Triangulation is a tool by which data can be validated, and they are the protocols used to ensure accuracy and alternative explanations. Triangulation arises as an ethical need to confirm the validity of the processes and to overcome the potential bias. Triangulation is a standard for data collection in case study research, which consists of the combined use of different methods to carry out study on the same phenomenon in order to substantiate the theory. Triangulation could either be a combination of qualitative and quantitative approaches within a single method, or a method that is neither purely qualitative nor purely quantitative. Multi-methods are useful when developing analysis that results in a richer data. McClure (2002) has identified interviews, observation, and documentation as effective strategies to use in qualitative studies. It is argued that an appropriate application and evaluation of information collected using these methods would result in effective outcomes, within the context of evaluating eGovernment implementation process.

In this research, triangulation had been achieved by using more than one method of data collection. Interview transcripts and documents were combined in order to obtain a broader view. The use of multiple sources of evidence allowed the researcher to address a broader range of issues. Especially for case study research, it is a major strength to use many different sources of evidence (Yin, 1994; Golafshani, 2003).

During the data analysis, the researcher used what was available from the documents within SLA and SLA. However, similar findings were produced from these different methods, which provided corroboration and reassurance for the researcher that the findings and conclusions were convincing and accurate. Some of the departments provided reports of technical issues for the past years as evidence of a lack IT infrastructure. The researcher used these reports and combined them with interview transcripts. Other processes provided documentation such as refusal letters from the top management of SLA indicating that funding was limited, and training courses would not be provided.

All these documents were used as reassurance for the researcher that the findings were accurate. Figure 4.2 illustrates findings from different sources: 
Figure 4. 2 Convergence of Multiple Sources of Evidence

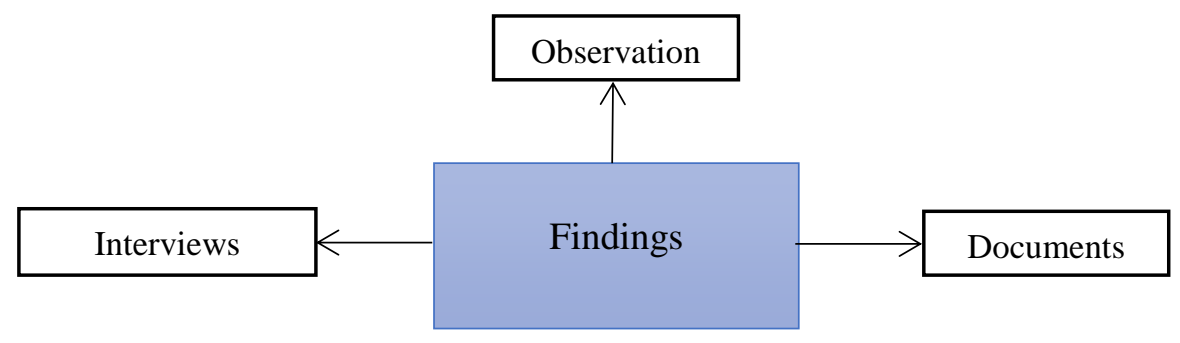

\subsection{Data Analysis}

Data analysis involves examining, categorizing, tabulating or otherwise recombining the collected data with the aim of achieving research objectives (Yin, 2003a). However, before discussing the data analysis that were used in this research, it is important to outline a general technique for the data analysis. The role of the technique was to help the researcher to choose from among different techniques and to complete the analytical phase of the research successfully. The technique of data analysis in this research was based on content analysis, since content analysis uses a set of procedures that ensures valid inferences. It helps to tell the story of the data through analysing its content and identifying main ideas. In this research, dimensions, factors and sub-factors had already been highlighted in the initial model and were coded. The researcher started to read through all the collected data (interviews, official documents and observation notes) with the aim of creating a rich picture of eGovernment including its challenges suggested in the model. Then the data were matched according to the sub-factors that belongs to each factor in each dimension (TOP) identified by the initial model. Any new sub-factor was separated and added to their respective factors and then added to the respective dimension. The analysis allowed the researcher to identify new factors which were used to revise the model.

As discussed above, the researcher used a combination of resources to collect the primary data, including: interviews, documents, and observation. This data was then analyzed following the analytical steps suggested by Creswell (2009) and illustrated in Table 4.9 The data analysis is an iterative process, and by moving backward and forward between the analysis steps a researcher obtains a better understanding and explanation of data (Abdalla and Fan, 2012; Creswell, 2009). Therefore, a number of iterations were made during the analysis process especially between the steps 1,2 and 3 .

Table 4. 9 Data Analysis Steps

\begin{tabular}{|l|l|l|}
\hline & \multicolumn{1}{|c|}{ Coding Steps } & \multicolumn{1}{c|}{ Description } \\
\hline 1. & Preparing data for analysis & Organising the documents and observation notes \\
\hline
\end{tabular}




\begin{tabular}{|c|c|c|}
\hline & & Prepared tables according to the pre-coded set of factors \\
\hline 2. & Reading through all the data & $\begin{array}{l}\text { The researcher went through the interviews for each dimension and } \\
\text { wrote the general idea }\end{array}$ \\
\hline 3. & Decide the level of analysis & $\begin{array}{l}\text { Word, set of words and phrases all accepted to constitute a } \\
\text { concept }\end{array}$ \\
\hline 4. & $\begin{array}{l}\text { Decide how many concepts to } \\
\text { code for }\end{array}$ & $\begin{array}{l}\text { Although there was a pre-defined set of codes, great flexibility was } \\
\text { introduced during analysis and new concepts were accepted for } \\
\text { coding. }\end{array}$ \\
\hline 5. & $\begin{array}{l}\text { Decide whether to code for } \\
\text { existence or frequency of a } \\
\text { concept }\end{array}$ & $\begin{array}{l}\text { The coding is for frequency as it indicates the importance of the } \\
\text { factor, but since most interviewees are decision makers and } \\
\text { expertise, concepts with one existence were not undervalued }\end{array}$ \\
\hline 6. & $\begin{array}{l}\text { Decide on how to distinguish } \\
\text { among } \\
\text { concepts }\end{array}$ & $\begin{array}{l}\text { The scheme of coding had a high level of generalization. Words } \\
\text { around, or with the same meaning, are coded under the same } \\
\text { category }\end{array}$ \\
\hline 7. & $\begin{array}{l}\text { Develop rules for coding your } \\
\text { texts }\end{array}$ & $\begin{array}{l}\text { One rule was created for translation to assure consistency: } \\
\text { - } \quad \text { Revise translation with professionals }\end{array}$ \\
\hline 8. & $\begin{array}{l}\text { Decide what to do with } \\
\text { irrelevant information }\end{array}$ & Irrelevant information is simply ignored in this analysis \\
\hline 9. & Code the texts & $\begin{array}{l}\text { This was done manually by the researcher as neither the number of } \\
\text { concepts nor the number of interviews were too large to manage }\end{array}$ \\
\hline
\end{tabular}

Chapter five report on the background to the case study organisations and the empirical data analysis of these case studies in more details.

\subsection{Ethical Considerations}

An ethical consideration refers to the ethical principles that are used when tackling a particular issue. Ethics are codes or rules which govern those practices of a profession. It dictates how information and client's relationships should be managed. Ethical considerations occur when a researcher is required to use these rules to better serve the respondents. Research ethics is significant as it relates to the behaving in appropriate manner when embarking on research study bearing in mind the rights of those who become the subject of research work or are affected by the work. 
The standards in ethics require that respondents must be respected and given maximum protection, especially where the respondents refuse to answer any part of the questions. The ethical requirements were met by the following procedures:

1. Making respondent aware of the research aim prior to the interview.

2. Assuring their privacy and anonymity.

3. Giving them chance to withdraw from the case study.

4. Giving them another opportunity to back out of the research during the review of the interview notes, by either modifying the interview notes or deleting any unwanted part of the interview notes/questions.

5. The interviews are conducted in their respected offices or at any protected avenue that they consider.

6. The researcher keen to behave in a manner that would not harm the integrity and reputation of the interviewees or the organisation.

In addition to the above points, the researcher clearly explained to the respondents the aim, purpose and objectives of the research study; this would enable them to decide whether or not they were willing to participate, as transparency is often observed as vital part of validating any collection of data from the respondents (Ghauri and Gronhaug, 2002; Saunders et al., 2003; Yin, 2009).

\subsection{Validation Method}

This section discusses the validation procedures adopted to ensure the quality and rigour of the research findings, and the usefulness of the developed model. This is done by discussing one of the well-known strategies that confer rigour on qualitative analysis, and how they were adopted in this research. The strategy was a respondent validation strategy, which was used for validating the model (Barbour, 2001) see Figure 4.3.

Figure 4. 3 Model Method

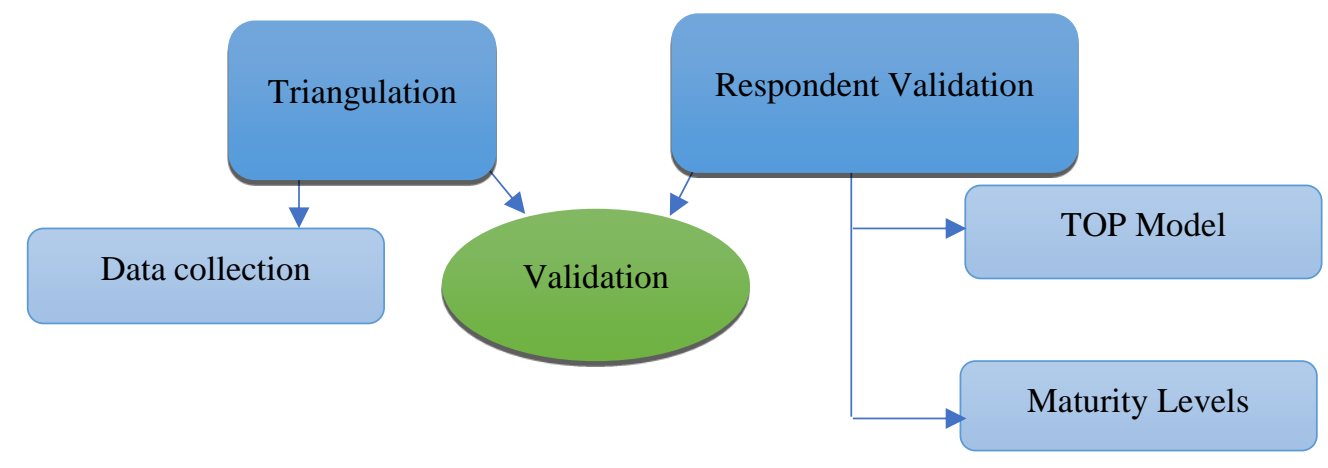




\subsubsection{Respondent Validation}

The use of respondent validation ensured stability. Long and Johnson (2000) stated that checking the results on completion of data collection, or of the whole study with the respondents, would meet the requirements of reliability. The researcher used this technique to cross check the research results with some of the senior officials from three different government organizations (SLA, University of Tripoli and the e-Libyan program) whose reactions to the findings helped taken into consideration. However, the researcher did not disregard his own findings in favors of those respondents, he rather considered their opinions as further interpretations and suggestions for improvements in explanations of the findings. It should be noted that data collection for the validation process was not solely from new interviewees; there was also a return to some of the original interviewees again, but this time to validate the findings of the model. This approach is advocated by Long and Johnson (2000) who recommended respondent validation as a check on the accuracy of the findings with members of the studied group. The respondent validation process was undertaken after the development and application of the model for the case studies. The total number of the discussion sessions for the validation was three (see Table 4.10). The researcher conducted the individual discussion for each participants after he agreed with all the participants on a certain date and time, it was agreed that the discussion will be conducted using Skype as it was hard for the researcher to travel back to Libya due to political conflict.

Table 4. 10 Interviewees for the Validation Process

\begin{tabular}{|l|l|l|}
\hline No & \multicolumn{1}{|c|}{ Job Role } & \multicolumn{1}{|c|}{ Organisation } \\
\hline 1. & Member of e-Libya committee & e-Libya Program \\
\hline 2. & Deputy manager/ Statistics and Information Technology & SLA \\
\hline 3. & Academic staff / Information technology & University of Tripoli \\
\hline
\end{tabular}


Three discussion sessions were conducted over one month, each session lasting for at least two hours. For each discussion session there was a brief presentation about the research background, the subject to be validated, and there was a clarification regarding the session's expectations. The respondent validation was based on the following:

- The validation of the categorization of the dimensions and its elements.

- The validation of the maturity levels and its definitions.

- The application of the maturity level in each process

A document containing the TOP model, and a brief of the case study findings, was sent by email to the respondents two weeks prior the interviews. The document also briefly described the case studies and the overall results for the revised model alongside with maturity levels for each department within SLA but there was no access to RLA due to political conflict at the time of the validation. The reason for sending this document to the respondents was to allow enough time to review all the relevant information and to explore the model and give their feedback and evaluation during the discussion session and discuss their opinions.

\subsection{Chapter Summary}

The aim of this chapter was to set out and describe the research methodology and design, and the analytical techniques used, and to propose a rationale for an appropriate methodology for this research. The research philosophy in this research was based on interpretivism which generally seek to describe, understand and translate phenomena through meanings that people assign to them in order to comprehend the context of information system and enables understanding of deeper structure of phenomenon within cultural and contextual situation.

As the research does not include statistical or empirical calculations and rather requires an exploration and explanation of detailed in-depth data, the research approach was based on a qualitative method which supports fieldwork where the researchers can observe behavior in its natural setting. The chapter also included a discussion of research strategy and selected the case study protocol which is usually used as a tool for an action plan with more than the survey instrument, thereby setting procedural rules and regulations for gathering of data. In justifying how multiple case study research is the most suitable approach, the researcher selected two LAs with different size as case representative. This chapter also included a justification that interviews, documentation analysis and observation is the best data collection strategy for this 
research as well as content analysis to explore these data. Finally, the validation method of the model was discussed and the selection of respondent validation as a method of validation justified. The next chapter presents research findings from the case studies. 


\section{Chapter Five - Case Study Findings}

\subsection{Introduction}

This chapter presents the case study background and the findings of the studies conducted in SLA and RLA to establish the implementation of e-Government. Case study interviews were undertaken, which covered all the three dimensions (Technology Deployment, Organisational Capability and Process Efficiency). The chapter is divided into five sections. Section 5.1 presents an introduction to the state of Libya. Section $\mathbf{5 . 2}$ provides information about Libyan local authorities and its managerial structure. Section 5.3 investigates the TOP model factors (discussed in Chapter three) that are influencing eGovernment in LAs. Section $\mathbf{5 . 4}$ presents a summary of the chapter.

\subsection{The State of Libya}

Libya is located in North Africa on the coast of the Mediterranean Sea. It is bordered on the east by Egypt; on the south by Sudan, Chad, and Niger; and on the west by Algeria and Tunisia. Libya's total area is $1,759,540$ square kilometres of landmass, which is approximately three times the size of France (See Figure 5.1). The current population of Libya is 6,526,626 based on the latest World Bank estimates (World Bank, 2017). 
Figure 5. 1 Map of Libya

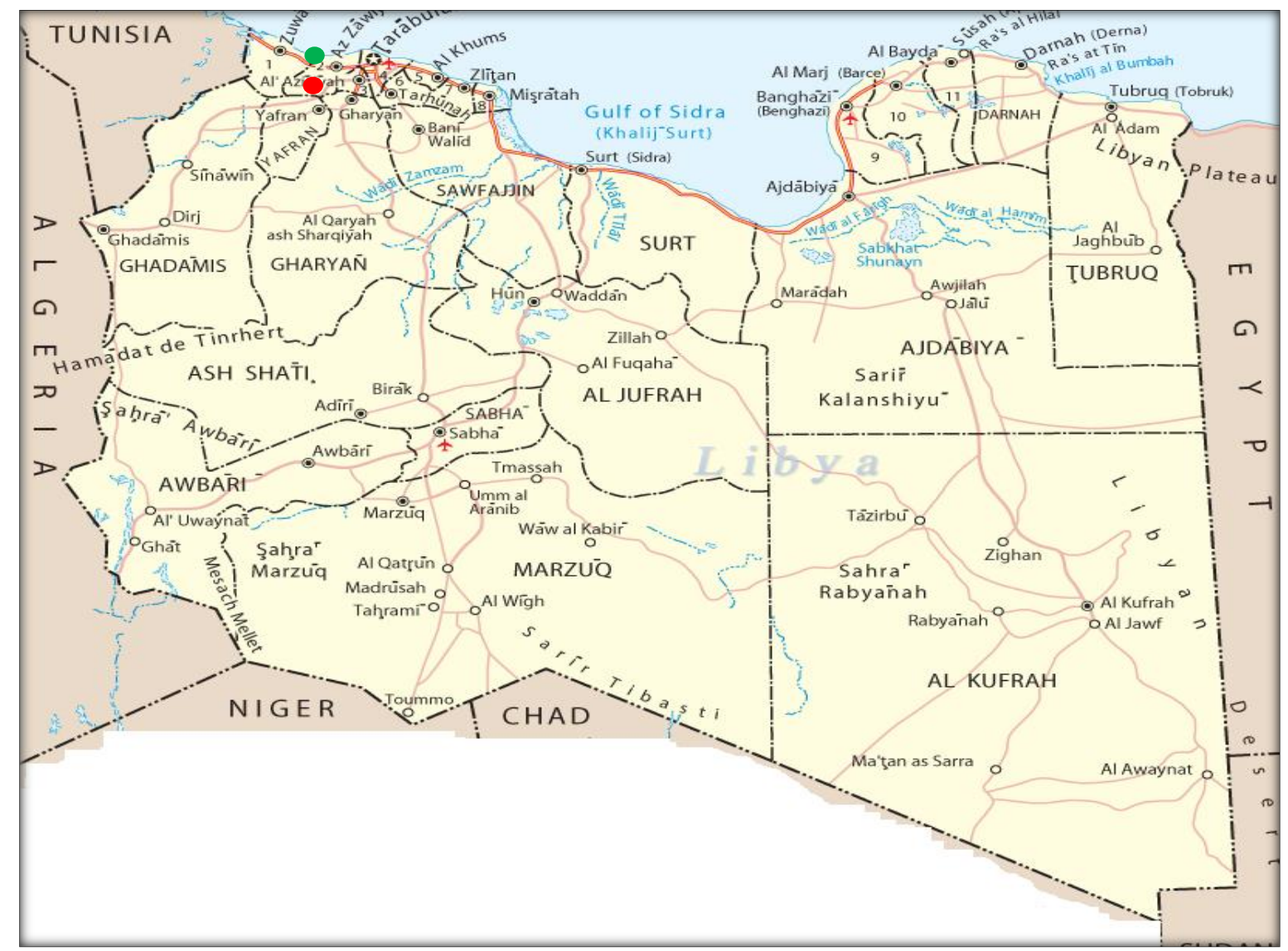

- Sabratha Local Authority

- Rujban Local Authority

\subsubsection{The Economic Context in Libya}

The Libyan economy depends mainly upon revenues from the petroleum sector, which account for over half of GDP and $97 \%$ of exports. Libya is considered to have the largest proven oil reserves in Africa and is an important contributor to the global supply of light crude. Apart from petroleum, the other natural resources are natural gas and gypsum. The International Monetary Fund estimated that Libya is expected to expand 55 percent in 2019 from the previous year due to the recovery in oil production. GDP annual growth rate in Libya averaged 4.95 percent from 2000 until 2018, reaching an all-time high of 104.37 percent in 2012 and a record low of -62.10 percent in 2011 (Trading Economics, 2019). The World Bank (2018) defines Libya as an upper middle-income economy, along with only seven other African countries giving Libya one of the highest per capita GDPs in Africa. 


\subsection{Libyan Local Authorities}

The important role of local authorities is not a new phenomenon in Libya. Local governance, exercised through popular committees, was present during the rule of Muammar Gaddafi from 1977 to 2011. In 2012 the Interim National Transitional Council adopted Law No. 59 of 2012 which affected the local authority system. Law 59 helped define the role and duties of local authorities, determined the powers given to governors and mayors, and decided the amount of financial resources to be allocated to provinces and municipalities (Ayan Libya, 2012).

Local authorities have been set up in Libya and their members are directly elected for the first time in 42 years. Local authorities fall under the purview of the Ministry of Local Governance. However, the duties and activities of local authorities should be reinforced. As of January 2017, more than $20 \%$ of Libya's forty local authorities suffered from political instability and the consequence was in some local authorities elected local officials have been replaced by military figures to reinforce the stability (Ayan Libya, 2018).

Local government is an important level of government; its policies and programs impact citizens, businesses, and other stakeholders on a daily basis. Therefore, local governments should be seen as the cornerstones that render services in defined geographical areas, primarily because of the inability of central government to attend in detail to all the requirements of society that have to be satisfied by a government institution.

\subsubsection{Structure of Local Authorities}

Process mapping suggests that there are five main processes (departments) operating at every LA and responsible for delivering the services to their stakeholders (see Figure 5.2). These main processes are as follow:

\section{- Procurement management}

The procurement management process is responsible for the purchase of supplies, services and constructions in support of the LA's business. Many activities are undertaken in this process including invitation to bid, requests for proposal, requests for quotations and the issue of contracts, as well as information about inventory and stock. The process is of significance because of the responsibilities and accountabilities in the expenditure of public funds. The process runs competitive bidding procedures by the MLA, regulations and laws. Projects and requirements for an LA vary widely and thus rely heavily upon businesses and, in some cases, 
citizens or other governments to meet its needs. The authorities encourage businesses to participate in the various bidding processes offered. The process is required to lead, manage and develop its sub-processes to ensure it achieves the highest possible standards of excellence in all its activities. Therefore, staff are employed in the process who monitor the work. The structure of the process follows a traditional hierarchical and rule-based management, which no longer produces efficiency in the new information era.

\section{- Legal Affairs management}

The legal affairs management process runs many activities including the supervision of all legal matters involving LA and its entities, to keep pace with the progress achieved by the LA in economic, social and developmental fields. The inspiring vision of the legal affairs management is excellence in government legal work and its mission was to enhance the level of legal services provided to those dealing with the process, in line with Libyan laws and practice. The process receives and considers all complaints and claims lodged against government entities and aims to seek amicable settlement of these. It also represents the government and government entities in claims and disputes before competent judicial entities and tribunals. The process has the authority to regulate the advocacy and legal consultancy professions. This includes licensing of advocacy and legal consultancy firms to operate in the LA, registration of advocates and legal consultants on the roll, qualifying and training advocates and legal consultants in all legal disciplines through training courses, programmes and workshops.

\section{- Human Resource management}

The human resource management process role is to plan, develop, and administer policies and programmes designed to make expeditious use of the LA's human resources, and concerns itself with hiring, motivating and maintaining people for the duration of all other processes, to ensure that human talent is used effectively and efficiently to accomplish the LA's goals.

\section{- Community and Services management}

The community and service management process is the largest process and provides services including, but not limited to: water services, taxation, billing, waste, housing, civil status, electric, etc.

\section{- Financial management}

The financial management process controls all financial functions of LA processes. The process is responsible for the management of the LA's cashflow and ensuring there are enough 
funds available to meet the day-to-day payments, as well as the day-to-day transactional accounting for the business. This includes the tracking of all transactions and the management of LA reporting.

\section{Sabratha Local Authority}
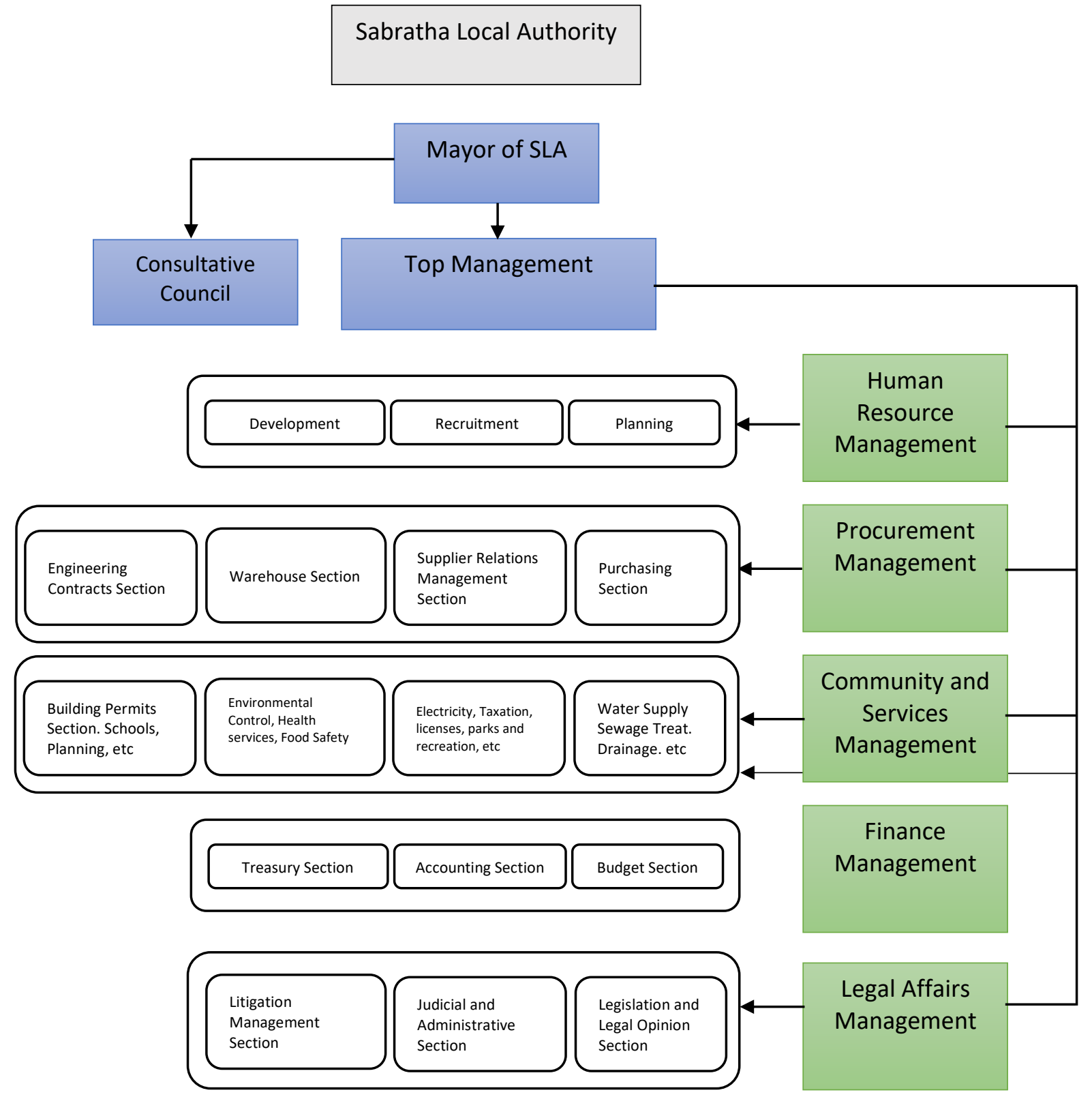

Figure 5. 2 Libyan LAs Functional Structure (left) and Main Processes (right)

Source: Ayan Libya (2018)

\subsubsection{Case Study 1: Sabratha Local Authority}

The first organisation selected was SLA. The city is located in the north western part of Libya 70 kilometres east of Tripoli, on a point of rocky land projecting into the Mediterranean Sea. The city was the westernmost of the ancient "three cities" of Roman Tripolis, and the population numbers 152,521 people (Ayan Libya, 2018). SLA provides a large number of 
different services to its stakeholders (citizens, businesses, governments). The most important services are water supply, sewage collection and disposal, refuse removal, electricity and gas supply, health services, roads and storm water drainage, street lighting, parks and recreation, taxation, licenses, schools etc. SLA is keen to provide affordable services in a sustainable way to all citizens, businesses and governments

\subsubsection{Case Study 2: Rujban Local Authority}

The second organisation studied is Rujban Local Authority. Rujban is a small city which lies on the chain of Nafusa mountain more than $150 \mathrm{~km}$ south-west of Tripoli and it is inhabited by 18,000 people (Ayan Libya, 2018). The LA have less financial and administrative powers compared with bigger local authorities such as SLA, but they have responsibilities also in planning and administering a number of core services for its stakeholders. There are four processes which have been investigated in this case study which are: the procurement management process, finance management process, human resource management process, and community and services management process. As in SLA, these management processes are located in different buildings across the city.

\subsection{Factors Influencing eGovernment in LAs}

\subsubsection{Case Studies: Technology Deployment Dimension}

This section aims to discuss and analysis the case study findings regarding the technology deployment dimension. This encompasses those key technological issues that affect the implementation of eGovernment from a broader perspective. This section includes the factors which have been defined in the conceptual model in chapter three: Software and Hardware, Communication, Security and Privacy, System Compatibility. As previously mentioned, these factors are deemed essential for eGovernment adoption in the context of a developing country. The analysis of the interviews revealed that all 9 respondents believe the technology deployment dimension is very important and considered as the backbone of e-Government.

\section{- Software and Hardware}

The study findings emphasise the importance of upgrading software and hardware within LAs to enable LA processes to participate in the eGovernment project. According to the MLA IT plan: 
"the importance of software and hardware tools is highly prioritized, and the MLA is planning to replace and upgrade the old gadgets and install new ones"

The plan's objectives seek to address the lack of modern technology within LAs by modernizing and automating the services and tasks in LAs in Libya. The scope of the plan is five years and the MLA strives to build automated services in each LA and enable them to reach and access ICT services easily and utilize them effectively.

The plan was criticized by many interviewees from both SLA and RLA; for example, S2 said:

"We really face big challenges with regard to the plan, because it was introduced in 2008 and until now we have not had any upgrades of the software and hardware in our processes, it seems to be unable to implement such a plan in such a situation”

In both LAs, software technology deployment can be seen in the processes as illustrated in Table 5.1. However, these technologies were implemented more than a decade ago, as S6 stated that:

“MLA provided LA's hardware and software tools in 2007; it hasn't provided us with new tools since then or support to overcome these issues"

He also stated:

" we always have issues of fund with both software and hardware to upgrade them"

In addition, some interviewees mentioned that one of the challenges facing eGovernment adoption is that the software are inadequate to work on a network, and the operating systems installed on the computers were also inadequate for which Microsoft has already stopped support. It is also noted that hardware tools cannot host new software. For example, S4 said:

"Although there were enough hardware and software tools, they were inadequate to host new software and failed to deliver on process requirements"

In regard to software packages, they are preferred by many organisations because there are easily adapted to their needs with little set-up time. Both LAs have purchased off-the-shelf software packages in order to facilitate the work within their processes. However, these software packages have never been used by the staff as a senior R8 explained: 
"We had purchased off-the-shelf software packages, such as Accounting software application (Sage) but unfortunately no training was given to the staff to use it, therefore it was abandoned and never been used, and this is the case also with Microsoft Outlook"

Table 5. 1 Technology Deployment in LAs

\begin{tabular}{|c|c|c|c|}
\hline Software & $\begin{array}{l}\text { Description and } \\
\text { Characteristics }\end{array}$ & Weaknesses & Local Authority \\
\hline $\begin{array}{c}\text { Purchasing } \\
\text { System } \\
\text { (In house) }\end{array}$ & $\begin{array}{l}\text { The purchasing system } \\
\text { managed the entire acquisition } \\
\text { process, from requisition, to } \\
\text { purchase order, to product } \\
\text { receipt, to payment. It used an } \\
\text { Access Database and Visual } \\
\text { Basic Platform }\end{array}$ & \multirow{2}{*}{$\begin{array}{l}\text { Isolated systems } \\
\text { Manual work was required } \\
\text { before data entry into the } \\
\text { systems. } \\
\text { The systems ran under the } \\
\text { Windows application platform } \\
\text { and didn't support .Net } \\
\text { Framework. }\end{array}$} & \multirow{3}{*}{ SLA } \\
\hline $\begin{array}{c}\text { Warehouse } \\
\text { Management } \\
\text { System } \\
\text { (WMS) } \\
\text { (In house) }\end{array}$ & $\begin{array}{l}\text { The system was used to avoid } \\
\text { product overstocking and } \\
\text { outages, and for organizing } \\
\text { inventory data which was } \\
\text { hitherto generally stored in } \\
\text { hard-copy form or in } \\
\text { spreadsheets. It uses an Access } \\
\text { database and Visual Basic } \\
\text { Platform }\end{array}$ & & \\
\hline Website & $\begin{array}{l}\text { Simple } \\
\text { dissemination }\end{array}$ & $\begin{array}{l}\text { One-way communication. The } \\
\text { website makes information } \\
\text { available, but there was no } \\
\text { capability for the user to } \\
\text { search, enter data or access } \\
\text { authority systems or databases. }\end{array}$ & \\
\hline Payroll & $\begin{array}{l}\text { The Payroll software is dealing } \\
\text { with payments, paying wages } \\
\text { and printing statements. The } \\
\text { system is located on isolated } \\
\text { computer }\end{array}$ & $\begin{array}{l}\text { Manual work is required } \\
\text { before data entry into the } \\
\text { system. does not support .Net } \\
\text { Framework }\end{array}$ & RLA \\
\hline
\end{tabular}




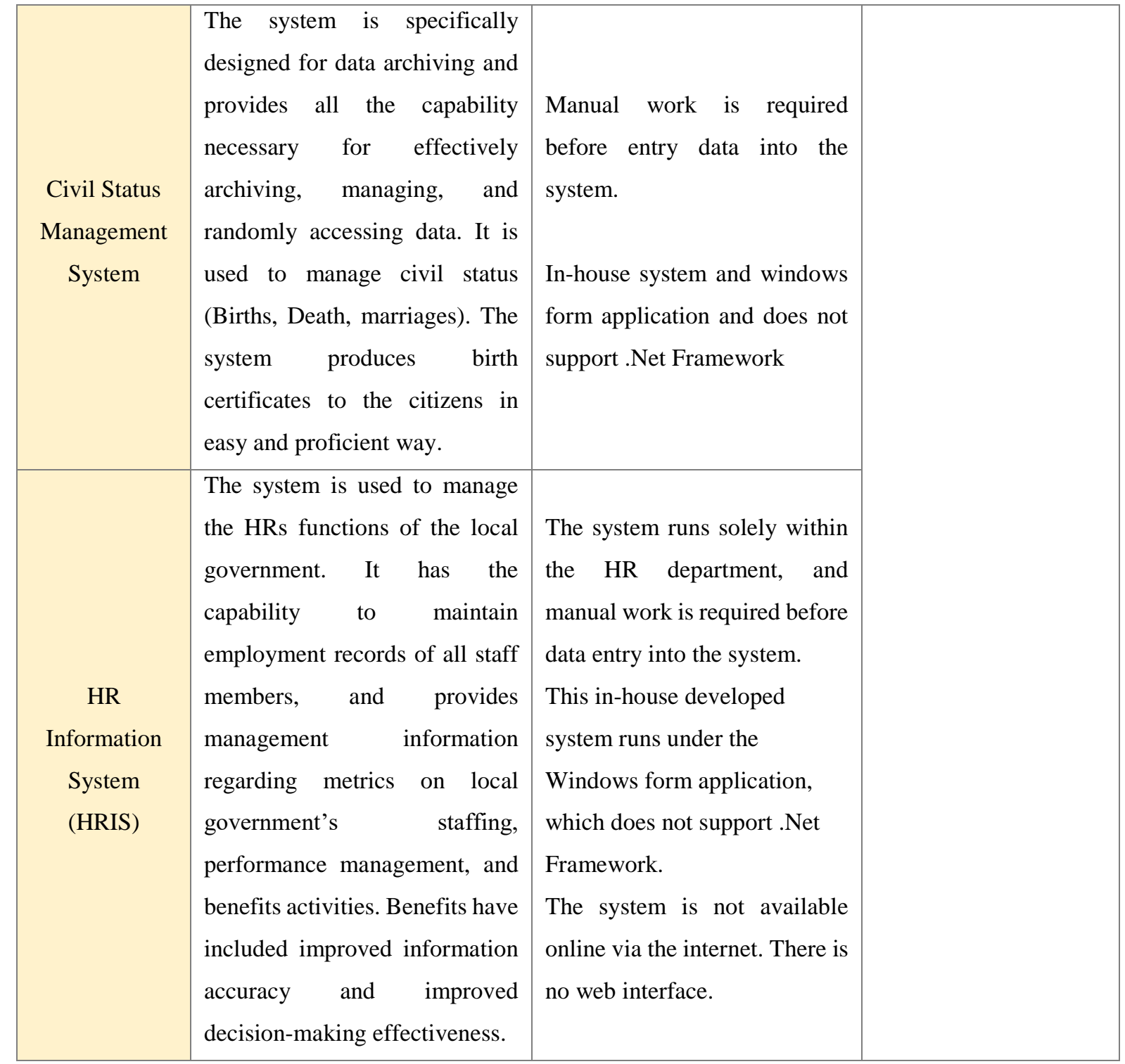

The above discussion confirmed that software and hardware tools within LAs are a significant challenge which is consistent with what has been illustrated in the conceptual model. participants also mentioned that an information and data is important challenge in eGovernment project. In a large government organisation such as an LA, it is easy to observe that there is a problem in capturing, storing, archiving, sharing and managing data. IT professionals who understand that eGovernment is about handling information believe that without standard classification of information and documentation, it is very hard to realise the benefits of e-Government. For example, S9 said:

"it is important to build strong and powerful database systems, refine public data and carefully manage information that distinguish between shared data or confidential data 
otherwise eGovernment will be meaningless, and the public sector will have poor levels of effectiveness"

He also said "there is always issue is data mismatch"

According to the comments of a number of IT professionals, the quality of data in the LAs sector suffers from a variety of problems. The accuracy of data can be very low, or old and not regularly updated.

This was also highlighted by the S4:

"Data was formerly frequently kept in and often not shared among other processes due to its proprietary, non-portable format or the inability to import/export data, He continued it also important to distinguish between information that can be revealed to the public and information that meant to be sensitive"

Participants also indicated that eGovernment requires cooperative effort to share data and knowledge. They assert that collaboration between processes and among other LAs is a significant factor in the adoption of e-Government. The findings showed that the lack of collaboration among LAs in terms of shared data and knowledge means that each process relies heavily on its own endeavours to conduct and accomplish day-to-day tasks. Participants explained that information and knowledge reside in the database, and in employees' minds. R8 said:

"The culture of sharing knowledge and information does not exist in the public sector and this will work as a barrier to an eGovernment project"

Participants from the case study LAs were however able to identify that sharing knowledge and information is additional challenge, which was not included in the conceptual model. This challenge is considered to be new challenge that can affect eGovernment adoption.

\section{- Communication}

Researchers such as Helbig et al. (2009) and Janssen et al. (2009) indicate that the implementation of client server networks makes a strong foundation to build a single eGovernment portal and provide a seamless, automatic and real-time communication between systems at back office and between process levels, which enhances the workflow across departments. 
In this regard, the IT experts from both LAs claim that communication is the most important and challenging component for implementing e-Government. Further, they argue it is the first step in bridging and narrowing the gap between citizens and LAs particularly within rural areas.

The empirical data found that, within most of the processes, in both cases a client/server network was available, and employees can share software, information and data located on the server, as well as the ability to share hardware (two printers). However, these networks work solely within specific process areas and there was no access to other processes. Further, there are also many issues that make the network down most of the time. As Expert staff/ IT Support said:

"One major disadvantage of networking was the breakdown of the whole network due to an issue of the server; this was always happening due to lack of trained staff, the issues also caused by misuse of the Windows server active directory by staff".

Another issue mentioned was that the cost of purchasing and upgrading the Windows server, which required more resources for the machine to operate properly

"Usually purchasing software will also involve upgrading the hardware. For instance, many software products require more internal memory and a faster powerful processor, and these needed budgets. It also requires several updates and security patches, usually referred to as service packs".

The LAs across Libya need a reliable, fast internet connection. Slow internet speeds cannot only impact employee productivity but the quality of customer service you offer can be impacted. R2 said:

"The internet is vital for day to day operations such as accessing emails and file transfers. With a dependable fast connection, eGovernment can provide e-services and boost productivity"

However, S2 IT consultant stated that a poor or slow internet service, including a slowly loading website, will turn customers off. He said: 
"nowadays most businesses rely on internet-based applications, but in our LA the internet connectivity was unreliable and at low speed; the issue with the internet was also caused by the power cuts that have happened all the time since 2011 ".

\section{- Security and Privacy}

eGovernment deals with highly sensitive information, which must be protected from hackers and internet criminals. Having a secure eGovernment system was given great attention by the participants as security issues are one of main obstacles facing the LAs' information and database. The MLA made a step forward and established a plan for information security. The plan is always to keep information safe and secure, as well as developing and determining security standards and measurements. However, this plan was neglected as a member of Technical committee stated:

"I was a member of MLA technical committee to introduce a security plan to keep information and data safe at all times in LAs across Libya. The problem is that, after we introduced the plan, it was neglected due to the country situation that affects the financial support"

The study findings of this research indicated that security and privacy in LA processes are still far behind what is necessary to host the eGovernment project. R6 said:

"The necessary background to deal with security problems threatening our computer networks, application systems and public information is still low among employees in $L A s ”$

Another IT expert S10 also said:

"employees lack the required knowledge and awareness of information privacy and security, this can cause a lot of harm, therefore LAs and other public organisations should work together to tackle the problem". He also added "As yet no major security incidents have been reported. This is mainly because employees have limited online access"

According to the interview, there was outdated security software installed on the machines; this was a possible danger that might exploit a vulnerability to breach security and cause potential harm. This was highlighted by $\mathrm{S} 9$ who said: 
"the security software installed on our machines is outdated, and there is not a disaster recovery plan to protect the process data"

The participants also mentioned that the importance of having security infrastructure such as Public Key Infrastructure (PKI) which is a framework of encryption and cybersecurity that protects communications between the server (website) and the client (the users). R6 who is a member of the technical committee said:

"this is very important because there is a deeply held belief that all government information is vulnerable and exposed"

The MLA IT plan, which was produced by the technical committee, emphasised the need to establish long term security infrastructure, to achieve this; the technical committee has planned two main milestones: a secure authentication system and a secure payment gateway. S2 who is a member of the technical committee emphasised the need for PKI and said:

"PKI will offer encourage both government and citizens to use eGovernment because it will provide security, privacy and information authenticity"

There are many important applications that must use PKI in terms of eGovernment services, as many participants mentioned. For instance, secure emails messages, protect websites where PKI can be used to authenticate users and perform security transactions. In addition, it can be used for electronic signatures which can be added to documents and forms; and more importantly, to secure and safeguard interaction between computers. There is no doubt that having such a security infrastructure will help the eGovernment developer develop more transaction services; this will also increase the trust of citizens when using e-services.

The study findings indicated that participants from the case study LAs were however able to identify that PKI is an additional challenge, which was not included in the conceptual model. Therefore, this challenge is considered to be a new sub-factor relating to security and privacy that can affect eGovernment adoption.

\section{- System Compatibility}

The development of system compatibility (interoperability) at LAs level is a milestone to enable interoperability across different processes or different LAs. System compatibility is defined as the ability of two or more systems or components to exchange information and to 
use the information that has been exchanged. Participants in this study emphasised the importance of building system compatibility that can be used in the whole public sector. In addition, the study indicated that IT infrastructure built within LAs do not adhere to specific standards and therefore lack system compatibility.

It should come as no surprise that government organizations usually have mixed views or what was sometimes referred to as heterogeneous computing environments. But with so many disparate systems, the issue of compatibility has become increasingly important. Many of these issues required access to data or transactions on existing systems. For example, S10 said:

“Each LA's process selects technology in accordance with its requirements and needs, ... For example, we have different database types across SLA processes; for example, staff working in other process areas send their data to us on USBs because some of them use Access database in their systems and others use Paradox database, but we use SQL database, this makes us work so hard to match their data to ours"

R2 also indicated that:

"We understand that without uniform standards overall eGovernment effectiveness cannot be achieved."

He further explained that the technical committee, in collaboration with the MCI, formulated many committees for setting hardware, software, training and information security standards. However, these committees have not issued any IT standards that unite systems between processes and across LAs.

R8 Software developer indicated that the development of system compatibility at process level was a milestone to enable compatibility across different processes. He underlined the importance of building system compatibility that can be used across the LA.

The research findings suppose that most of the factors and characteristics identified as influencing eGovernment implementation are similar to those discussed in the conceptual model and there were not any additional sub-factors identified in regard to system compatibility.

\section{Findings}


From the technological perspective, the initial factors that were proposed in the initial conceptual model were found to be relevant and important for eGovernment adoption and participants asserted that would affect the development of eGovernment projects in both LAs. For example, in terms of hardware and software factor, in both LAs the technologies were available within the processes; however, they were old and outdated technologies, the bespoke systems were isolated and works only on one or two computers. Manual work was required before data entry into the system. The system ran under the Windows application platform and didn't support .Net Framework.

The analysis also revealed why these IT systems fail to deliver a good service within LAs. The IT staff who developed these systems carried out automation before process redesign which is a common problem with IT projects that the system is designed around processes as they are, rather than around processes as they should be. Developers are unwilling to put the serious design effort in up front and want to get right to the programming phase as R2 mentioned:

"the systems were developed without understanding the whole problem which means the developers go straight for coding rather than investigating the whole issue"

Other reason which is also related to automating before redesigning is that developers suddenly realize that the data they are working with has to be moved from the old system to the new system and that it cannot be done easily as S4 stated:

"We realized that we have old data from the old system that does not much the new system which made us work hard and spend more money to convert it to become accessible”

In terms of communication, although most of the processes use a client/server network, it was not facilitated to share data and information between computers. In addition, there was no access to other processes via the network and the internet was unreliable. Security and privacy remained an issue as basic security software was installed on the server, and security policies were not implemented, nor disaster recovery was in place, and data back-up was not scheduled on a regular basis. The compatible operating system was installed; however, these operating systems were outdated (Windows 2000 and Windows XP); there were also incompatible databases between the processes, which remained an issue in data exchange. 
The system compatibility issues have hindered the exchange of information and compatibility between systems across the LAs. It is confirmed in the literature that system compatibility is a major issue to be addressed by every eGovernment agency. The participants also highlighted that system compatibility for future projects are also challenges from a technical perspective, as the information systems have to be integrated with numerous other organisations. The findings revealed that attaining system compatibility is a big challenge, especially as decentralisation in MLA has led each LA to create its own policies and regulations that are incompatible with one another and that in turn inhibits the interoperation of the entities.

Many participants emphasised the existence of these barriers on many occasions. S2 confirmed:

"Problems related to infrastructure limitations are always hindering the automation of the process, the technologies that you mentioned in your study are the core of any IT project and we faced many issues when the bespoke systems were introduced to the process as there were always network issues, hardware issues and software issues"

The findings revealed that the technological barriers within the LAs would remain as a future challenge too. These challenges prevent the LAs from fully benefiting from the eGovernment projects as well as limiting the stakeholders from benefiting from e-Services. Additionally, the challenge lies in the constant need to upgrade hardware, the security settings, the encryption keys and algorithms. System compatibility or interoperability and multiple service delivery channels for future projects is also a challenge from a technical perspective, as the information systems have to be integrated with numerous other organisations.

The participants were also able to identify three important challenges in technology deployment as illustrated in Table 5.2 that were not included in the conceptual model in chapter three.

Table 5. 2 New and proposed Factors

\begin{tabular}{|l|c|l|}
\hline \multicolumn{1}{|c|}{ Factor } & New/Predefined & \multicolumn{1}{c|}{ Source } \\
\hline Information Sharing & New & Interviews \\
\hline Public Key Infrastructure & New & Interviews \\
\hline Local Industry Partners & New & Interviews \\
\hline
\end{tabular}

\subsubsection{Case Studies: Organisational Capability Dimension}


This section aims to discuss and analyse the study findings regarding the organisational capability dimension. The study deals with those key organisational issues that affect the implementation of eGovernment from a broader perspective. Therefore, this section includes the factors which have been defined in the conceptual model in chapter three: Skills and Capabilities, Organisational Culture, Top Management. As previously mentioned, these factors are deemed essential for eGovernment adoption in the context of a developing country. The analysis of the interviews revealed that all 9 respondents from both LAs believed organisational capability dimension was very important and considered as the backbone of e-Government, and the adoption of eGovernment requires LAs to have the basic organisational capability to move towards a new eGovernment system.

\section{- Skills and Capability}

Many skills are required to run e-Government, including technical and managerial. All participants agreed that one of the major areas of concern in public organisations is skills and human capability development and they emphasise that this will require a sizeable training programme, not only for LAs but for most of the country's public sector.

S3, a Member of the Recruiting Committee said:

"Functional skills are necessary to make the employees comfortable with the new automated systems"

and he continued:

"there was a lack of functional skills among employees to use computers at a basic level; we only have a few employees who could use the in-house system, despite the fact that some of our employees hold university degrees they revealed the weakness of functional skills".

S7, an expert staff/Consultant and Adviser, also mentioned:

"despite the fact some employees hold university degrees and possess good employability skills, however, the majority holds inadequate qualifications and experiences and revealed a lack of employability skills such as communication, team work and others interpersonal skills". 
Regarding staff training, a member of the recruiting committee emphasized the importance of staff training to enhance the productivity of the process. However, training programmes have been affected by the financial crises that hit all public sectors due to the political situation. He said:

"we had in the past a few courses, such as IT courses, performance management, interpersonal and communication skills; these courses improved some employees' skills, but the majority still need more courses. Unfortunately, the courses were stopped due to financial crises caused by political situation of the country”.

The case study findings confirmed the importance of the employees' training issues and this has to be treated well and considered an important issue, mainly in relation to technical employees that are involved in the development of the eGovernment project.

The case study findings identified new challenges to eGovernment adoption which were not included in the conceptual model proposed in chapter three. The participants show that that there is a limitation of capabilities in LAs and the top management at RLA have realised the reason for this limitation, which is the LAs' size, population and capabilities. For instance, small size LAs always have a shortage of expertise in all sectors. R7, deputy manager of community and services, highlights that:

"the challenge is that, we don't have a forum where we get in collaborations and discussions with a wide range of IT expertise and to share ideas, knowledge and concepts because IT projects need collaborations from different expertise"

This was also highlighted by S1, a management and leadership specialist, who said:

"we don't have a workshop or a forum that gathers employees and experts from the private sector, mainly IT managers to come and discuss the efforts, and to feel that they are part of these transformation efforts"

The findings also showed that participants from both LAs claim that consulting companies such as IT, finance or business partners and other alliances are not sufficiently strong between LAs and the private sector. A Member of Law Consultancy Team highlighted that to implement projects such as e-Government, private companies should be encouraged towards taking part so that eGovernment can benefit from their experiences. 


\section{- Organisational Culture}

The organisational culture is a complex issue within the public sector. The findings from the interview revealed participants agreed that the impact and consequences of a culture characterized by negative attitudes reduces the commitment of employees. S3 said:

"The value of time does not exist within the mentality of the employees in LA, a term of 'Come tomorrow' is a normal saying that a citizen can hear from employees"'

S5 emphasised this by giving another example, he said:

"each employee was assigned to tasks but their commitment to finish their tasks by the time scale has never been met and is still a big issue".

Another issue related to staff commitment was absenteeism. For example, R1 an expert staff / consultant and adviser mentioned that, after the revolution in 2011, RLA suffered from absenteeism, which had negative consequences for productivity.

With respect to resistance to change, the research findings showed that there was fear and resistance when new technologies were introduced due to mistrust or fear of weaknesses in computer skills. This can negatively affect eGovernment projects, as R5 said:

"There was resistance to change among the staff to use technology, many of them feared to use technology, the issue is related to their weaknesses in computer skills; for example, the in-house systems were abandoned until we trained some staff to use them".

$\mathrm{R} 3$, a member of the recruiting committee, emphasised that the attitude of the employees towards technology was still an issue and fear of using technology within the process could be noted. He said:

"due to limited training courses, our staff have always refused to use new procedures and preferred to do their work manually, for example: when the in-house system was introduced the first time, employees refused to use it".

S7 explained that the resistance took many shapes, such as prejudice by employees with traditional views against new technology. He believes that introduction of modern technology would lead to streamlining their services and eventually take away their jobs. He said: 
"Employees in our process resisted to accept technology and preferred to use traditional way, He further explained when the new in-house system was introduced, employees resisted its use, and they preferred to use traditional ways"

The findings from the interview also revealed certain important factors that were not included in the conceptual model, and that may influence the adoption of eGovernment and need to be considered and treated carefully. For example, issues such as power distribution, corruption, reward systems. These challenges were mentioned by most of the participants and assert that they could impede the implementation process of eGovernment or any other projects.

With respect to power distribution challenges, the participants indicated that eGovernment implementation is influenced by power distribution as a result of organisational change and shifts within the organisation. S1 said that:

"quick developments and changes that are happening within the government will cause power distribution, and this is found to be a major challenge to the eGovernment plan, we had this experiences in the past when we introduced in-house system and rescheduled priories in the work"

S7, a member of law consultancy team, also claimed that eGovernment projects need restructuring at a very high level of governance. Such a shift and change will result in redistributing the power within LAs and redesigning jobs. Those consequences would lead to changes of priorities and resistance to these changes. Therefore, eGovernment implementers should plan this change and treat the changes as resistance to the eGovernment plan, or otherwise it may lead to a project failure.

With respect to the corruption challenge, the participants mentioned that the move to new forms of eGovernment system was a hard task, particularly in an environment characterised with corruption, such as public sectors. They also mentioned that administrative corruption is one of the fundamental issues in Libya. Corruption in Libya is a result of failed legislation and administrative complications and it manifests itself in Wasta, flouting regulation and laws, negligence and unequal provision of services (Libyan Audit Bureau, 2018).

Participants stated that for e-Government, corruption will be a major challenge to implementation, especially in the field of tenders, some of which are granted on the basis of 
who has the greatest power and influence in the government. For example, hardware and software bought in the past for the processes within LAs have frequently been below acceptable standards because of corruption during the tender process. R5 said:

"decisions on tenders are often made before the competition or even before the publication of the tender in the newspaper or media, this is happening because some employees who are in charge taking bribes and pass the tender to the bribers"

As mentioned, corruption comes in different forms, such as favouritism ("Wasta"). The Libyan Audit bureau report (2018) reported that favouritism eases the way to jobs, promotions and much else in business and government which negatively impact on the organisations. It is also stated that favouritism plays an important role since Libya is a tribal country and those who have favouritism can jump the queue and acquire permits and obtain favourable rulings from agencies, get government contracts and benefit from government rules that limit competition.

In this regard, participants mentioned that favouritism is a fundamental factor in corruption in the public sector and that it is a hindrance to the development process in Libya. They also highlighted that in e-Government, favouritism may play a role in hindering the implementation process and cause project failure. S5 said:

"Wasta leads to the appointment of unqualified people at the expense of qualified ones," he continued, "I have been working here for more than ten years, I have witnessed many cases that unqualified people who are relatives to big managers in the ministry been appointed who later became head of departments and projects”

R3, a member of the recruiting committee, further explained that favouritism affects not only recruitment in the public sector, but also the employee's promotions:

"the problem is that, the promotion system, because promotion is based on Wasta, they consider who has the Wasta but not who is qualified, therefore, you find employees are very disappointed and lazy to do the jobs"

In addition, participants mentioned that government contracts always signed with those who have favouritism in the LAs, for instance, contracts related to training courses to train SLA staff. S7 said: 
"Most of the training contracts go to one company because the company has good relationship with the top management in MLA, despite the fact that the employees always complain against the quality level of training but still the same company wins the tender".

Participants also asserted that the Libyan government, particularly Libyan Audit bureau, should aim to minimise favouritism in the government organisations by issuing legislation to deal with favouritism just as any other illegal activities. Otherwise favouritism will continue to inhibit any initiative that seeks to improve people's lives.

Regarding reward system, the participants emphasised that reward system must be associated with any changes within LAs, including the adoption of e-Government. They highlighted that reward system will overcome resistance to change and increase employees' commitment towards e-Government, or any other project activities. However, a structured reward system within LAs does not presently exist. Therefore, participants emphasised the introducing a reward system prior to the adoption of eGovernment that offers benefits and rewards beyond the salaries and other monetary compensation to satisfy and encourage employees. R3 said:

" a structured reward system doers not exist in our LA and therefore, the employees in return do not work hard to meet their goals, but if the top management formulate a reward system then things will change, and employees will work harder"

The findings showed that, where there is a lack of reward system, the employees were reluctant and unwilling to contribute in new projects and would not accept responsibilities. R7 stated that top management can encourage employees to be involved in eGovernment projects by appreciating their contributions. He also mentioned that employees could express their willingness to adopt eGovernment initiative if the LAs would address their needs in terms of monetary benefits, careers progression and job retention.

"employees in LAs will contribute and dedicate their time and effort to eGovernment if their top management can acknowledge and appreciate their contribution"

\section{- Top Management}

Top management is one of the organisational capability factors identified by participants as essential to the implementation of e-Government. The Libyan government organisations are 
highly hierarchic in their structure and MLA is not exceptional. Most of the decision-making processes are transmitted from top management to the middle management until reaching the base.

In MLA the reform of the work processes is usually initiated as a result of decisions by top management to the demands and needs of the work environment that affect the LAs' performance. Therefore, the top management is considered one of the key factors that support or hinder the adoption of e-Government. The findings from the interviews revealed that for eGovernment to be successful needs support from senior management. However, some participants doubt about such support. For example, R1 stated that some of senior managers do not understand the eGovernment system due to lack of awareness of the eGovernment benefits.

He continued: "The MLA should take more responsibility for raising awareness of eGovernment among employees, particularly senior management"

S5 stated that workshops about eGovernment have been taken, he said "during the workshop which was done by MIT the awareness was highlighted as priorities in the ICT strategy and were part of the eGovernment master plan of MIT",

The aim of raising awareness was to provide government senior management with the necessary knowledge and skills for interacting with the new working environment. He also stated that among the members there were few managers from LAs.

S9 also highlighted that awareness of eGovernment benefit among the senior management and employees was relatively low, he said:

"we knew a little bit about the benefit of e-Government, some of our seniors had contributed in eGovernment workshops at e-Libya program, but in general, the awareness was insufficient because not enough workshops or presentation were provided"

With regard to funding, RLA and SLA were aware and realised that implementing an IT project such as eGovernment system is a radical change and a long-term project that requires attention and continuous financial support in order to achieve success in the project. 
The findings revealed that the budget for the IT support project, training courses and any other fund support was simply a lump sum, without any details of spending and allocation for the project before 2011. Later, after the 2011 revolution, however, the fund was not provided to support the LAs with essential needs. S7 agreed that implementing an eGovernment system was a radical change and a long-term project that required attention and continuous financial support to achieve success in the project, he said:

"we used to have budget support, but for the last three years, particularly after the crises started in Libya, we have struggled to secure the minimum budget support, and I think in terms of eGovernment as a long-term project, it would be difficult for us to secure funding to adopt it as long as the political crises continue "

S1 argued that senior management support to funding was one of the key issues within LAs. He stated that the funding resources to provide training to their employees was insufficient.

"in recent years there has not been enough funding provided to our LA due to political and economic issues, which affected the productivity and services we provided to the citizens".

Some directors had a different view about eGovernment and still considered it a luxury project, maintaining other area have to be prioritized and budget support should be allocated to these areas. For example, R7 said:

"This is a very complex problem; financial authorities should consider eGovernment initiatives as luxury projects compared to the basic needs for citizens, like water issues, health care, education and more importantly assistance for families affected by political conflict over recent years"

Regarding vision and strategy, participants emphasised planning to adopt eGovernment needs to include, it its strategy, a roadmap on how to reach the intended objectives, then this becoming the goal for all decision makers in all processes within LAs. R7 stated the importance of having a vision before the implementation of the project and he said:

"Planning and strategic vision would help to avoid issues in adopting e-Government. Unfortunately we didn't have a vision and strategy to adopt eGovernment in the LA; it would be a long journey until we could have a vision or plan to host eGovernment " 
$\mathrm{R} 1$ also stated that there is no detailed strategy or vision to adopt eGovernment in our LAs or even from MLA:

"There was no strategy or vision that the process would follow, I believe that eGovernment would be successfully adopted in LAs if the MLA planned a vision and strategies"

Some participants also indicated that eGovernment that lacked clear vision and strategy would be time consuming and therefore it is not really in their interest to host it. Thus, it is important for senior management within LAs to plan for developing strategy and also link their vision and strategy with eGovernment national strategy (e-Libya).

The findings from the interview also revealed an important factor that was not included in the conceptual model, and it may influence the adoption of eGovernment which laws and legislation of e-Government. this challenge has been mentioned by some senior managers.

For example, S8 asserted that eGovernment requires legislation to preserve the rights of citizens and businesses, who would deal with e-services and this legislation should be enacted prior to the adoption of e-Government. Such legislation should include electronic signature laws, computer crimes etc. He continued:

"the government will need to amend its existing laws and establish an e-business infrastructure by involving other sectors such as banks and finical institutions as part of eGovernment adoption process, this would also increase citizen participation and maximise their trust and usage."

\section{Findings}

The analysis of the case study shows that employees in both LAs were aware of the importance of the employees" skills and capabilities in facilitating successful eGovernment implementation. Thus, they offered incentives to attract capable skilled. However, the skills and capability within the processes were inadequate and work performance was insufficient. In terms of training the researcher found that top management have facilitated some types of tailored trainings, targeted few employees from different processes to experience and share the activities from the success of other organisations such National Oil Corporation regarding organisations productivity but the participants complained these training are limited training 
and workshops to sharpen employees' skills. The case study also shows that the majority of the employees have inadequate functional and employability skills as the employees revealed weak computer skills and communication skills, team work, self-management and problem-solving weaknesses. S1sated:

"employees ' training issue it has to be treated well and considered an important issue mainly in relation to employees that are involved in the development of the eGovernment if it was adopted".

The resistance to change is a common among employees in both LAs, and even increased when applying IT systems such as eGovernment to improve and develop its services. The reason is that these developments require fundamental changes in current bureaucratic procedures, while the employees still follow the old regime they are used to. Some of them do not know anything other than doing this job this way; they fear the loss of a certain authority and power or being fired. Some others know they are not skilled enough and they fear starting something new from scratch as they do not want to learn something new, which they are afraid of. They also fear that the new position holds more duties, or will deprive them of their source of power, or they will be replaced by younger, computer-literate civil servants, and the worst scenario when some managers are not really keen for change. They are indifferent about applying new systems to their work cycles. They are not aware of the advantages of the change, and if the managers are not enthusiastic about any project, there is the probability of its failure. The finding also revealed that processes fail or do not achieve their goals in both LAs due to work commitment, as recent years since 2011 employee's absenteeism increased which heavily affected on LAs' productivity.

Another problem is low awareness of the eGovernment services at both top management and employee levels. Although MIC conducted several workshops regarding eGovernment to increase awareness, eGovernment online services benefits awareness is still low. It has been noticed that the top management does not prioritise to increasing employee's awareness and this is a huge drawback in raising the acceptance of eGovernment adoption within LAs. One of the senior managers (S5) explained that the problem of awareness continues as the decision on how to increase awareness is very difficult to make and not simple because it needs funding to run workshops and give training to the employees. 
Top management support in terms of budget is perceived by some interviewees as a very strong challenge that is essential for the success of the transition to e-Government. This is true in terms of guaranteed long-term commitment steps and stages of the project and the provision of government and public support to this project at all levels. Sufficient funding for these projects is certainly an incentive, especially when these projects are long term and needs continues budget. R1 argued that fund is not an issue if the political situation in Libya settled and gets back to normal because in the past and before the revolution the MLA used to provide enough fund.

The final sub factor emphasised by many participants is the strategies used to implement the projects. The selection of strategies used affects to a great extent the success or failure of the projects. The case study finding revealed that the LAs have no detailed strategies to implement big IT projects such as eGovernment to align it with the national eGovernment initiative.

The findings revealed that the organisational capability factors which have been proposed in the initial conceptual model would remain as a future challenge too. The participants were also able to identify three important challenges in technology deployment dimension as illustrated in Table 5.3 that were not included in the conceptual model in chapter three.

Table 5. 3 Organisational Capability New Factors

\begin{tabular}{|l|l|l|}
\hline \multicolumn{1}{|c|}{ Factor } & New & \multicolumn{1}{c|}{ Source } \\
\hline Power Distribution & New & Interviews \\
\hline Favouritism and Corruption & New & Interviews \\
\hline Reward System & New & Interviews \\
\hline Laws and Legislation & New & Interviews \\
\hline
\end{tabular}

\subsubsection{Case Studies: Process Efficiency Dimension}

The adoption of eGovernment requires LA to have basic process efficiency to move towards a new eGovernment system. Therefore, SLA and RLA need efficiency and competence in their process tasks to implement eGovernment effectively. However, the case study findings revealed many issues related to process efficiency dimension in the model.

\section{- Documentation}

Documentation reveals a great deal about business philosophy. Documentation that is poorly written, mapped and out-of-date can signal a lack of caring. Current and polished mapping of processes empowers teams and improves efficiency. 
In this regard, the case study findings show that there was a lack of process documentation within the process, as R4, an IT specialist said:

"We don't have documentation that describes how tasks are performed or roadmaps for our business processes; this makes the duties of the employees more difficult when someone did not come to the work. We completely depend on the skills that employees hold, therefore, when an employee leaves we fall into chaos and tasks are delayed".

The observation also found that sub-processes are incompletely mapped out and documented. Moreover, there is still more work to do to complete the processes mapped out and documented. The researcher also found out that the quality of the documentation was poorly written, with missing information and includes unnecessary and distracting information. There is also a lack of using IT tools to capture existing processes into an interactive application, which can be built on, for all future process documentation.

S4 also asserted that lack of documentation for the sub-processes in all processes, as he said:

"there is no documentation for the sub-process, even though employees understand what their role entails and what their responsibilities are, but we still need to write their roles to streamline the business and make it more efficient"

S6, a statistics and information technology manager, further added that documentation had the potential to cause issues with the consistency of output and poor performance:

"Although, we use technologies in our processes, no documentation is used to achieve consistency. For instance, there are different ways to complete same tasks, this causes issues with the consistency of output.

\section{- Standardization}

The findings revealed a lack of standardization for the tasks, which always increases the probability of mistakes, lowers productivity levels, and fails to assure continuity of process and quality when employees leave or are on holidays. Participants also asserted that that there was no standardization and tasks were always done in different ways. R3 said: 
"we don't have standard procedures to follow, and tasks are always done in different ways based on employees' experiences, there is always complaints from top management about our reports provided to them"

The finding showed that most processes were chaotic and disorganized. There was duplication of effort, which meant different employees carried out the process in a slightly different way, or the same employee did something slightly different each time. This is stressful for employees and costly for organizations. S6 mentioned that work flow should have been changed to meet the requirement of nowadays technology he said:

"this could be done by adopt redesign core processes which is a radical change in an organisation's process management to improve its performance and increase its efficiency"

According to the MLA IT plan, LAs encouraged along two lines: building office automation systems; and adopting redesign core processes. The plan is to apply both concurrently; office automation is a base for redesign core processes, whilst at the same time redesign core processes directs the building of office automation systems. R3 indicated that, if redesign core process is adopted properly it will decrease headcount and increase productivity, this is because redesign core processes will enforce the rethinking of processes, which may lead to the removal and/or automation of some process steps, as well as the reengineering of a part or the whole of the process flow.

\section{Findings}

The findings revealed that lack of documentation for the tasks, which impacted on productivity levels and doesn't assure continuity of process and quality when employee leave or were on holidays. The findings of the case study also revealed that there is no standardization and tasks always done in different ways. the new identified is Core Processes Redesign.

\subsection{Summary}

As reviewed in the literature, there have been limited studies on the factors, barriers and challenges of eGovernment implementation in developing countries. The researcher carried out case study research on local authorities (LAs) in Libya. The overall picture developed from the findings and analysis in this chapter has helped to develop a deeper understanding of the fundamental factors that affect eGovernment implementation within LAs and any new challenges identified during the case study findings will be added to their respective factors 
and then added to the respective dimension. The investigation process and analysis in this chapter has also led to the identification of more specific critical factors. These include the sharing of knowledge and information, PKI, local industry partners, power distribution, favouritism and corruption, reward system, and laws and legislation. These factors emerged as significant for eGovernment adoption. In the next chapter these factors are explained and added to their respective dimensions. 


\section{Chapter Six: Model Revised and Model Application}

\subsection{Introduction}

Before the actual collection of data, an initial conceptual mode was developed for explaining the main dimensions that affect eGovernment projects implementation. The initial conceptual model has been built based on prior literature in the area of eGovernment in government organisations. The relevant literature facilitated a better understanding of the nature of the eGovernment and e-Service development process, particularly to identify barriers and challenges hindering eGovernment implementation. Based on the research findings and data analysis, this chapter deliberates on the additional factors and sub-factors identified, which were not part of the literature or initial conceptual model. As a result of the research findings and analysis, the researcher has been able to explain the issues of the emergent factors and subfactors and thereby refine the initial conceptual model. The researcher was also able to extract the maturity level definition from the revised model and apply at individual process level at SLA.

The rest of this chapter is organized as follows: Section 6.2 analyses the newly identified factors and sub-factors. Section 6.3 then discusses the revised conceptual model. Section 6.4 discusses the application of the model and Finally, Section 6.5 presents a conclusion, with a summary and overview of the maturity level for each process.

\subsection{Analysis of Newly Identified Factors}

In the previous chapter, findings from the analysis of the cases were discussed. This chapter now discusses the refinement of the initial conceptual model by adding the identified challenges to their respective factors and to the respective dimension.

\subsubsection{Technology Deployment Dimension}

The participants were also able to identify two important challenges in technology deployment dimension that were not included in the conceptual model in chapter three. These challenges are: 


\section{Sharing of Information:}

Participants asserted that there was a lack of information sharing among processes within and across LAs. This is a serious issue that threatens the implementation of eGovernment adoption. Technically, the sharing of information can be a complex task; for example, in LAs with bureaucratic systems, the problem is that flow within organizations is strictly controlled with limited access to, and sharing of, information and knowledge. The participants also asserted that information needs to be well regulated to improve LAs efficiency. S6 said:

"For public government agencies, information sharing is a crucial factor in achieving important public benefits: increased productivity, improved policymaking and integrated public services"

Fundamentally, sharing information reduces the "paperwork burden" on citizens, streamlines work processes, and enriches the formulation, implementation, and evaluation of policy. Although there are many obvious advantages for information sharing, the existing barriers significantly impede the information sharing process across Las' boundaries. The recognition of the value of information by the employees increases the successes of eGovernment adoption, therefore the researcher considers it as an important factor and should be included in the model.

Information sharing describes the exchange of data between processes and across LAs. The participants revealed that data frequently was kept within processes and often not shared among other processes due to many reasons, such as being in proprietary, non-portable format or the inability to import/export data. For example, R4 said:

"Even simple items such as dates were stored in a whole range of different formats, making the sharing of such a simple field a potential nightmare".

Sharing of information necessitates a culture that promotes collaboration between government agencies. However, the culture of information sharing does not exist in many Libyan government organisations and greater effort by top managements will be required to address this issue. R1 indicated that some processes store similar and sometimes contradictory data due to absence of information sharing and he emphasised that projects such as eGovernment would provide solutions to this issue.

The findings revealed that the same applied to a whole range of data, and even if it was compatible, it was often not possible to physically transfer the data from one process to another. 
To conclude: the findings reveal that information sharing is an important new factor before effective eGovernment adoption can take place, because it allows decision makers to manage information from several sources at the same time and it has the potential to support the transformation of organizational structures and to provide communication channels between multiple processes working in different locations.

\section{Public Key Infrastructure}

Participants from the case studies were able to identify PKI as an additional challenge. They asserted the need for developing and designing Public Key Infrastructure (PKI) in order to provide a safe environment that will guarantee security and secrecy in e-services.

S2 explained that the basis on which governments can execute safe and reliable transactions, whether between individuals, businesses, governments or inter-government relationships, is PKI. It allows public entities to securely authenticate all participants in a transaction. He continued:

"The combination of software, encryption technologies, and services that enables LAs to protect the security of their communications and transactions on networks is only done by PKI, so combining public key cryptography, certification authorities and digital certificates into a complete enterprise-wide network security architecture will make eGovernment secure and stakeholders will trust it"

The interview evidence clearly shows that, the PKI is important and increases security of eGovernment transactions, therefore it has been considered a sub-factor of the security factor and should be taken into account before eGovernment adoption takes place.

\section{Local Industry Partners}

The participants believed that a local industry/partner alliance is an interesting challenge, and eGovernment transformation journey will not be a success unless there is a strong industry/private partners alliance that supports the project. The findings also showed that IT private partners and alliances in LAs were not strong. R3 claimed the RLA would like to encourage local companies towards implementing any project, including eGovernment on the condition that there is long term commitment from these government organisations; this is important to ensure sustainability of e-Government. The interview evidence clearly shows that participants had already realised the importance of this factor to achieve eGovernment 
implementation success, therefore, it was considered as a new factor that should be taken into consideration.

\subsubsection{Organisational Capability Dimension}

The interview evidence clearly revealed that all factors and sub-factors are related and important to making the adoption of eGovernment work. The participants were also able to identify six important challenges that were not included in the conceptual model discussed in chapter three. These challenges are:

\section{Power Distribution}

Participants highlighted that IT projects were influenced by power distribution as a result of organisational change and shifts within the organisation. Such shifts and changes will result in redistributing the power within LAs and redesigning jobs. Those consequences could lead to changes of priorities and resistance to these changes. For example, R1 stated that:

"the implementation of new IS/IT in public organisations may result in employee resistance as well as employees losing their authority and power over traditional business processes"

Those employees who feel a loss of power or control, will try to resist the eGovernment project because it is seen as a threat to their skills, power and position. Therefore, the researcher considers that Power Distribution is a sub-factor of organisational culture and should be assessed before eGovernment is implemented.

\section{$\underline{\text { Favouritism and Corruption }}$}

The participants mentioned that the move to new forms of eGovernment systems was a hard task, particularly in an environment that was characterised by corruption, such as that evident in the public sector. They assert that for e-Government, corruption is a major challenge especially in the field of tenders, some of which are granted on the basis of who has the greatest national power and influence in the LAs. Participants also mentioned that favouritism was a fundamental factor in corruption in the public sector and that it was a hindrance to development process in Libya. They also highlighted that in e-Government, favouritism may play a role in hindering the implementation process and cause project failure.

In this regard, favouritism and corruption is considered a sub-factor of organisational culture because it could be overcome if LAs educated their employees and make them aware that 
favouritism and corruption damage the whole organisation and its productivity, therefore and it should be assessed before eGovernment takes place.

\section{Reward System}

The participants emphasised that reward system must be associated with any changes within LAs, including the adoption of e-Government. The findings from the case studies showed that where there was a lack of reward system, employees were reluctant and unwilling to participate in new projects. S3 stated that top management can encourage employees to be involved in any new technology projects by recognising and appreciating their contributions. On the other hand, participants also expressed a willingness to adopt eGovernment if their top management would address their needs in terms of monetary benefits, job retention and career progression. S3 also said:

"Employees within LAs will be willing to dedicate their times to eGovernment if the top management can appreciate their effort and contribution."

R4 also stressed that the reward system is an important way of encouraging employees of both government and private sector to adopt IT projects. He indicated a lack of the reward system in RLA:

"Unfortunately, many mangers do not care about rewarding their employees, consequently employees are not willing to do their best to achieve productivity"

The findings from the case studies showed that a lack of reward system results in employees who are unwilling to participate in any new projects. In summary, the reward system is an important challenge that increases the successes of e-Government. However, the findings showed that a structured reward system within LAs does not presently exist. Therefore, the interview evidence clearly revealed that, the reward system is a sub-factor of the top management factor and should be considered before eGovernment implementation.

\section{Laws and Legislation}

The empirical evidence gathered from the case studies showed that participants from both LAs agreed that legislation was important and highlighted this factor as a key issue that impacts on eGovernment system. 
The participants asserted that eGovernment requires many regulations and legislative acts to cope with the new changes. This legislation may include electronic signatures, archiving data protection, preventing computer crimes and hackers. Moreover, R1 stated that:

"Legal risks in terms of technology may expose government organisations to serious liabilities and therefore new eGovernment or e-Service legislative acts have to be settled and updated periodically to avoid unexpected results or the delaying of projects"

The participants reported that they shared the same perceptions that law and legislation was an influential factor prior to and during the implementation of a large-scale IT project in government, such as e-Government. The interview evidence clearly showed that law and legislation as a new pivotal factor for eGovernment implementation and is an important factor that lies under the Organisational capabilities dimension.

The absence of a legal framework meant there was a lack of an umbrella under which eGovernment operations and electronic transactions were carried out legitimately. Mberi et al. (2017) consider the development of a legal framework to be an essential element for successful adoption of eGovernment in the public sector. However, as the data collection of the research progressed, it was found that regulatory issues were more recognised as a crucially important factor for eGovernment adoption.

\subsubsection{Process Efficiency Dimension}

The participants were also able to identify one important challenge that were not included in the conceptual model in chapter three.

\section{Business Processes Redesign}

The participants stated that eGovernment required a rethink of their process workflow. However, a series of errors was produced, with a high rate of failures in both LAs' processes. Many difficulties originated from the need to transform the way in which the activities of the LAs were traditionally executed, to take advantage of new technologies. These difficulties may force top management to rethink adopting information tools like BPR to carry out such change, as the S5 stated:

"Reaching higher eGovernment levels is related to business processes redesign to take advantage of IT capabilities" 
Participants recommended BPR, as this allows the essence of business systems to be understood, process visions to be developed, processes for change to be identified, new processes to be designed and prototyped and the impact of proposed changes on key performance indicators to be evaluated.

A member of committee R3 stated that public sector organizations such as LAs face challenges that differ to the challenges of private sector. LAs have to meet multiple, often conflicting goals and they are subject to constraints of a financial, legal, contractual, personnel and institutional nature and generally, these constraints are much more onerous than they are in the private sector. He stated:

"Radical change in government agencies can only be achieved through deep changes in their bureaucratic practices"

The participants agreed that reform of business processes involves changing the way that, within each process in the LA, daily tasks are undertaken in an effort to increase productivity, reduce cost, and improve services delivery to citizens and other stakeholders. This requires reduction of red tape and the elimination of overlapping responsibilities. Redesign of business processes is essential prior to and during the implementation of an eGovernment project. They also stressed that reform would have to start within each process in the LAs and would be more citizen oriented. They also emphasised that automation would improve the situation and the results would be good services and they highly recommended that BPR should be adopted before and during the transition to e-Government.

In summary, the finding revealed that BPR as a new pivotal factor for eGovernment implementation and an important factor that lies under the Process Efficiency dimension.

\subsection{Revised Conceptual Model}

Based on the research findings and data analysis, the above sections discuss the additional factors identified, which were not part of the literature or the initial research model. As a result of the research findings and analysis, the research has been the basis for an explanation of some issues and limitations, thereby requiring updates to the initial conceptual model and recommendations for effective implementation of eGovernment systems in the LAs' organisations. The final conceptual model, as shown in Figure 6.1 below, identifies the three dimensions influencing eGovernment evaluation and implementation - Technology 
Deployment Dimension - Organisational Capability Dimension - Process Efficiency Dimension. It also identifies the main factors and sub-factors involved in eGovernment evaluation, which enable eGovernment implementers to adopt the appropriate guidelines required for successful implementation at every phase of the development life cycle.

Figure 6. 1 The Revised Conceptual TOP Model

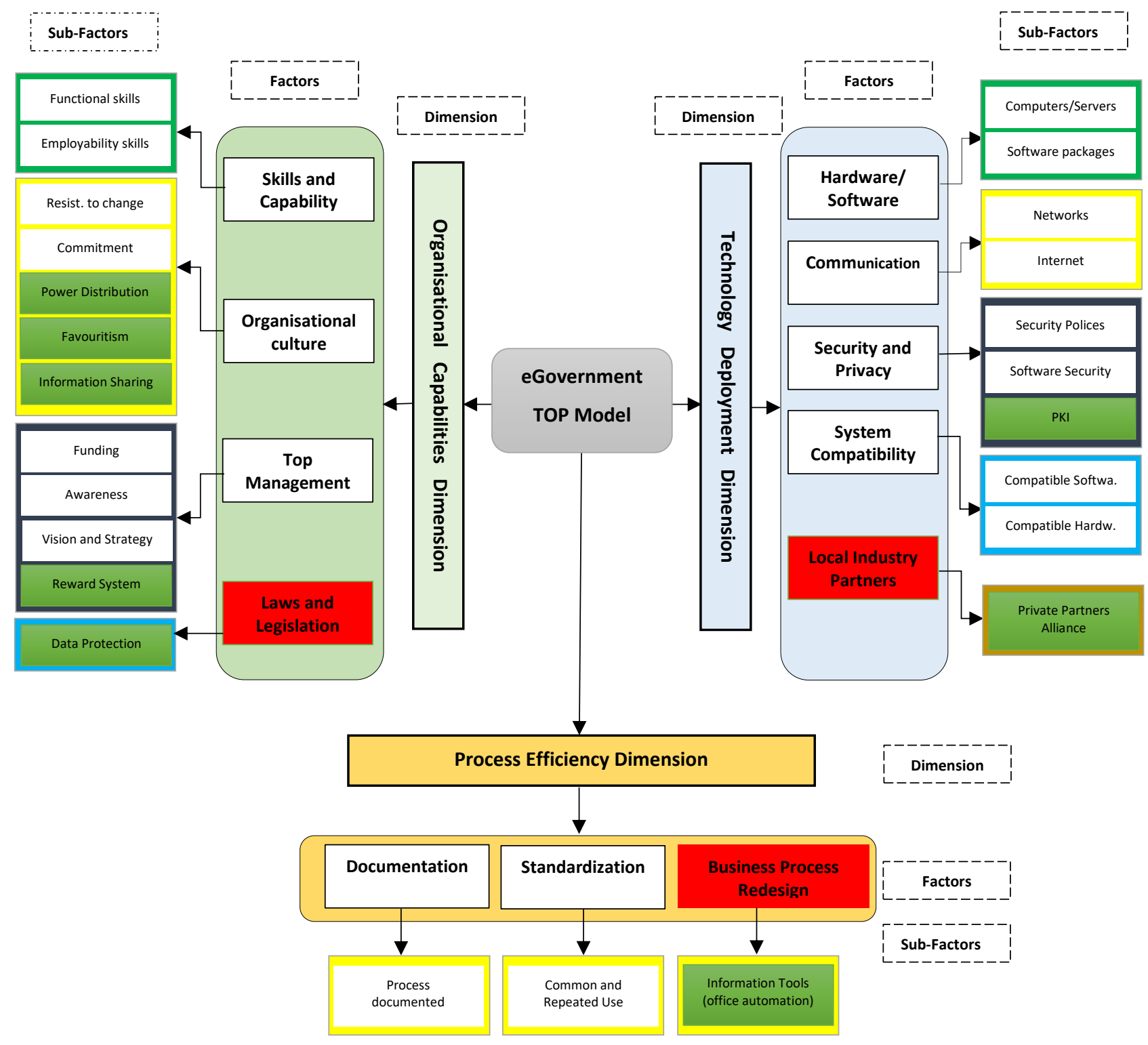

New Factors

New Sub-factors

\subsubsection{Capability Level Definitions}

After revising the conceptual model, the researcher attempted to extract a staged level approach. In this staged approach, specific definitions are provided for the model maturity scale 
for each dimension (TOP). The maturity levels are not designed for use as a threshold model, where one cannot move to the next higher level without having fulfilled all conditions of the lower level. This model is likely to result in the dimensions being assessed as being at different maturity levels, as illustrated in Figure 6.2.

The maturity model will be used at individual process level for SLA and RLA. However, the revised model in Figure 6.1 is structured into three main layers (Dimensions, Factors and SubFactors) which together enable an LA's processes to be positioned at a staged maturity level. Each main process will be assessed against the three dimensions (TOP). The dimension layer comprises factors and each factor comprises sub-factors. Generally, each dimension has a staged level scale range (Chaotic, Basic, Intermediate, Standardized, Optimized), and is associated with qualitative definitions (see Tables 6.1, 6.2 and 6.3). The dimension must mature further in practice and therefore is subject to evaluation, which is done by measuring its capabilities through their Factors and Sub-Factors.

Figure 6. 2 Dimension Maturity Model Levels

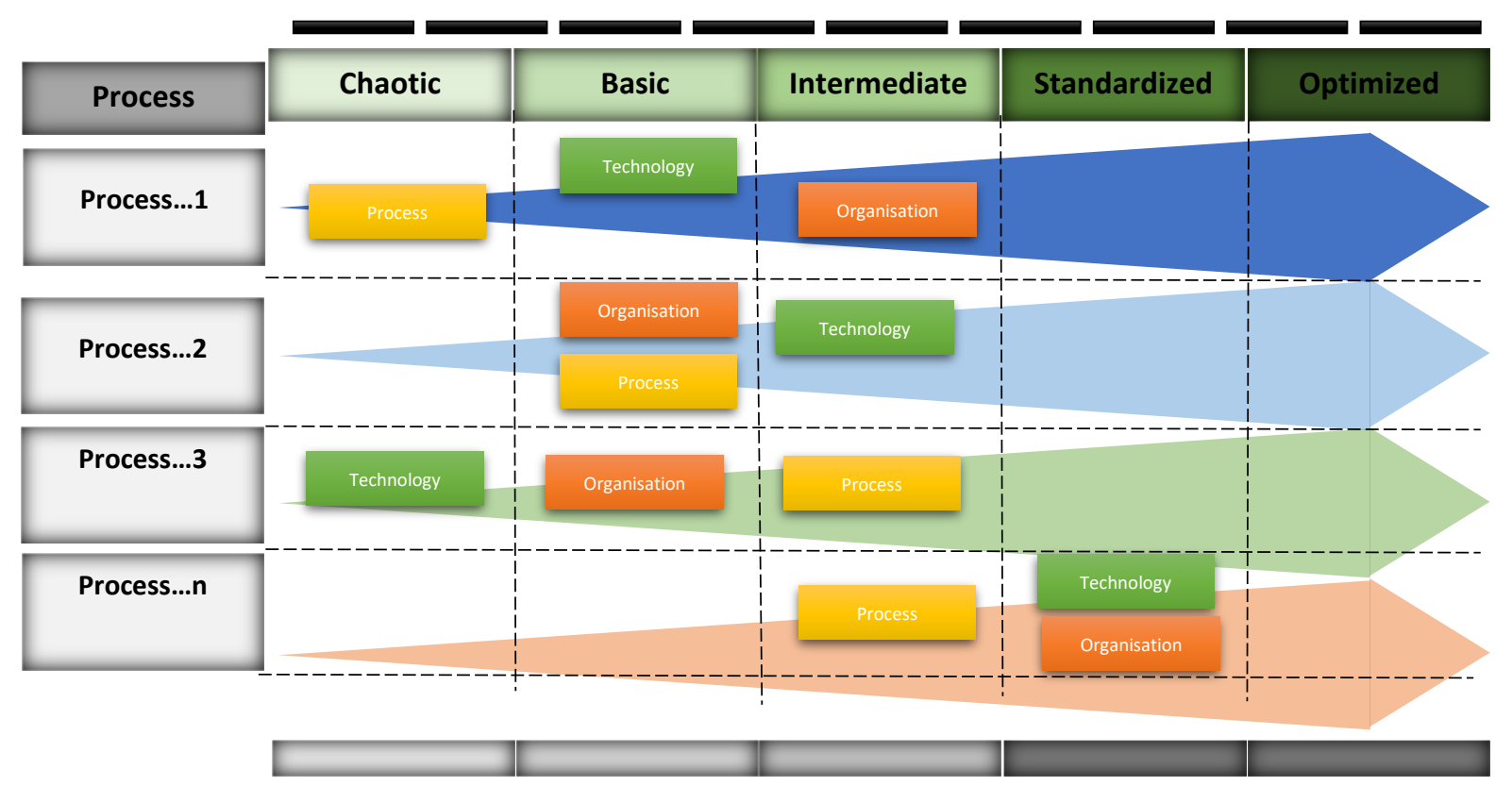


Table 6. 1 Qualitative Model Definitions of Technology Deployment Dimension

\begin{tabular}{|c|c|}
\hline Capability & Definitions \\
\hline Chaotic & Process is non-technical and completely relays on manual work \\
\hline Basic & $\begin{array}{l}\text { There is hardly any facilitating ICT Infrastructure, process is accomplished manually, and the } \\
\text { dimension characterized as inadequate. At this stage, there is hardware such as computers, } \\
\text { software such as Microsoft and printers. These tools are partially used to facilitate the tasks and } \\
\text { data exchange is primarily paper or telephone-based. There is no IT support. }\end{array}$ \\
\hline Intermediate & $\begin{array}{l}\text { There is hardly any facilitating infrastructure, but the processes and activities in the department } \\
\text { are semi-coordinated. At this stage, there are computers and printers used within the department. } \\
\text { The data within the department is compatible and data exchange happens only within the } \\
\text { department and based on a LAN. The internet is slow and unreliable. There is vulnerability in } \\
\text { security and privacy and there is limited IT support provided. }\end{array}$ \\
\hline Standardized & $\begin{array}{l}\text { The infrastructure enabling the information to be exchanged within and between departments in } \\
\text { the local government exists. Software security is installed, polices are in place and there is } \\
\text { adequate IT support. }\end{array}$ \\
\hline Optimized & $\begin{array}{l}\text { The infrastructure enabling integration between systems in different departments in the back- } \\
\text { end and data can be exchanged between department within and across local governments, which } \\
\text { enables local government to deliver IT services to its employees and customers. IT standards are } \\
\text { in place across local governments (ex. Same Operating systems, .Net Platform, Java Technology, } \\
\text { Compatible Database). There is professional IT support. }\end{array}$ \\
\hline
\end{tabular}

Table 6. 2 Qualitative Model Definitions of Organisational Capability Dimension

\begin{tabular}{|c|c|}
\hline Capability & Definitions \\
\hline Chaotic & The organisational capability within the process is inadequate and poorly controlled and defined \\
\hline Basic & $\begin{array}{l}\text { There is a lack of functional and employability skills, staff are resistant to change to new } \\
\text { procedures and resistant to accepting technologies; there is a lack of awareness of eGovernment } \\
\text { from top management. The local government recognise that there is an issue to be addressed but } \\
\text { there is no strategy or vision and there is no funding allocated to improve the local government } \\
\text { work. }\end{array}$ \\
\hline Intermediate & $\begin{array}{l}\text { There is a degree of the necessary skills, and awareness of the need for a training and education } \\
\text { programme in order to encourage staff to adopt new procedures. There is limited awareness that } \\
\text { eGovernment improves work, staff show some commitment to tasks, there is no clear vision or } \\
\text { strategy to improve services online and funding is still an issue. }\end{array}$ \\
\hline Standardized & $\begin{array}{l}\text { There is a comprehensive training and education programme that yields measurable results and } \\
\text { there is management support and commitment. Management is also aware of eGovernment } \\
\text { advantages and funding is allocated to improve the local government human capacity. }\end{array}$ \\
\hline Optimized & $\begin{array}{l}\text { Training results in an improvement of individual performance. Sufficient budgets, resources, } \\
\text { facilities and instructors are provided for the training and education programmes. Strategy and } \\
\text { vision are aligned with the national eGovernment plan; there is steering committee monitoring } \\
\text { and staff are able to adopt e-Government. }\end{array}$ \\
\hline
\end{tabular}


Table 6. 3 Qualitative Model of Process Efficiency Dimension

\begin{tabular}{|c|c|}
\hline Capability & Definitions \\
\hline Chaotic & Process is Chaotic and poorly controlled and defined. \\
\hline Basic & $\begin{array}{l}\text { There is no standardised, documented process; instead, there are ad hoc approaches that tend } \\
\text { to be applied on an individual or case-by-case basis. The overall approach to management is } \\
\text { disorganised. }\end{array}$ \\
\hline Intermediate & $\begin{array}{l}\text { Processes have developed to the stage where similar procedures are followed by different } \\
\text { people undertaking the same task. There is no formal training or communication of standard } \\
\text { procedures and responsibilities; therefore errors are likely }\end{array}$ \\
\hline Standardized & $\begin{array}{l}\text { Procedures have been standardised and documented, and communicated through training. } \\
\text { Processes are under constant review and improvement, and provide good practice. } \\
\text { Automation and tools are used in a limited or fragmented way. }\end{array}$ \\
\hline Optimized & $\begin{array}{l}\text { Processes have been refined to a level of good practice, IT is used in an integrated way to } \\
\text { automate the workflow, providing tools to improve quality and effectiveness, allowing a } \\
\text { smooth transition to new improved processes. }\end{array}$ \\
\hline
\end{tabular}

\subsection{Application of the Maturity Model}

The maturity model is used to assess the processes against the defined dimensions. This enabled each LA to identify its current state of maturity and capability in an integral manner and compare itself with other processes evaluated with the same model in their own and other LAs. Figure 6.3 proposes five main process areas in Libyan LAs (Government of National Accord, 2012). These have been assessed in terms of their maturity in SLA, as illustrated below:

Figure 6. 3 Main Processes for Libyan Local Administrations

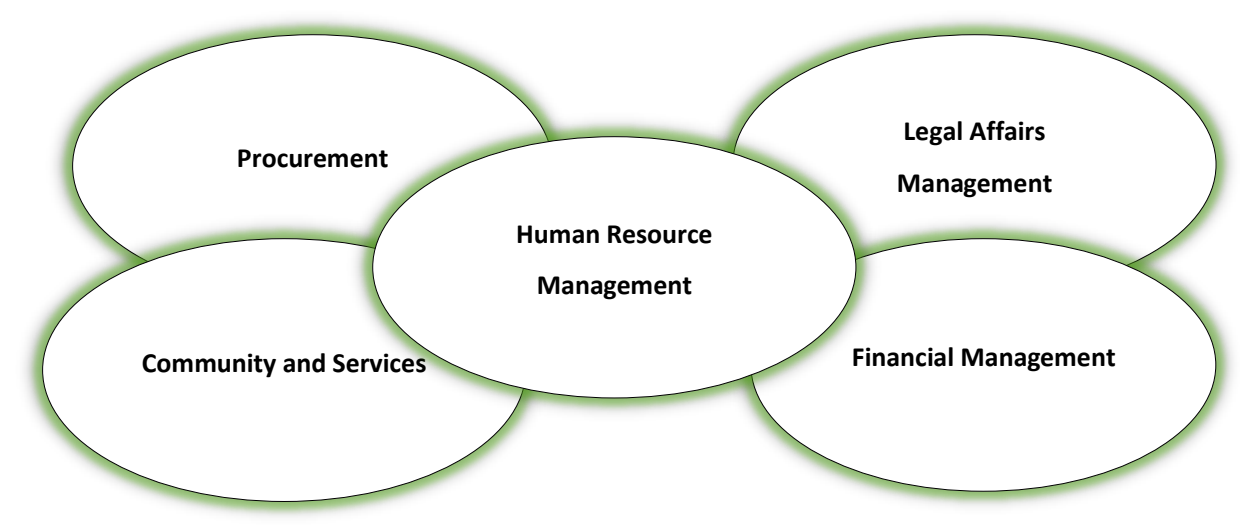


The maturity model assesses the maturity of each process. This is of significance in a developing country context, where most eGovernment initiatives are still considered to be immature and many problems originate at the strategy phase, leading to inappropriate decisions and actions.

The next two steps explaining how to use the maturity model. The researcher believes that by following these steps, decision makers can obtain the best results and guidance for the adoption process.

1. Review the current status of each process level and discuss it with one of the experienced participants according to the revised model.

2. Compare results that have been analysed in the previous step and between the qualitative model definition in the maturity model and position it to determine to which level it belongs.

\subsubsection{Case Study One: Maturity levels of SLA}

The researcher held individual discussions with seven participants from SLA (see Table 4.1 in chapter four). The discussion was organised according to the three steps explained. After the discussion, each participant was asked to review a qualitative model definition and share his opinion with the researcher to determine which maturity level definition the process belongs to. The results were as shown in next sections:

\subsubsection{Technology Deployment dimension}

\section{Procurement Management (PM)}

Hardware and software were available within the process; however, they were outdated technologies. There was a client/server network, which facilitated sharing data and information located on the server; printers were connected to the network but there was no access to the other four processes via network. The internet was unreliable and always disconnected. Security remains an issue as basic outdated security software was installed on the server. No security policies implemented, nor disaster recovery was in place, and data back-up was not scheduled on a regular basis, there was no PKI implemented. A compatible operating system was installed; however, these operating systems were outdated (Windows 2000 and Windows $\mathrm{XP})$, there was also the issue of the inability of systems to connect and communicate with one another readily due to incompatible database between the processes. In terms of private 
partners alliance factor, SLA had an issue to get outsourced support due to internal regulation that forbade outsourcing technical support.

To conclude, discussion suggests that the technology deployment dimension within PM is in accordance with the Basic Level of the TOP model maturity definitions.

\section{Financial Management (FM)}

The FM has slightly advanced hardware as the top management decided to build robust technology within the FM to meet their requirement. For example, computers with i7 processor with speed technology were available and laser printers were connected. However, the software used in the computers were outdated, such as Windows XP and some other software packages such as MS Office 2000 still used. A client/server network with fifteen computers was connected to the server. There was an issue of accessing the other four processes via the network and the internet was often disconnected and unreliable. Basic security software was installed on the server with limited security features that provide no valuable security to the systems; there was also a lack of awareness of security risks among employees and security policies were not applied to reduce security breaches; there was no disaster recovery in place that would reduce the risk of losing data, and the FM management has no plan to implement PKI to enhance security. In terms of system compatibility, FM management process uses one operating system on their computers, however, this operating system was outdated (Windows XP) and Microsoft no longer provides security updates or technical support for the Windows XP operating system. Other issue was the incompatible database across the processes, this works as a barrier between process to exchange data. In terms of private partners alliance factor, SLA having an issue to get outsourced support due to internal regulation that forbidden outsource technical support from private companies.

To conclude, discussion suggests that the technology deployment dimension within FM is in accordance with the Intermediate Level of the TOP model maturity definitions.

\section{Human Resource Management (HRM)}

Within HRM process, hardware as well as software were available. Nevertheless, these technologies were outdated and inadequate to adopt eGovernment system. For example, the computers use a Celeron processor, whose performance is typically significantly low (Moreno and Azevedo, 2016). In terms of software, HRM process still uses Windows XP and other software packages such as MS Office 2000 which was outdated, and for which Microsoft no longer provide support. In terms of the communication factor, there was peer to peer network, 
with twenty-four computers and four dot matrix printers connected to the network. Data on this type of network can be stored on any computer, which means there was no organisation to data storage and each computer needs its own anti-virus scanner, another issue was that there was no access to other four processes via the network and the internet was unreliable. Basic security software was installed on the computers and there was lack of awareness of security risks among the employees, which put the data always at risk. There was also an issue of security policies or disaster recovery not in place, there was no PKI plan for future use. Regarding system compatibility factor, there was outdated Windows operating system installed on the computers (Windows 2000). Incompatible data between the processes remained an issue as a different database was used. In terms of private partners alliance factor, SLA is having an issue to obtain outsourced support due to internal regulation that forbids outsourced technical support from private companies.

To conclude, discussion suggests that the technology deployment dimension within HRM is in accordance with the Basic Level of the TOP model maturity definitions.

\section{Legal Affairs Management (LAM)}

In the LAM process, there were only two inadequate computers to adopt the eGovernment project, this is because the computers have Celeron processor which is too slow (Moreno and Azevedo, 2016), and the other issue, employees in this process did not use computer in their daily work. Windows 2000 was installed which was outdate and there was no software packages nor in-house systems were used. Since there were only two computers the process does not need to use network and internet, there was no need for software security nor PKI as computers were not used. There was no database exchange between process. Therefore, there was no system compatibility. In terms of private partners alliance factor, SLA having an issue to get outsourced support due to internal regulation that forbidden outsource technical support from private companies.

To conclude, discussion suggests that the technology deployment dimension within LAM is in accordance with the Chaotic Level of the TOP model maturity definitions.

\section{Community and Services Management (CSM)}

In CSM process, there were computers that can facilitate the adoption of eGovernment as most of the computers use Pentium processors, which are entry-level products that Intel rates as two stars meaning that they are above the low-end Celeron series (Moreno and Azevedo, 2016). There were also three bespoke in-house systems (Housing System, Invoices System, Civil 
Status Management System). The systems were developed by IT developers from SLA used Visual Basic and Access Database. Notwithstanding, the implementation of these systems represents a major step forward in SLA. There was no access via web-portal to these systems, and their online presence was limited to display information only. Despite that fact that an important sub-task was automated, there were still semi-manual processes required to work on these systems. For example, Housing and Civil Status sub-processes data were collected manually and then provided for in the process via Excel spreadsheets before entry into these systems by the staff. Regarding communication, there was a client/server network which facilitated the sharing of the data and information located on the server; printers were also connected to the network. However, there was no access to the other four processes via the network, and the internet is unreliable. Regarding security and privacy, there was basic security software installed on the server and no security policies were applied, nor was disaster recovery in place and there was no PKI. Regarding system compatibility, there was a Windows operating system installed; however, some computers used out-dated operating systems such as Windows XP. There was also a database incompatible with other processes. In terms of private partners alliance factor, SLA has an issue to get outsourced support due to internal regulation that forbids outsourcing technical support from private companies.

To conclude, discussion suggests that the technology deployment dimension within CSM is in accordance with the Intermediate Level of the TOP model maturity definitions.

\subsubsection{Organisational Capability Dimension}

\section{Procurement Management (PM)}

Skills and capability within the process were inadequate and work performance was insufficient, there was lack of training course; inadequate functional skills and employability skills as the employees revealed weak computer skills and communication skills, team work, self-management and problem-solving weaknesses. Regarding organisational culture, there was resistance to change to accept new technologies and there was lack of commitment to work and fear of power distribution among the employees. S1 agreed that many staff will refuse to adopt eGovernment because of losing their positions, the findings also reveal a practice of giving unfair preferential treatment to one employee at the expense of another, which means favouritism is a cultural issue among the government organisations in Libya. Senior management factor also presented many issues: there was lack of support from senior management, there was also lack of funding, lack of eGovernment benefits awareness among 
the senior management and employees, and there was lack of vision and strategy for eGovernment adoption in the future, an a lack of reward system to encourage staff to enhance productivity. In terms of legislation factor, there is a lack of e-signatures legislation, many software used without an end-user license agreement.

To conclude, discussion suggests that the organisational capability within PM is in accordance with the Chaotic Level of the TOP model maturity definitions.

\section{Financial Management (FM)}

Skills and capability were inadequate and the performance within the process was insufficient, there wasn't training course provided and employees possess low functional skills except few who can run in-house system and have basic computer skills; the employability skills were also inadequate as most of the employees revealed weak interpersonal skills. Regarding organisational culture, it was low among the employees as there was resistance to change when new technology was introduced; the employees also showed low commitment to work to their tasks, there was also fear of power distribution among the employees which meant many staff will refuse to adopt eGovernment because of fear of losing their positions. There was also a favouritism issue where unfair support was shown to some employees. Regarding senior management, the findings showed a lack of support from senior management; funding had been stopped since the revolution in 2011, eGovernment benefit awareness among the senior management and employees was low and there was lack of vision and strategy for eGovernment adoption in the future. There also no bonuses or reward system to encourage staff to enhance productivity. In terms of the legislation factor, there was a lack of e-signatures legislation planned to future use and a lot of the software within the process lacked an end-user license agreement.

To conclude, the findings suggest that the organisational capability within FM is in accordance with the Chaotic Level of the TOP model maturity definitions.

\section{Human Resource Management (HRM)}

There were inadequate skills and capability among the employees who made insufficient work performance in the process. Regarding functional skills, there were few employees with basic computer skills. The employability skills also remained an issue as most the employees didn't have interpersonal skills, such as communication skills, teamwork, problem-solving, planning and organizing or self-management. Regarding organizational culture, it was too low among the employees as there was resistance to change to technology and lack of commitment to work, 
there also fear of power distribution among the employees which meant many staff will refuse to adopt eGovernment because of fear of losing their positions, the finding also revealed an inclination to favour some employees at the expense of another. In terms of Senior management, the findings revealed that there was lack of support from top management, lack of funding, lack of awareness of eGovernment benefit and lack of vision and strategy to adopt eGovernment in future. There also no bonuses or reward system to encourage staff to enhance productivity. In terms of legislation factor, there was lack of e-signatures legislation planned for future use and a lot of software within the process lacked an end-user license agreement. To conclude, discussion suggests that the organisational capability within HRM is in accordance with the Chaotic Level of the TOP model maturity definitions

\section{Legal Affairs Management (LAM)}

It was evident from the interviews that the employees possessed reasonable employability skill, but functional skills were too low and there was a lack of training courses to improve functional skills. Organisational culture was reasonable among the employees; this was evidenced by the fact that employees were committed to their work and tasks were mostly completed within time scale. In terms of technology acceptance, there was resistance to change from employees when new technology was introduced, there was also fear of power distribution among the employees which means many staff will refuse to adopt eGovernment because of fear of losing their positions, the finding also revealed some employee complain about unfair treatment of an employee on the basis of prejudice. Regarding senior management, there was lack of support from senior management; there was also lack of funding. Awareness of eGovernment benefits among the top management and employees was too low despite the fact that seminars for eGovernment were provided to the senior management to educate managers about eGovernment. There was also lack of vision and strategy for eGovernment adoption, there also no bounces or reward system to encourage staff to enhance productivity. In terms of legislation factor, there was a lack of e-signatures legislation planned to future use and many software within the process were without an end-user license agreement.

To conclude, discussion suggests that the organisational capability within LAM is in accordance with the Chaotic Level of the TOP model maturity definitions.

\section{Community and Services Management (CSM)}

Skills and capability within the process were insufficient and the performance was inadequate, training course was not provided. Some employees hold basic computer skills, but the majority 
had weak functional and employability skills. In terms of organisational culture factor, there was resistance to change when new technologies are introduced, employees' commitment to work was an issue which always affect the whole process because tasks were often delayed or never done, there was also fear of power distribution among the employees, which means many staff will refuse to adopt eGovernment because of fear of losing their positions. There was also favouritism, with some employees getting more promotions that others. The case study also revealed that support from top management in terms of funding was an issue because there were no funds provided to buy the minim requirement, such as stationary needs or to buy new computers and develop the whole process. It is clear that the benefit of eGovernment is not clearly understood among the employees and there is also lack of vision and strategy for eGovernment adoption at top management level, there was no reward system, there were no bonuses or rewards to encourage staff to enhance productivity. In terms of the legislation factor, there was a lack of e-signatures legislation planned to future use and much of the software deployed within the process was without an end-user license agreement.

To conclude, discussion suggests that the organisational capability within CSM is in accordance with the Chaotic Level of the TOP model maturity definitions.

\subsubsection{Process Efficiency Dimension}

\section{Procurement Management (PM)}

The findings revealed that there was a lack of documentation for the tasks, which always increases the probability of mistakes, lowers productivity levels and doesn't assure continuity of process and quality when employees leave or are on holidays. The findings of the case study also revealed that there was no standardization and tasks were always done in different ways. In terms of BPR, the PM management process had no automated systems that work together, such as ERP or CRM systems which can improve workflow and reduce human errors, the PM also has no plan to rethink and reengineer the tasks.

To conclude, discussion suggests that the process efficiency dimension within PM is in accordance with the Chaotic Level of the TOP model maturity definitions.

\section{Financial Management (FM)}

A sign of documentation was evidenced, but the majority of the sub-processes were not well documented and there was still a probability of mistakes. Productivity levels is acceptable compared to other processes and some employees know how to continue task when someone 
left or were on holidays. The case study also revealed that there is a sort of standardization of the task that was documented, which indicates tasks were done in the same way every time. In terms of BPR, the FM management process had no automated systems that linked work together such as ERP or CRM systems, which can improve workflow and reduce human errors, the FM also has no plan to rethink and reengineer the tasks.

To conclude, discussion suggests that the process efficiency dimension within FM is in accordance with the Basic Level of the TOP model maturity definitions.

\section{Human Resource Management (HRM)}

The findings revealed that sub-processes were unstructured and undocumented, it was also clear that there was inconsistency for process which resulted in multiple employees doing the same task in different ways, and the overall approach to management was disorganised. In terms of BPR, the HR management process had no automated systems that linked work together, such as ERP or CRM systems which can improve workflow and reduce human errors. The HR also has no plan to rethink and reengineer the tasks.

To conclude, discussion suggests that the process efficiency dimension within HR is in accordance with the Chaotic Level of the TOP model maturity definitions.

\section{Legal Affairs Management (LAM)}

The findings revealed that the LAM process was relatively mapped out and its sub-processes documented. However, the documentation and structure of the process were poorly written and there was a lack of using software tools to capture existing processes into an interactive application which could be built on, for all future process documentation. The findings also revealed that there was some standardization and tasks more organised and completed in one way. In terms of BPR, the LAM management process had no automated systems that linked work together, such as ERP or CRM systems which can improve workflow and reduce human errors, the LAM also has no plan to rethink and reengineer the tasks.

To conclude, discussion suggests that the process efficiency dimension within LAM is in accordance with the Basic Level of the TOP model maturity definitions.

\section{Community and Services Management (CSM)}

The findings revealed that there was lack of task documentation and inefficient process performance that increased the probability of mistakes, there were also lower productivity 
levels. There was also a lack of standardization and tasks were always done in different ways. In terms of BPR, the CSM process had no automated systems that linked work together such as ERP or CRM systems which can improve workflow and reduce human errors, the CSM also had no plan to rethink and reengineer the tasks.

To conclude, discussion suggests that the process efficiency dimension within CSM is in accordance with the Basic Level of the TOP model maturity definitions.

\subsubsection{Case Study Two: Maturity levels of RLA}

At SLA had investigated only four main processes (see Figure 6.1), this due to many issues that have been encountered during data collection from SLA. One of the main issues was that the communications tools (internet connection) between the researcher and SLA was weak most of the times of the interviews.

\subsubsection{Technology Deployment dimension}

\section{Procurement Management (PM)}

The case study findings revealed that hardware and software were available within the process, but they were not sufficient due to outdated technologies. There was a peer to peer network with limited data sharing and no printer connected to the network. There was also issue of internet connection as the internet was unreliable. Regarding security, it clear that security tools were inadequate and outdated and no security policies were applied, nor disaster recovery was not in place, there is also lack of PKI. The Windows operating system was installed; however, this operating system was outdated (Windows 2000 and XP). Incompatible database between the processes remains an issue as different database were used. In terms of private partners alliance factor, RLA had an issue to get outsourced support due to internal regulation that forbade outsourcing technical support.

To conclude, discussion suggests that the technology deployment dimension within PM is in accordance with the Basic Level of the TOP model maturity definitions.

\section{Financial Management (FM)}

Hardware and software were available within the process; however, it need upgrade. In terms of communication, there was peer to peer network which allowed sharing of the data and information between computers, printers were connected to the network, the internet was unreliable as slow and weak internet connection across RLA. Security tools were outdated as 
inadequate security software was installed, there was also lack of awareness of using security policies among the employees and disaster recovery wasn't in place, there also no PKI implemented. Regarding system compatibility, there was Windows XP operating system installed on the computers and compatible database within the process, but across other processes remained an issue as different database were used. In terms of private partners alliance factor, RLA had an issue to get outsourced support due to internal regulation that forbade outsourcing technical support.

To conclude, discussion suggests that the technology deployment dimension within FM is in accordance with the Basic Level of the TOP model maturity definitions.

\section{Human Resource Management (HR)}

Within HRM there was only one automated sub-process and uses a bespoke in-house system human resource information system (HRIS). The system was developed by the third-party company and fitted the process's need. The system provided a solution for the data entry, data tracking, and data information needs of the human resources, payroll, management, and accounting functions within a SLA. However, the use of paper-based forms remains for recording data before entry into the system using MS Word and Excel. In terms of compunction, there was client/server network which facilitates sharing to the data located on the server; printers were connected to the network. However, there was no access to other three processes via a network and the internet was unreliable. There was also outdated security software installed with basic features and no security policies were applied, nor disaster recovery was in place and no PKI. Compatible Windows operating system was installed and database within the process was compatible, but with other processes remained an issue as different database were used. In terms of private partners alliance factor, RLA had an issue to get outsourced support due to internal regulation that forbade outsourcing technical support.

To conclude, discussion suggests that the technology deployment dimension within HRM is in accordance with the Basic Level of the TOP model maturity definitions.

\section{Community and Services Management (CSM)}

The CSM process employs twenty-one employees, carrying out tasks that directly touches its stakeholders, such as (Water, Electric, Waste, Tax, Housing, Civil Status, etc.). The process utilizes the in-house system to facilitate civil status sub-process, which is the only automated 
sub-process within CSM. The findings revealed that there were hardware and software available, however; these tools weren't inadequate to adopt e-Government. There was peer to peer network, with one printer connected to it and the internet was always unavailable. Basic security software was installed on the computers, and no security polices applied, nor were disaster recovery procedures was in place, there was no PKI. Windows operating system was installed; however, this operating system was outdated (Windows 2000) and incompatible database between the processes remained an issue as different database across was used. In terms of private partners alliance factor, RLA had an issue to get outsourced support due to internal regulation that forbade outsourcing technical support.

To conclude, discussion suggests that the technology deployment dimension within HRM is in accordance with the Basic Level of the TOP model maturity definitions.

\subsubsection{Organisational Capability Dimension}

\section{Procurement Management (PM)}

The case study findings revealed that skills and capability within PM process weren't inadequate as well as the work performance was insufficient, there was lack of training course, and inadequate functional and employability skills and the employees possess weak computer and interpersonal skills. In terms of organisational culture, there was an issue with commitment to work and employees always resistance to change. Regarding senior management, there was lack of support from senior management, lack of funding, lack of eGovernment benefits awareness among the senior management and employees and lack of vision and strategy for eGovernment adoption in the future. There was no reward system or bonuses. In terms of the legislation factor, there was no e-signatures legislation planned to future use and much of the software deployed within the process was without an end-user license agreement.

To conclude, discussion suggests that the organisational capability within PM is in accordance with the Chaotic Level of the TOP model maturity definitions.

\section{Financial Management (FM)}

The case study findings confirmed that skills and capability relatively adequate and work performance were to somehow sufficient, functional skills were acceptable among the employees as they all showed reasonable standard computer skills, employability skills were also adequate. However, there was lack of training to improve the skills to best practice. 
Regarding organisational culture it was clear that there was a commitment to work; it was also clear that there was a sign of resistance to change to accept new technology as some employees were not willing to change the traditional manual. In terms of senior management, there was lack of support from top management, lack of funding, and lack of eGovernment benefits awareness among the top management and employee; there was no detailed vision or future plan to adopt e-Government, there was also no reward system or bonuses. There was no reward system or bonuses. In terms of the legislation factor, there was no e-signatures legislation planned to future use and much of the software deployed within the process was without an end-user license agreement.

To conclude, discussion suggests that the organisational capability within FM is in accordance with the Basic Level of the TOP model maturity definitions.

\section{Human Resource Management (HRM)}

According to government official documents from RLA, the HRM process responsibilities represented in career and individual management. These activities normally include recruiting and hiring a new employee and individual management entails helping employees identify their strengths and weaknesses and make their best contribution to the LA. However, the case study findings within HRM process revealed that skills and capability were inadequate and the work performance was insufficient. Functional and employability skills were weak, there was no training courses planned to improve employees' skills and quality of work. Regarding organisational culture, there was no commitment to work which affected the whole process's outcomes and there was also resistance to change when new producers or technology were introduced. In terms of senior management, there was lack of support from top management, the awareness of eGovernment benefits among the top management and employees was relatively low, lack of funding and lack reward system, there was also no detailed plan to adopt IT projects including e-Government. In terms of the legislation factor, there was no esignatures legislation planned to future use and much of the software deployed within the process was without an end-user license agreement.

To conclude, discussion suggests that the organisational capability within HRM is in accordance with the Chaotic Level of the TOP model maturity definitions.

\section{Community and Services Management (CSM)}

Although, the CSM is the largest process in RLA. However, it is unlike CSM in SLA and displays less use of technologies. There were only ten employees responsible for running the 
sub-processes including (water services, taxation, billing, waste, housing, civil status). The evidence from the interviews revealed that skills and capability within the process were inadequate and work performance was insufficient. Functionals and employability skills were weak among the employees and there weren't training courses provided or planned to improve and enhance the skills. Regarding organisational culture, there was lack of commitment to work and resistance to change among the employees and favouritism was an issue as many employees complained that they had been ignored and never been promoted while other who were new and favoured. In terms of senior management, there was lack of top management support, lack of funding and there was no reward system, lack of awareness of eGovernment benefits among the top management and employees and there was no detailed future plan to adopt e-Government. In terms of the legislation factor, there was no e-signatures legislation planned to future use and much of the software deployed within the process was without an end-user license agreement.

To conclude, discussion suggests that the organisational capability within CSM is in accordance with the Chaotic Level of the TOP model maturity definitions.

\subsubsection{Process Efficiency Dimension}

\section{Procurement Management (PM)}

The findings revealed that lack of sub-process documentation, which always increases the probability of mistakes, lower productivity levels and doesn't assure continuity of process and quality, when employee left or were on holidays. The findings of the case study also revealed that there was no standardization and tasks always done in different ways. In terms of BPR, the PM process had no automated systems that linked work together such as ERP or CRM systems which can improve workflow and reduce human errors, the PM also had no plan to rethink and reengineer the tasks.

To conclude, discussion suggests that the process efficiency dimension within PM is in accordance with the Chaotic Level of the TOP model maturity definitions.

\section{Financial Management (FM)}

The case study findings revealed that there was payroll task was relatively documented compared to other tasks which showed lack of documentation. The findings also revealed that apart from payroll, the other tasks were done in different ways due to lack of process documentation and standardisation. The findings of the case study also revealed that there was 
no standardization and tasks always done in different ways. In terms of BPR, the FM process had no automated systems that linked work together such as ERP or CRM systems which can improve workflow and reduce human errors, the FM also had no plan to rethink and reengineer the tasks.

To conclude, discussion suggests that the process efficiency dimension within FM is in accordance with the Basic Level of the TOP model maturity definitions.

\section{Human Resource Management (HRM)}

The case study findings revealed that HRM process also was disorganized, it was clear the subprocesses were unstructured and undocumented, it was also clear that there was lack of standardization and inconsistency in the sub-process outputs and employees done the same task in different ways. In terms of BPR, the HRM process had no automated systems that linked work together such as ERP or CRM systems which can improve workflow and reduce human errors, the HRM also had no plan to rethink and reengineer the tasks.

To conclude, discussion suggests that the process efficiency dimension within HRM is in accordance with the Chaotic Level of the TOP model maturity definitions

\section{Community and Services Management (CSM)}

The case study findings revealed that there was lack of documentation, and the work was inefficient and always there were mistakes in the outputs. It also clears that lack of standardization and tasks always done in different ways. In terms of BPR, the CSM process had no automated systems that linked work together such as ERP or CRM systems which can improve workflow and reduce human errors, the CSM also had no plan to rethink and reengineer the tasks.

To conclude, discussion suggests that the process efficiency dimension within CSM is in accordance with the Chaotic Level of the TOP model maturity definitions.

\subsection{Chapter Summary}

From the above discussion, it can be noted there was a general lack of technologies within most processes; however, there were some encouraging signs of change in some processes. Basic IT was deployed in most process areas, which could provide the platform for the progression of e-Government. Network infrastructure was readily available within most of the processes, 
which will widen access to the systems and data. In-house applications were in place in some key process areas. Online, there was a web portal, but it provides only very basic services whereby the display of information was available. It is increasingly recognised by staff that a new web-portal is needed and that this would afford the LAs an opportunity to move forward. Data sharing between processes was an issue because each process kept their data. The findings also showed that lack of staff capability can be noted within most of the processes as the employees showed inadequate functional and employability skills, resistance to change and weak awareness of eGovernment benefits. Funding was also issue, and there were no detailed or planned strategies at process level or authority levels. Employees also fear that eGovernment leads to organisational change that may result in redistributing the power and redesigning jobs or losing them. Another issue is that favouritism, which was a fundamental factor in corruption in the public sector, results in hampering the development process in LAs and Libya. Despite the fact that information sharing can be easy done by the automated systems in the processes, however, employees showed that they work in a culture where information is considered an asset, best kept to themselves and cannot be shared with other processes when needed.

In addition to the lack of awareness of eGovernment benefits, lack of funding and lack of a detailed strategy to adopt e-Government, the findings also revealed the lack of a reward system at all levels in both LAs. Laws and legislation issues have been more recognised as a crucially important factor for eGovernment adoption which can regulate the use of the personal data. Regarding process efficiency, the processes were inefficient regarding documentation and standardisation. One notable conclusion from this analysis is that the process efficiency dimension seems to be lagging behind, and was not aligned with, the technology and organizational dimensions. Effective process management can help organisations scale up and improve efficiency for new and existing employees (see Figure 6.4 and Figure 6.5). However, most of LAs were disorganised and daily tasks were neither adequately documented nor standardized, despite the fact that some of these tasks had already been automated. Processes as a whole were not particularly well advanced, although the FM and CSM from SLA processes had a reasonable basis from which to move forward, in terms of technology deployment. It is clear, however, that process maturity is generally low, and this area needs appropriate focus and investment to allow the SLA to transition to eGovernment in a planned and effective manner. 


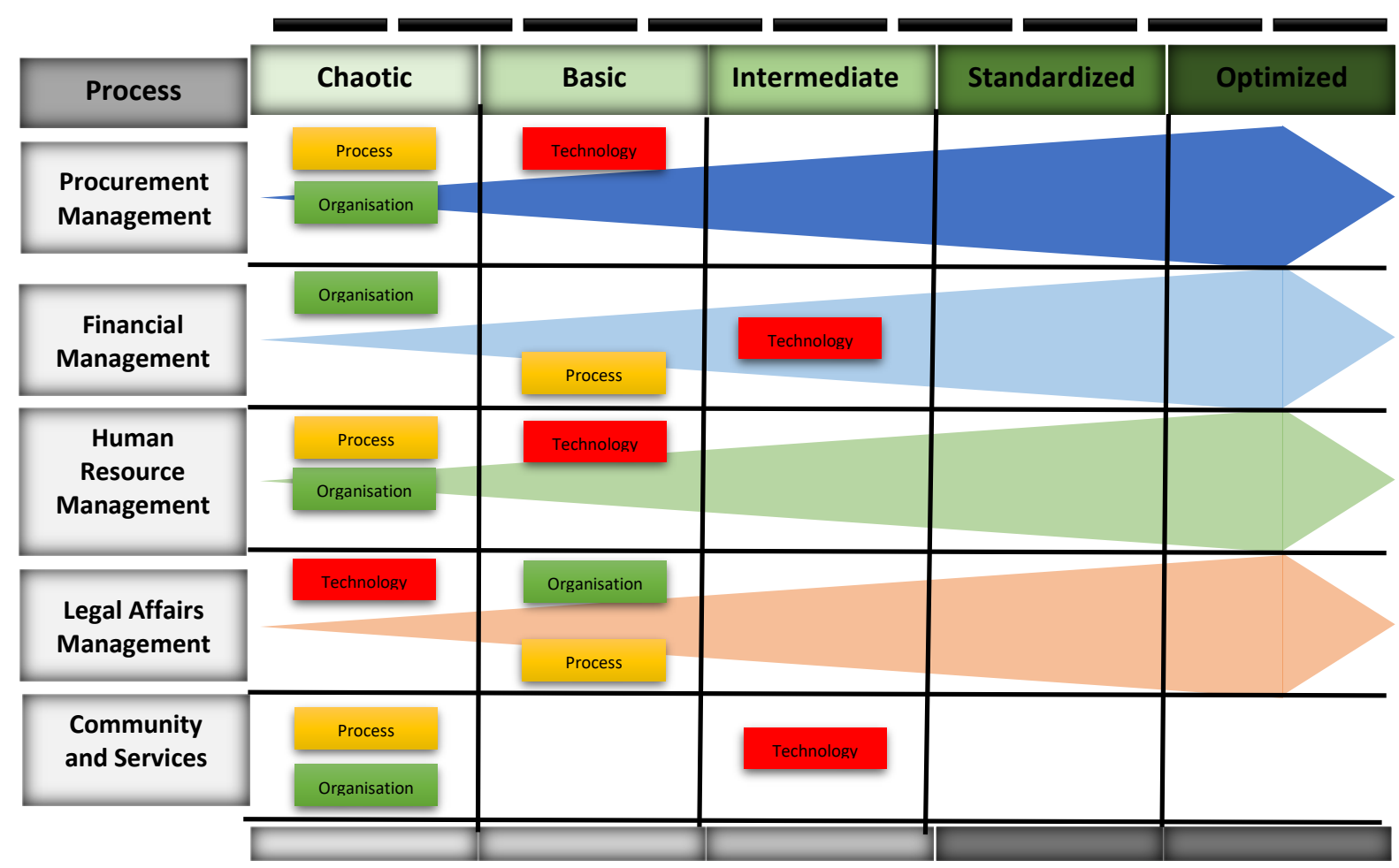

Figure 6. 2 Overall eGovernment Maturity Level for SLA

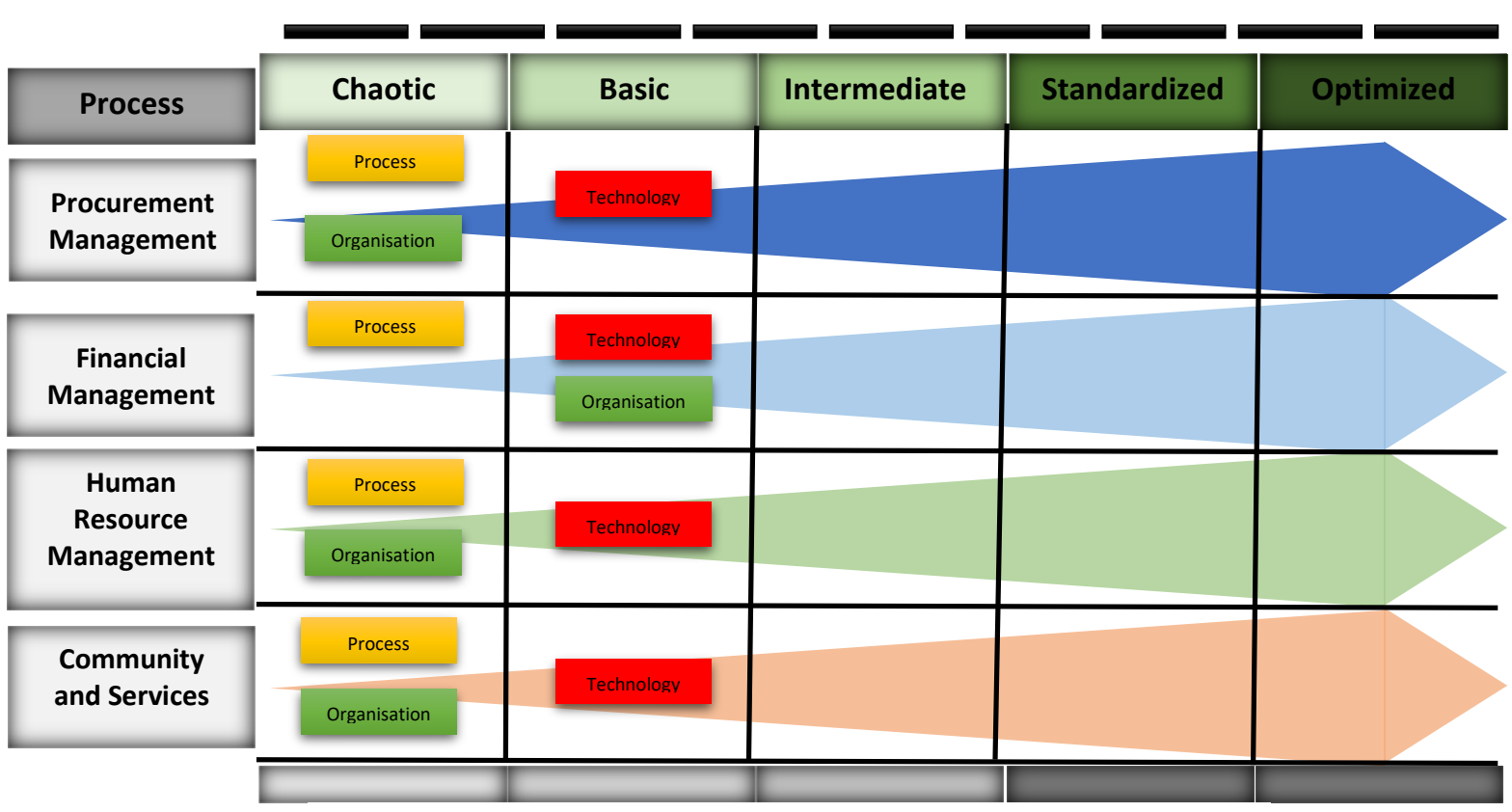

Figure 6. 3 Overall eGovernment Maturity Level for RLA 


\section{Chapter Seven: Model Validation}

\subsection{Introduction}

This chapter discusses the method adopted to ensure the quality and rigour of model and validate the usefulness of the developed model. This is done by of following two strategies as illustrated in chapter three that confer rigor on qualitative analysis, and how they are adopted in this research. These strategies are triangulation and respondent validation (Barbour, 2001). The rest of this chapter is organized as follows: Section 7.2 discusses triangulation of data collection. Section 7.3 discusses the validation of the model's three dimensions and their factors and sub-factors. Section 7.4 discusses the validation of the maturity levels. Section 7.5. concludes with a summary.

\subsection{Triangulation}

Triangulation has been used to address the issue of internal validity. This is done by using more than one method of data collection. Interview transcripts, documentary and observation have been combined in order to obtain a broader view. The use of multiple sources of evidence (especially tape-recorded interviews) allowed the researcher to Find out a range of new technical and attitudinal and behavioural issues. However, similar findings were produced from these different methods which provided corroboration and reassurance for the researcher that the findings and conclusions are convincing and accurate (Table 7.1).

Table 7. 1 Triangulation

\begin{tabular}{|c|l|}
\hline Source of data & \multicolumn{1}{c|}{ Triangulation } \\
\hline Interviews & $\begin{array}{l}\text { semi-structured interviews. The interviewee positions and experiences enabled the } \\
\text { researcher to obtain valuable information regarding the factors and sub-factors and } \\
\text { their influence in the adoption process }\end{array}$ \\
\hline Documents & $\begin{array}{l}\text { Use of different types of documents collected at the LAs and } \\
\text { The documents are with high credibility and contain detailed and updated } \\
\text { information. The documents include: } \\
\text { workshops materials - organisational reports - meeting minutes }\end{array}$ \\
\hline Observation & $\begin{array}{l}\text { The researcher conducted field trips to the SLA and RLA. The research visits were } \\
\text { successfully carried out to obtain first-hand information about certain issues and }\end{array}$ \\
\hline
\end{tabular}




\begin{tabular}{|c|c|}
\hline & $\begin{array}{l}\text { gave the researcher the opportunity to meet some employees including decision } \\
\text { makers }\end{array}$ \\
\hline Secondary Data & $\begin{array}{l}\text { Use of secondary data. This provided important information and data } \\
\text { supporting and confirming the analysis and findings of the study. The source of } \\
\text { secondary data was mainly from previous researches and studies }\end{array}$ \\
\hline Observation & $\begin{array}{l}\text { The researcher conducted field trips to the SLA and RLA. The research visits were } \\
\text { successfully carried out to obtain first-hand information about certain issues and } \\
\text { gave the researcher the opportunity to meet some employees including decision } \\
\text { makers }\end{array}$ \\
\hline
\end{tabular}

\subsection{Validation of the Model}

The researcher followed the method of validation that have been discussed in chapter three section 4.8. The model was examined by three participants. the researcher provided the model to the participant and once the model was presented and explained, the discussion began with over Skype.

The feedback regarding the elements of the model (dimensions, factors and sub-factors) suggested most were satisfied with the dimensions in the context of organizations in the Libyan government. They were also mostly satisfied about the selection of the factors and sub-factors into groups within the dimensions. Likert scale was used as method to measure the participant's satisfaction, these scales range from a group of categories (least to most) asking participant to indicate how much he agree or disagree with the model dimensions, factors and sub-factors and the maturity levels for LAs' processes (see table 7.2).

Table 7. 25 Points Likert Scale

\begin{tabular}{|l|l|l|l|l|}
\hline & 2 & 3 & 4 & \\
\hline Strongly disagree & Disagree & Neutral & Agree & Strongly Agree \\
\hline
\end{tabular}

Director of Steering committee and Academic scholar suggested that a new dimension should be added; for example, the academic and the director of the steering committee of the e-Libya program suggested that the political environment was critical in the context of a developing country such as Libya and it had a vital role to play in terms of implementing projects such as e-Government. They asserted that political situation across the country affected LAs, particularly in terms of financial support. Moreover, they emphasized the importance of 
including political environment for further improvements in the model, to accommodate any emergent factors in the future.

The second discussion was about the factors and sub-factors that are associated with each dimension (see table 7.3).

Table 7. 3 Dimension Factors and Sub-Factors: Survey Assessment

In relation to the dimension's factors and sub-factors: to what extent do you agree with these factors and sub-factors?

\begin{tabular}{l|c|c|}
\multicolumn{1}{|c|}{ Participant } & Organisation/Ministry & Choice number from 1 to 5 \\
\hline Director of Steering committee & e-Libya & 4 \\
\hline Senior Manager & SLA & 4 \\
\hline Academic scholar & University & 3 \\
\hline
\end{tabular}

The participants explored the factors and sub-factors and they stated that the factors and subfactors, as captured by the researcher, were well-organised and represented a comprehensive set of factors, which will be valuable to decision makers when they first attempt to plan for such projects. For instance, the director of the steering committee from e-Libyan stated that:

“ The technology dimensions factors and sub-factors are relevant and suit Libyan government organisations, because developing countries such as Libya are lagging far behind in adopting modern technology, and from what I have explored within our government organisations there is not sold IT infrastructure to facilitate the adoption of any big IT projects, for example cloud computing which is a type of computing that relies on shared computing resources rather than having local servers or personal devices to handle applications. He continued "this means that the TOP model meets the minimum requirement of technology to automated their processes which would suit Libyan organisations at least to host the first stage of e-Government".

They also stated that dimension of organisational capability related factors reflect the case within Libyan government organisations. However, he emphasized the importance of power distribution and reward system within the government organisations as an important factor:

"The implementation of a new IT environment to facilitate eGovernment will involve major organisational change and shift of power within the organisation will result in government employee resistance as well as employees losing their authority and power over traditional 
business processes. Those employees, who feel a loss of power or control, will try to resist the eGovernment project because it is seen as a threat to their skills, power and position, but if the top management adopt a good reward system it would help employee to educate themselves and accept the changes"

It could be noted that what the academic scholar portrayed is similar to what the researcher found from the analysis that power distribution and system reward are important factors. However, losing power and position was included in the revised mode as important factor which could be one of the reasons for resistance to change. Reward system is an important factor that encourages employee to accept eGovernment adoption.

The discussions also provided valuable information for putting some emphasis on certain relationships between the factors, including modifications to some of the dimensions (for example: Academician suggested excluding Process Efficiency dimension and combine its factor under organisational capability.

Regarding process efficiency, the senior anager agreed with the factors and sub-factors included in the process efficiency dimension. Nevertheless, He emphasised that an importance factor which will affectively play role in successful implementation IT projects such as eGovernment is BPR and how the LAs can adopt it and change the traditional methods. He asserted that BPR can save costs, increase customer focus.

"By analysing and rebuilding existing business processes, organisations can radically innovate and change especially in the IT infrastructure"

The participants were also asked to give their opinions about any contradiction between model dimension, factors and sub-factors that were found in the literature review with those were by the analysis. Their answer clearly suggested that different environments place a slightly different emphasis on and preference for the factors and the comparison of different practices initiated fruitful discussions, which helped to refine the model.

\subsection{Validation of the Maturity Levels}

The validation of the maturity level was conducted, and questions were asked about the process scale on the TOP maturity level. The answers added certainty that the maturity levels drawn were satisfactory (see Table 7.4). 
Table 7. 4 Maturity Levels: Survey Assessment

In relation to process maturity levels: to what extent do you agree with this scaling?

\begin{tabular}{l|c|c|}
\hline \multicolumn{1}{|c|}{ Participant } & Organisation/Ministry & Choice of number from 1 to 5 \\
\hline Director of Steering committee & e-Libya & 4 \\
\hline Senior Manager & SLA & 4 \\
\hline Academic & University & 4 \\
\hline
\end{tabular}

A question was asked about the maturity level for each process. The answers included a discussion on why the dimensions were at different maturity levels. They argued, for example, that the organisational capability dimension should focus on intensive training to the employees to improve their employability and IT skills to reinforce the importance of the eGovernment systems, these training courses will also eliminate resistance to change. Another important factor in organisational capability determination was also discussed which could be explained in the manner that if detailed strategies and finance funds weren't forthcoming that would lead to project failure. They also argued that, process efficiency was continually neglected in every government organisation.

\subsection{Summary}

A brief explanation of the overall main findings of the research was discussed with the three participants after the validation session, and clarifications were given regarding the session expectations, so that they had the opportunity to give overall feedback and they started to give comments.

Participants thought that the research approach was straightforward to use. The only concern from their point of view was how this model would be implemented within other LAs whilst the country suffered from political issues and no support was being provided until strong government could be formed. The researcher explained that this is an issue that would not be resolved during the time of the research and he suggested this could be seen as future work. The senior manager thought that outputs of the model were good, the model was developed to provide an outline of the factors for eGovernment development in different stages, and he considered that enough accuracy was achieved for the purpose to be satisfactory.

The academic scholar was not convinced that the model was something that could be used in every LA. But when they need to look at the possible scenarios for evaluating the readiness of LAs, then definitely the findings of this research could be of great help. He also thought that 
the details of the dimensions and factors were good. Overall, they agreed that an advantage of the model was that whenever there was a need to know and understand the factors affecting the implementation process in one easy attempt, the model would be a good reference point.

The chapter also discussed model refinement where it has been developed to address the gap in the literature regarding eGovernment assessment. Moreover, the revised model includes many new factors and sub-factors, explained their presence and impact on the eGovernment assessment process. This revised model will be very useful to scholars and practitioners, particularly decision makers and the implementers of e-Government. 


\section{Chapter Eight: Discussion and Conclusions}

\subsection{Introduction}

In this chapter, section 8.2 provides a research overview. Section 8.3 presents a comparison of the TOP maturity model with some other previous maturity models presented in literature review in chapter two. Section $\mathbf{8 . 4}$ provide the advantages and disadvantages of the TOP maturity model. Section 4.5 discusses the research objectives. Section 8.6 discusses the research contribution to the body of knowledge, including contributions to theory and to practice. Section 8.7 discusses the limitations of the research. Section 8.8 discusses recommendations on eGovernment implementation in LAs. Section 8.9 discusses suggestions of future work, and finally, Section $\mathbf{8 . 1 0}$ provides a summary of the chapter

\subsection{Research Overview}

Chapter one defined the research problem and showed various motivations for conducting this research. It also, stated the aim of this study, which is to develop new model for the assessment and management of eGovernment services in Libyan local government.

Chapter two discussed the issues related to eGovernment in general with a view of identifying the scope of the research problem. It started by presenting an overview of the eGovernment, and then went on to focus upon the eGovernment definitions and the possible reasons behind the debatable issues between researchers in search of an agreed definition. As a result, a taxonomy for eGovernment definition classifications was proposed. eGovernment interaction categories were also discussed G2C, G2B and G2G. These categories explained initiative and the interaction-patterns of each sector. Chapter two also discussed a global perspective of eGovernment and the indicator that measuring the use of ICT by governments to deliver public services at national level (EGDI), it is further indicates the world eGovernment leaders and eGovernment in the Middle East and North Africa in particular. Challenges, issues and barriers have also been discussed and as a result it was clear that there is no single way of listing eGovernment challenges. Its further discussed the different models of developmental stages of eGovernment, alongside with eGovernment maturity assessment models. Finally, the key issues and challenges were categorized into three dimensions (TOP). 
Chapter three amid to provide a clear model for this research. In doing so, the researcher examined in detail eGovernment challenges that influence the adoption of eGovernment taking into consideration developing countries. For better understanding the implementation aspects of eGovernment, a provisional conceptual model was proposed which was influenced by many studies.

Chapter four outlined the research approach, methodology, and design to carry out the research under study. The research methodology was developed and adapted by discussing and justifying a selection of qualitative research approaches to collecting data in an eGovernment context that covers LA processes. The chapter also discussed the data collection which further explained the interview, interview designed plan, pilot study and data analysis. Lastly, the chapter discussed the method that has been used to validate the model.

Chapter five presents the case study background and the findings of the study conducted in LAs. This chapter also offers an analysis of the combination of RLA and SLA that describes the major aspect of this research. The chapter further presented the findings obtained from the interviews from both LAs which helped the researcher to identify the new challenges that were not part of the initial conceptual model.

Chapter six deliberates on the additional factors and sub-factors identified, which were not part of the literature or initial conceptual model. As a result of the research findings and analysis were able to explain the issues of the emerged factors and sub-factors and thereby refine the initial conceptual model. The researcher was also able to extract the maturity level definition from the revised model and then he applied the maturity staged approach at individual process level at SLA and RLA.

Chapter seven presented model validation. It discussed and validated the revised model for eGovernment implementation and adoption by three participants from e-Libya project, SLA and academic scholar from university of Tripoli.

Finally, in chapter eight, the researcher identifies how the new model compares with previous models of eGovernment and provided its advantages and disadvantages for use within developing countries. The chapter also discusses how the objectives of the research were met and summarises the research contributions both theoretical and practical, and based on research limitations recommendations were made for future studies on eGovernment implementation, as well as for the MLA. 


\subsection{TOP Model: Comparison with Existing Models}

This section presents a description of eGovernment maturity models available in literature that to be compared with TOP model. This includes the following models: World Bank, Layne and Lee and United Nation. These well-known models determine the maturity of the eGovernment portals which means these maturity models offer a way to rank eGovernment portals from outside perspective and guide agencies to enhance their portals' quality. These models have different stages varying from 3 to 5 . Table 8.1 summarize the maturity models with 3,4 and 5 stages, respectively.

Table 8. 1 Maturity models' stage names

\begin{tabular}{|c|c|c|c|c|}
\hline${ }_{\mathrm{MM}}$ Stage & Stage 1 & Stage 2 & Stage 3 & Stage 4 \\
\hline World Bank & $\begin{array}{l}\text { Variety of information } \\
\text { - Rules, regulations, } \\
\text { documents and forms }\end{array}$ & $\begin{array}{l}\text { - Citizen self-service portal } \\
\text { - Electronic payments }\end{array}$ & $\begin{array}{l}\text { - Services consolidated and } \\
\text { shared across } \\
\text { various government } \\
\text { jurisdictions } \\
\text { - Personalization } \\
\text { - Interactive communication } \\
\text { - Identity management } \\
\text { - Content security }\end{array}$ & NA \\
\hline $\begin{array}{c}\text { Layne and } \\
\text { Lee }\end{array}$ & $\begin{array}{l}\text {-Present on the web } \\
\text {-Download forms } \\
\text {-Consult presentation } \\
\text { catalogue }\end{array}$ & $\begin{array}{l}\text { - Make transactions } \\
\text { - Fill forms with a } \\
\text { confirmation of } \\
\text { receipt } \\
\text { - Online working } \\
\text { databases }\end{array}$ & $\begin{array}{l}\text { - Integration to higher } \\
\text { stage systems } \\
\text { - Within similar } \\
\text { functionalities }\end{array}$ & $\begin{array}{l}\text { - Systems integrated } \\
\text { across various } \\
\text { jurisdictions } \\
\text { - Portals are real one } \\
\text { stop shops }\end{array}$ \\
\hline United Nation & $\begin{array}{l}\text { - Web sites contain } \\
\text { Static information } \\
\text { - Web sites contain } \\
\text { links to ministries and } \\
\text { other government } \\
\text { branches } \\
\text { - Laws, regulations, } \\
\text { relevant } \\
\text { documentation and } \\
\text { information on public } \\
\text { policy }\end{array}$ & $\begin{array}{l}\text { - One way } \\
\text { communication } \\
\text { - Downloadable } \\
\text { forms } \\
\text { - The portal } \\
\text { features audio } \\
\text { and video clips } \\
\text { and are } \\
\text { multilingual }\end{array}$ & $\begin{array}{l}\text { - Two-way interaction } \\
\text { with citizen } \\
\text { - E-voting } \\
\text { - Citizen identity } \\
\text { - Applying for } \\
\text { certificates, licenses } \\
\text { and permits } \\
\text { - Secure online } \\
\text { payments }\end{array}$ & $\begin{array}{l}\text { - Web sites are } \\
\text { proactive } \\
\text {-Agencies are citizen } \\
\text { centric } \\
\text { - Services organized in } \\
\text { a through life } \\
\text { events or segmented } \\
\text { groups } \\
\text { - Citizens involved } \\
\text { activities and } \\
\text { decision making } \\
\text {-Data is transferred } \\
\text { through integrated } \\
\text { applications }\end{array}$ \\
\hline
\end{tabular}

Although the maturity models' stage names are different from one maturity model to another; their content may have some similarities and differences. For instance, the first stage for Layne 
and Lee is named "Catalogue" where the public authority is presented on the web, while for United Nations this stage is named "Emerging information services" where government websites provide static information. Moreover, almost all of them contain:

- A stage related to the availability of the portal in the Web (presence).

- A stage where the citizens can interact with governments (interaction).

- A stage where the citizens can transact with governments (transaction).

- An advanced stage that covers advanced features such as information sharing between agencies(integration).

Regarding the focus of the maturity models, the researcher grouped the stages of those maturity models according to their focus:

The first stage of all the maturity models is mainly concerned with presence on the web. In fact, the maturity models used different words while they all focus on the same aspects (present, emerging information, presence on the web, information, presence, information interaction, Web presence, bill-board, simple information dissemination, publish information publishing, online presence, initial conditions, catalogue, cataloguing and basic site).

The second stage of all the maturity models is mainly concerned with allowing citizens to find enhanced information in the portal and to interact and transact with the government.

The third stage of all the maturity models is mainly concerned with allowing citizens to interact and transact with the government and making the e-portal a real one stop shop.

The fourth stage of all the maturity models is mainly concerned with allowing citizens to transact with the government and making the e-portal integrated and personalized according to citizens' needs.

The idea of these maturity models is often to be able to distinct good from bad practices and provide incentives for improvements. These types of maturity models access the level of eGovernment often from the outside, i.e. what is directly observable at the front-end aiming to give a performance rating of national governments. Assessment focuses predominantly on the front (primarily counting the number of services offered) and not on the back-office processes. This is a logical focus when taking the stakeholders' point of view who are not directly involved in improving the back-end. Whereas, senior managers and decisions-makers who are keen in improving the back-end have the concern to understand and measure the performance of the back-end which none of the above models can offer such assessment. 
In contrast, the TOP maturity model presented in this study is different, the model combines assessment of three dimensions (TOP) simultaneously. The TOP maturity model has been applied at the back-end of each individual process level. The results of for the process's maturity level at each dimension has given overview to the managers and decision makers who are interested in improving the back-end and have the concern to understand and measure the performance of the back-end. They have a need to have an understanding of the insides of the issues, not to a level of detail to understand all processes and system components, but at a level of measuring to enable the benchmarking with others and learning from each other's practices. Table 8.2 compares between TOP maturity model and previous maturity models

Table 8. 2 Comparison between TOP maturity model and previous models

\begin{tabular}{|c|c|c|c|c|}
\hline Features & $\begin{array}{c}\text { TOP Maturity } \\
\text { Model }\end{array}$ & United Nation & Layne and Lee & World Bank \\
\hline $\begin{array}{c}\text { Number of } \\
\text { Stages }\end{array}$ & $\begin{array}{l}\text { 1. Chaotic } \\
\text { 2. Basic } \\
\text { 3. Intermediate } \\
\text { 4. Standardized } \\
\text { 5. Optimized }\end{array}$ & $\begin{array}{l}\text { 1. Emerging presence } \\
\text { 2. Enhanced presence } \\
\text { 3. Transactional presence } \\
\text { 4. Connected presence }\end{array}$ & $\begin{array}{l}\text { 1. Catalogue } \\
\text { 2. Transaction } \\
\text { 3. Vertical Integration } \\
\text { 4. Horizontal } \\
\quad \text { Integration }\end{array}$ & $\begin{array}{l}\text { 1. Publishing } \\
\text { 2. Interactive } \\
\text { 3. Completing } \\
\text { transaction }\end{array}$ \\
\hline $\begin{array}{c}\text { Type of } \\
\text { Assessment }\end{array}$ & Back-End office & Front-End & Front-End & Front-End \\
\hline $\begin{array}{c}\text { Level of } \\
\text { Assessment }\end{array}$ & $\begin{array}{c}\text { Back end at } \\
\text { Individual } \\
\text { Process level }\end{array}$ & Front end assessment & Front end assessment & $\begin{array}{l}\text { Front end } \\
\text { assessment }\end{array}$ \\
\hline Concepts & $\begin{array}{c}\text { Multi- } \\
\text { dimensional } \\
\text { concept } \\
\text { 1. Technology } \\
\text { deployment } \\
\text { 2. Organisation } \\
\text { Capability } \\
\text { 3.Process } \\
\text { Efficiency }\end{array}$ & $\begin{array}{c}\text { One concept } \\
\text { Front-end Services }\end{array}$ & $\begin{array}{c}\text { One concept } \\
\text { Front-end Services }\end{array}$ & $\begin{array}{c}\text { One concept } \\
\text { Front-end } \\
\text { Services }\end{array}$ \\
\hline
\end{tabular}




\subsection{Model Advantages and Disadvantages}

The TOP maturity model can provide a better understanding of the strengths and limitations of LAs at individual process levels. The strength of the TOP maturity level model is that:

- It allows LAs to be evaluated against multidimensions in the area of eGovernment, including the technology deployment, organizational capabilities of human resources and process efficiency simultaneously. For each of these three dimensions, a number of key change factors are identified and assessed to allow a positioning of the LA in the maturity level.

- It highlights the need for process improvement to accompany technology deployment, and the key role of organisational capabilities factors in bringing about the necessary change for the move to eGovernment.

- It can provide a specific roadmap for capability improvement, i.e., directives about where the financial and human resources of LAs should be allocated to improve its ability to carry out eGovernment initiatives.

- It can enable each LA to identify its current state of maturity and capability in an integral manner.

- It can enable each LA to compare itself with other LAs evaluated with the same model.

- The model can provide information about the LA's eGovernment readiness to allow the top management to determine whether they are ready and prepared to join the national eGovernment initiatives, and to define improvement programs in case they are not yet prepared.

Consequently, the model has been awarded the best model in 2017 by the $17^{\text {th }}$ European Conference on Digital Government which was held by Military Academy Lisbon, Portugal between 12-13 June 2017 (ACPI, 2019), this mean that the model proved to respond adequately to become a useful tool for the government to assess the preparedness of local authorities to join the new national eGovernment directives.

The disadvantages of the model can be reporter on the following points:

- The model works only on Libya local authority and may not be suitable for every organization.

- May require a considerable amount of time and effort for implementation.

- The data collection involves many experts and decision makers which in the case of developing countries such as Libya those people cannot be caught easily and need personal contacts

\subsection{Meeting Research Objectives}

\subsubsection{Objective One:}

To critically analyse the existing literature and current practice regarding eGovernment in both the developed and developing worlds 
Objective one has been addressed by chapter two, which critically discussed the issues related to eGovernment in general with a view of identifying the scope of the research problem. It started by presenting an overview of the eGovernment, and then went on to focus upon the eGovernment definitions and the possible reasons behind the debatable issues between researchers in search of an agreed definition. As a result, a taxonomy for eGovernment definition classifications was proposed. eGovernment interaction categories were also discussed and classified into G2C, G2B and G2G. These categories explained initiative and the interaction-patterns of each sector. Chapter two also discussed a global perspective of eGovernment and the indicator that measuring the use of ICT by governments to deliver public services at national level (EGDI), it is further indicates the world eGovernment leaders and eGovernment in the Middle East and North Africa in particular. Challenges, issues and barriers have also been discussed and as a result it was clear that there is no single way of listing eGovernment challenges. The chapter further discussed the different models of developmental stages of eGovernment, alongside with eGovernment maturity assessment models. Finally, the key issues and challenges were categorized into three dimensions (TOP).

The next points summarized the finding from the literature review:

- The literature review found that eGovernment has many definitions and it has been a debatable issue between scholars. The reasons why many eGovernment initiatives fail are related to poor understanding of eGovernment's processes and concepts.

- The literature review revealed that eGovernment applications around the world are not usually successful, and international failure rates in developing countries are high and range between $60 \%-85 \%$.

- The literature review found that eGovernment in developing countries is still in its infancy and requires more effort to catch up with counterparts in developed countries. The gap between them in ICT infrastructure, practices and usage has been getting wider rather than narrower.

- The literature review also found that implementation and experiences from developed countries may not be directly applicable to developing countries. Because of this, eGovernment projects in developing countries are often either never implemented or abandoned immediately after implementation or partially failing in their major goals, causing significant undesirable outcomes.

- The literature review provided a generic list of barriers to eGovernment development based on a wide range of prior literature (see Table 2.6 in chapter two). 
- The literature reviewed many models, frameworks and concepts. It was found that the majority of existing research was based on western countries, and it also found that there is an absence of a suitable comprehensive theoretical model that could be used for the assessment of authority capabilities prior to eGovernment adoption in developing countries. Hence, a gap existed regarding an adoption of the framework in government organisations in developing countries in general and in Libya in particular. This led the researcher to review and analyse these models, frameworks and aspects in order to formulate a model to address this issue.

\subsubsection{Objective Two:}

To explore and analyse the issues, factors and challenges faced by Libya local government (at individual process level within the organization) with respect to the provision of eGovernment services.

Chapter three has been set to address objective two. In this context, the researcher developed a conceptual model able to incorporate models from critical success factors models, such as the eGovernment architecture model that was developed by Ebrahim and Irani (2005), which has been successfully applied to eGovernment implementation in Bahrain, and the drivers and barriers model developed by Hamed (2009), which has been applied to eCommerce adoption in Libya. This model has been validated and modified to contribute an innovative proposal for eGovernment implementation and adoption. The proposed model encapsulates a review of eGovernment implementation challenges under three dimensions, namely: technology deployment, organisational capability, process efficiency. The model was examined and validated in chapter five. as result the model has included new factors and sub-factors. Therefore, the model was refined, and the new factors and sub-factors were embedded to its relevant dimensions.

\subsubsection{Objective Three:}

To develop a new maturity model for the assessment and management of eGovernment services in Libyan Local authority administrative systems.

In chapter six, after revising the conceptual model, the researcher proposed a maturity model. In this maturity model, specific definitions were provided to scale each dimension (TOP). This model is resulted in the dimensions were assessed as at different maturity levels in SLA and RLA. 


\subsubsection{Objective Four:}

To apply and evaluate the model using at least two Libyan local government administrations as case studies.

Chapter six addressed objective four; this chapter reported two case studies, the model was applied followed by a discussion of the empirical evidence derived from the case studies of SLA and RLA. The model was applied and investigated technology deployment, organisational capability and process efficiency. The empirical data confirmed the conceptual challenges and issues that were identified in chapter two from the literature and chapter three where the challenges had been described and categorized in detail. The result of the case studies confirmed that there were many weaknesses in both LAs and the maturity levels of the processes scaled relatively low.

\subsection{Research Contribution to the Body of Knowledge}

Creating a new model for eGovernment adoption constitutes the central contribution of this research and is based on empirical work that provides a comprehensive model of eGovernment in the public sector. This model reduces the confusion surrounding the eGovernment implementation process in Libyan LAs at individual process levels, by promoting the understanding of the adoption process by identifying the maturity level of the technology, organisational capability and process efficiency dimensions and highlighting the requirement for each dimension. The outcome of this research has extended the boundaries of knowledge in the area of eGovernment by making a valuable and innovative contribution to implementation and adoption.

\subsubsection{Contribution to Theory}

The new model is a completely innovative contribution to the field of eGovernment assessment. Implementations of eGovernment in developing countries fail, with higher percentage being classified as total failures and partial failures. This model may allow public sector organisations to assess their readiness before adopting eGovernment. The model focuses on measuring the readiness of LAs at individual process level and assessing the maturity level for each process in terms of technology, organisational capability and process efficiency.

\section{Contribution 1:}

This research is contributing to the body of knowledge by investigating critical factors that influence the eGovernment adoption process. This process has not been previously examined 
in LAs in Libya; therefore, the findings represent a novel contribution for both researchers and practitioners. The findings which are based on empirical evidence from LAs (chapter five) cover sets of 3 dimensions, 9 factors and 17 sub-factors as in conceptual model which was developed in chapter three, for which the researcher was able to identify and assess eGovernment at individual process level within the two case studies. New factors have been identified in addition to the ones in the initial conceptual model that was discussed in the chapter three. The initial conceptual model was revised; although, dimensions have been remained 3, however, factors and sub-factors were increased by 3 new factors and 8 sub-factors which increases the knowledge of critical factors and elements surrounding the process of change. This would help managers and decision makers understand what is needed before taking the action of eGovernment implementation.

\section{Contribution 2:}

This research helps in producing a maturity model with different stages to analyse the eGovernment capability on the basis of three dimensions, Technology, Organisational capability as well as Process efficiency. Each of the three dimensions involve a number of significant change factors as well as sub-factors that were identified and assessed for ascertaining the position of the organisation in the stage model. This is being applied at an individual level of the process in the entire organisation. This study reports on utilisation of the model within the two local authorities, namely Sabratha local authority as well as Rujban local authority. The study also illustrates the model's potential to assess the operational readiness of eGovernment as well as identify the investment opportunities. Although the model was specifically designed for Libyan LAs, it consist of good practice guidelines that would enable generalisation in order to extend to other developing countries.

\subsubsection{Contribution to Practice}

\section{Contribution 1:}

The revised model in Figure 6.1 and its staged level definitions formed in this study is unique and it is appropriate for the MLA context in Libya. It will give better understanding of the situation of LAs before adopting eGovernment and allow them to consider what is needed to increase the chance of successful implementation of eGovernment services.

The model can also be recommended and used as a frame of reference for decision-making by other government officials in Libya or in other developing countries particularly in MENA 
region. This could be done by reviewing and amendment of the dimensions, factors and subfactors that have been used in the model in this study. The maturity stage definitions of the model could also be reviewed and defined according to the other countries' requirements. The possibility of turning the model into a software model that can be adopted to different environments is also a practical contribution to the knowledge as illustrated in (see Figure 8.2).

\section{Contribution 2:}

Several issues and challenges have been faced during the interview times which had impacted on the time scale of the research, for instance. There were some participants who were not interested to take part of the interviews and the researcher was able to overcome this issue by explanation of the purpose of the research and encouraging them that it's an opportunity for their opinions to be heard. There was also an issue that some employees excusing that they were too busy and have no time, but the researcher was able to reschedule many times until got convenient time (even with confirmed times thee participants did not turn up and appointment was rescheduled again). Fear of being inadequate, the researcher was able to reiterate why the research is important and provided more information on the research. In terms of confidentiality concerns, all the participants were given a letter that there is no risk to participate in the interview and agreed that it would remain confidential. Other crucial issue had impacted on the interview was internet connection, particularly in RLA, there was always weak connection which affected the time of interview over Skype in RLA premises. To overcome this issue the researcher used an expensive internet $3 \mathrm{G}$ over mobile phones to complete the interviews.

\subsection{Limitations of the study}

There are many limitations to this research summarized in the next points:

- Firstly, each country is unique with regards to its potential for eGovernment adoption, its unique challenges, and its goals for an eGovernment services programme. Hence, any research or study that aims to respond to the general issue of adopting and implementing eGovernment services may be forced to oversee some specific issues unique to particular countries. Yet the model has been built and designed to be applied to Libya as developing countries, the ease by which this model can be applied to eGovernment services implementation may vary from country to country. As a result, it is important for future researchers to apply the model while consistently acknowledging their country's unique issue, challenges and situation. 
- Secondly, the researcher considers that the data and case studies in this research aren't necessarily representative of the entire public sector in Libya. Rather, the researcher conducted these case studies in order to provide a maturity model perspective on the prospect of the readiness of two LAs out of 30 to adopt eGovernment services at process level and illustrate the potential challenges and areas for improvement to allow a positioning of the organisation in the TOP maturity model. Though the data derived in this study is instructive, it represents only 6\% of MLA's local authorities, readers shouldn't interpret its findings as the ultimate pronouncement on the readiness of eGovernment services in MLA.

\subsection{Recommendation on eGovernment Implementation}

The implementation of eGovernment within Libyan local authorities requires a conducive environment to realize its potential for development. Before preparing an eGovernment action plan, it is very important that the MLA assesses its e-readiness and tries to adjudge how prepared for adoption of eGovernment. In light with this, an assessment of the existing environment at SLA and RLA revealed that they are lagging far behind the levels needed to successfully implement eGovernment applications. Therefore, a roadmap has been suggested to minimize the risks of failure of adoption of eGovernment in these local authorities.

The recommendation can be conducted to bridge the gap between stages (see Figure 8.1). 
Figure 8. 1 Maturity Levels Strategic Gap

\section{TOP Model}

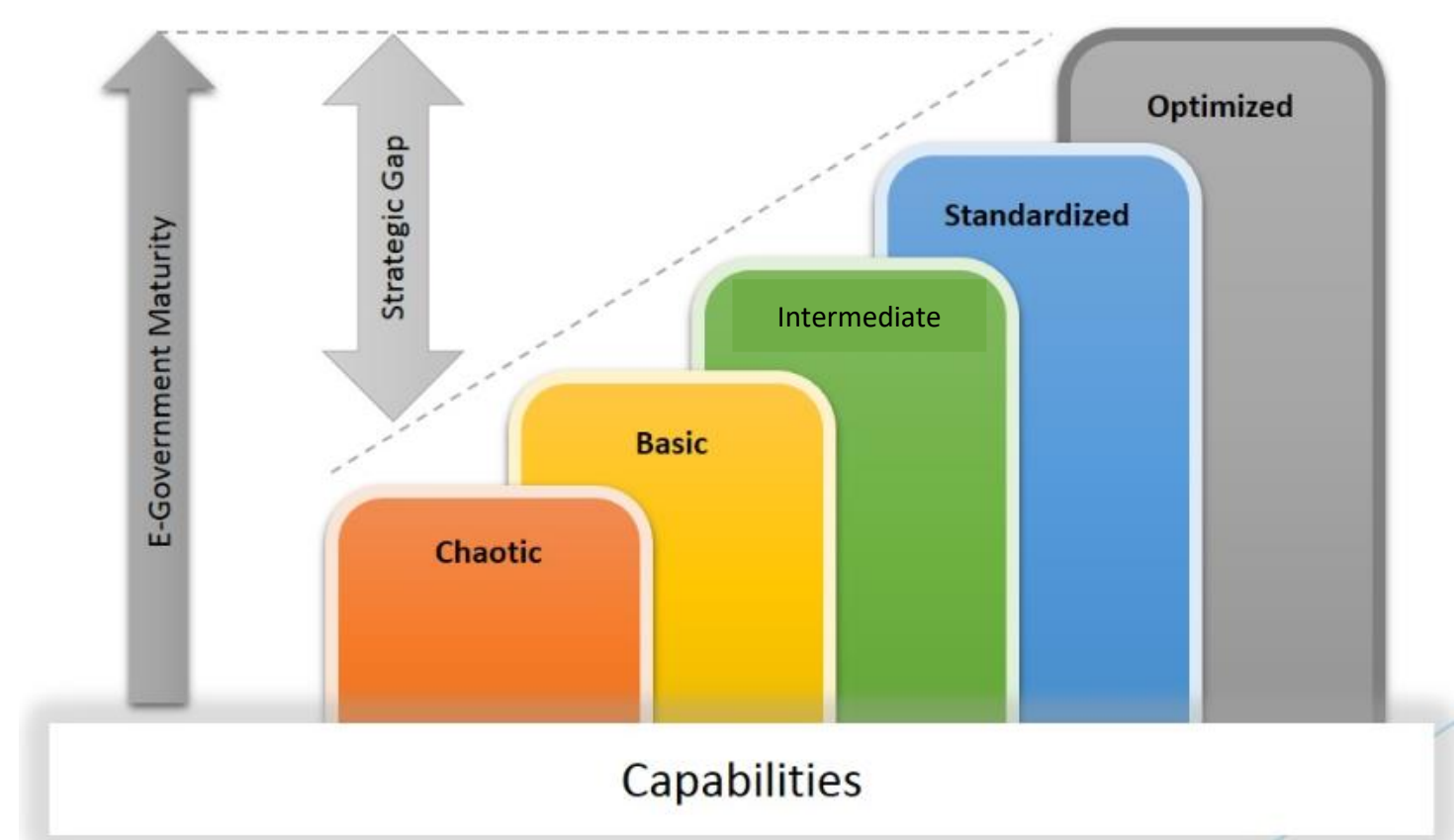

\subsubsection{Build Technology Infrastructure}

The MLA should provide minimum specifications for commonly used IT equipment, as a measure of ensuring standardization of equipment used across its local authorities:

- For eGovernment to be successfully implemented in local authorities, it is imperative that communication infrastructure be developed. A coherent strategy may be worked out, in consultation with the MLA for ensuring connectivity in the entire LA. This is because it has been observed that many functions still suffer from low penetration of the fixed line telecom infrastructure and low teledensity all over the regions which in turn impacts on the on the availability of the internet.

- Besides communication, the local authorities need to look into computing infrastructure (Hardware and Software) for development and delivery of applications online. They should ensure that the IT hardware parts and related accessories are easily upgradable with new features to avoid IT products being disposed prematurely; this has been observed in many processes that use outdated hardware and cannot be upgraded. The local authorities shall in addition ensure that a list of all upgradable parts (including up to what capacity the parts can be upgradable) of the products supplied is provided by the supplier. IT component installations that need updates shall be updated according to the latest official versions 
available. Software systems need to be developed to enable backend data processing services.

- As local authorities hold enormous sensitive database, the need to protect these databases and equipment, and the operational environment from loss is essential. Therefore, this needs to incorporate advanced security approaches and technologies such as public key infrastructure (a set of rules, policies, and procedures needed to create, manage, distribute, use, store, and revoke digital certificates and manage public-key encryption), reliable firewall, biometrics, digital signature and certificate, and sophisticated encryption techniques, which secure eGovernment interoperation, government electronic transactions, and delivery systems to ensure protection against fraudulence and other vulnerabilities at all levels of the government information infrastructures.

- System compatibility was an issue within many processes in SLA and SLA. In this regard, they should consider that all hardware equipment display the ability to run applications from different vendors, and to interact with other IT hardware across local or wide-area networks regardless of their physical architecture and operating systems. This should be possible through hardware and software components that conform to open standards such as those used for internet; this seeks to facilitate the exchange of information between potentially heterogeneous systems through conformance to open standards.

- eGovernment systems are expected to deliver its services to the citizens and other stakeholders on a $24 * 7$ basis. To achieve this, the local authorities have to set up a stable infrastructure that could be operational round the clock. For instance, utilisation of internet data centres. It shouldn't at all be cost effective if each process starts installing data centres, because running data centres need a lot of recurring resources. It is, then, suggested that the LA should setup a high-grade data centre to be used by all the processes, so they can manage their applications from their own premises in a secure manner. In addition, the LAs have to consider setting up of a disaster recovery mechanism to protect data centres.

- Partnerships with local companies to participate in the implementation of the national strategy in general and ICT in particular.

The above recommendation provides the ability to IT equipment components to effectively and efficiently work together in an integrated system which could increase the chance of successful eGovernment adoption. 


\subsubsection{Building Organisational Capability}

It should be kept in mind that eGovernment will require human resources skilled in a number of disciplines apart from just IT knowledge.

- The LAs should consider functional and employability skills as an important factor. The LAs should give intensive training courses to the employees to improve functional skills and employability skills. It should also give IT staff intensive training on evaluation, procurement and management of technologies as well as an adequate training on the usage of software applications.

- The lack of awareness has been noted in both LAs. Therefore, the LAs should improve employee's awareness, this can be achieved by delivering training courses on the online services and the role of eGovernment services by using workshops, conferences and seminars and giving employees a chance to look at successful eGovernment stories. It is important to incorporating the experiences with other countries which share similar cultural backgrounds and has successful eGovernment projects such as Bahrain and Emirates.

- Attitude and adaptability to change is an important prerequisite for the eGovernment implementation. Therefore, the LA should consider that change management skills are required to guide the process of transformation. This could be done by hiring consultants who would be responsible for instilling confidence into the employees that eGovernment is being ushered in to assist and help in carrying out their duties more efficiently and isn't a threat to their jobs or authority besides helping them to adapt new paradigms of delivery of government services.

- Draw a clear vision of the goals, objectives, priorities and strategies and align it with eLibya initiative. With such a dramatic change, LA cannot continue to proceed with the same vision, goals, objectives and priorities. Therefore, re-defining the vision of the LA, goals, objectives, priorities and strategies will provide a roadmap to move in the required direction with e-Libya strategy.

- Seniors management should support eGovernment services initiatives. Those senior managers can help to seek and build political support across other government bodies, push for change and resources, publicly take ownership of the project and commit their time on a sustained basis.

- Securing funding to meet the LAs' requirements, this can be done by partnership with the private sector. Create incentives to help local companies grow and become viable partners 
in eGovernment services. The private sector can be a source of cost-sharing, technology and project management expertise.

\subsubsection{Process Efficiency Improvement}

- The LA should be documenting tasks to reduce operational ambiguity. This can be achieved by using methods to document all tasks including software tools. Then these documents act as the store of collective organisational knowledge regarding the tasks and can be accessed by anyone in times of need and look at the detailer documentation and the dispute can be resolved.

- From the case study findings, it has been observed that sub-processes in the processes are confusion, poorly planned and creates chaotic and ineffective environment. Therefore, it is important that LAs apply complete description of how to execute a given sub-process, this can be done by step-by-step method which is a common method that document and describe the tasks. Then these documents act as the store of collective organisational knowledge regarding the sub-processes and can be accessed by anyone. once documentation achieved, then it must be standardized to ensure that tasks are done in similar way each time.

\subsection{Suggestions for Future Research}

Research can usually be further developed, and the research presented here is no exception. However, there are some areas that relate to this research which need to be investigated and explored further. Also, there are some alternative recommended directions that further work could be embarked upon. These are as follows:

- A number of challenges facing eGovernment implementation were proposed in the study based on literature and two case studies. The researcher proposes that these can be further studied and may lead to an exploration of more challenges facing eGovernment implementation within Libyan LAs.

- The model was based on Libyan LAs as case study. Therefore, the researcher recommends validating this model in different contexts to extend the generalisability and contribution of the model, this can be done by utilizing the model in different government agenise such as Ministry of Education, Ministry of Health etc.

- The researcher also suggests systemizing the TOP model to be used as software application rather than manual analysis, this can be achieved by generating questionnaires for the three dimensions (Technology Deployment, Organisational Capability, Process Efficiency) and supplied to computer software that produce maturity levels, (see Figure 8.2). 
Figure 8. 2 Suggested Systemized TOP Model

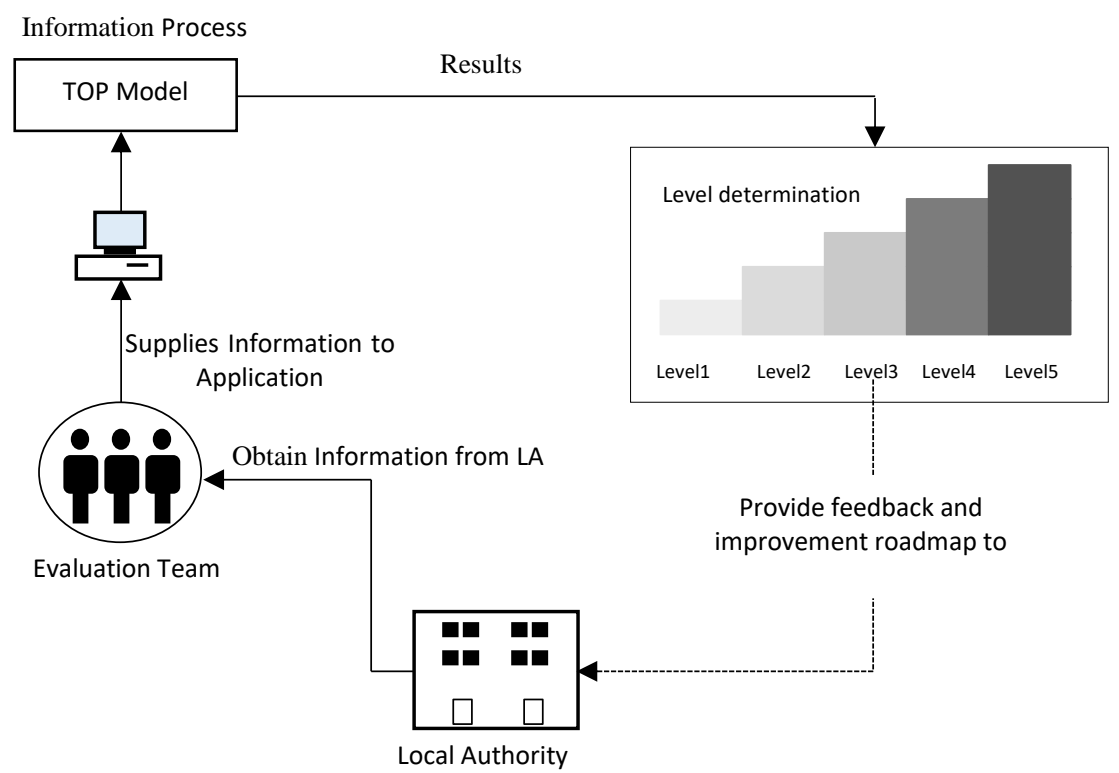

\subsection{Summary}

This chapter presented conclusions derived from the literature analysis and the empirical research. It presents the contribution made by this study in the form of a new model that deals with assessing government organisation before eGovernment take place. In light of this, the research attempted to add significant inputs to knowledge in this field by shedding light on specific dimensions, factors and sub-factors regarding eGovernment adoption. Case studies were conducted in order to determine the maturity level at individual process level in each authority. It is believed that the research objectives and outcomes will assist Sabratha, Rujban and other LAs with similar characteristics, regarding eGovernment adoption plan. 


\section{References}

Abdallah, S., and Fan, I. S. (2012). 'Framework for eGovernment assessment in developing countries: case study from Sudan', Electronic Government, an International Journal, vol. 9, no. 2, pp. 158-177.

Abdel Nasser, H., Faraj, A. and Wael, A. (2007). 'Assessing e-Readiness in the Arab Countries: Perceptions Towards ICT Environment in Public Organizations in the State of Kuwait', The Electronic Journal of e-Government, vol. 5, no 1. pp 77-86

Affisco, J. F. and Soliman, K. S. (2006). 'e-Government: a strategic operations management framework for service delivery', Business Process Management Journal, vol. 12 no 1, pp.13-21.

Ahmed, A.M., Mehdi, Q.H., Moreton, R. and Elmaghraby, A. (2013). eGovernment Services Challenges and Opportunities for Developing Countries: The Case of Libya. In: Second International Conference on Informatics and Applications, 2013. Lodz, Poland: IEEE.

Akemi, T. and Omar, A. (2009). 'A Cross-Country Comparative Analysis of eGovernment Service Delivery among Arab Countries', Information Technology for Development, vol. 15, no.3, pp. $151-170$

Akesson, M., Skålén, P. and Edvardsson, B. (2008). ‘eGovernment and Service Orientation: Gaps Between Theory and Practice', The International Journal of Public Sector Management, vol. 21 , no. 1 , pp. 74-92.

Alenezi, A. Feng. X. Amin, S. Liu, H. (2013) Issues associated with citizens in developing countries trusting the security of online services. In: 2013 International Conference on Computer Applications Technology (ICCAT), 20-22 Jan. 2013. Sousse, Tunisia. IEEE

Al-Fakhri, M., Cropf, R., Higgas, G. and Kelly, P. (2008). 'eGovernment in Saudi Arabia: between Promise and Reality', International Journal of Electronic Government Research, vol.4, no 2, pp. $59-82$ 
Aliyu, A. Muhammad, B. Rozilah, K. David, M. (2014) 'Positivist and Non-Positivist Paradigm in Social Science Research: Conflicting Paradigms or Perfect Partners', Journal of Management and Sustainability, vol. 4, no. 3, pp 79-94.

Alkhalifah A. (2017) 'A research Methodology to Explore the Adoption of eGovernment', International Journal of Computer Engineering and Information Technology (IJCEIT), vol 9, Issue 9. pp217-222

Alkhilani, W. and Sulaiman, H. (2014) Identification of factors influencing G2C services acceptance in developing countries. In: Proceedings of the 6th International Conference on Information Technology and Multimedia, 18-20 Nov. 2014. Putrajaya, Malaysia. IEEE

Al-Mabrouk, K. and Soar, J. (2009). 'A delphi examination of emerging issues for successful information technology transfer in North Africa a case of Libya', African Journal of Business Management, 3, 107-114.

Almarabeh, T. And AbuAli, A. (2010). 'A General Framework for E-Government:Definition Maturity Challenges, Opportunities, and Success', European Journal of Scientific Research, vol.39, no1, pp. 29-42

AlRashidi, H.J. (2012). The Role of Stakeholders and Influencing Factors during E Government Initiative Implementation. Unpublished PhD Thesis, Brunel University, London.

Alshehri, M. and Drew, S. (2010). 'Challenges of eGovernment services adoption in Saudi Arabia from an e-ready citizen perspective', World Academy of Science, Engineering and Technology, vol. 66. Pp 891-897

AL-Shehry, A., Rogerson, S., Fairweather, N., Prior, M. (2006) 'The Motivations for Change Towards eGovernment Adoption: Case Studies from Saudi Arabia. In: eGovernment' Workshop, London, UK, vol. 6, pp. 5-11

Alshenqeeti, H. (2014) Interviewing as a Data Collection Method: A Critical Review. vol. 3, no. 1, pp 39-45 
AlShihi, H. (2006). Critical Factors in the Adoption and Diffusion of eGovernment Initiatives in Oman (unpublished PhD thesis). School of Information Systems, Faculty of Business and Law, Victoria University.

Al-Sobhi, F., Weerakkody, V. and Kamal, M. M. (2010). An Exploratory Study on the Role of Intermediaries in Delivering Public Services in Madinah City, Transforming Government: People, Process and Policy, vol. 4, no. 1, pp. 14-36.

Al-Solbi, A. and Mayhew, P. J. (2005). Measuring e-readiness assessment in Saudi organisations preliminary results from a survey study, The Proceeding of the First European Conference on Mobile Government, 10-12 July, University of Succex, Citeseer, Brighton, UK, pp. 467.

Altameem, T. A. (2007). The critical factors of eGovernment adoption : An empirical study in the Saudi Arabia public sectors (Ph.D. thesis). Brunel University, Uxbridge.

Andersen, K. V. and Henriksen, H. Z. (2006). eGovernment Maturity Models: Extension of the Layne and Lee Model, Government Information Quarterly, vol. 23, no. 2, pp. 236-248.

Anderson, V. K. and Henriksen, Z. H. (2006) eGovernment maturity models: Extension of the Layne and Lee model, Government Information Quarterly, vol. 23, no. 2, pp. 236-248.

Ashaye, O. R. and Irani, Z. (2014). eGovernment Implementation Benefits, barriers and Risks: Evidence from Nigeria. US-China Education Review B, ISSN 2161-6248, January 2014, 4 (1): $13-25$.

Ashaye, O.O.R. and Irani, Z. (2012). eGovernment Implementation Factors: A Conceptual Framework. In Proceedings of World Conference on E-Learning in Corporate, Government, Healthcare, and Higher Education. pp. 480-489.

Atkinson, R. D. and Ulevich, J. (2000) Digital Government: The Next Step to Reengineering the Federal Government, Technology and New Economy Project. Democratic Leadership Council and Progressive Policy Institute, Washington.

Ayan Libya (2018). [online] Available from: < https://www.eanlibya.com/ [21 Sep 2018] 
Backus, M. (2001) E-Governance and Developing Countries, Introduction and examples, Research Report, no 3

Bakry, S. H. (2004). 'Development of e-Government: a STOPE view', International Journal of Network Management, vol. 14, no. 5, pp. 339-350.

Barbour, R. (2001). 'Checklists for Improving Rigour in Qualitative Research: a Case of the Tail Wagging the Dog', British Medical Journal, vol. 322, no. 7294, pp. 1115-1117.

Basu, S. (2004). eGovernment and Developing Countries: An Overview, International Review of Law, Computers and Technology, vol. 18, no. 1, pp. 109-132.

Benbasat, I., Goldstein, D. and Mead, M. (1987). The Case Research Strategy in Studies Of Information Systems. Management Information Systems Research Center, vol 11. pp 369386.

Bennett, O. (2009) Electronic Government (e-Government) • [Online] Available from: file:///C:/Users/Summer/Downloads/SN01202.pdf (accessed October 2018).

Bhuiyan, S. (2010). eGovernment in Kazakhstan: Challenges and Its Role to Development, Public Organization Review, vol. 10, no. 1, pp. 31-47.

Bolgherini, S. (2007). The technology trap and the role of political and cultural variables: A critical analysis of the e-government policies, Review of Policy Research, vol. 24, no. 3pp. 259-275.

Bose, R. (2004). 'e-Government: infrastructure and technologies for education and training', Electronic Government, an International Journal, vol. 1, no 4, pp. 349-361.

Bryman, A. (2012) Social Research Methods, Oxford University Press, Oxford

Budd, L. and Harris, L. (2004). E-Economy: Rhetoric or Business Reality, Routledge, London.

Busoud A. and Zivkovic (2016) eGovernment in Libya, International Scientific Conference on ICT and E-Business Related Research 
Schuppan T. (2009) eGovernment in developing countries: Experiences from sub-Saharan Africa. Government Information Quarterly, vol 26, no 1. pp 118-127

Bwalya, K. J. and Healy, M. (2010). 'Harnessing eGovernment adoption in the SADC region: A conceptual underpinning', Electronic Journal of e-Government, vol. 8, no. 1, pp. 23-32

Cabinet Office. (2000). e-Government: A strategic Framework for Public Services in the Information Age. Cabinet Office, London, UK, 2000.

Cahyaningsih, E. Sensuse, D. Arymurthi A. Wibowo, W. (2016) Knowledge management strategy of government human capital management. In: 2016 IEEE Student Conference on Research and Development (SCOReD), 13-14 Dec. 2016. 13-14 Dec. 2016. IEEE

Caldow, J. (2001). Seven eGovernment leadership milestones, IBM Institute for Electronic Government.

Carroll, J. M. and Swatman, P. A. (2000). 'Structured-case: a methodological framework for building theory in information systems research', European Journal of Information Systems, vol. 9, no. 4, pp. 235-242.

Carter, L. and Belanger, F. (2004). Citizen adoption of electronic government initiatives, Proceedings of the 37th Annual Hawaii International Conference on System Sciences (HICSS'04) - Track 5, vol. 5, 5 - 8 January, IEEE, pp. pp.50119c.

Carter, L. and Bélanger, F. (2005), 'The Utilization of E-Government Services: Citizen Trust, Innovation and Acceptance Factor', Information Systems Journal, vol. 15, no. 1, pp. 5-25.

Cavaness, J. P. and Manoochehri, G. H. (1993). 'Building quality into services', SAM Advanced Management Journal, vol. 58, pp.4-4.

Červená, K. and Románová, A. (2016) eGovernment Current problems in public administration in the Member States EU, Akadémia policajného zboru, Bratislava, pp 51-59. 
Chalhoub, M. (2010). 'Public Attitudes Towards Government Restructuring of IT Public Services: Application to eGovernment in the Middle East', International Journal of Management, vol. 27 , no. 3 , pp. $541-580$.

Chen, Y. N., Chen, H. M., Huang, W. and Ching, R. K. H. (2006). 'eGovernment Strategies in Developed and Developing Countries: An Implementation Framework and Case Study', Journal of Global Information Management, vol. 14, no. 1, pp. 23-46

Choudrie, J. and Weerrakody, V. (2007) 'Horizontal process integration in e-Government: the perspective of a UK local authority', International Journal of Electronic Government Research, vol. 3, 22-39.

Collis, J. and Hussey, R. (2009). Business Research: A Practical Guide for Undergraduate and Postgraduate Students. 3rd edition. New York: Palgrave MacMillan.

Corbin J, Strauss A. (2008). Basics of Qualitative Research: Techniques and Procedures for Developing Grounded Theory. 3rd ed. Thousand Oaks, California: Sage Publications; 2008.

Creswell, J. (2009). Research design: Qualitative, quantitative, and mixed methods approaches, Sage Publications, Inc.

Creswell, J. W. (2013). Research Design: Qualitative, Quantitative, and Mixed Methods Approaches (4th ed.). Thousand Oaks, CA: SAGE.

Ciarniene R and Stankeviciute G (2015) Theoretical framework of e-business competitiveness Procedia - Social and Behavioral Sciences 213 ( 2015 ) pp 734 - 739

Deakins, E., Dillon, S., Namani, H. and Zhang, C. (2010). 'Local eGovernment Impact in China, New Zealand, Oman, and the United Kingdom', The International Journal of Public Sector Management, vol. 23, no. 6, pp. 520-534.

Department of Trade and Industry (2003). Business in the Information Age: International Benchmarking Study 2003, Booz Allen Hamilton, London. 
Dul, J. and Hak, T. (2008). Case study methodology in business research. Oxford: Elsevier Ltd.

Dwivedi, Y. K. (2009). An Analysis of eGovernment Research, Transforming Government: People, Process and Policy, vol. 3, no. 1, pp. 7-15.

Easterby, S. M., Thorpe, R. and Lowe, A. (2002). Management Research: An Introduction. 2nd edition. London: Sage Publications Ltd.

Ebrahim, Z. and Irani, Z. (2005). 'eGovernment Adoption: Architecture and Barriers', Business Process Management Journal, vol. 11, no. 5, pp. 589- 611.

Ebrahim, Z., Irani, Z. and Alshawi, S. (2004). A strategic framework for eGovernment adoption in public sector organisations. In: Americas Conference on Information Systems, 2004. Association for Information Systems, pp 1116-1125

Edington, B. and Shin, N. (2006). An integrative framework for contextual factors affecting IT implementation, Proceedings of the 39th Hawaii International Conference on System Sciences, 04 - 07 January, Hawaii, IEEE, pp. 7a.

Eisenhardt, K. M. (1989). Building Theories From Case Study Research, The Academy of Management Review, vol. 14, no. 4, pp. 532-550.

EIU (2009). The e-readiness rankings 2009: The usage imperative, A white paper from the economist Intelligence Unit and the IBM institute for Business Value, http://www.eiu.com/site_info.asp (accessed 11 July 2013).

Elaswad, O. and Jensen, C. (2016) Introducing eGovernment in developing countries analysis of Egyptian eGovernment services. In: 2016 IST-Africa Week Conference, 11-13 May 2016. Durban, South Africa. IEEE

Eynon, R. and Dutton, H. W. (2007). Barriers to networked governments: Evidence from Europe, Prometheus, vol. 25, no. 3, pp. 225-242.

Eyob, E. (2004). 'e-Government: breaking the frontiers of inefficiencies in the public sector', Electronic Government, an International Journal, vol. 1, no 1, 107-114 
Fedorowicz, J., Gogan, J. and Culnan, M. (2010). Barriers to Interorganizational Information Sharing in e-Government: A Stakeholder Analysis, Information Society, vol. 26, no. 5, pp. 315-329.

Fountain, J. E. (2001). Building the virtual state: Information technology and institutional change, Brookings, Washington D.C.

Gagnon, Y., Posada, E., Bourgault, M. and Naud, A. (2010). 'Multichannel Delivery of Public Services: A New and Complex Management Challenge', International Journal of Public Administration, vol. 33, no. 5, pp. 213-222.

Gall, M. D., Borg, W. R. and Gall, J. P. (1996). Educational research: An introduction, Longman Publishing, London.

Galliers, R. (1994). Information systems research: issues, methods, and practical guidelines, Henley-on-Thames, Oxfordshire.

Gharibi, W. and Khan, M. (2014) eGovernment in the Arab world: Analysis and perspective, 2014 World Congress on Computer Applications and Information Systems (WCCAIS)

Ghauri, P and Grønhaug, K. (2002). Research Methods in Business Studies.2nd Edition. Harlow: Pearson Education Limited.

Gilbert, D., Balestrini, P. and Littleboy, D. (2004). 'Barriers and benefits in the adoption of egovernment', International Journal of Public Sector Management, vol. 17, no. 4, pp. 286301.

Gil-García, J. R. and Pardo, T. A. (2005). eGovernment success factors: Mapping practical tools to theoretical foundations, Government Information Quarterly, vol. 22, no. 2, pp.187-216.

Golafshani, N. (2003). Understanding Reliability and Validity in Qualitative Research, The Qualitative Report, vol. 8, no. 4, pp. 597-607.

Government of National Accord (2016). Development and the rule of law. Available at: http://www.pm.gov.ly/ . [Accessed 10 Oct 2016] 
Grant, G. and Chau, D. (2005). 'Developing a generic framework for e-Government', Journal of Global Information Management, vol. 13, no. 1, pp. 1-30.

Grundén, K. (2009). 'A social perspective on implementation of e-Government: A longitudinal study at the county administration of Sweden', Electronic Journal of e-Government, vol. 7, no. 1 , pp. $65-76$.

Gunter, B. (2006), Advances in E-Democracy: Overview, Aslib Proceedings, vol. 58, no. 5, pp. $361-370$.

Hafizi, R. Miskon, S. Rahman A.(2014) Shared service in eGovernment sector: Case study of implementation in developed countries. In: 2014 International Conference on Advanced Computer Science and Information System, 18-19 Oct. 2014. Jakarta, Indonesia. IEEE

Haider, M. Khan, M. Farooq, S. (2015) e-Government: An empirical analysis of current literature. In: 2015 International Conference on Information and Communication Technologies (ICICT). 12-13 Dec. 2015. Karachi, Pakistan. IEEE

Hamed, A. (2009). E-Commerce and Economic Development in Libya. Unpublished PhD Thesis, submitted to University of Wales Institute, Cardiff.

Hammersley, M. (2013). What is Qualitative Research? London and New York: Bloomsburry

Hamner, M. and Al-Qahtani, F. (2009). Enhancing the Case for Electronic Government in Developing Nations: A People-Centric Study Focused in Saudi Arabia, Government Information Quarterly, vol. 26, no. 1, pp. 137-143.

Hassan, H. (2011). An Investigation of E-services in Developing Countries: The Case of eGovernment in Egypt. PhD. School of Applied Sciences: Cranfield University.

Hatsu, S. and Ngassam, E (2016) An integrated framework for benchmarking eGovernment projects. In: 2017 IST-Africa Week Conference (IST-Africa), 09 November 2017. Windhoek, Namibia. IEEE 
Heeks, R. (2003). Most eGovernment for Development Projects Fail: How Can Risks Be Reduced? Institute for Development Policy and Management.

Heeks, R. (2006). Implementing and Managing e-Government: an international Text. London: Sage.

Heeks, R. and Bailur, S. (2007), Analyzing eGovernment Research: Perspectives, Philosophies, Theories, Methods, and Practice, Government Information Quarterly, vol. 24, no. 2, pp. 243-265.

Helbig, N., Gil-García, R. J. and Ferro, E. (2009). Understanding the Complexity of Electronic Government: Implications from the Digital Divide Literature, Government Information Quarterly, vol. 26, no. 1, pp. 89-97.

Hien, N.M. (2014). A Study on Evaluation of eGovernment Service Quality. International Scholarly and Scientific Research and Innovation vol 8, no., pp 16-19

Hunter, D. R., and Jupp, V. (2001). eGovernment leadership: Rhetoric vs. reality-closing the gap: Accenture. [online] Available from <http://www.accenture.com> [13 June 2013].

Hussey, J. and Hussey, R. (1997). Business Research. A Practical Guide for Undergraduate and Postgraduate Students. Basingstoke, UK: Palgrave.

InfoDev (2002), The eGovernment Handbook for Developing Countries, Information for Development Program and The Center for Democracy and Technology, Washington, DC. International Telecommunication Union (2008). Electronic Government for Developing Countries: ICT Applications and Cybersecurity Division Policies and Strategies Department, International. Telecommunication Union, Geneva.

International Telecommunication Union (2009) eGovernment implementation toolkit: eGovernment readiness assessment. Telecommunication Union, Geneva.

Irani, Z. Jones S. Love, P. Elliman, T. and Themistocleous, M. (2005). Evaluating e-government: learning from the experiences of two UK local authorities, vol. 15, no 1. pp. 61-82. 
Irani, Z., Al-Sebie, M. And Elliman, T. (2006). Transaction Stage of eGovernment Systems: Identification of Its Location and Importance, System Sciences, 2006. In: Proceedings of the 39th Annual Hawaii International Conference on 2006, pp. 82-82.

Irani, Z., Ezingeard, J., Grieve, R. J. and Race, P. (1999). 'A Case Study Strategy as Part of an Information Systems Research Methodology: A Critique', International Journal of Computer Applications in Technology, vol. 12, no 2. pp 190-198.

Jadi, Y. and Jie, L. (2014) GBC implementation strategy of eGovernment system for emerging countries. In: International Conference on Information Society (i-Society 2014), 10-12 Nov. 2014. London, UK. IEEE

Jaeger, T. and Thompson, M. (2015). eGovernment Around the World: Lessons, Challenges, and Future Directions, Government Information Quarterly, vol. 20, no. 4, pp. 389-394.

Janssen M., Maria A., Jean C., Hans J. (2014). Measuring and benchmarking the back-end of eGovernment: a participative self-assessment approach, Electronic Government, pp.156167.

Janssen, M., Chun, S. and Gil-García, J. R. (2009). Building the Next Generation of Digital Government Infrastructures, Government Information Quarterly, vol. 26, no. 2, pp. 233237.

Johnson, P. and Harris, D. (2002). Qualitative and Quantitative Issues in Research Design, Essential Skills for Management Research, Sage Publications, London, UK., pp. 99-116.

Johnson, R. B. and Onwuegbuzie, A. J. (2004). Mixed Methods Research: A Research Paradigm Whose Time has come. SAGE Publications Ltd

Joia, L. A. (2007). Sources of resistance to G2G endeavours: Evidence from a case study in the Brazilian context. Information Technology for Development, vol. 13, no 3. pp 233- 251 
Jones, S., Weerakkody, V., and Olsen, E. (2007) 'e-Government: a Comparison of Strategies in Local Authorities in the UK and Norway', International Journal of Electronic Business, vol.5, no 2. pp 141-159.

Kassim, E.S. and Hussin, H. (2010). Information technology and government-to-business: What are the values derived? Information and Communication Technology for the Muslim World. International Conference on 2010, pp. 14-20.

Keng Siau, Yuan Long, (2005) Synthesizing eGovernment stage models - a meta- synthesis based on meta-ethnography approach, Industrial Management and Data Systems, vol. 105, no 4. pp. $443-458$

Kigwana I. Kebande, V. Venter, H. (2017) Towards an eGovernment framework for the Republic of Uganda. In: 2017 IST-Africa Week Conference (IST-Africa), 30 May-2 June 2017. Windhoek, Namibia. IEEE

Kim, C. (2007). A cross-national analysis of global e-Government, Public Organization Reveiw, vol. 7 , no. 4, pp. 317-329.

Klein, H. K. and Myers, M. D. (1999). A set of principles for conducting and evaluating interpretive field studies in information systems. MIS Quarterly: Management Information Systems, vol. 23, no 1. pp 67-94.

Lagzian, M. (2006). Barriers of eGovernment Development: An Iranian Case Study, eGovernment Asia Conference, Centre for Science, Development and Media Studies Bangkok, Thailand.

Lam, W. (2005). 'Barriers to eGovernment Integration', Journal of Enterprise Information Management, vol. 18, no. 5, pp. 511-530.

Layne, K. and Lee, J. W. (2001). Developing fully functional e-Government: A four stage model, Government Information Quarterly, vol. 18, no. 2, pp. 122-136.

Lee, A. S. (1991). Integrating Positivist and Interpretive Approaches to Organizational Research. Organization Science, vol. 2, no 4. pp 342-365. 
Leedy, P. D. (1997). Practical research: planning and design, 6th edition. Upper Saddle River, NJ: Prentice-Hall, Inc.

Lenk, K. and Traunmüller, R. (2002), Preface to the Focus Theme on EGovernment, Electronic Markets, vol. 12, no. 3, pp. 147-149.

Lessa, L. (2019) Sustainability Framework for eGovernment Success: Feasibility Assessment. Melbourne, Australia.

Long, T. and Johnson, M. (2000). Rigour, Reliability and Validity in Qualitative Research, Clinical Effectiveness in Nursing, vol. 4, no. 1, pp. 30-37.

Lowery, D. and Evans, K. G. (2004). The Iron Cage of Methodology: The Vicious Circle of Means Limiting Ends Limiting Means, Administration and Society, vol. 36, no. 3, pp. 306-327.

Lowery, L. M. (2001). Developing a Successful eGovernment Strategy, Department of Telecommunications and Information Services, San Francisco.

Lutui R. Hopoi S. Maeakafa S. (2017) Security readiness evaluation framework for Tonga eGovernment initiatives. Proceedings of the 15th Australian Information Security Management Conference.

Mberi, T. Sevilla, J. Olukuru, J. Mutegi, L. Weru, T. (2017) Challenges to the successful implementation of e-governance systems in Africa: A case of Taita Taveta County, Kenya. In:

McClure, R. D. (2002). Common Data Collection Strategies Effective in Qualitative Studies Using Action Research in Technical /Operational Training Programs [online] Available from: < http://evokedevelopment.com/uploads/blog/commonData.pdf> [21 December 2018]

Means, G. and Schneider, D. M. (2000), Metacapitalism: The E-Business Revolution and the Design of 21st-Century Companies and Markets, John Wiley and Sons, Inc., New York, United States. 
Ministry of Communication and Informatics, 2013. e-Libya Program. eLibya Newsletter, 1 July 2013.

Mintzberg, H. (1979). An emerging strategy of direct research. Administrative Science Quarterly, vol. 24, no 4. pp 582-589.

Mohajan, H. (2018). 'Qualitative Research Methodology in Social Sciences and Related Subjects', Journal of Economic Development, Environment and People. vol-7, no 1, 2018, pp. 23-48

Moon, M. J. (2002). The evolution of eGovernment among municipalities: Rhetoric or reality?, Public Administration Review, vol. 62, no. 4, pp. 424-433.

Moon, M. J. and Norris, D. F. (2005). Advancing eGovernment at the Grassroots: Tortoise or Hare?, Public Administration Review, vol. 65, no. 1, pp. 64-75.

Myers, M. (1997). Qualitative Research in Information Systems. MIS Quarterly vol. 21, no 2. pp 241-242.

Myers, M. and Avison, D. (2002). An Introduction to Qualitative Research in Information Systems. London: Sage Publications Ltd.

Napitupulu, D. Sensuse, D. Sucahyo, Y (2017) Critical Success Factors of eGovernment Implementation Based on Meta-Ethnography. In: 2017 5th International Conference on Cyber and IT Service Management (CITSM), 30 October 2017. Denpasar, Indonesia. IEEE.

Noor, K. B. M. (2008). 'Case study: A strategic research methodology', American Journal of Applied Sciences, vol. 5, no. 11, pp. 1602-1604.

Oates, B. (2006). Researching Information Systems and Computing. California: Sage Publications Inc.

OECD. (2001). The Hidden Threat to E-Government: Avoiding large government IT failures. Public Management (PUMA) Policy Briefing no.8, March 2001. [Online] Available from: <http://www.oecd.org/governance/pem/1901677.pdf> [17 July 2013] 
Ojo, A., Janowski, T., Estevez, E. and Khan, I. K. (2007). Human capacity development in eGovernment, UNU-IIST. Technical Report 362, United Nation University.

Organisation for Economic Co-operation and Development (2003). The eGovernment imperative: main finding. Paris, Organization for Economic Cooperation and Development.

Orlikowski, W. and Baroudi, J. (1991). Studying information technology in organizations: Research approaches and assumptions. Information systems research.

Otieno, I and Omwenga, E. (2015) Citizen-centric critical success factors for the implementation of e-government: A case study of Kenya Huduma Centres. In: 2015 IST-Africa Conference, 6-8 May 2015. Lilongwe, Malawi. IEEE.

Otubu, A K. (2009). eGovernment and Land Administration in Nigeria-A Recipe for Lagos State. Working paper Series of Social Services Research Network (SSRN)

Parikh, M. A. (2002). Knowledge Acquisition through Case Study Development: A Student Researcher Perspective. Communications of the Association for Information Systems vol. 8, no 1. pp 360-379.

Patton, M., (1990). Qualitative Evaluation and Research Methods, California, CA: Sage Publications.

Pina, V., Torres, L. and Royo, S. (2010). Is eGovernment Leading to More Accountable and Transparent Local Governments? An Overall View, Financial Accountability and Management, vol. 26, no. 1, pp. 3-20.

Ponelis, S. R. (2015). 'Using interpretive qualitative case studies for exploratory research in doctoral studies: A case of Information Systems research in small and medium enterprises', International Journal of Doctoral Studies, 10, 535-550

Porras, A. and Amaya, H. (2018) eGovernment Development Index Analysis in South America Region: Challenges and Improvement Opportunities. In: 2018 International Conference on eDemocracy and eGovernment (ICEDEG), 4-6 April 2018. Ambato, Ecuador. IEEE 
Pudjianto, B. and Hangjung, Z. (2009). Factors affecting eGovernment assimilation in developing countries, Proceeding in 4th Communication Policy Research, South Conference, Negombo. Sri Lanka.

Queiros, A. Faria, D. Almeida, F. (2017). 'Strengths and Limitations of Qualitative and Quantitative Research Methods', European Journal of Education Studies. vol 3. No 9. Pp 369386.

Qin Hu L, Liu H and Zou X (2018) An Evaluation of the User Experience on C2C Online ShortTerm Rentals IOP Conference Series: Earth and Environmental Science 199 (3)

Rammea, L. Grobbelaar, S. (2017) The evaluation of eGovernment implementation: A case study of the Lesotho Company Registry System. In: 2017 IEEE Africon. 18-20 Sept. 2017. Cape Town, South Africa. IEEE

Rates, S. J. (2004) Doing social science research, SAGE Publications, London

Ravenswood, K. (2011) 'Eisenhardt's impact on theory in case study research', Journal of Business Research, vol 64, no 7, 680-686

Reddick, C. G. (2004). A Two-Stage Model of eGovernment Growth: Theories and Empirical Evidence for US Cities, Government Information Quarterly, vol. 21, no. 1, pp. 51-64.

Reffat, R. (2003). Developing a Successful e-Government, Proceedings of the Symposium on eGovernment: Opportunities and Challenge, Muscat Municipality, Oman.

Robson, C. (2002). Real World Research: A Resource for Social-Scientists and Practitioner Researchers. 2nd edition. Oxford: Blackwell Publishers Ltd.

Rust, R. T. and Kannan, P. K. (2002). E-Service: New Directions in Theory and Practice, M.E.Sharpe, Inc., Armonk, New York.

Ryan, F., Coughlan, M. and Cronin, P. (2007). 'Step-By-Step Guide to Critiquing Research. Part2: Qualitative Research', British Journal of Nursing, vol. 16 no 12. pp 738-744. 
Sarantis, D. and Askounis, D. (2010) 'Electronic Government Interoperability Framework in Greece: Project Management Approach and Lessons Learned in Public Administration', Journal of US-China Public Administration, vol 7, no 3. Pp.39-49.

Saunders, M., Lewis, P. and Thornhill, A. (2007). Research Methods for Business Students. 4th edition. Essex: Pearson Education Limited.

Schein, E. H. (2010). Organizational culture and leadership, 4th edition, Jossey-Bass, USA.

Scholl, H. J. (2003). E-government: a special case of ICT-enabled business process change. Proceedings of the 36th Annual Hawaii International Conference on System Sciences (HICSS 36), IEEE Computer Society.

Scholl, H. J. (2005). 'e-Government- induced Business Process Change: An empirical study of current practices', International Journal of Electronic Government Research, vol. 1, no. 2, pp. $27-49$.

Seifert, J. W. and Petersen, R. E. (2002). The Promise of All Things: Expectations and Challenges of Emergent Electronic Government, Perspectives on Global Development and Technology, vol. 1, no. 2, pp.193-212

Sensuse, D. Prima, P. Cahyaningsih, E. Noprisson, H. (2017) Knowledge management practices in e-Government. In: 2017 3rd International Conference on Science in Information Technology (ICSITech), 15 January 2018. Bandung, Indonesia. IEEE.

Sharma, S. K. and J. N. D. Gupta (2003). 'Building Blocks of an e-Government- A Framework', Journal of Electronic Commerce in Organizations, vol. 1, no 4. pp 34-49.

Sheridan, W. and Riley, T. B. (2006), Comparing eGovernment Versus eGovernance, Available at: http://www.electronicgov.net/pubs/research_papers/SheridanRileyComparE gov.pdf (accessed October 2017).

Software Engineering Institute (SEI) (2006). CMMI for Development, Version 1.2. 
Stewart, C., and Cash, W. (2006). Interviewing principles and practices, Eleventh edition. New York: McGraw-Hill.

Stoltzfus, K. (2005). Motivations for implementing e-Government: an investigation of the global phenomenon, Digital government research, Proceedings of the 2005 national conference on Digital government research. Atlanta, Georgia, USA.

Stratigaki C. Nikolaidou M. Loucopoulos P. Anagnostopoulos, D.(2016) Business Process Elicitation from Regulatory Compliance Documents: An eGovernment Case Study. In: 2016 IEEE 18th Conference on Business Informatics (CBI), 29 Aug.-1 Sept. 2016. Paris, France. IEEE.

Straub, D., Gefen, D. and Boudreau, M. C. (2005). Quantitative Research. In Research in Information Systems: A Handbook for Research Supervisors and Their Students. Avison, D. and Pries-Heje, J. (Ed.). Elsevier. Amsterdam.

Strauss, A., and Corbin, J. (2007). Grounded Theory in Practice. Thousand Oaks, Ca: Sage

Sweisi, N. A. and Adams, C. (2006) eGovernment Challenges for Developing Nations: The Case of Education in Libya. the 2nd International Conference on eGovernment University of Pittsburgh, USA, Academic Conferences Limited.

Sweisi, N. A. and Adams, C. (2007). Proposed Framework to Manage The Change to EGovernment (Lessons From Libya). Information Management in the Networked Economy Dublin, Ireland, 8th IBIMA.

Sweisi, N. A. and Adams, C. (2008). Transformation To eGovernment In Developing Countries: Lessons from Libya. ECEG. Ecole Poly technique, Lausanne, Switzerland, Academic Publishing Limited, Reading, UK.

Sweisi, N. Adams, C. (2006) eGovernment Challenges for Developing Countries: The Case of Education in Libya. In: The 2nd International Conference on e-Government, 2006. University of Pittsburgh, USA, Academic Conferences Limited. 
Thong J. Y. L. (1999). 'An Integrated Model of Information Systems Adoption in Small Businesses', Journal of Management Information Systems, vol. 15, no 4. pp 187-214

Thong, J., Yap, C. and Seah, K. (2000). 'Business process reengineering in the public sector: The case of housing development board in Singapore', Journal of Information Management Systems, vol. 17, no. 1, pp. 245-270.

Tornatzky, L. G. and Fleischer, M. (1990). The processes of technological innovation, Lexington Books.

Tuli, F. (2010). The basis of distinction between quantitative and qualitative in social science: reflection on ontological, epistemological and methodological perspectives. Ethiop.journal of education and science, vol 6, no 1, pp. 97-108

United Nations (2008). Government to Connected Governance, Department of Economic and Social Affairs, Division for Public Administration and Development Management, New York, United States.

United Nations (2010). e Government Survey: Leveraging eGovernment at a Time of Financial and Economic Crisis, Department of Economic and Social Affairs, UN Publishing Section, New York, United States.

United Nations (2012). eGovernment Survey: eGovernment for people, Department of Economic and Social Affairs, UN Publishing Section, New York, United States.

Van Der Molen, M. and Wubbe, M. (2007). eGovernment and E-Land Administration - As an example: The Netherlands. Presented at the 6th FIG Regional Conference, San Jose, Costa Rica.

Van Maanen J. Ed. (1983). Qualitative Methodology, Beverly Hills, CA: Sage Publications.

Vassilakis, C., Lepouras, G., Fraser, J., Haston, S. and Georgiadis, P. (2005). 'Barriers to Electronic Service Development', E-Service Journal, vol. 4, no. 1, pp. 41-63. 
Veenstra, A., Klievink, B. and Janssen, M. (2011). 'Barriers and impediments to transformational government: Insights from literature and practice, Electronic Government', an International Journal, vol. 8, no. 2-3, pp. 226-241.

Verkijika, S. and Wet, L. (2016) eGovernment development in Sub-Saharan Africa (SSA): Relationship with macro level indices and possible implications. In: 2016 IST-Africa Week Conference, 08 August 2016. Durban, South Africa. IEEE

Walsham, G. (1995). 'Interpretive Case Studies in IS Research: Nature and Method', European Journal of Information Systems, vol. 4, no. 2, pp. 74-81.

Wang, M. (2003). 'Assessment of e-Service Quality via E-Satisfaction in Ecommerce Globalization', The Electronic Journal of Information Systems in Developing Countries, vol. 11 , no. 10 , pp. 1-4.

Warkentin, M., Gefen, D., Pavlou, P. A. and Rose, G. M. (2002). Encouraging citizen adoption of eGovernment by building trust, Electronic Markets, vol. 12, no. 3, pp. 157-162.

Weber, R. (2004). The Rhetoric of Positivism Versus Interpretivism: A Personal View, MIS Quarterly, vol. 28, no. 1, pp. 3-12.

Weerakkody, V. and Choudrie, J. (2005). 'Exploring eGovernment in the UK: Challenges, Issues and Complexities', Journal of Information Science and Technology, vol. 2, no. 2, pp. 2545.

Wüllenweber K., Beimborn D., Weitzel T., König W., (2008) the impact of process standardization on business process outsourcing success. vol 10, no 2, pp 211-224

Wynn, M., Turner, P, and Lau, E. (2013). 'e-Business and process change in the UK SME sector', Journal of Small Business and Enterprise Development, vol. 20, no 4, pp 913-933.

Wynn, M., Turner, P., Banik, A. and Duckworth, A. G. (2016). The impact of customer relationship management systems in small businesses, Strategic Change, vol. 25, no 6. pp 655-670. 
Wirths B W and Peter D (2015) E-government strategy process instruments German University of Administrative Sciences Speyer Chair for Information and Communication Management Germany

Yang, K. (2003). Neoinstitutionalism and e-Government, Social Science Computer Review, vol. 21, no. 4, pp. 432-442.

Yin, R. K. (2009). Case study research: Design and methods, 4th ed, SAGE, Thousand Oaks. CA. Yin, R.K. (2003). Applications of Case Study Research. 2nd Edition. London, UK: Sage Publications.

Zaied, A. N. H., Khairalla, F. A. and Al-Rashed, W. (2007). 'Assessing e-readiness in the Arab countries: Perceptions towards ICT environment in public organisations in the state of Kuwait', Electronic Journal of e-Government, vol. 5, no. 1, pp. 77-86.

Fatonah S, Yulandari A and Wibowo F W 2018 A Review of E-Payment System in E-Commerce Journal of Physics: Conference Series 1140 (1) 012033 


\section{Appendix 1}

\section{The interview aims}

The interview agenda used to collect the data from the interviewees personally during semistructured interview. The questionnaire is demonstrated for the interviews explained to them by the researcher and then filled by the researcher to verify the accuracy and validity of answers.

\section{Interview Guidance}

1. Give an overview of the study and its objectives and aims

2. Ask for a permission to write down the answers and use the recorder if necessary

3. Explain the nature of the confidentiality and the use of the quotes

4. Explain that the interviewee can refuse to answer any question

5. Explain that an opportunity will be available for comments off the record at the end

6. The following letter was provided to the interviewers: 


\section{Dear Participant}

Thank you for taking the time to contribute in this research. I appreciate your contribution. This interview is being conducted as a part of a $\mathrm{PhD}$ research project at University of Gloucestershire, and seeks to investigate the issues, factors and challenges faced by Libya local authority (at individual process level) with respect to the provision of eGovernment services. The participants for this interview are considered to be those who are working closely in the main processes at the local authority (ICT related questions for IT staff and Organisational related questions for decision and policy makers in the targeted process level).

The questions results will be available for all participants. Your contribution is appreciated and really does count. However, as much as I value your responses to the questions, it is important to note that the participation is voluntary and have the opportunity to withdraw at any time. The interview will take approximately 30-45 minutes to complete, and all responses will be treated as confidential and anonymous to protect the respondent identity in any published data. Should you have any questions about the study, please contact the researcher, Yousef Forti through the e-mail given below.

[Email redacted]

Thank you for your participation

Yousef Forti 


\section{Appendix 2}

\section{Technology questionnaire}

1. Does the process have computers, printers and scanners?

a. Are they always working properly?

b. Can you explain to how important these technology tools to the process?

2. Does the process have in-house systems or software application?

a. Are they off-the-shelf software package, or a bespoke software developed?

b. How do you rate this application in terms of operation?

c. Are they networked based applications?

3. What are the issues and challenges in the process in terms of software and hardware, which you think is a hindrance to the implementation of the eGovernment program?

4. Does the process have its own webpage on the Internet or is it part of the LA's page?

a. What type of online services does the webpage provide?

5. Does the process have local area network?

a. What type of network?

b. Does the printers and scanners are connected to the computers throughout the network?

c. Does the network have connection to the other processes?

6. Does the process have internet?

a. Is it reliable and fast speed internet?

7. What are the issues and challenges in the process in terms of networks, which you think is a hindrance to the implementation of the eGovernment program?

8. Is there software security on the computers?

a. Are there security policies that prohibit employees from unauthorized programs?

b. Is there a disaster recovery plan to protect the process's data in case it is disrupted?

9. What are the issues and challenges in the process face the protection of the data and the privacy which you think is the obstacle to the implementation of the eGovernment program?

10. Is there compatibility in the process's hardware and software?

11. is there ability of different information technology systems and software applications between the processes to communicate and exchange data? 
12. What are the issues and challenges of compatibility in the process that you think is a hindrance to the implementation of the eGovernment program?

\section{Organisational capability Questionnaire}

1. What is the level of functional skills of the employees? "such as ICT skills, maths skills etc"

2. What is the level of the employability skills of the employees? "such as teamwork skills, communication methods, Problem solving, Planning and organising, Self-management"

3. Does senior management provide training to employees?

a. If yes, can you give more detail and describe what is the courses are?

b. Do the employees motivated to learn?

c. Are they qualified and what qualifications do they have?

4. Is there a refusal by employees when a new system is introduced?

5. If the work is automated so that the LA can adopt the e-Government, do you think it will face challenges from the employees? if so, why?

6. Are the employees committed to completing the tasks assigned to them on time? if not, what is the reason?

7. What is the level of knowledge of the eGovernment in senior management?

8. What is the level of knowledge of the eGovernment of employees?

9. Is there fund and administrative support and from senior management when decide to buy or adopt new technology?

10. Is there a vision, plan or strategy from the senior management to adopt e-Government?

\section{Process Efficiency questionnaire}

1. To what extent do the sub-tasks are organised?

a. Do you use documentation process to organise the sub-processes? "Process documentation is a complete description of how to execute a given process"

2. To what extent do the roles are followed?

a. Do you use standardization? "Process Standardization aims to unify the procedures in organizations that use different practices to do the same process"

b. Is the employee able to perform the tasks entrusted to him/her with the same guidance every time he/she is asked to perform procedure? 


\section{Appendix 3}

\section{Technology questionnaire}

1. هل يوجد لدى القسم حاسابات, طابعات, و ماسحات ؟ اذا كان كذلك هل هذه المعدات دائما تشتغل و في حالة جيدة و هل القسم مستقيد منها في العمل اليومي؟

2. هل يوجد لدى القسم برمجيات معدى من قبل مهندسين البلدية؟ اذا كان كذللك هل من الممكن ان تعددهم ؟ كيف تقيم هذا البرنامج من ناحية العملية؟

هل هو مربوط بشبكة ؟

3. هل من الممكن ان تكتب لي كل البرمجيات الجاهزة التي يستخدمها القسم ؟ اقصد بالجاهزة مثل ميكروسفت

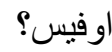

هل هو كامل بجميع اجر ائه؟

4. هل يوجد لدى القسم صفحة خاصة به على الانترنت او هل هي جزء من صفحة البلدية ؟ 5. ما هي اهم المشاكل في القسم من ناحية البرمجيات و العتاد و التي تعتقد انها تقف عائق لتنفيد برنامج الخكومة هئ

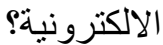

6. هل يوجد شبكة في القسم؟

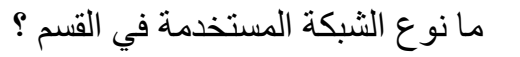

هل منصلة بالطابعات او الماسحات؟

هل الثبكة متصلة بالاقسام الاخرى ؟ - إن

7. هل يوجد انترنت في القسم؟

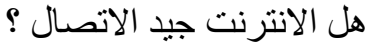

8. هل يوجد في القسم مخزن بيانات؟

9. ما هي اهم المشاكل في القسم من ناحية الثبكات و التي تعتقد انها تقف عائق لتنفيد برنامج الخكومة الالكترونية؟

10. هل يوجد بر امج حماية و خصوصية على اجهزة الكمبيوتر؟

11. هل يوجد قو انين تمنع الموظفين من استخدام الحو اسيب و المعدات و ذلك بتحميل برامج على حو اسيبهم او ربطها

USB Flash Memory بـ او استخدام اي برامج غير مرخصة ؟

12. هل يوجد خطة disaster recovery plan للبيانات و الاجهزة في حالة تعطبها؟

13. كيف يتعامل القسم مع المخاطر الداخلية و الخارجية؟

14. ما هي اهم المشاكل في القسم من الحمايةز الخصوصية و التي تعتقد انها تقف عائق لتنفيد برنامج الخكومة

الالكترونية؟

15. كيف تقييم التو افقية في البرمجيات و العتاد في القسج؟

سما هي اهم المشاكل في القسم من التو افقية و التي تعتقد انها تقف عائق لتنفيد برنامج الخكومة الالكترونية؟ 


\section{Organisational capability questionnaire}

1. كيف يمكن وصف المهار ات العملية للموظفين في القسم مثل مهار ات استخدام الكمبيوتر ؟ 2. كيف يمكن وصف المهار ات الوظيفية للموظفين في القسم مثل المهار ات العمل في فريق, طرق التواصل, ايجاد الحلول, التخطيطو التنظيم في العمل؟

3. هل الادارة العليا تقدم و توفر التدريب للموظفين؟ اذا كان نعم , هل من المكن ان تتحدث بتفصيل اكثر؟ هل من الممكن معرفة ما هي الدور ات التدريبة؟ 4. هل الموظفين ملتزمين بإنهاء المهام الموكلة اليهم في الوقت المحدد ام انهم يتجازون الاوقات المحددة؟ ما هي اسباب التأخير ان وجدت؟ 5. هل الموظفين دائما متحفزين للتعليم و يكتسبون المعرفة بسر عة عندما تقدم لهم الدور ات التدريبية؟ 6. هل الموظفين مؤ هلين علميا و ما هي المؤهلات التي بحوزتهج؟

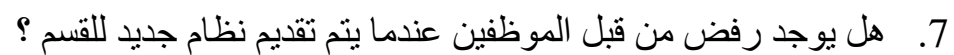

اذا نم ميكنة العمل حتى تتمكن البلدية من تبني الحكومة الالكترونية هل تعتقد انها ستو اجه مشاكل من قبل الموظفين؟ 8. هل يوجد خوف لدى الموظفين عندما يتم تقديم نظام جديد؟ 9. ما هو مستوى المعرفة بالحكومة الالكتروونية لدى الادارة العليا؟ 10. ما هو مستوى المعرفة بالحكومة الالكتروونية لاى الموظفين؟

11. هل يوجد دعم اداري من الادارة العليا في البلدية لتبني تكنولوجية جديدة؟

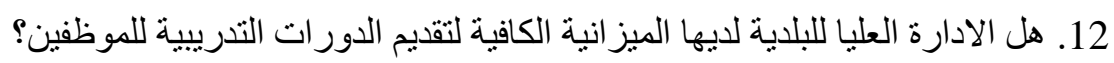

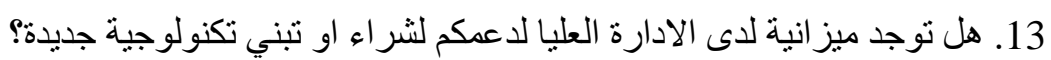
14. هل يوجد روؤية او خطة او استرتيجية من الادارة العليا لتنبي الحكومة الالكترونية؟ 15. كم عدد الوظفين في القسم?

\section{Process Efficiency questionnaire}

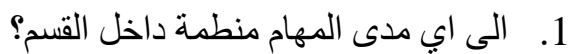
2. هل الموظف يستطيع تنفيد المهام الموكلة له بنفس الارشادات و اتعلميات في كل مرة يطلب منه تتفبد العملية او الاجر اء؟

3. هل الموظفين يعو حجم المسؤولية الموكلة اليهح و كذلك علاقة عمهم باعمال بالاخرين؟ 


\section{Appendix 4}

\section{Sample of Some Answers from interview}

هل يوجد لاى القسم حاسابات, طابعات, و ماسحات ؟ اذا كان كذلك هل هذه المعدات دائما تثتتفل و في حالة جيدة و هل

$$
\text { القسم مستفيد منها في العمل اليومي؟ }
$$

يوجد لدينا حاسبات و كذلك طابعات و لكم للاسف كلها قديمة و لا تؤدي الوظيفة المناط بهاو اجيانا تتعطل هذه الحاسبات لفتر ات طو يلة نظر العدم وجود الدعم الفني الكافي لاصلاحها. اما بخصوص اسقفادة القسم من هذه الحاسبات فنعم يستقيد منها القسم و لكن ليس بكامل الاستفادة لعدة عو امل اهمها انها قديمة و بطيئة و كنلك ضعف المهار ات لدى الموظفين لاستخدامها بالثكل المطلوب

هل يوجد لاى القسم برمجيات معدى من قبل مهندسين البلديةٌ؟ اذا كان كذلك هل من الممكن ان تعددهم ؟ كيف تقيم هذا البرنامج من ناحية العملية؟

نعم يوجد برمجيات قام فريق من المبرمجين بتطوير ها مند سنوات و هي تثتغل الا انها تحتاج الكثير من التطوير فعلا سبيل المثال لا تشتغل على خادم. يوجد لدينا عدد 1 برمجيات قام الفريق التتفني بتظوير هاو هي منظومة المشتريات. تقيمي لهذه المنظومة هو جيد ولكن كما اسلفت تحتاج الى تطوير. هل هو مربوط بشبكة ؟ لا لا لا تشتغل على شبكة.

هل من الممكن ان تكتب لي كل البرمجيات الجاهزة التي يستخدها القسم ؟ اقصد بالجاهزة مثل ميكروسفت اوفيس؟ هل هو كامل بجميع اجرائه؟

$$
\text { لدينا ميكروسفت اوفس على الاجهزة. }
$$

هل يوجد لاى القسم صفحة خاصة به على الانترنت او هل هي جزء من صفحة البلاية ؟ ليس للينا صفحة على الانترنت

مـا هي اهم المشاكل في القسم من ناحية البرمجيات و العتاد و التي تعتقد انها تقف عائق لتنفيد برنامج الحكومة الالكترونية؟

كل البرمجيات التي في القسم لا تدعم تقنية الانترنت و هي وندوز ابليكيشن و هى لن تقدم الكثير للحكومة الالكترونية طالمة لم يتم تطور ها. 


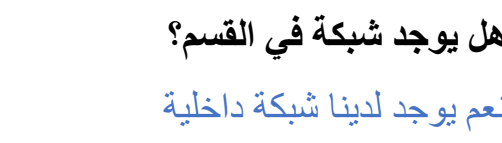

ما نوع الشبكة المستخدمة في القسم ؟

P2P شبكة الند للند

هل متصلة بالطابعات او الماسحات؟

متصلة بطابعة و احدة

هل الثبكة متصلة بالاقسام الاخرى ؟

لا ليست متصلة بالاقسام الاخرى فهذا يحتاج تطوير للبنية التحنية في البلدية

هل يوجد انترنت في القسم؟

يو جد لدينا انترنت و لكن ضعيف جداو ليس عملي

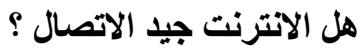

الانترنت ضعيف جداو ليس جيد الاتصال

هل يوجد في القسم مخزن بيانات؟

لا يوجد مخزن للبيانات شامل و انما كل جهاز يخزن بياناته على الهاد دسك الخاص به و لهذا دائما للدينا مشاكل في

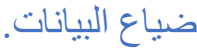

ما هي اهم المثاكل في القسم من ناحية الثبكات و التي تعتقد انها تقف عائق لتنفيل برنامج الخكومة الاكترونية؟ العديد من المشاكل اهمها عدم وجود بنية تحنية تستو عب السر عات العالية من الانترنت و كذلك قطع الكهرباء المستمر هذه العو امل هى اهم شي في تفيد الحكومة الالكترونية.

هل يوجد برامج حماية و خصوصية على اجهزة الكمبيوتر؟ لدينا برنامج حماية قديم و لم يصل تحديث مطلقاو كذلك هذا البرنامج مثاح فقط بمز ايا اولية و ليس مز ايا منطورة.

هل يوجد قو انين تمنع الموظفين من استخدام الحواسيب و المعدات و ذلك بتحميل برامج على حواسيبهم او ربطها بـ USB Flash Memory او استخدام اي برامج غير مرخصة ؟ لا يوجد اي سياسات او قو انين تمنع استخدام اجزة خارجية على الحاسبات و هذا الامر عرضها دئما للخطر من من بردئ الفيروسات.

هل يوجد خطة disaster recovery plan للبيانات و الاجهزة في حالة تعطبها؟ 
لا يوجد خطة لحفظ البيانات في حالة تعطبت و هذا الامر بحدث كثير ا ما نفقد البيانات بسبب الفيروسات و سوء

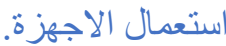

كيف يتعامل القسم مع المخاطر الداخلية و الخارجية؟ لا يوجد اي سياسات لمتع اي احتر اق سو اء من الداخل او الخارج ما هي اهم المشاكل في القسم من الحمايةز الخصوصية و التي تعتقد انها تقف عائق لتفيل برنامج الخكومة الالكترونية؟ لا يوجد خطط لحماية البيانات, لا يو جد برمجيات مكافحة الفيروسات , لا بوجد و عي عند الموظفين بخطوة استخدام اجهزتهم الثخصية على الاجهزة القسم.

\section{كيف تقييم التوافقية في البرمجيات و العتاد في القسم؟} لا يوجد تو افت في اليبانات و هذا امر غاية في الاهمية لان عندما تستورد البيانات هن الاقشام الاخرى فهي لا تتو افق معنا فنضطر لاعادة كتابتها بشكل يتو افق من بياناتنا. اما من نحية انظمة التشغيل فيها متو افقة.

ما هي اهم المشاكل في القسم من التوافقية و التي تعتقد انها تقف عائق لتففيد برنامج الخكومة الاكترونية؟ عدم وجود ثو افق بين قو اعد البيانات

كيف يمكن وصف المهارات العملية للموظفين في القسم مثل مهارات استخدام الكمبيوتر؟ تعتبر المهار ات العملية هن اهم المعايير لانجاح المؤسسة و التي اعتبرها انا شخصيا مفقودة بين الموظفين, حيث ان هيث معظم موظيفين ادارة خدمات المو اطنين لا يتمتعون بمهار ات كافية من ناحية تثغيل اجهزة الحاسب الالى و تقبل التكنولوجية كذلك بعني الموظفين من ضعف في المهار ات الوظيفية مثل كفاءة التو اصل الجيد مع المو اطنين, ضعف لوف ايجاد حلول جدرية لمشاكلهم و التى يجدر بكل موظف ان يتمتع بالحد الادنى من هذه المهار ات. كذللك عدم تلقي الموظفين لدور ات تدريبية منتظمة نظر العدم وجود الامو ال زاد من تدهو الوضع و اصبحنا احيانا عجزين عن تلبية متطلبات المواطنين دوي المصلحة.

كيف يمكن وصف المهارات الوظيفية للموظفين في القسم مثل المهارات العمل في فريق, طرق التواصل, ايجاد الحلول, التخطيطو التنظيم في العمل؟ ضعيفة جدا, لا يتمتع الكثير من الموظفين بمهار ات وظيفية جيدة تأهلهم من تشغيل الحكومة الالكترونية بل يجد على البلدية و بالتعاون مع جهات اخرى ان تنظم دور ات تأهيل مكتفة للموظفين هل الادارة العليا تقدم و توفر التنريب للموظفين؟ اذا كان نعم , هل من المكن ان تتحدث بتفصيل اكثر؟

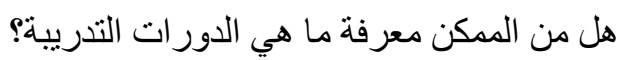
هل الموظفين ملتزمين بإنهاء المهام الموكلة اليهم في الوقت المحدد ام انهم يتجازون الاوقات المحددة؟

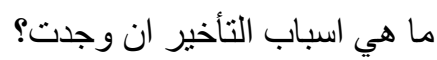


هل الموظفين دائما متحفزين للتعليم و يكتسبون المعرفة بسرعة عندما تقدم لهم الدورات التدريبية؟ الموطفين يكونو ا متحفزين للدور ات التنريبة عندما يتم ترشيحهم لدور ات خاريجية و هذا النوع من الدور ات يكلف البلدية مبالغ طائلة و لكن للاسف عندما يتم ترشيح الموظفين لدور ات داخلية فالمخرجات دئما تكون ضعبة جدا.

هل الموظفين مؤهلين علميا و ما هي المؤهلات التي بحوزتهج؟ لدينا موظفين دو شهادات علياو كذللك اخرين يحملون شهادات تدريبية و هم يشكلون اكثر الموظفين.

هل يوجد رفض من قبل الموظفين عندما يتم تقديم نظام جديد للقسم ؟ نعم بشكل دائم من بعض الموظفين للاسف , فبعض الموظفين لايهم هاجس بأن الميكنة سوف تقضي على وظائفهر بشكل او بأخر و من نم يتم رفضها, هناك نوع اخر من الموظفين يرفض الميكنة لجهله بمز اياها.

اذا تم ميكنة العمل حتى تتمكن البلدية من تبني الحكومة الاكترونية هل تعتق انها ستواجه مشاكل من قبل الموظفين؟ في هذا المستوى المتدني للموظفين نعم سوف تفشل الحكومة الالكترونية. هل يوجد خوف لاى الموظفين عندما يتم تقديم نظام جديد؟ نعم كما اسلفت في السابق

ما هو مستوى المعرفة بالحكومة الاكتروونية لدى الادارة العليا؟

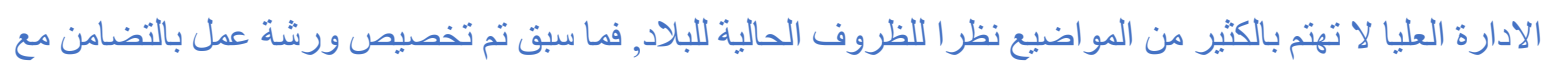
مشروع ليييا او لاين و لكن لم يؤخد بمحمل الجدية و توقف البرنامج التوعوي و لم يستمر, فالادارة العلية ليس لديها در اية كافية بمز ايا الحكومة الالكترونية

ما هو مستوى المعرفة بالحكومة الالكتروونية لاى الموظقين؟ متدني جدا نظر ا لعدم اشر اكهم في حملات الثتو عية بفو ائد الحكومة الالكثرونية.

هل يوجد دعم اداري من الادارة العليا في البلدية لتبني تكنولوجية جديدة؟ كان في السابق يوجد دعم من الادارة العليا للبدلية و كذلك من الوز ارة و لكن بعد احداث الثورة توقف كل الدعم و اصبح الموضوع بيد المليشيات التى تسرق كل الدعم المقدم من رئاسة الوزر الداة.

هل الادارة العليا للبلاية لايها الميزانية الكافية لتقديم الدورات التدريبية للموظفين و لشراء او تبني تكنولوجية جديدة $?$ لا يوجد ميز انية اصلا مند سنو ات , كلها تسرق من قبل المليشيات. 
هل يوجد رووية او خطة او استرتيجية من الادارة العليا لتبني الحكومة الاكترونية؟

$$
\text { لا يوجد خطة و لا يوجد رؤية لتبني الحكومة الالكترونية }
$$

الى اي مدى المهام منطمة داخل القسج؟

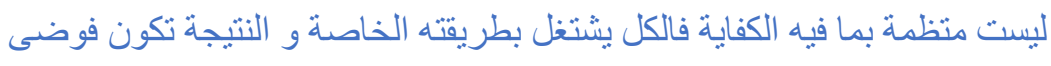
هل الموظف يستطيع تنفيد المهام الموكلة له بنفس الارشادات و اتعلميات في كل مرة يطلب منه تنفيد العملية او

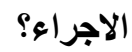

لا للاسف, دائما هنالك اختلاف في تنفيد المهام و لا يهتمو بالارشادات او التعلميات في كل انو اع المهام دئما هنالك اخطاء في المخرجات مما نضطر بالاستعانة بموظفين دوي خبرة لكي بر اجعوا الاخطاء و لكن للاسف كثرت الاخطاء اصبح الموظفين دوي الخبرة يرفضون المرجعة.

هل الموظفين يعو حجم المسؤولية الموكلة اليهم و كنلك علاقة عملهم باعمال بالاخرين؟ لا يهتمون بالمخرجات و لا بجدية العمل للاسف, كما اسلفت , المليشيات تفرض على الادارة العليا تعبين اناس من غير شهادات و لا خبرة و هذا من اهم اسباب فنل البلدية بأن تقدم الافضل للمو اطن, فالمو اطن منضرر مثلك مثل البلدية . 


\section{Appendix 5}

\section{Translation of the Sample of Some Answers from interview}

Does the process have computers, printers and scanners?

Are they always working properly?

Can you explain to how important these technology tools to the process?

We have computers as well as printers, but unfortunately, they all are old and slow.

Sometimes these computers are broken for long periods due to the lack of sufficient technical support to fix them. Regarding the department's benefit from these computers, yes, the department uses them, but it is not as required as I mentioned they are old and slow also the poor skills of the employees to use them as required.

Does the process have in-house systems or software application?

Are they off-the-shelf software package, or a bespoke software developed?

How do you rate this application in terms of operation?

Are they networked based applications?

Yes, there is software that a team of programmers developed for years and it works, but it needs a lot of development, for example, it does not work on a server. We have 1 software that the development team developed, which is the procurement system. My evaluation of this system is good but as I mentioned earlier you need to development.

Is it connected to a network?

No, don't work on a network.

Could you give me list of all the ready software that the department uses if possible?

We have full Microsoft Office on our devices.

Does the department have website on the Internet or is it part of the municipality website?

We do not have website on the Internet 
What are the issues in the department in terms of software and hardware, which you think affect the implementation of the e-government program?

The software applications in the department do not support DOT NET technology and they are Windows Application, which will affect negatively on the project.

Is there a network in the department?

Yes, we have an internal network

What kind of network is used?

$\mathrm{P} 2 \mathrm{P}$ peer-to-peer network

Is it connected to printers or scanners?

Connected to one printer

Is the network connected to other departments?

No, it is not as this requires the development of municipal infrastructure

Is there internet in the department?

We have internet, but it is very weak connection

Is the Internet fast

The internet is very weak and not reliable

Is there a data store in the department?

There is no data store, but every device stores its data on its own disk, so we always have problems with losing data.

What are the issues in the department in terms of networks, which you think will affect the implementation of the e-government project?

The most important issue is the lack of infrastructure to accommodate the high speeds of the Internet, as well as the continuous cutting of electricity, these factors are the big problems.

Are there security to protect the software applications and data on the computers? 
We have an old anti-virus program that need update and this program is also available only with initial benefits, not advanced features.

Are there regulations that prevent employees from using any unlicensed software on the computers or linking them to USB Flash Memory of them owns?

There are no policies or laws that prohibit the use of external devices on computers and this one of the issues that our computers sometimes down.

Is there a disaster recovery plan for data in case of malfunction?

There is no plan to save data in the event of a malfunction, and this happens frequently, we lose data due to viruses and misuse of devices.

How does the department deal with internal and external risks?

There are no policies to prevent any breaches, from either inside or outside risks.

What are the issues in the department of that you think stands as an obstacle to the implementation of the e-government project?

There are no plans to protect the data, there is no anti-virus software, there is no awareness among employees of using their personal devices on the devices section.

How do you evaluate compatibility in software and hardware in the department?

There is no compatibility in the data, and this is very important because when we import data from other departments, we face an issues of data entry because of the incompatible with our data. Regarding the operating systems, they are compatible.

What are the issues in the department which you think stands as an obstacle to the implementation of the e-government program?

Lack of compatibility between databases

How can the practical skills of employees in the department be described, such as computer skills?

Practical skills are considered one of the most important criteria for the success of the institution, which I personally consider missing among the employees, as most employees of 
the department do not have sufficient skills in terms of operating computers and accept technology as well as employees suffer from weakness in job skills such as the efficiency of good communication with citizens, the weakness of finding worthy solutions to their problems that each employee should have a minimum of these skills.

How can the job skills of employees in the department be described, such as skills working in a team, ways of communicating, finding solutions, planning and organizing at work? Very weak, many employees do not have good job skills that qualify them to operate the egovernment.

Are the employees always motivated to learn and gain knowledge quickly when they are given training courses?

The employees are motivated for the training courses when they are nominated for external courses such as courses given in Turkey or Tunisia, and this type of course costs the municipality large sums, but unfortunately when the employees are nominated for internal courses, the outputs are always weak.

What type of qualification that the employees hold?

We have university degree staff, and others hold training certificates and they are the most.

Is there a refusal by staff when a new system is introduced for the department?

Yes, permanently from some employees, unfortunately, some employees have an obsession that mechanization will eliminate their jobs in one way or another. Another type of employee rejects mechanization because he is unaware of its advantages.

If the work is automated so that the municipality can adopt the e-government, do you think it will face problems from the employees?

At this low level of employees, yes, e-government will fail.

Is there a fear for employees when a new system is introduced?

Yes, as I mentioned earlier.

What is the level of knowledge about e-government in senior management? 
The senior management does not care about many issues due to the current conditions of the country. What was previously allocated for a workshop in solidarity with the Libya First project, but it was not taken seriously, and the educational program stopped and did not continue. Senior management does not have sufficient knowledge of the advantages of egovernment

What is the level of knowledge about e-government among employees?

Very low due to their lack of workshops to educate them about the benefits of e-government.

Is there administrative support from the higher management in the municipality to adopt a new technology?

Previously, there was support from the senior management of the municipality and also from the ministry, but after the events of the revolution all support ceased due to political situation.

Does the municipality's senior management have the budget to provide training courses for employees and to purchase or adopt new technology?

There has been no budget for years.

Is there a vision, plan or strategy for senior management to adopt e-government? There is no plan and no vision for adopting e-government

To what extent are the tasks organized within the department?

Not organized enough, everyone works in their own way, and the result is chaos

Can the employee perform the tasks assigned to him with the same instructions? No, unfortunately, there is always a difference in the implementation of tasks. There are always errors in the outputs, which we have to use staff with experience in order to review the errors, but unfortunately with the size of the mistakes, the experienced employees refuse to do the cooperate.

Are employees aware of the size of the responsibility assigned to them, as well as the relationship of their work to the work of others?

Unfortunately, they do not care about the outputs or the seriousness of the work. As I mentioned before, the militias force the senior management to appoint people without 
qualifications or experience, and this is one of the most important reasons for the municipality's failure to provide the best for the citizen. 